\title{
A Two-Generational Child-Focused Program Enhanced with Employment Services
}

Eighteen-Month Impacts from the Kansas and Missouri Sites of the Enhanced Services for the Hard-to-Employ Demonstration and Evaluation Project

\author{
JoAnn Hsueh \\ Erin Jacobs \\ Mary Farrell (MEF Associates)
}

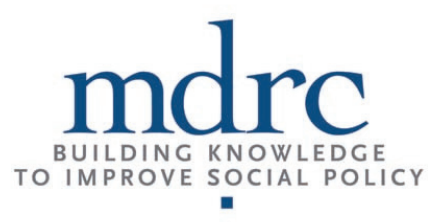

March 2011 
MDRC is conducting the Enhanced Services for the Hard-to-Employ Demonstration and Evaluation Project under a contract with the Administration for Children and Families (ACF) and the Office of the Assistant Secretary for Planning and Evaluation (ASPE) in the U.S. Department of Health and Human Services (HHS), funded by HHS under a competitive award, Contract No. HHS-233-01-0012. The project officers are Girley Wright (ACF) and Kristen Joyce and Amy Madigan (ASPE). Additional funding has been provided by the U.S. Department of Labor (DOL). The Lewin Group and MEF Associates, our partner organizations, assisted with site development, implementation research, and cost analysis. HumRRO, a subcontractor, fielded the 18-month survey of parents and direct assessments of children's developmental outcomes.

The findings and conclusions in this report do not necessarily represent the official positions or policies of HHS.

Dissemination of MDRC publications is supported by the following funders that help finance MDRC's public policy outreach and expanding efforts to communicate the results and implications of our work to policymakers, practitioners, and others: The Ambrose Monell Foundation, The Annie E. Casey Foundation, Carnegie Corporation of New York, The Kresge Foundation, Sandler Foundation, and The Starr Foundation.

In addition, earnings from the MDRC Endowment help sustain our dissemination efforts. Contributors to the MDRC Endowment include Alcoa Foundation, The Ambrose Monell Foundation, Anheuser-Busch Foundation, Bristol-Myers Squibb Foundation, Charles Stewart Mott Foundation, Ford Foundation, The George Gund Foundation, The Grable Foundation, The Lizabeth and Frank Newman Charitable Foundation, The New York Times Company Foundation, Jan Nicholson, Paul H. O'Neill Charitable Foundation, John S. Reed, Sandler Foundation, and The Stupski Family Fund, as well as other individual contributors.

For information about MDRC and copies of our publications, see our Web site: www.mdrc.org.

Copyright (C) 2011 by MDRC. ${ }^{\circledR}$ All rights reserved. 


\section{Overview}

Children living in poverty face considerable developmental risks. This report presents interim results from an evaluation of parental employment and educational services delivered within a two-generational, early childhood program targeting low-income families who are expecting a child or who have a child under age 3. This study is part of the Enhanced Services for the Hardto-Employ Demonstration and Evaluation project, sponsored by the U.S. Department of Health and Human Services, with additional funding from the U.S. Department of Labor.

The program model tested here aims to dually address both the employment and educational needs of parents who are at risk of unemployment and the developmental needs of their young children. The program's effects are being studied by examining 610 families who were randomly assigned to a program group, which received the enhanced two-generational program, or to a control group, which could only access alternative services in the community.

\section{Key Findings}

- The programs increased their focus on parental employment and educational needs, but the implementation of the enhancements was weak. Programs hired on-site "selfsufficiency" specialists, developed tools to assess parents' employment and educational needs as well as resource guides of employment and educational services in the community, and conducted trainings for program staff and participating families that focused on these topics. However, programs struggled to provide as one of their core services a proactive focus on parental employment and educational needs.

- Take-up of the enhanced parental employment and educational services was lower than expected. Only 63 percent of families in the program group ever discussed employment, educational, and self-sufficiency needs with program staff.

- The program increased families' receipt of child-focused developmental services, but the control group also reporting receiving high levels of such assistance. Among program group families, 91 percent reported receiving assistance in this area, compared with 80 percent of control group families.

- The short-term impacts of the program 18 months after families entered the study are mixed. For the full research sample, the program affected the use of center-based child care but had limited impacts on other outcomes. Beneficial program impacts were evident among families who were expecting a child or who had an infant less than 12 months old at study entry; for this subgroup, the program had positive impacts across several outcomes related to employment, child care, parenting, and children's social and emotional adjustment. Program impacts were more variable among families with a toddler who was 12 months old or older at study entry.

This evaluation is in an early stage and will eventually include three and a half years of followup. Future investigation will be valuable in determining the extent to which the patterns of impacts presented here are enduring and robust over time. A final report is planned to be released in 2011. 



\section{Contents}

Overview iii

List of Tables, Figures, and Boxes vii

Acknowledgments $\quad x i$

Executive Summary $\quad$ ES-1

\section{Chapter}

1 Introduction

The Background and Policy Relevance of the Evaluation 2

Evidence from Research on Two-Generational Services 3

Description of the Program Model 4

The Program Model's Theory of Change $\quad 6$

The Research Design, Sites, Characteristics of Sample Members, and Data Sources 10

$\begin{array}{ll}\text { The Structure of This Report } & 20\end{array}$

2 Program Implementation 21

$\begin{array}{ll}\text { Key Findings } & 21\end{array}$

The Framework of the Early Head Start Program 23

$\begin{array}{ll}\text { Self-Sufficiency Enhancements } & 25\end{array}$

Participation in Early Head Start Services $\quad 31$

Challenges of Implementing Self-Sufficiency Enhancements 41

Conclusion $\quad 44$

3 Impacts on Service Receipt 45

Receipt of Family Development Services $\quad 45$

Participation in Job Search, Education, and Training $\quad 54$

Participation Rates, by Child's Age $\quad 56$

Summary of Impacts on Service Receipt $\quad 62$

$4 \quad$ Impacts on Child Care and Early Educational Experiences 65

Full-Sample Impacts on the Use of Child Care 65

Subgroup Impacts on Child Care Experiences, by Child's Age 71

Summary of Impacts on Child Care $\quad 75$

$5 \quad$ Impacts on Employment, Earnings, and Household Income 77

Full-Sample Impacts on Employment, Earnings, and Income 78

Subgroup Impacts on Employment, Earnings, and Income, by Child's Age 83

Summary of Impacts on Employment, Earnings, and Income 92 
6 Impacts on Parenting Practices, Parental Psychological Well-Being, and Child Outcomes

Full-Sample Impacts on Parenting Practices and Parental Psychological Well-Being

Subgroup Impacts on Parenting Practices and Parental Psychological

Well-Being, by Child's Age

Summary of Impacts on Parenting Practices and Parental Psychological

Well-Being

103

Full-Sample Impacts on Child Outcomes

Subgroup Impacts on Child Outcomes, by Child's Age

108

Summary of Impacts on Child Outcomes

Appendix

A Response Bias Analysis: 18-Month Survey of Parents and Direct Child Assessments

B Characteristics of Sample Members at Baseline, by Child's Age

C Cost Analysis of the Programs in the Study Sites

D Impacts on Service Receipt

153

E Impacts on Child Care

165

F Impacts on Employment

171

G Impacts on Parent and Child Outcomes

References

195

Earlier MDRC Publications on the Enhanced Services for the Hard-to-Employ Demonstration and Evaluation 


\section{List of Tables, Figures, and Boxes}

\section{Table}

ES.1 Core Components and Service Delivery Options of Traditional EHS and

Service Delivery Options of Enhanced EHS

ES-3

ES.2 Impacts on Selected Outcomes for the Full Research Sample 18 Months After Random Assignment

ES.3 Impacts on Selected Outcomes 18 Months After Random Assignment, by Age of Child at Random Assignment

ES-9

1.1 Characteristics of Sample Members at Baseline, by Research Group Status

2.1 Engagement in Enhanced EHS in 18 months After Random Assignment

2.2 Topics Addressed in Meetings with EHS Staff, by Type of Meeting

2.3 Employment/Education Topics Addressed in Meetings with EHS Staff

2.4 Establishment of Family Goals

2.5 Screenings and Referrals

2.6 Reasons for Exiting Early Head Start in 18 Months After Random Assignment

2.7 Engagement in Enhanced Early Head Start in 18 Months After Random Assignment, by Age of Child at Random Assignment

2.8 Establishment of Family Goals in 18 Months After Random Assignment, by Age of Child at Random Assignment

2.9 Topics Addressed in Meetings with EHS Staff in 18 Months After Random Assignment, by Age of Child at Random Assignment

3.1 Impacts on Receipt of Family Development, Child-Focused, and Case Management Services 18 Months After Random Assignment, EHS/HS Providers Only

3.2 Impacts on Receipt of Family Development, Child-Focused, and Case Management Services 18 Months After Random Assignment, Both EHS/HS and Non-EHS/HS Providers

3.3 Impacts on Participation in Job Search, Education, and Training Activities

3.4 Impacts on Receipt of Family Development, Child-Focused, and Case Management Services 18 Months After Random Assignment, by Age of Child at Random Assignment, EHS/HS Providers Only 


\section{Table}

3.5 Impacts on Receipt of Family Development, Child-Focused, and Case Management Services 18 Months after Random Assignment, by Age of Child at Random Assignment, Both EHS/HS and Non-EHS/HS Providers

3.6 Impacts on Participation in Job Search, Education, and Training Activities, by Age of Child at Random Assignment

4.1 Impacts on Child Care Outcomes 68

4.2 Impacts on Child Care Outcomes, by Age of Child at Random Assignment 73

5.1 Impacts on Mothers' Quarterly Employment and Earnings 79

5.2 Impacts on Characteristics of Current Job $\quad 81$

5.3 Impacts on Household Income and Poverty Status 84

$5.4 \quad$ Impacts on Mothers' Quarterly Employment and Earnings, by Age of Child 86

5.5 Impacts on Characteristics of Current Job, by Age of Child at Random Assignment 88

5.6 Impacts on Household Income and Poverty Status, by Age of Child at Random $\begin{array}{ll}\text { Assignment } & 90\end{array}$

6.1 Impacts on Parenting Practices and Parental Psychological Well-Being 98

6.2 Impacts on Parenting Practices and Parental Psychological Well-Being, by $\begin{array}{ll}\text { Age of Child at Random Assignment } & 101\end{array}$

6.3 Impacts on Child Outcomes 107

6.4 Impacts on Child Outcomes, by Age of Child at Random Assignment 109

A.1 Baseline Characteristics of Parent Survey Respondents, by Research Group 119

A.2 Baseline Characteristics of Child Assessment Respondents, by Research Group 121

A.3 Baseline Characteristics of Parent Survey Respondents and Nonrespondents 123

A.4 Baseline Characteristics of Child Assessment Respondents and Nonrespondents 125

A.5 Six-Quarter Impacts for the Research Sample, Parent Survey Respondent and Nonrespondent Samples, and Child Assessment Respondent and Nonrespondent Samples

A.6 Impacts on Selected Outcomes for the Full Research Sample 18 Months After Random Assignment, Unweighted and Weighted for Nonresponse

A.7 Impacts on Selected Outcomes, by Age of Child at Random Assignment, 18 Months After Random Assignment, Unweighted and Weighted for Nonresponse 


\section{Table}

B.1 Characteristics of Sample Members at Baseline, by Age of Child at Random Assignment

C.1 Unit Costs for EHS and HS Activities

C.2 Estimated Gross and Net Costs per Sample Member Within 18 Months After Random Assignment (in 2008 Dollars)

C.3 Estimated Gross and Net Costs per Sample Member Within 18 Months After Random Assignment, by Age of Child at Random Assignment (in 2008 Dollars)

D.1 Impacts on Receipt of Family Development, Child-Focused, and Case Management Services 18 Months After Random Assignment, by Site, EHS/HS Providers Only

D.2 Impacts on Receipt of Family Development, Child-Focused, and Case Management Services 18 Months After Random Assignment, by Site, Both EHS/HS and Non-EHS/HS Providers

D.3 Impacts on Receipt of Family Development, Child-Focused, and Case Management Services 18 Months After Random Assignment, by Number of Parents in the Household at Random Assignment, EHS/HS Providers Only

D.4 Impacts on Receipt of Family Development, Child-Focused, and Case Management Services 18 Months After Random Assignment, by Number of Parents in the Household at Random Assignment, Both EHS/HS and Non-EHS/HS Providers

D.5 Impacts on Participation in Job Search, Education, and Training Activities, by Site

D.6 Impacts on Participation in Job Search, Education, and Training Activities, by Number of Parents in the Household at Random Assignment

E.1 Impacts on Child Care Outcomes, by Site

E.2 Impacts on Child Care Outcomes, by Number of Parents in the Household at Random Assignment

F.1 Impacts on Quarterly Employment and Earnings for the Household 173

F.2 Impacts on Characteristics of Current Job, by Site 174

F.3 Impacts on Household Income and Poverty Status, by Site 176

F.4 Impacts on Characteristics of Current Job, by Number of Parents in the Household at Random Assignment

F.5 Impacts on Household Income and Poverty Status, by Number of Parents in the Household at Random Assignment

F.6 Impacts on Mothers' Quarterly Employment and Earnings, by Site 


\section{Table}

F.7 Impacts on Mothers' Quarterly Employment and Earnings, by Number of Parents in the Household at Random Assignment

G.1 Impacts on Parenting Practices and Parental Psychological Well-Being, by Site

G.2 Impacts on Parenting Practices and Parental Psychological Well-Being, by Number of Parents in the Household at Random Assignment

G.3 Impacts on Child Outcomes, by Site

191

G.4 Impacts on Child Outcomes, by Number of Parents in the Household at Random Assignment

Figure

1.1 Conceptual Model of Enhanced EHS 7

1.2 Random Assignment Flow Chart 12

C.1 Simplified Diagram of Major Cost Components 140

Box

2.1 Core Features of the Early Head Start Programs 24

3.1 How to Read the Estimated Impact Tables in This Report 46

3.2 Other Community Programs Providing Family Development Services 53

4.1 Measures of Child Care Outcomes 66

6.1 Measures of Parenting Practices and Parental Psychological Well-Being 96

6.2 Measures of Child Outcomes 105

A.1 Key Analysis Samples 116 


\section{Acknowledgments}

This evaluation would not have been possible without the ongoing commitment of our sponsor, the U.S. Department of Health and Human Services, and supplemental funding from the Department of Labor.

For their support of this research, we are grateful to the staff and administrators at all levels of Southeast Kansas Community Action Program (SEK-CAP) and Youth in Need and the Early Head Start (EHS) and Head Start (HS) Policy Councils. We extend a heartfelt thanks to the many current and former home visitors, family support workers, and center-based staff of the EHS programs for their commitment to the families and children whom they serve and for giving their time and sharing their experiences with the research team. At SEK-CAP, we owe special thanks to Linda Broyles, Joanie Burke, Allison Grabs, and Regina Decker. At Youth in Need, we extend special thanks to James Braun, Daryl Rothman, Michelle Gorman, Laura Harrison, Joyce Rogers, and Michele Sexton.

This research received support from administrators and staff at all levels of the Kansas Department of Social and Rehabilitation Services and the Missouri Department of Social Services. We especially thank Mary Weathers, Paula Gibson, Alice Womack, and Carolyn Stemmons, who were generous with their advice and steadfast support of the evaluation.

Our gratitude goes out to our professional colleagues outside MDRC, including Nancy Pindus, Aaron Chalfin, and Jennifer Yahner at Urban Institute, who assisted in the cost analysis; Rachel Cook, Bret Barden, Michael Mueller, and Emily Rosenberg at The Lewin Group, who compiled and analyzed case file data for the implementation research; Christopher Smith at the University of Kansas, who compiled and analyzed program services data; and Lee Robeson at HumRRO, who oversaw the fielding of the survey and direct child assessments.

At MDRC, we are indebted to Pamela Morris, who spearheaded the launch of the evaluation and gave invaluable guidance throughout every stage of the project and the writing of the report. We owe much thanks to John Martinez, who reviewed multiple drafts of the report and provided much-needed support during the start-up phase of the project and our collaboration with the sites. Dan Bloom, David Butler, Ginger Knox, and Charles Michalopoulos provided guidance at various stages of the project and reviewed multiple drafts of the report; Johanna Walter oversaw the processing of the administrative data and contributed to the impact analysis; John Hutchins reviewed and edited multiple drafts of the report; Joel Gordon and Galina Farberova managed the random assignment process; Sally Dai processed the data from administrative records; Ximena Portilla and Francesca Longo tirelessly monitored the administration of the direct child assessments; Julia Gomez provided assistance on early drafts of the report; Tojuana Riley, Emily Terwelp, and Julianna Alson coordinated its production and fact- 
checking; Robert Weber edited the report; and David Sobel and Stephanie Cowell prepared it for publication.

Finally, we are deeply grateful to the families and children in the study sample. Whether participating in Enhanced EHS or as members of the control group, these families went through random assignment, granted us access to confidential information about themselves, and participated in surveys and assessments as part of the research effort. Without these families, our research would not have been possible.

The Authors 


\section{Executive Summary}

Living in poverty can have profound effects on young children's development and their prospects for the future. One promising strategy for addressing the challenges that low-income parents and their young children face is through two-generational services that aim to address both children's developmental risks and the often-precarious and unstable economic circumstances of low-income families.

As part of the multisite Enhanced Services for the Hard-to-Employ Demonstration and Evaluation Project (the Hard-to-Employ project), MDRC, together with its research partners, is conducting a rigorous evaluation of an enhanced version of the Early Head Start (EHS) program. In the program model being tested here, formalized parental employment and educational services were implemented within EHS, resulting in "Enhanced EHS," a two-generational, early childhood developmental program that serves low-income families who are expecting a child or who have a child under age 3. The Hard-to-Employ project is sponsored by the Administration for Children and Families and the Office of the Assistant Secretary for Planning and Evaluation in the U.S. Department of Health and Human Services (HHS), with additional funding from the U.S. Department of Labor.

This report discusses the challenges faced in implementing this Enhanced EHS program and presents short-term effects of the program on parents and their children approximately 18 months after families first enrolled in the study. MDRC randomly assigned families either to a program group that was eligible to receive Enhanced EHS or to a control group that was not enrolled in EHS services but could receive alternate services available in the local community. Any subsequent differences between families in the program and control groups can be attributed to Enhanced EHS.

\section{Key Findings}

- Though the programs in Kansas and Missouri were able to increase their focus on parental employment, educational, and self-sufficiency needs, enhanced EHS employment and educational services were modest in intensity, and participation rates were lower than expected.

- Consistent with a traditional EHS model, Enhanced EHS provided comprehensive child-focused, parent education, and family support services through home visits and center-based child care; however, receipt of similar services was also high among control group families. 
- Aside from affecting the type of child care used by families, Enhanced EHS had few impacts on parental employment, parenting behavior, and child well-being and development among the full research sample. These findings are not entirely surprising, given that programs had difficulties implementing enhanced EHS employment and educational services and that there was a relatively small differential in receipt of child development, parent education, and family support services between research groups.

- Beneficial impacts of Enhanced EHS are more evident among families who were expecting a child or who had an infant (a child younger than 12 months old) when they entered the study and are more variable among families who had a toddler (a child 12 months old or older), but this finding should be interpreted with caution because the research subgroups are small.

\section{What Is the Program Model?}

The program model that is being tested in two sites in Kansas and Missouri is an expanded version of EHS. It includes an array of intensive early childhood developmental services, parent education, family support, and social service assistance that are commonly found in traditional EHS programs plus formalized services aimed at proactively addressing parents' employment, educational, and self-sufficiency needs. The programs utilized mixedapproach service delivery models whereby families had the flexibility of receiving EHS services through either home-based or center-based delivery options. (See Table ES.1.) Families could cycle from one service option to the other, depending on their needs, but they could not receive both home- and center-based service options at the same time.

The programmatic enhancements that were aimed at parents' employment, educational, and self-sufficiency needs include:

1. Hiring on-site "self-sufficiency" specialist(s) to oversee and develop the programs' employment and educational services; to work directly with families on employment, educational, and self-sufficiency needs and goals; and to act as "resource experts" by developing resource guides to help staff identify available employment and training-related opportunities in the community

2. Building partnerships with welfare agencies and local programs that provide employment and training services

3. Conducting staff trainings on the use of employment and educational resource guides to further develop the skills and competencies of frontline EHS 
The Enhanced Services for the Hard-to-Employ Demonstration

Table ES.1

\section{Core Components and Service Delivery Options of Traditional EHS and Service Delivery Options of Enhanced EHS}

Early Head Start with Enhanced Self-Sufficiency Services

\begin{tabular}{|c|c|}
\hline Component & \\
\hline Home-based service option & $\begin{array}{l}\text { Families receive weekly home visits with bimonthly group socialization } \\
\text { experiences that facilitate interaction among families receiving EHS. Home } \\
\text { visits are conducted by EHS program staff and primarily focus on conducting } \\
\text { individualized developmental activities with children, demonstrating activities } \\
\text { that parents and children can engage in together to foster parent-child } \\
\text { interaction, modeling appropriate parenting behaviors, assessing children's } \\
\text { developmental progress, and addressing families' social service needs. }\end{array}$ \\
\hline Center-based service option & $\begin{array}{l}\text { Families receive high-quality, center-based child care for at least } 6 \text { hours a day, } \\
5 \text { days a week, either directly through EHS/HS centers or through child care } \\
\text { centers in the community that provide care in line with EHS quality and safety } \\
\text { requirements. While in center-based care, children receive daily lesson plans } \\
\text { and activities tailored to their individual developmental needs and those of other } \\
\text { children in the classroom. Families also engage in parent-teacher conferences or } \\
\text { home visits conducted on at least a quarterly basis (depending on the program } \\
\text { site and where children receive center-based care) in which parent education and } \\
\text { family support and social service needs are addressed. }\end{array}$ \\
\hline Other specialized EHS services & $\begin{array}{l}\text { All families, regardless of whether they receive home- or center-based service } \\
\text { options, also are offered an array of health, mental health, nutrition, and child } \\
\text { disability services directly through EHS or through referrals to other providers } \\
\text { in the community. }\end{array}$ \\
\hline
\end{tabular}

staff, so that they were able to work with parents on employment, training, and self-sufficiency goals as needed

4. Conducting parent trainings focused on employment, educational, and selfsufficiency issues

\section{Whom Did the Program Serve?}

Enhanced EHS targeted low-income families with infants and toddlers or families who were expecting a child. Beginning in 2004 and ending in 2006, in two program sites in Kansas and Missouri, a total of 610 families who were new applicants to Enhanced EHS were random- 
ly assigned in this study. ${ }^{1}$ About 90 percent of the primary parents who are identified on the EHS application forms are women. More than half were single and never married when they entered the study. Of the parents in the sample, 86 percent identified themselves as white, 8 percent as black, and 5 percent as Hispanic/Latino(a) regardless of race. Slightly more than half worked more than 12 months in the three years prior to random assignment; about one-third worked 12 months or less; and 15 percent had not worked at all during that period. Slightly less than one-third of families were receiving Temporary Assistance for Needy Families (TANF), and slightly less than half reported ever having received TANF before random assignment. At study entry, relative minorities of the sample were pregnant (11 percent) or teenage parents (12 percent). As expected, children in the sample were about evenly distributed between boys and girls. On average, they were about 17 months old on entering the study.

Although the study's sample mirrors in many ways the range of characteristics of families being served by EHS programs across the United States, it does include more white and fewer black and Hispanic/Latino(a) parents and children. ${ }^{2}$ This difference could have implications for the impacts detected here. Among sample members in the Early Head Start Research and Evaluation Project examining the effects of traditional EHS services, for example, impacts are larger in magnitude for ethnic minority families. ${ }^{3}$

\section{How Was Enhanced EHS Implemented?}

Following are the key findings about how Enhanced EHS was implemented in the two program sites in Kansas and Missouri.

- Programs were able to increase their focus on parental employment and educational needs; however, they struggled to make employment, educational, and self-sufficiency services core components of Enhanced EHS.

Programs successfully developed tools to assess parents' employment and educational needs and resource guides of available employment and educational services in the community,

\footnotetext{
${ }^{1}$ As is true with all applications to EHS, families identify a particular child who is up to age 3 or during the prenatal period and who will be enrolled in the program. In this study's 18-month parent survey and direct child assessments, this child is identified as the focal child who is the target of program services and is the focus of all questions related to child care and early educational experiences, parenting practices, and child development and well-being.

${ }^{2}$ Center for Law and Social Policy, "Early Head Start Participants, Programs, Families, and Staff in 2006" (Washington, DC: Center for Law and Social Policy, 2008).

${ }^{3}$ U.S. Department of Health and Human Services, Administration for Children and Families, Making a Difference in the Lives of Infants and Toddlers and Their Families: The Impacts of Early Head Start, Vol. I: Final Technical Report (Washington, DC: U.S. Department of Health and Human Services, Administration for Children and Families, 2002).
} 
and they hired on-site specialists who worked with program staff and families on issues related to parental employment, education, and self-sufficiency needs. Programs struggled, however, to integrate into their core EHS services and interactions with families a proactive focus on parental employment, educational, and self-sufficiency issues. Shifting the culture of a childfocused program to address parental employment and educational needs was difficult. Many frontline staff had little experience discussing such issues with parents. Some staff also did not feel comfortable encouraging parents to spend time away from their children in pursuit of employment or educational activities. Furthermore, Enhanced EHS staff noted in these interviews that some parents were not interested in receiving employment or educational services because they preferred to stay at home, especially when their children were young.

- The strength of Enhanced EHS was the provision of comprehensive home visiting and center-based child care aimed at enhancing infants' and toddlers' development and well-being, even though participating programs did not enhance these aspects of program services as part of this evaluation.

The Enhanced EHS programs in Kansas and Missouri did not seek to further enhance basic home visiting and center-based child care services as part of this evaluation. Like most traditional EHS programs, Enhanced EHS provided a comprehensive array of intensive childfocused developmental services, parent education, and family support and social service assistance, even as they sought to implement enhanced services aimed at addressing parents' employment, educational, and self-sufficiency needs.

- Among program group families, receipt of Enhanced EHS was relatively high, but receipt of enhanced parental employment and educational services was relatively low.

About 81 percent of families in the program group ever met with program staff or enrolled in Early Head Start or Head Start (EHS/HS) child care. Although 63 percent of program group families ever discussed employment, educational, or self-sufficiency issues with program staff, only 32 percent of parents in the program group ever met with the programs' self-sufficiency specialists. These participation rates likely reflect the voluntary nature of EHS programs, the lack of interest on the part of some families in receiving EHS employment and educational services, and difficulties in implementing the programmatic enhancements that focused on parental employment, educational, and self-sufficiency needs.

- Programs engaged a higher percentage of families with infants and pregnant women in Enhanced EHS services, and for longer periods of time, than families with toddlers (children 12 months or older) at study entry. 
In the program group, about 90 percent of families with infants and pregnant women ever met with Enhanced EHS program staff or enrolled in EHS center-based child care, compared with 73 percent of families with toddlers. Families with infants and pregnant women were also engaged in Enhanced EHS services for longer periods of time than their counterparts with older children, since they were less likely to age out of Enhanced EHS over the course of the 18-month follow-up period.

Furthermore, families with infants and pregnant women receiving Enhanced EHS were more likely than families with toddlers at study entry to receive home-based services, which provided more opportunities to interact directly with parents on a regular basis. Families receiving home-based services were also more likely to receive employment and educational services from the participating Enhanced EHS programs than families receiving center-based services.

- Enhanced EHS increased families' receipt of early childhood development, parent education, and family support services, but control group families also reported high levels of assistance in these areas.

Not surprisingly, a high proportion of families (91 percent) in the program group reported receiving assistance across these domains. Yet it appears that other early childhood development, parent education, and family support services were also readily available in these communities. Eighty percent of families in the control group reported receiving assistance in these areas, though the services provided by other community programs were generally less intense in terms of dosage and scope of services offered.

\section{Did Enhanced EHS Make a Difference for Parents and Children?}

Enhanced EHS had few overall impacts for the full research sample, but it shows some evidence of differential impacts on key employment, parenting, and child well-being outcomes, depending on the child's age.

- For the full research sample, Enhanced EHS affected the type of child care that families used but had no statistically significant impacts on employment, economic, and parenting outcomes. The program slightly increased children's abilities to regulate their behaviors, but it had no significant impacts on other aspects of child well-being and development.

As shown in Table ES.2, Enhanced EHS significantly increased families' use of formal child care, by 20 percentage points, and their use of EHS/HS center-based care, in particular, by 33 percentage points. However, Enhanced EHS did not significantly affect parental employment, economic, and parenting outcomes for the full research sample. The program did slightly 
The Enhanced Services for the Hard-to-Employ Demonstration

Table ES.2

\section{Impacts on Selected Outcomes for the Full Research Sample 18 Months After Random Assignment}

Early Head Start with Enhanced Self-Sufficiency Services

\begin{tabular}{|c|c|c|c|c|c|}
\hline Outcome & $\begin{array}{r}\text { Program } \\
\text { Group }\end{array}$ & $\begin{array}{r}\text { Control } \\
\text { Group }\end{array}$ & $\begin{array}{r}\text { Difference } \\
\text { (Impact) }\end{array}$ & $\begin{array}{r}\text { Effect } \\
\text { Size }^{\mathrm{a}} \\
\end{array}$ & P-Value \\
\hline \multicolumn{6}{|l|}{ Child care use outcomes (\%) } \\
\hline Any formal care & 57.2 & 37.1 & $20.1 * * *$ & 0.40 & 0.000 \\
\hline Early Head Start/Head Start care & 42.1 & 8.7 & $33.4 * * *$ & 0.77 & 0.000 \\
\hline Other formal care & 21.3 & 30.5 & $-9.2 * *$ & -0.21 & 0.018 \\
\hline Any home-based care & 54.7 & 63.6 & $-8.9 * *$ & -0.18 & 0.044 \\
\hline Care provided by relative & 42.9 & 47.3 & -4.4 & -0.09 & 0.333 \\
\hline Care provided by nonrelative & 24.1 & 38.4 & $-14.3 * * *$ & -0.31 & 0.001 \\
\hline \multicolumn{6}{|l|}{ Employment and income outcomes } \\
\hline Ever employed, Quarters 1-6 (\%) & 86.2 & 84.0 & 2.3 & 0.06 & 0.422 \\
\hline Total household income in prior month $(\$)$ & 1,904 & 2,001 & -96 & -0.07 & 0.439 \\
\hline Hours worked per week & 20.9 & 21.8 & -0.9 & -0.05 & 0.572 \\
\hline Hourly wage $(\$)$ & 5.4 & 6.0 & -0.6 & -0.11 & 0.209 \\
\hline Any job benefits $(\%)$ & 38.3 & 43.7 & -5.4 & -0.11 & 0.220 \\
\hline \multicolumn{6}{|l|}{ Parenting outcomes (\%) } \\
\hline \multicolumn{6}{|l|}{ Frequency of parenting warmth: } \\
\hline At least once a day & 98.2 & 98.5 & -0.2 & -0.02 & 0.839 \\
\hline \multicolumn{6}{|l|}{ Frequency of social play and cognitive stimulation: } \\
\hline At least once a day & 59.4 & 54.2 & 5.2 & 0.11 & 0.245 \\
\hline $\begin{array}{l}\text { Percentage of parents who suggest using only mild } \\
\text { disciplinary strategies in hypothetical situations }\end{array}$ & 86.4 & 82.4 & 4.0 & 0.11 & 0.240 \\
\hline \multicolumn{6}{|l|}{ Parental psychological well-being outcomes } \\
\hline Parenting stress and aggravation ${ }^{\mathrm{b}}$ & 1.5 & 1.5 & 0.0 & -0.02 & 0.851 \\
\hline Parental psychological distress ${ }^{\mathrm{c}}$ & 5.1 & 4.6 & 0.5 & 0.13 & 0.146 \\
\hline \multicolumn{6}{|l|}{ Child social and emotional outcomes } \\
\hline \multicolumn{6}{|l|}{ Self-regulation } \\
\hline Behavioral regulation $^{\mathrm{d}}$ & 0.9 & 0.7 & $0.2 * *$ & 0.22 & 0.026 \\
\hline Delay of gratification/impulse control ${ }^{\mathrm{e}}$ & 15.7 & 17.5 & -1.8 & -0.09 & 0.374 \\
\hline Total social and emotional problems & 11.6 & 11.8 & -0.2 & -0.03 & 0.754 \\
\hline Total social and emotional competencies & 17.6 & 17.4 & 0.2 & 0.09 & 0.321 \\
\hline Sample size $($ total $=481)$ & 237 & 244 & & & \\
\hline
\end{tabular}


Table ES.2 (continued)

SOURCES: MDRC calculations based on responses to the 18-month survey, direct child assessments of children's self-regulation outcomes, and the National Directory of New Hires database.

NOTES: Statistical significance levels are indicated as follows: $* * *=1$ percent; $* *=5$ percent; $*=10$ percent. The significance level indicates the probability that one would incorrectly conclude that a difference exists between research groups for the corresponding variable.

Results in this table are regression-adjusted using ordinary least squares, controlling for pre-random assignment characteristics.

aThe effect size is calculated by dividing the impact of the program (difference between program and control groups) by the observed variation for that outcome within the control group (the control group standard deviation).

bParenting stress and aggravation are measured by a composite scale (from 1 to 5 ) that averages seven items assessing the degree of difficulty that parents experienced in caring for the focal child (Abidin, "Parenting Stress Index — Short Form,” 3rd ed. Odessa, FL: Psychological Assessment Resources, Inc., 1995).

"Parental psychological distress is measured on a scale of 1 to 25 using the K-6 Mental Health Screening Tool (Kessler, Barker, Colpe, Epstein, Gfroerer, Hiripi, Howes, Normand, Manderscheid, Walters, and Zaslavsky, "Screening for Serious Mental Illness in the General Population," Archives of General Psychiatry 60: 184-189 [2003]).

${ }^{\mathrm{d} C h i l d r e n ' s ~ b e h a v i o r a l ~ r e g u l a t i o n ~ i s ~ m e a s u r e d ~ b y ~ a ~ c o m p o s i t e ~ m e a s u r e ~ b a s e d ~ o n ~ w h e t h e r ~ t h e ~ c h i l d ~ s l o w e d ~}$ down during none, one, or two direct child assessment tasks in which the child was asked to draw circles and to walk a line at varying speeds.

'Children's delay of gratification is measured by a single direct assessment in which children are asked to wait and not to peek while the interviewer noisily pretends to wrap a "gift." The outcome is the latency to first peek, in seconds, during the waiting period.

increase children's abilities to regulate their behaviors, but it had no impacts on other aspects of children's language, cognitive, and social and emotional outcomes, for the full research sample. It is likely that the lack of overall significant impacts for the full research sample reflects difficulties in implementing enhanced EHS employment and educational services, lower-thanexpected participation rates and service receipt among program group families, and high levels of engagement in child-focused, parent education, and family support services among control group families.

- Consistent with prior studies of EHS, positive impacts of Enhanced EHS seem to be more evident among families who had infants and pregnant women when they first entered the study, but this finding should be interpreted with caution because the research subgroup is small.

As shown in Table ES.3, a clustering of more pronounced positive impacts on key parent and child outcomes was found among families who were expecting a child or had infants at study entry. It could be that families with infants and pregnant women were more likely to benefit from Enhanced EHS because they were engaged in program services, particularly Enhanced EHS home-based services, at higher rates and for longer periods of time than their counterparts with older children at study entry. 


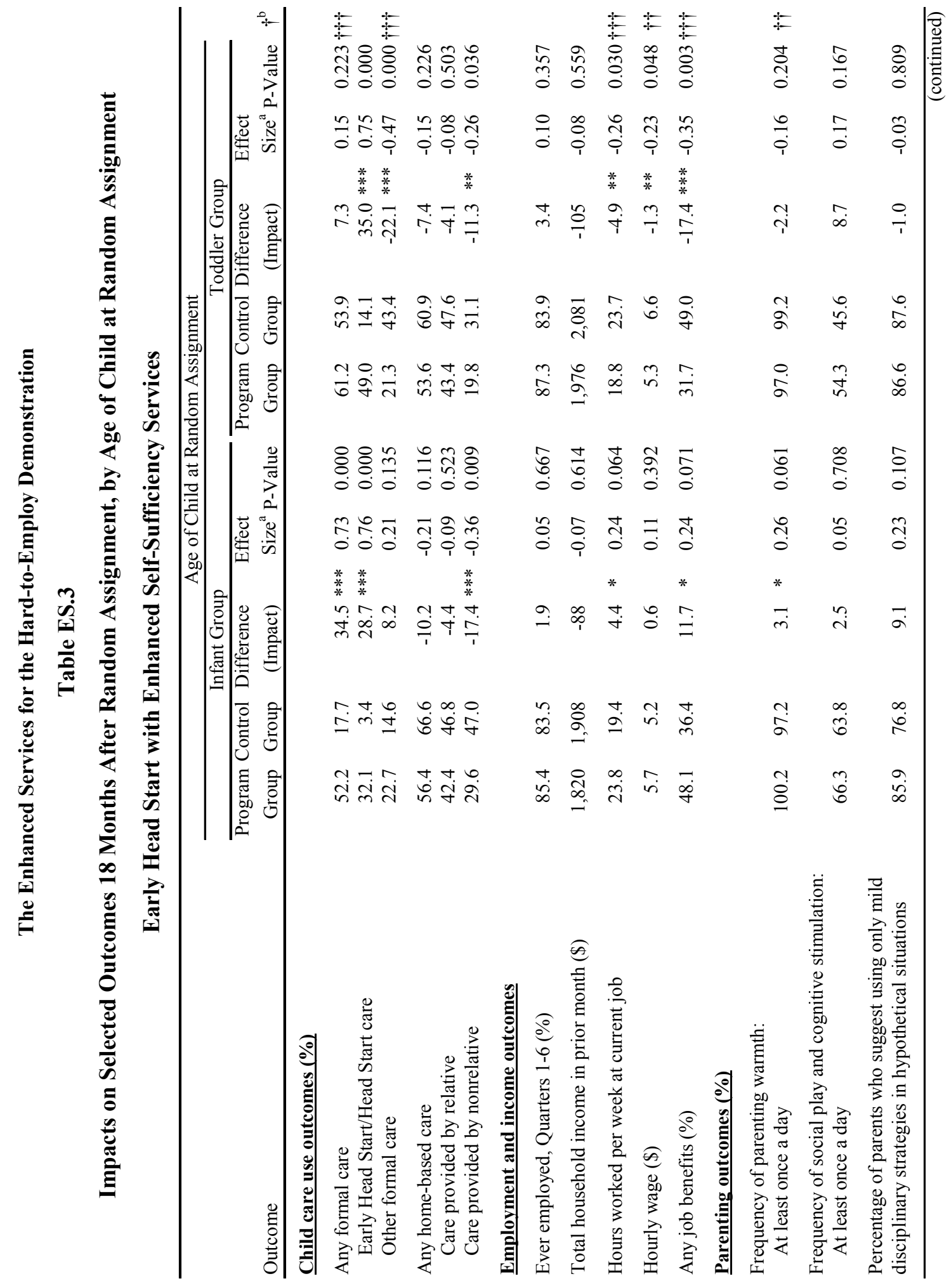




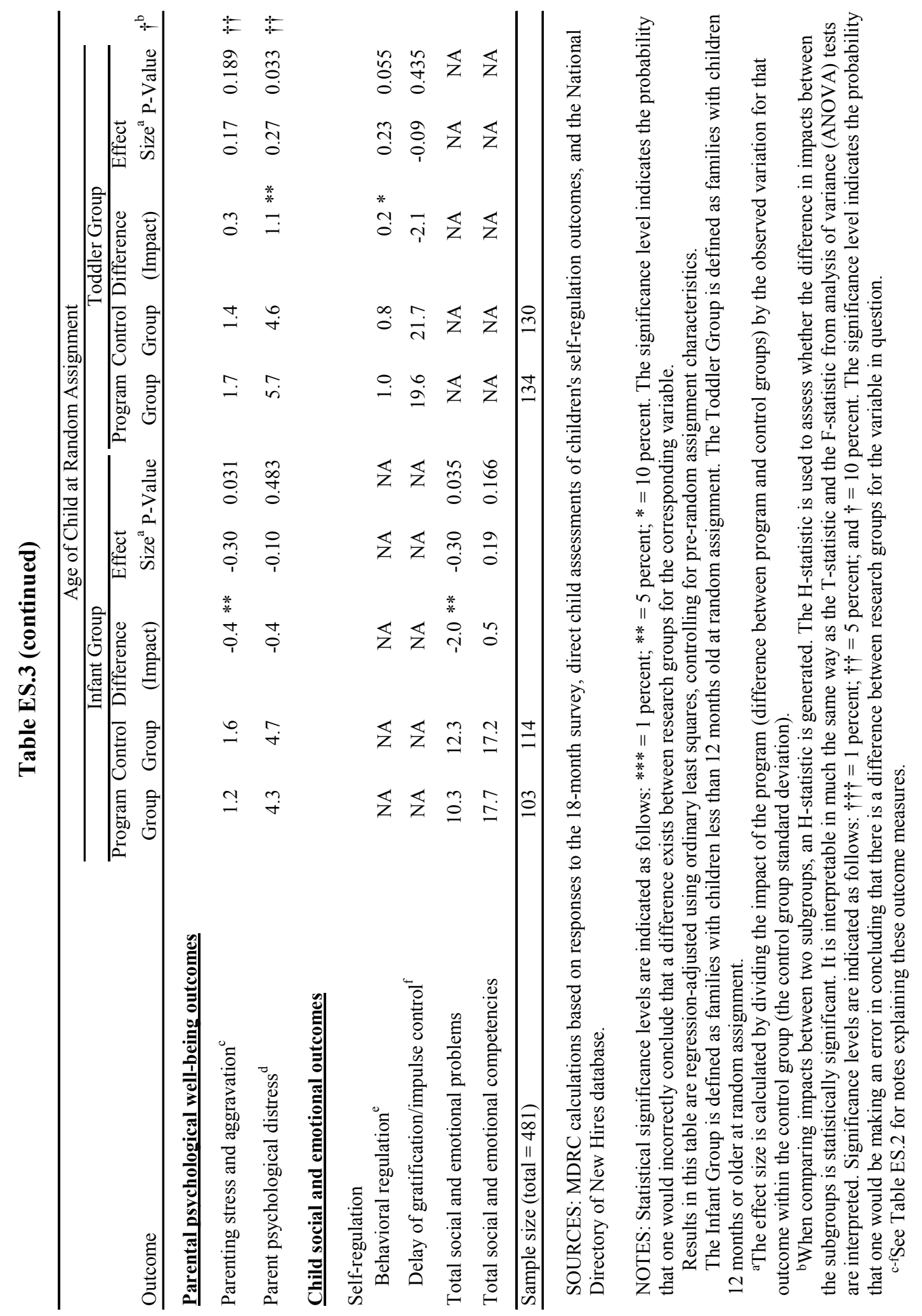

ES-10 
Consistent with impacts for the full research sample, Enhanced EHS appears to have increased the use of formal child care, and of EHS/HS care in particular, while decreasing the extent to which families with infants and pregnant women on study entry relied on home-based care arrangements provided by nonrelatives.

Enhanced EHS did not affect most employment and economic outcomes examined; however, it appears to have improved parents' earnings late in the follow-up period among families who were pregnant or had infants (not shown). In addition, Enhanced EHS might have improved employment and job-quality outcomes for parents in this subgroup of families (Table ES.3): parents with infants and pregnant women at study entry in the program group worked more hours, were more likely to receive such benefits as sick or vacation days with full pay and health insurance coverage, and perceived greater workplace flexibility to tend to the needs of their families and children than parents with infants and pregnant women in the control group.

Lastly, Enhanced EHS increased parental warmth and decreased parenting-specific stress and aggravation among families who were pregnant or had infants when they entered the study (Table ES.3). Again, these effects are generally modest in magnitude. Parents in the program group also reported that infants showed fewer social and emotional behavior problems than parents in the control group did.

\section{- Enhanced EHS appears to have had varying impacts among families} with toddlers at study entry, but this finding should be interpreted with caution because this research subgroup is small.

Enhanced EHS increased the extent to which families with toddlers relied on EHS/HS care and decreased their reliance on home-based care provided by nonrelatives. However, in contrast to impacts among families with infants at study entry, Enhanced EHS decreased the use of other forms of formal care but did not affect the overall use of formal child care among families with toddlers at study entry (Table ES.3).

Although Enhanced EHS did not affect most employment and economic outcomes examined, toward the end of the follow-up period, program group parents with toddlers appear to have earned slightly less than their counterparts in the control group (not shown). Enhanced EHS also appears to have reduced the hours that parents worked, their wages, and whether they received benefits at their jobs (Table ES.3). Yet, among families with toddlers (not shown), Enhanced EHS appears to have facilitated the balance between family and work demands by reducing the extent to which family life interfered with parents' abilities to go to work.

Lastly, Enhanced EHS did not significantly affect parenting behaviors or parentingspecific stress, but it appears to have increased parents' reports of psychological distress among families with toddlers at study entry (Table ES.3). However, in line with earlier findings for 
families with infants, Enhanced EHS also appears to have enhanced toddlers' self-regulation, as evidenced by their abilities to regulate their behaviors on tasks when they were asked to walk a line and draw circles at varying speeds.

\section{What Are the Implications of the Results?}

The foregoing findings illuminate the real-world challenges of implementing enhanced parental employment and educational services within the scope of an early childhood intervention. First, it can be difficult to ensure that program staff view addressing parents' employment, educational, and self-sufficiency needs as core components of program services and are comfortable encouraging parents to pursue employment and educational activities, particularly when children are very young. Second, some parents who seek out early childhood development services prefer to be at home while their children are young.

The story is still unfolding as to whether a parental employment, educational, and selfsufficiency enhancement to an early childhood, two-generational program - such as Enhanced EHS - can be effective at promoting better employment, economic, and child wellbeing outcomes for low-income families. The short-term results of this study are mixed. The study finds little evidence that the program improved outcomes for low-income parents and children in the full research sample approximately 18 months after families first enrolled in the study. However, preliminary evidence suggests that beneficial impacts of the program may be evident among families who were expecting a child or had a very young infant when they first entered the study.

To better understand the long-term effects of Enhanced EHS, this study will continue to track sample members and will collect information on key employment, economic, parenting, and child well-being outcomes about 42 months after families first entered the study. Future analyses will also aim to disentangle the mechanisms by which Enhanced EHS might influence outcomes for parents and children. 


\section{Chapter 1}

\section{Introduction}

Are there strategies that can improve low-income parents' employment and economic self-sufficiency while enhancing their young children's development? Living in poverty can have profound effects on young children's development and their prospects for the future. One promising way to address the precarious economic circumstances of low-income families and the developmental risks that young children face is through two-generational services aimed at dually addressing low-income parents' employment and economic self-sufficiency needs and the developmental needs of their young children.

This report presents interim results from a rigorous evaluation of an enhancement to a two-generational, early childhood program aimed at addressing the needs of low-income parents who are at risk for unemployment. In the program being evaluated here in two sites in Kansas and Missouri, a proactive program focusing on parental employment and the economic self-sufficiency needs of families was implemented within a traditional Early Head Start (EHS) program. The enhancements together with traditional EHS services offered by the program are referred to as "Enhanced EHS." It included the addition of on-site self-sufficiency specialists to work with program staff and families on topics related to employment, education, and selfsufficiency; formalized employment and self-sufficiency services; and community partnerships with local employment-focused and educational agencies. This program represents one of four strategies being studied in the Enhanced Services for the Hard-to-Employ Demonstration and Evaluation Project (the Hard-to-Employ project). The evaluation is sponsored by the Administration for Children and Families and the Office of the Assistant Secretary for Planning and Evaluation in the U.S. Department of Health and Human Services (HHS), with additional funding from the Department of Labor.

The results of the evaluation indicate that Enhanced EHS had few overall effects on parental employment, family functioning, and child well-being over the 18-month follow-up period. Although there is some evidence to suggest that the program's positive impacts in these areas were concentrated among families who were expecting a child or had a very young infant when they first entered the study, these results should be interpreted with caution, given the relatively small size of the research sample. The lack of overall impacts for the full research sample could reflect difficulties in enhancing EHS services with a focus on parental employment and self-sufficiency. Though program operators aimed to add employment and self-

sufficiency services to the existing EHS programs, the full potential of these enhancements may not have been realized. First, shifting the culture of an early childhood educational program toward a focus on parental employment, education, and self-sufficiency needs was difficult; 
some frontline staff had little experience addressing parental employment and educational issues or did not see their primary role as pushing parents - primarily mothers with very young children - to spend time away from their children in pursuit of employment or educational activities. Similarly, some parents expressed a preference for staying at home, especially when their children were young. Second, the implementation and impact analyses indicate that control group families received a relatively high dosage of family development, parenting education, and child-focused services from other early childhood and child development programs in the community - services that were similar to but less intense than what the program group received in Enhanced EHS. This might have diluted the degree to which the program was capable of producing measurable changes in the lives of parents and children relative to their counterparts in the control group.

This chapter first explains the background and relevance of the evaluation and summarizes the related research. Then it presents an overview of the Enhanced EHS model and its theory of change - hypotheses about how the program might lead to improved outcomes for low-income parents and their young children. That is followed by descriptions of the study's research design and sites, the characteristics of the sample members when they entered the study, and the sources of data used in the analysis. The chapter concludes by outlining the structure of the report.

\section{The Background and Policy Relevance of the Evaluation}

The rate of child poverty in the United States remains persistently high. In 2007, over 13 million children under the age of 18 lived in families with incomes below the federal poverty level. When families living at or near poverty thresholds are considered - that is, below 200 percent of the federal poverty level - the number of children living in low-income families jumps to more than 28 million, or 39 percent of all children in the United States. ${ }^{1}$ The statistics isolating the economic plight of families with infants and toddlers (children age 3 or younger) are even more troubling. Of the 12 million infants and toddlers living in the United States in 2007, 5.4 million (43 percent) lived in low-income families, and 2.7 million (21 percent) lived in families with incomes below the federal poverty level. ${ }^{2}$

Families' economic hardships and unstable financial circumstances can have harmful consequences for children. Numerous studies have found that living in poverty can impede young children's cognitive development and can contribute to poorer physical health outcomes

\footnotetext{
${ }^{1}$ Fass and Cauthen (2008).

${ }^{2}$ Douglas-Hall and Chau (2008).
} 
as well as social, emotional, and behavioral problems. ${ }^{3}$ The children who appear to be at greatest risk are infants and toddlers and children whose families experience chronic and severe economic hardships. ${ }^{4}$ Thus, there are particular concerns about the plight of very young children whose parents or families face serious obstacles to achieving stable employment and economic self-sufficiency; in essence, such risk factors as depression, severe stress, low levels of education, substance abuse, and family violence can make it difficult for parents to achieve economic stability and are often the same factors that impinge on their abilities to support and nurture their children and that place children at developmental risk. ${ }^{5}$ At the same time, these relationships tend to be bidirectional, such that having children with chronic and severe developmental and physical health issues can also interfere with parents' abilities to maintain sustained employment and economic self-sufficiency. ${ }^{6}$

\section{Evidence from Research on Two-Generational Services}

In most two-generational programs, early childhood educational services are offered to children, while parents are offered services to help them enhance their parenting skills and, sometimes, to address their social service needs.

A review of several major studies of early childhood programs highlights the potential of two-generational approaches for enhancing children's cognitive, ${ }^{7}$ language, ${ }^{8}$ and social, emotional, and behavioral development. ${ }^{9}$ Such programs have also been shown to improve parenting behaviors (for example, by decreasing harsh parenting and increasing emotional warmth and support ${ }^{10}$ and parental employment and economic self-sufficiency. ${ }^{11}$ This evidence suggests that a combined approach of home- and center-based services might be particularly

${ }^{3}$ Duncan and Brooks-Gunn (1997, 2000).

${ }^{4}$ Duncan, Brooks-Gunn, and Klebanov (1994).

${ }^{5}$ Evans (2004); Evans and English (2002).

${ }^{6}$ Danziger, Kalil, and Anderson (2000).

${ }^{7}$ U.S. Department of Health and Human Services, Administration for Children and Families (2002); Brooks-Gunn, Klebanov, Liaw, and Spiker (1993); Campbell and Ramey (1994); Dokecki, Hargrove, and Sandler (1983); Ramey and Campbell (1991); St. Pierre, Layzer, Goodson, and Bernstein (1997); Wasik, Ramey, Bryant, and Sparling (1990).

${ }^{8}$ U.S. Department of Health and Human Services, Administration for Children and Families (2002); Wasik, Ramey, Bryant, and Sparling (1990).

${ }^{9}$ Brooks-Gunn, Klebanov, Liaw, and Spiker (1993); St. Pierre, Layzer, Goodson, and Bernstein (1997).

${ }^{10}$ U.S. Department of Health and Human Services, Administration for Children and Families (2002); Dokecki, Hargrove, and Sandler (1983); Travers, Nauta, and Irvin (1982); Olds et al. (1999); St. Pierre, Layzer, Goodson, and Bernstein (1997).

${ }^{11}$ Administration for Children and Families (2002); Olds et al. (1999); St. Pierre, Layzer, Goodson, and Bernstein (1997). 
powerful for mitigating multiple family risk factors and affecting the broadest range of parent and child outcomes. ${ }^{12}$

At the same time, the short-term effects - particularly in terms of parental employment and economic outcomes - are often modest in magnitude, and many of the programs' effects tend to fade over time, ${ }^{13}$ suggesting that there may be ways to further enhance key programmatic components of two-generational services. Furthermore, there is great diversity in the approaches taken by two-generational programs in serving low-income families, not only in terms of the timing, duration, and intensity of child-focused and parenting services but also in the nature and degree to which services proactively focus on parents' social service needs particularly their employment, educational, and economic self-sufficiency needs. ${ }^{14}$ In general, programs tend to react to parents' employment and economic crises (such as job loss), rather than proactively assisting parents to achieve more stable employment in order to become economically self-sufficient.

Taken together, earlier research demonstrates the promise of a multipronged approach to address challenges that low-income parents and their young children face, ${ }^{15}$ and yet it also highlights opportunities to enhance early childhood, two-generational programs with a more proactive focus on parents' employment and economic self-sufficiency needs.

\section{Description of the Program Model}

This evaluation tests a model consisting of a proactive program focusing on the employment and economic self-sufficiency needs of low-income parents that was implemented within a two-generational, early childhood education program. The evaluation builds on two existing EHS programs that operated in Kansas and Missouri. The program model being tested includes all the home- and center-based, early childhood developmental, parent education, and family development services that are typically found in traditional EHS programs plus an expanded parental self-sufficiency component aimed at helping parents work toward educational, employment, and economic self-sufficiency goals.

\footnotetext{
${ }^{12}$ U.S. Department of Health and Human Services, Administration for Children and Families (2002); Brooks-Gunn, Klebanov, Liaw, and Spiker (1993); St. Pierre, Layzer, Goodson, and Bernstein (1997).

${ }^{13}$ U.S. Department of Health and Human Services, Administration for Children and Families (2002); Olds et al. (1999); St. Pierre, Layzer, Goodson, and Bernstein (1997); Wasik, Ramey, Bryant, and Sparling (1990).

${ }^{14}$ U.S. Department of Health and Human Services, Administration for Children and Families (2002).

${ }^{15}$ Brooks-Gunn, Berlin, and Fuligni (2000); Yoshikawa (1994).
} 


\section{Early Head Start}

Early Head Start (EHS), an early childhood program that serves pregnant women and families with children under age 3, emerged as an early candidate for the Hard-to-Employ project for three reasons. First, EHS focuses on promoting children's school readiness and developmental outcomes by providing a range of intensive child-focused, parent education, and family development services through home visits and high-quality, center-based child care. Second, a strong programmatic emphasis is placed on directly enhancing young children's physical, behavioral, language, and cognitive development and on indirectly supporting their well-being by promoting positive parent-child relationships and addressing parents' mental health and families' social service needs, as well as by promoting healthy prenatal outcomes for pregnant women. Third, EHS targets and places a priority on high-needs and low-income families, many of whom experience multiple barriers to employment and financial self-sufficiency.

The goals of traditional EHS are generally achieved through a variety of program options, including (1) center-based services, which provide all child-focused and family development services to families through center-based child care services; (2) home-based services, which provide all services to families through weekly home visits, and the program is responsible for ensuring that families who need child care find high-quality care in the community; and (3) mixed-approach services, whereby families receive a combination of home-based and center-based services at the same time or they cycle from one service option to the other but do not receive both types of services at the same time. In the Hard-to-Employ project, the focus is placed on EHS services that are delivered using a mixed-approach program model.

\section{Programmatic Enhancements to Existing EHS Self-Sufficiency Services}

The program model tested here is an expanded version of EHS, which has been enhanced with a more explicit programmatic focus on parental employment, education, and economic self-sufficiency. The EHS programs participating in this evaluation were interested in increasing their focus on these issues and were enhanced with additional funding from the Head Start Bureau and close technical assistance from MDRC. A brief description of the Enhanced EHS services is provided below, and Chapter 2 presents a more detailed description of the Enhanced EHS programs that were implemented in Kansas and Missouri. Through this collaborative effort, formalized parental employment, educational, and self-sufficiency EHS services were developed, including:

1. Hiring on-site "self-sufficiency" specialists(s) to oversee and develop the programs' employment and self-sufficiency services; to work directly with families on employment, educational, and self-sufficiency needs and goals; and to act as "resource experts" by developing resource guides to help staff 
identify available employment and training-related opportunities in the community

2. Building partnerships with welfare agencies and local programs that provide employment and training services

3. Conducting staff trainings on the use of employment and educational resource guides to further develop the skills and competencies of frontline EHS staff, so that they were able to work with parents' employment, training, and self-sufficiency goals as needed

4. Conducting parent trainings focused on employment, educational, and selfsufficiency issues

\section{The Program Model's Theory of Change}

The ultimate goals of interventions being studied in the Hard-to-Employ project are to help individuals who face significant barriers to employment achieve stable employment and reduce their risk of dependency on public assistance, in order to benefit themselves and their families and children. Figure 1.1 depicts the logic behind how Enhanced EHS might lead to improved parental employment and economic self-sufficiency and to enhanced children's wellbeing. As shown in this conceptual model, Enhanced EHS could affect a range of services that participating families receive, including (1) child-focused services delivered in center- and/or home-based settings; (2) employment, educational, and self-sufficiency services; and (3) parenting, parent education, and family development services.

The following section discusses how program-driven changes in service receipt are expected to improve parental employment and economic self-sufficiency outcomes as well as children's development and well-being. Direct and indirect pathways and the synergistic effects by which Enhanced EHS could affect parental and child outcomes are hypothesized. Lastly, the section considers how the impacts of Enhanced EHS might vary with the child's age.

\section{Enhancing Parental Employment and Economic Self-Sufficiency}

Enhanced EHS is expected to directly improve parents' abilities to sustain employment and their families' financial circumstances by way of a proactive programmatic focus on parental employment and economic self-sufficiency needs. At the same time, Enhanced EHS may also indirectly improve parental employment and self-sufficiency outcomes by targeting common barriers to sustained parental employment - such as low levels of education, child 


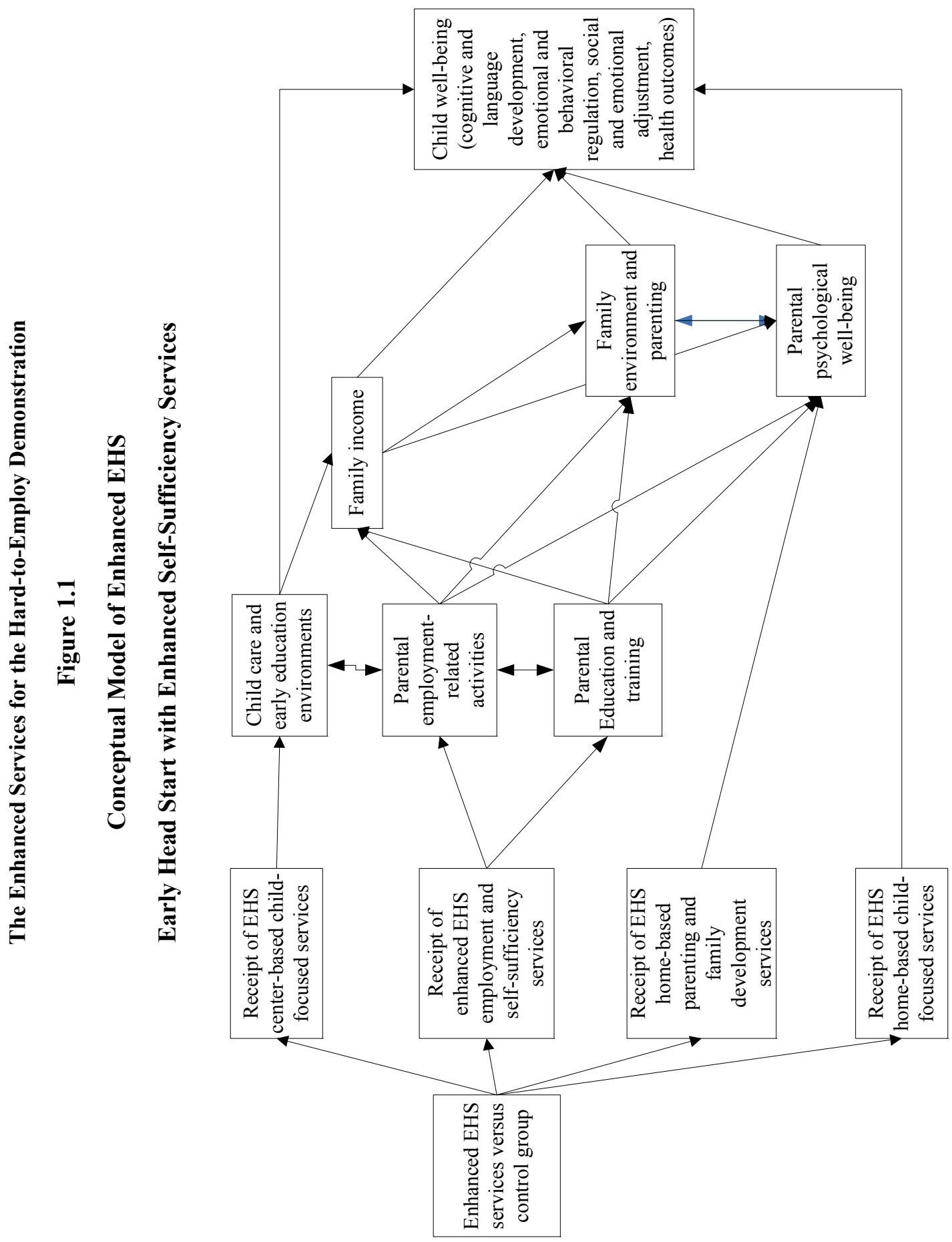


care problems, and parental mental health issues ${ }^{16}$ - through the provision of reliable, highquality center-based care and other home-based and mental health services directly aimed at supporting parents' and children's well-being.

\section{Benefiting Children's Development and Well-Being}

Enhanced EHS is also expected to benefit children directly through child-focused home-based services and the provision of reliable, high-quality, center-based care - a form of child care that experimental and nonexperimental research has generally linked with better cognitive development and positive behavior. ${ }^{17}$ At the same time, the provision of parenting, parent education, and family development services could directly and indirectly result in psychological benefits for parents and more positive family environments and parenting, such as the use of more effective disciplinary strategies, emotionally supportive parent-child relations, and parental engagement in more cognitively stimulating activities in the home. As such, Enhanced EHS can have synergistic benefits for children by changing multiple aspects of child care and early educational experiences outside the home - as well as experiences in the home, by improving parental psychological well-being, family functioning, and parenting practices.

This pattern of impacts on children's well-being may become more evident if Enhanced EHS also improves parental employment, education, and economic outcomes. First, parents' reliance and need for nonparental child care may increase as a result of receiving Enhanced EHS. Thus, children in families receiving the program may spend more time in child care overall and notably more time in EHS center-based child care, which could benefit their wellbeing. Second, program-driven increases in income and parental employment and education might contribute to positive parenting, not only by enhancing parents' ability to buy cognitively stimulating materials for their children but also by enhancing parents' psychological well-being, which enables them to engage in more supportive and educational interactions with their children, such as talking, reading, teaching, showing affection to, and encouraging them. ${ }^{18}$

It could also be that parental employment and families' uncertain financial circumstances interfere with child care and children's early educational experiences and parenting, if parents find only low-wage or poor-quality jobs as result of receiving Enhanced EHS services. There can be more constraints on how parents' spend their money, and earnings may not offset work-related costs, such as child care and domestic help. ${ }^{19}$ These stressors can impinge on

\footnotetext{
${ }^{16}$ Danziger, Kalil, and Anderson (2000).

${ }^{17}$ NICHD Early Child Care Research Network (2002a, 2002b); NICHD Early Child Care Research Network and Duncan (2003).

${ }^{18}$ Hoffman (1989); McLoyd (1990); Sears and Galambos (1992).

${ }^{19}$ Edin and Lein (1997).
} 
parents' mental health over time. However, it is less likely that such stressors will outweigh the program's potential benefits for parental psychological well-being and parent-child relations because Enhanced EHS takes a multipronged approach to support nurturing parent-child relations; healthy physical, cognitive, and socioemotional child development; and parents' employment, educational, and self-sufficiency needs.

\section{How Might the Impacts of Enhanced EHS Differ by a Child's Age?}

There are a number of reasons to expect that the effects of Enhanced EHS might vary with children's ages at the time that families receive program services.

First, because families are no longer eligible for EHS services when children turn 3 years old, mothers who were pregnant and families with newborns and infants could be enrolled in the program for potentially longer periods of time than those who enrolled when children were toddlers. This could result in potentially stronger effects for pregnant women and families with younger children at study entry.

Second, prior evaluation evidence of two-generational programs - like the Early Head Start Research and Evaluation project - and other child-focused and family development programs suggest that early intervention, either before or immediately after the birth of a child, is a particularly effective strategy for improving family functioning and parenting behaviors. ${ }^{20}$ This suggests that Enhanced EHS might be more effective at promoting positive outcomes among families who first enrolled in the program when children were newborn infants or mothers were pregnant.

Third, in the literature, it has often been debated whether early maternal employment and nonparental care, particularly center-based care, has beneficial effects for very young children. For example, in contrast to the research summarized above, some recent nonexperimental findings suggest that early maternal employment - especially when a mother is employed full time during the first year of a child's life - can have adverse effects on some aspects of child development. ${ }^{21}$ These findings coincide with nonexperimental evidence elsewhere suggesting that center-based child care can, at times, have negative consequences for children, such as increased behavior problems and aggression in preschool and early school when children enter center-based care at an early age or are in child care for extended hours. ${ }^{22}$ In general, however, the expectation is that the high-quality, child-focused nature of Enhanced

\footnotetext{
${ }^{20}$ U.S. Department of Health and Human Services, Administration for Children and Families (2002); Brooks-Gunn, Klebanov, Liaw, and Spiker (1993); Olds et al. (1999).

${ }^{21}$ Waldfogel, Han, and Brooks-Gunn (2002); Brooks-Gunn, Han, and Waldfogel (2002).

${ }^{22}$ Belsky (2001); NICHD Early Child Care Research Network (2003a, 2003b).
} 
EHS center-based services - as well as the social support, parent education, and family development EHS services - will benefit very young infants and their families and that these benefits would outweigh potential risks that early nonparental care or maternal employment might have on young children.

Taken together, the prior research leads to questions about whether the impacts of Enhanced EHS will depend on the focal child's age. ${ }^{23}$ To disentangle these competing hypotheses, the impact analysis centers on whether there are differential effects of Enhanced EHS for families who were expecting a child or who had children younger than 12 months at random assignment (collectively defined as "families with infants") and for families with children 12 months or older at random assignment (defined as "families with toddlers").

It is worth noting that a number of additional competing hypotheses can also be generated about how the program's impacts might vary by other family characteristics, such as single- and two-parent status. For example, one could imagine how the program's impact on parental, and particularly maternal, employment might vary depending on whether another parent is present in the household and whether that parent is employed. Therefore, impact analyses were explored separately for single- and two-parent households as well.

Finally, it is possible that impacts could vary by site. As discussed in Chapter 2, the program sites took various approaches to implementing core and enhanced EHS services focused on parental employment and self-sufficiency needs and differed in site-level characteristics, such as urbanicity, employment and educational opportunities, and available services in the local communities. It is possible that certain program approaches are more effective or less effective at increasing parental employment in urban/suburban settings, as opposed to more rural areas. Though it is impossible to disentangle which service and contextual factors would drive any differences in impacts, impact analyses were explored separately by site as well.

\section{The Research Design, Sites, Characteristics of Sample Members, and Data Sources}

This evaluation uses a random assignment research design to test the effects - on parents and their young children - of the package of Enhanced EHS services, including programmatic enhancements to self-sufficiency services. This section first describes how families

\footnotetext{
${ }^{23}$ As is true with all applications to EHS, families identify a particular child who is up to age 3 or during the prenatal period and who will be enrolled in the program. In this study's 18-month parent survey and direct child assessments, this child is identified as the focal child who is the target of program services and is the focus of all questions related to child care and early educational experiences, parenting practices, and child development and well-being.
} 
became part of the research sample and were randomly assigned. Then it describes the sites participating in the evaluation and some characteristics of the study's sample members. The section concludes with a discussion of the data sources used in this report and the follow-up periods for the impact analysis.

\section{The Research Design, Sample Intake, and Random Assignment Process}

The target population for the study included low-income families with infants and toddlers and pregnant women who were new applicants to Enhanced EHS. The programs targeted families who met the following eligibility criteria: ${ }^{24}$

- Had a family income at or below the federal poverty threshold ${ }^{25}$

- Had a child under the age of 3 or were expecting a child

- Lived in the Enhanced EHS program's designated service area

New applicant families were recruited and randomly assigned into Enhanced EHS on a rolling basis beginning in late July or early August 2004 and ending in December 2006. A total of 610 families were randomly assigned - 305 families in each research group.

Figure 1.2 illustrates the sample intake and random assignment process. Families who were interested in receiving Enhanced EHS completed an application. After verifying their eligibility for Enhanced EHS, families were assigned a priority score based on their specific needs, barriers to employment, or circumstances. Priority was given to pregnant women and families who had infants or toddlers and those who had particular characteristics related to employment, welfare receipt, parent or child disability, or teenage parental status. ${ }^{26}$ For the purposes of the evaluation, program staff then explained the study and the random assignment

\footnotetext{
${ }^{24}$ These eligibility criteria mirror those that were utilized by the existing EHS programs prior to participating in this evaluation.

${ }^{25}$ In some cases, the income requirement could be waived if the child or family had special needs or other selected criteria, like an older sibling enrolled in Early Head Start or Head Start (EHS/HS). Programs participating in this evaluation set their own criteria for circumstances in which the eligibility criteria could be waived. However, no more than 10 percent of a program's enrolled caseload could exceed the income eligibility requirement at any time.

${ }^{26}$ To ensure that the neediest families (such as those with children who had disabilities) were not excluded from receiving services and that the programs were able to meet Head Start Program Performance Standards while random assignment continued, each program was given a set number of exemptions from random assignment per year (determined as a percentage of projected new enrollees to the program), to be used for families based on specific criteria defined by the programs before the start of the study (such as having a child with a disability or a sibling already enrolled in EHS/HS services). A small number of families who met these exemption criteria were allowed to bypass random assignment and were enrolled in Enhanced EHS, but they were excluded from the study sample and from this report's implementation and impact analyses.
} 
The Enhanced Services for the Hard-to-Employ Demonstration

Figure 1.2

\section{Random Assignment Flow Chart}

\section{Early Head Start with Enhanced Self-Sufficiency Services}

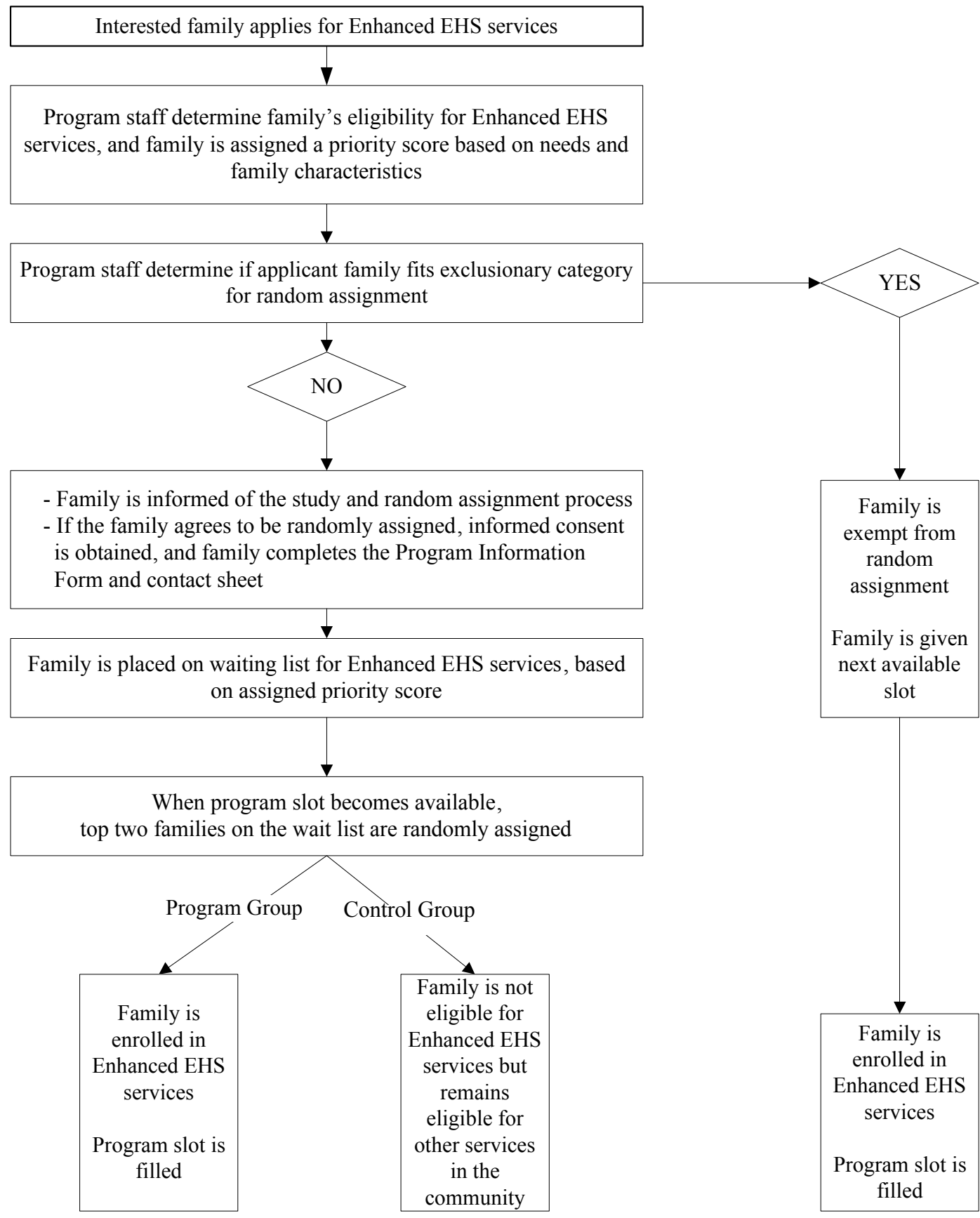


process. Families were not required to participate in the evaluation, but the only way they could receive program services was to consent to being randomly assigned. Families who agreed to this completed the Program Information Form and contact sheet and were then placed on the waiting list for Enhanced EHS in priority order, based on their needs and circumstances. When a program slot became available, paired random assignment was conducted with the top two eligible and interested families on the waiting list.

Families were randomly assigned to one of two research groups:

- The Enhanced EHS program group. If assigned to the program group, the family was enrolled in Enhanced EHS services, which included enhanced EHS self-sufficiency services as well as traditional EHS services.

- The control group. If assigned to the control group, the family was not able to access Enhanced EHS or traditional EHS provided by the two participating programs in Kansas and Missouri, but it was able to seek alternative services available in the community.

After the random assignment process was completed, program staff informed families about their research group designation. Families in the Enhanced EHS program group were contacted to set up their initial enrollment meeting with program staff and were enrolled in either the home-based or the center-based Enhanced EHS service option, depending on which program slot was available. Once families were enrolled in Enhanced EHS, they could cycle from one service option to the other, depending on their needs and on service option availability, but they could not receive both home- and center-based service options at the same time. Families who were assigned to the control group were given a resource list of available services that they could access in the community.

Parents and children in both research groups were tracked over time to determine the impacts of Enhanced EHS. Random assignment helps ensure that parents' and children's characteristics - both measured (such as child's gender and age) and unmeasured (such as motivation, parenting attitudes and beliefs) - are, on average, similar across the two groups at the beginning of the study. Hence, any subsequent average group differences in outcomes for parents and children in the program and control groups that are measured at the follow-up point can be attributed with a high level of confidence to Enhanced EHS. 


\section{The Study Sites}

This study evaluates two EHS programs in Kansas and Missouri that enhanced their existing services with formalized employment and self-sufficiency services. ${ }^{27}$ These programs were selected based on their histories of delivering high-quality EHS services, the use of a mixed-approach program model (a combination of home- and center-based services that the Early Head Start Research and Evaluation project points to as being potentially most effective for enhancing young children's developmental outcomes), ${ }^{28}$ their capacities to build sufficient waiting lists to sustain and justify random assignment, and support by their EHS policy councils for a random assignment study and programmatic enhancements to existing EHS services.

\section{Southeast Kansas Community Action Program (SEK-CAP) Early Head Start (Girard, Kansas)}

SEK-CAP is a community-based agency that serves low-income families and children in 12 rural counties of southeast Kansas. It receives funding from a combination of federal and state grants to provide a mix of services, including family outreach, transportation, and housing services, in addition to the early childhood educational services of EHS and Head Start (HS) programs. When families were first being enrolled in the study in Kansas, the SEK-CAP EHS program was able to serve up to 50 families at a time. In August 2006, the program received an additional grant from the state to serve an additional 30 families and to expand the service area, bringing the total number of families served by the EHS program to 80 families at a time. At the start of the evaluation, all participating families were offered a mix of EHS home-based services and center-based services through EHS community partnership child care centers; families could move seamlessly from one service option to another. All families received weekly home visits by family educators, and twice a month they attended group socialization sessions at which parents and children interacted with other EHS families, regardless of whether they also received child care through EHS community partnership centers. In 2007, the EHS program expanded services and opened EHS centers providing child care, at which time families who received EHS centerbased child care services received home visits from program staff twice a month.

\section{Youth in Need Early Head Start (St. Charles, Missouri)}

Youth in Need is a multiservice agency that serves low-income families and children in eastern Missouri. In addition to operating EHS and HS programs, the agency provides residential treatment programs, outreach services for homeless individuals and families, after-school

\footnotetext{
${ }^{27}$ Initially, three programs in Kansas and Missouri were identified that met the selection criteria, and all three agreed to participate in the evaluation. However, one site dropped out of the study because of programmatic challenges, including difficulties sustaining a waiting list.

${ }^{28}$ U.S. Department of Health and Human Services, Administration for Children and Families (2002).
} 
leadership and educational programs for youth, and individual and group mental health services. During the time that families were enrolled in the study, the Youth in Need EHS program, which was supported exclusively by federal grants, was funded to serve 199 families in four suburban and rural counties surrounding St. Louis, Missouri. The EHS program provided both home-based and center-based services. Families could move seamlessly from one service option to the other but generally did not receive both service options at once. Families who were exclusively enrolled in EHS center-based child care services received parental support and child development services through daily interactions with teachers and center-based managers at EHS child care centers. Families who did not receive EHS center-based child care received weekly home visits by family educators and attended group socialization sessions twice per month, where parents and children interacted with other EHS families. However, families who received child care through collaborative partnerships at other community-based child care centers also received home-based services in the form of quarterly visits from a home visitor.

\section{Characteristics of Sample Members at Baseline}

Table 1.1 presents selected characteristics of parents and children in the study sample at the time of random assignment, by research group, as well as the baseline characteristics of the full, pooled research sample (610 families). The sample is split evenly across study sites. Information on the demographic and background characteristics of families, parents, and children is drawn from the EHS application forms and assessments that are completed just before families were randomly assigned to research groups in SEK-CAP and Youth in Need. As expected with random assignment, the two research groups are very similar. Nearly all the primary parents who are identified on the EHS applications in the pooled sample are women (90 percent). More than half were single and never married (54 percent) at study entry. Of the parents in the sample, 86 percent identified themselves as white, 8 percent as black, and 5 percent as Hispanic/Latino(a) regardless of race. Slightly more than half the sample (52 percent) worked more than 12 months in the three years prior to random assignment; one-third worked 12 months or less; and 15 percent had not worked at all during that period. Slightly less than one-third of families (29 percent) were receiving Temporary Assistance for Needy Families (TANF) on entering the study, and slightly less than half (47 percent) reported ever having received TANF before random assignment. Small minorities of the sample members were pregnant women (11 percent) or teen parents (12 percent) at study entry. Slightly more than half the children in the sample (53 percent) are boys. On average, children in the sample were about 17 months old on entering the study. 
The Enhanced Services for the Hard-to-Employ Demonstration

Table 1.1

Characteristics of Sample Members at Baseline, by Research Group Status

Early Head Start with Enhanced Self-Sufficiency Services

\begin{tabular}{|c|c|c|c|}
\hline Characteristic & $\begin{array}{r}\text { Program } \\
\text { Group } \\
\end{array}$ & $\begin{array}{r}\text { Control } \\
\text { Group }\end{array}$ & Total \\
\hline \multicolumn{4}{|l|}{ Primary parent } \\
\hline Female & 89.8 & 89.4 & 89.6 \\
\hline Average age (in years) & 25.7 & 25.9 & 25.8 \\
\hline $\begin{array}{l}\text { Marital status }(\%) \\
\text { Single, never married } \\
\text { Married } \\
\text { Separated/divorced/widowed }\end{array}$ & $\begin{array}{l}54.8 \\
26.2 \\
18.9\end{array}$ & $\begin{array}{l}53.5 \\
31.4 \\
15.1\end{array}$ & $\begin{array}{l}54.2 \\
28.8 \\
17.0\end{array}$ \\
\hline Spanish/Hispanic/Latino(a) (\%) & 3.3 & 7.0 & $5.1 * *$ \\
\hline $\begin{array}{l}\text { Race/ethnicity }{ }^{\mathrm{a}}(\%) \\
\text { White } \\
\text { Black or African-American } \\
\text { Some other race/ethnicity }\end{array}$ & $\begin{array}{r}87.7 \\
7.3 \\
5.0\end{array}$ & $\begin{array}{r}84.3 \\
9.4 \\
6.4\end{array}$ & $\begin{array}{r}86.0 \\
8.3 \\
5.7\end{array}$ \\
\hline $\begin{array}{l}\text { Highest education }^{\mathrm{b}}(\%) \\
\text { GED certificate/high school diploma } \\
\text { Postsecondary degree } \\
\text { None of the above }\end{array}$ & $\begin{array}{r}69.8 \\
7.9 \\
22.3\end{array}$ & $\begin{array}{r}64.7 \\
7.2 \\
28.1\end{array}$ & $\begin{array}{r}67.2 \\
7.5 \\
25.3\end{array}$ \\
\hline $\begin{array}{l}\text { Primary parent employed during the past } 3 \text { years }(\%) \\
\text { Did not work at all } \\
\text { Worked } 1 \text { year or less } \\
\text { Worked more than } 1 \text { year }\end{array}$ & $\begin{array}{l}15.3 \\
29.7 \\
55.0\end{array}$ & $\begin{array}{l}15.1 \\
36.6 \\
48.3\end{array}$ & $\begin{array}{l}\left.15.2^{[}\right] \\
33.1 \\
51.7\end{array}$ \\
\hline Prenatal $^{\mathrm{c}}(\%)$ & 10.8 & 10.5 & 10.7 \\
\hline Teen parent $(\%)$ & 11.5 & 12.5 & 12.0 \\
\hline Two-parent household (\%) & 39.0 & 44.9 & 42.0 \\
\hline Currently on $\mathrm{TANF}^{\mathrm{d}}(\%)$ & 29.2 & 28.9 & 29.1 \\
\hline Ever on $\mathrm{TANF}^{\mathrm{d}}(\%)$ & 48.2 & 45.1 & 46.6 \\
\hline \multicolumn{4}{|l|}{ Child $^{\mathrm{e}}$} \\
\hline $\begin{array}{l}\text { Gender }(\%) \\
\text { Girls } \\
\text { Boys }\end{array}$ & $\begin{array}{l}47.5 \\
52.5\end{array}$ & $\begin{array}{l}46.5 \\
53.5\end{array}$ & $\begin{array}{l}47.0 \\
53.0\end{array}$ \\
\hline Average age (in months) & 17.7 & 16.3 & 17.0 \\
\hline Sample size & 305 & 305 & 610 \\
\hline
\end{tabular}




\section{Table 1.1 (continued)}

SOURCE: MDRC calculations from Early Head Start (EHS) Program Information Forms (PIFs).

NOTES: In order to assess differences in characteristics across research groups, chi-square tests were used for categorical variables, and t-tests were used for continuous variables.

Statistical significance levels are indicated as follows: $* * *=1$ percent; $* *=5$ percent; $*=10$ percent. The significance level indicates the probability that one would be making an error in concluding that there is a difference between research groups for the variable in question.

Open brackets [ ] indicate that 20 percent or more of the categories for the variable in question have cell sizes less than 5 .

a"Other" race/ethnicity was self-identified by the parent and may include biracial or multiracial individuals or a race/ethnicity category other than white, black, American Indian, or Asian/Pacific Islander.

${ }^{b}$ Calculations of highest education at baseline are based on responses to the 18-month survey and are available only for the survey sample. At the 18-month follow-up, respondents were asked about their highest credential - a GED certificate, high school diploma, associate's degree, bachelor's degree, or graduate degree - and, if any, when they received it. The highest credential at baseline includes only those that were obtained prior to random assignment. "Postsecondary degree" is defined as an associate's, bachelor's, or other graduate degree.

'Prenatal status indicates whether the mother was currently pregnant at random assignment.

${ }^{\mathrm{d} C}$ Current TANF receipt indicates whether the family was currently receiving TANF at random assignment. "Ever on TANF" indicates whether the family had ever received TANF prior to random assignment.

ePrenatal cases are not included in this computation.

Overall, the Enhanced EHS study population's characteristics are in line with the range of characteristics of families being served by EHS programs across the United States in 2006, ${ }^{29}$ with one noted exception. This study sample includes more white parents and fewer black and Hispanic/Latino(a) parents, regardless of race. According to Program Information Report data available on EHS programs across the United States from the 2005-2006 program year, 42 percent of families identified as being white, 25 percent as black, and 30 percent as Hispanic/Latino(a). Differences in the racial and ethnic composition of the study sample from the broader EHS population could have implications for the impacts detected here. Among sample members in the Early Head Start Research and Evaluation project examining the effects of traditional EHS services, for example, impacts are clustered and are larger in magnitude for ethnic minority families. ${ }^{30}$ Given that the present study sample includes very few ethnic minority families, this suggests that the impacts of the program evaluated here could be somewhat smaller than the impacts identified by prior evaluation research.

\footnotetext{
${ }^{29}$ Center for Law and Social Policy (2008).

${ }^{30}$ U.S. Department of Health and Human Services, Administration for Children and Families (2002).
} 


\section{Data Sources}

To study the effects of Enhanced EHS services in Kansas and Missouri, the analyses presented in this report rely on several data sources, described below.

\section{Baseline Data}

Demographic information on the sample members was drawn from common information across all the programs' intake forms and assessments, which are completed as part of the EHS application process. The assessments generally have two components: a program eligibility determination and priority score assignment and an in-depth interview with the parent that covers certain aspects of family life.

\section{The 18-Month Survey of Parents}

A survey was administered to all the primary caregivers in the research sample approximately 18 months after random assignment. ${ }^{31}$ Response rates are very high: Nearly 81 percent of parents completed the survey. ${ }^{32}$ The survey included questions about a wide range of topics, including parental and child service receipt, child care use, parental psychological well-being, parenting, and family functioning - such as activities with children (social play and discipline) - and family routines that are direct targets of the program and that might account for the effects of Enhanced EHS on young children's development, parents' employment and job characteristics, family and parental income, receipt of public assistance, and children's social, emotional, and cognitive development; early academic outcomes; and health and safety outcomes.

\section{Direct Assessments of Children's Developmental Outcomes}

Approximately 18 months after random assignment, interviewer assessments of children's functioning were also conducted with all children 12 months and older at the time of the assessment. This information is intended to supplement the information learned about child well-being that is captured by the 18-month survey of parents. An interviewer asked children ages 2 to 4 to perform several self-regulation tasks that assess motor control, attention skills, impulsivity, and emotional state at the time of the assessment. Two such tasks are walking along a line and drawing circles at varying speeds, and waiting and not peeking while the interviewer pretends to wrap a gift that will later be given to the child. The early academic skills of these same children were assessed using the broad math and reading subscales of the Wood-

\footnotetext{
${ }^{31}$ The survey sample was restricted to participants who were able to complete the survey in English. Less than 1 percent of the research sample was excluded from the survey sample because of a language barrier.

${ }^{32}$ See Appendix A for an analysis of the response rates for the 18-month survey and any implications for the impact analysis.
} 
cock-Johnson III-R. For these children as well as for children between ages 1 and 2, a subset of the Reynell Developmental Language Scales — which assesses receptive language abilities was collected. The response rates for child assessments are high: 73 percent of children in the research sample completed at least one of the assessments. ${ }^{33}$

\section{Data from the National Directory of New Hires}

Parental employment and earnings data for all sample members were assessed using the wage data from the National Directory of New Hires. This national database maintained by the Office of Child Support Enforcement can provide information on earnings from employment both within and outside Kansas and Missouri.

\section{Data on Program Participation}

A case file review was conducted for families participating in Enhanced EHS. Files were collected for 270 of the 305 families assigned to the program groups in the two sites. ${ }^{34}$ In reviews of case files, MDRC and The Lewin Group staff recorded information about program group members' participation, including the dates of home visits, child care attendance (Youth in Need only), ${ }^{35}$ assessments that were conducted for the children, referrals to outside agencies, goals set by the families, and topics discussed during visits and meetings as recorded on forms completed after each visit. Data provide information on each family's participation in EHS - such as the number and frequency of home visits and attendance at parent training workshops - over the course of the 18 months following random assignment. Chapter 2 uses the case file data to describe the existing EHS program and the implementation of the self-sufficiency enhancements, as well as program group participants' engagement in various components of Enhanced EHS.

\section{Field Research}

Periodically throughout the implementation of Enhanced EHS, MDRC and Lewin staff visited SEK-CAP and Youth in Need to interview the self-sufficiency coordinators in each site as well as many program administrators, home- and center-based staff, and other lead staff

\footnotetext{
${ }^{33}$ See Appendix A for an analysis of the response rates for the direct child assessments and any implications for the impact analysis.

${ }^{34}$ Case files were missing for 34 families in SEK-CAP and for one family in Youth in Need. Analysis of baseline data collected by MDRC found that the families with missing case files were more likely to have enrolled early in the study (before 2006). SEK-CAP data also indicate that the families with missing case files were more likely never to have participated in the EHS program: about 38 percent of SEK-CAP families with missing files never enrolled, compared with 24 percent of SEK-CAP families who had case files.

${ }^{35}$ At the time that the case file review was conducted, SEK-CAP did not maintain child-specific attendance records for child care, making it difficult to identify each child's attendance from the program records.
} 
providing mental health, child disability, nutrition, and health services. ${ }^{36}$ The interviews provided information on the operation of the existing EHS program and the implementation of the parental employment and self-sufficiency enhancements. MDRC and Lewin staff observed some EHS home visits and toured EHS child care centers. Chapter 2 uses the field research to describe services in the existing EHS program and the implementation of the self-sufficiency enhancements.

\section{The Structure of This Report}

The remainder of this report is organized as follows:

- Chapter 2 presents information on the implementation of the core EHS services and the enhanced services that focused on parental employment and self-sufficiency needs. The chapter also discusses the challenges that the program sites encountered in implementing the enhancements and presents participation data reflecting the level of families' engagement in Enhanced EHS.

- Chapter 3 uses survey-reported data to present the effects of Enhanced EHS on an array of services - such as child-focused, parenting education, and family development services and job training and job search assistance that families in the two research groups might have received either through the program or through other early childhood programs in the community

- Chapter 4 summarizes the impacts of Enhanced EHS on children's receipt of nonparental child care.

- Chapter 5 presents the impacts of Enhanced EHS on parental employment, earnings, job characteristics, and household income.

- Chapter 6 summarizes the impacts of Enhanced EHS on parenting practices, parental psychological well-being, and child development and well-being.

\footnotetext{
${ }^{36}$ Site visits to SEK-CAP were conducted in June 2006 and April 2007. Site visits to Youth in Need were conducted in May 2006 and May 2007.
} 


\section{Chapter 2}

\section{Program Implementation}

As described in Chapter 1, the Enhanced Services for the Hard-to-Employ Demonstration and Evaluation Project (the Hard-to-Employ project) is evaluating the effectiveness of formalized parental employment and educational services aimed at improving families' economic circumstances and self-sufficiency needs, as implemented within two traditional Early Head Start (EHS) programs in Kansas and Missouri.

This chapter first briefly describes the basic framework and core services of the traditional EHS programs. Then it discusses the enhancements made to these EHS programs to focus more explicitly on parental employment, education, and economic self-sufficiency. Next, the chapter examines the extent to which program group members participated in Enhanced EHS and received traditional and enhanced services. The chapter concludes with a discussion of some of the challenges that these programs encountered in implementing the enhancements.

The chapter draws on information obtained from several rounds of site visits, a review of case files conducted in the spring of 2007, and analyses of program data.

\section{Key Findings}

There is evidence that Enhanced EHS increased the focus on parents' employment and education. Still, the programs faced several implementation challenges that led to a relatively weak enhancement that was never fully integrated into the core EHS services. Following are the key findings on the implementation of Enhanced EHS:

- Not all families received the core EHS services. Approximately 81 percent of the sample members who were randomly assigned to the program group received any EHS services. Others moved from the area or chose not to enroll in Enhanced EHS after their assignment to the program.

- Many who received the core EHS services did not receive the Enhanced EHS employment and education services. Among the families who received services, 78 percent had discussions on employment and education with staff, and about 40 percent met with the self-sufficiency specialist at some point during the 18 months following random assignment. (Considering all families in the program group - regardless of whether they ever received any EHS services - 63 percent ever discussed employment, educational, or self-sufficiency issues with program staff.) While most families had 
at least one discussion on employment or education with staff during the follow-up period, most did not discuss these issues with staff regularly (that is, at every meeting).

- Lack of interest on the part of some families might have reduced the overall level of self-sufficiency assistance that they received. Staff noted that some parents were not interested in finding employment or pursuing an education, believing it was better that they spend time at home during their children's early years, and staff wanted to honor this choice. This was reinforced by the lack of well-paying jobs and limited transportation and child care services in the more rural areas.

- Compared with parents who received home-based services, parents who received EHS center-based services were less likely to receive employment and education services from Enhanced EHS programs. Parents in the center-based service option did not meet one-on-one with frontline staff weekly, as did parents receiving home-based services. In addition, parents receiving Enhanced EHS center-based services were often already employed or in school and were less likely to request self-sufficiency assistance.

- The Enhanced EHS programs provided more months of services to families with infants than to families with toddlers. Families with younger children were more likely to receive home-based services, which provided opportunities to interact more directly with parents on a regular basis. Partly because of their age at program entry, younger children spent more time in Enhanced EHS; that is, they could not age out of the program within the evaluation's 18-month follow-up period. In the full sample, by the time parents completed the follow-up survey, about 80 percent of families with toddlers had focal children who had turned 3 years old (the age at which they likely would have transitioned out of the program because they were no longer eligible for it). ${ }^{1}$ In contrast, almost all the families with infants (97

\footnotetext{
${ }^{1}$ As is true with all applications to EHS, families identify a particular child who is up to age 3 or during the prenatal period and who will be enrolled in the program. In this study's 18-month parent survey and direct child assessments, this child is identified as the focal child who is the target of program services and is the focus of all questions related to child care and early educational experiences, parenting practices, and child development and well-being.
} 
percent) at study entry were still age-eligible for Enhanced EHS at the 18month follow-up point. ${ }^{2}$

- There was variation in the extent to which program staff delivered the enhanced employment, educational and self-sufficiency services. Some frontline staff felt that they lacked the expertise to help their families with self-sufficiency issues and called upon the self-sufficiency specialists when assistance was requested by the families; other frontline staff provided more direct assistance to families. One program, which employed two specialists, sought out assistance from outside agencies to help the EHS families, but the other program, which had just one specialist, devoted less time to this effort.

\section{The Framework of the Early Head Start Program}

The Southeast Kansas Community Action Program (SEK-CAP) Early Head Start program in Girard, Kansas, and the Youth in Need Early Head Start program in St. Charles, Missouri, provided EHS services to families living in four counties in each service area. ${ }^{3}$ SEK-CAP operates in four rural counties in southeast Kansas, while Youth in Need serves families in three suburban counties outside St. Louis City as well as one rural county. ${ }^{4}$ Both SEK-CAP and Youth in Need provided home-based and center-based services during the study's follow-up period, though SEK-CAP did not begin providing EHS center-based services until January 2007; before that, it provided EHS child care through partnerships with community child care centers.

Box 2.1 presents the core features of the EHS programs, the target population, and staff qualifications. Both programs employed home visitors and teachers to provide the home-based and center-based services, respectively. Home visitors were expected to meet with their assigned families once a week to assist the parents with the child's development, educate them on effective parenting techniques, and help families with their social service needs. The center-

\footnotetext{
${ }^{2}$ This estimates the percentage of children who likely transitioned out of Enhanced EHS because they reached age 3 during the follow-up period. In some cases, children were allowed to remain in the program until a spot became available in the Head Start programs at SEK-CAP or Youth in Need. At the same time, some children younger than 3 transitioned out of Enhanced EHS because they moved out of its coverage area or their family was dropped from the program due to nonparticipation.

${ }^{3}$ Both sites also operated Head Start (HS) programs for children ages 3 to 5 as well as EHS programs in counties other than the ones that participated in this study. (SEK-CAP operated EHS in four other counties, and Youth in Need offered EHS in St. Louis City.)

${ }^{4}$ The counties are defined as being rural if they are not in Metropolitan Statistical Areas (MSAs), using the Office of Management and Budget (OMB) classification of counties in identifying rural or urban status.
} 
Box 2.1

\section{Core Features of the Early Head Start Programs}

\section{Enrollment}

- Target population. Low-income families with infants (younger than 12 months) and toddlers (12 months or older) and pregnant women.

- Recruitment. EHS staff recruited families at a number of settings, including community events, government agencies (such as the welfare agency), schools, health departments, doctors' offices, and community-based organizations that provide services to low-income families. Staff also left flyers at the doors of apartments and housing complexes.

- Enrollment. After families were assigned to EHS, staff met with parents individually to complete enrollment forms and sign an agreement outlining the program's and the parents' responsibilities. Staff collected documentation on the child's health history, assisted the family in developing a goal plan, and conducted assessments of the child's hearing and vision as well as motor, language, cognitive, and social-emotional development.

\section{Staff}

- Staff qualifications. Most staff had a four-year college degree, and some had a master's degree or were working toward an advanced degree. The most common degrees were in early childhood development and education; the most common past work was in child care, education, or social services.

- Staff training. Formal training took place each August. Staff were trained on the curriculum, conducting assessments, home visitation, sexual harassment, and other issues that emerged.*

(continued)

NOTE: *For staff training, both programs used the Parents as Teachers (PAT) Born-to-Learn curriculum until 2007, when they transitioned to the Creative Curriculum.

based services were generally limited to parents who were employed or attending school. ${ }^{5}$ Unlike the home-based program, which focused on supporting child development through parent education, the center-based teachers provided the child development services and had less one-on-one interaction with parents. Although center-based staff had parent education meetings throughout the year, they met with parents less often than home visitors did.

${ }^{5}$ Youth in Need parents who were not working or in school might be eligible to receive center-based services if they were having difficulty caring for a child who had a disability or medical condition. 


\section{Box 2.1 (continued)}

\section{Core Program}

- Home-based service option. Families received weekly home visits lasting 90 minutes and, twice a month, could attend group socialization sessions that facilitated interaction among families receiving EHS. During visits, home visitors typically spent 60 minutes conducting individualized developmental activities with children, demonstrating activities that parents and children could engage in together to foster parent-child interaction, modeling appropriate parenting behaviors, and assessing children's developmental progress; the remaining 30 minutes were spent addressing the family's social services needs.

- Center-based service option. Families received high-quality, center-based child care for at least six hours a day, five days a week, either directly through EHS/HS centers or through child care centers in the community that provide care in line with EHS quality and safety requirements. While in center-based care, children received daily lesson plans and activities tailored to their individual developmental needs and those of other children in the classroom. Families also engaged in parent-teacher conferences or home visits conducted at least quarterly (depending on the program site and where children received center-based care) in which parent education and family support and social service needs were addressed.

- Parental involvement. The programs offered activities throughout the year as well as monthly parent committee meetings, organized by the parents, that featured guest speakers who spoke on topics of interest to the parents. In addition, the Head Start policy council included several parents to ensure that parents had a voice in decision-making.

- Specialized services. All families, regardless of whether they received home- or center-based service options, also were offered an array of health, mental health, nutrition, and child disability services directly through EHS or through referrals to other providers in the community.

\section{Self-Sufficiency Enhancements}

As noted in Chapter 1, each program received funding from the Head Start Bureau to enhance its existing EHS services with a more explicit focus on parental employment and economic self-sufficiency. The services of Enhanced EHS were intended to (1) help parents who were unemployed move into employment; (2) assist parents who had low levels of education in pursuing educational goals as a means of improving their employment and financial circumstances; and (3) help parents who were employed to find more stable employment, advance in their jobs, and earn higher wages. 
To meet these general goals, the programs were directed to use some of the funding to hire an on-site self-sufficiency specialist to work with EHS staff and families on topics related to employment, education, and self-sufficiency. With the assistance of the specialists, the programs were expected to increase EHS's programmatic focus on self-sufficiency issues by helping parents set employment- and training-related goals and regularly monitoring their progress toward them. In recognition that the programs lacked the expertise or the resources available elsewhere in the community, the specialist was also directed to tap external employment and educational agencies and organizations to fill the gaps in existing EHS services.

\section{Employment and Educational Goals}

Families identified goals for themselves and their families when they enrolled in the program, and these goals were monitored and updated over time. As part of the enhancements to EHS, frontline staff were responsible for ensuring that all families set at least one employment or educational goal. An examination of a sample of families' goals early on in the study suggested that many families had not established self-sufficiency goals or that the goals were too broad for example, "Get a job" or "Go to school."

To help staff develop more specific employment and education goals, both programs' self-sufficiency specialists prepared guides for goal setting and provided training to help staff break down broader goals into achievable steps and action plans. For example, the Youth in Need guide provided a sample plan that divided the common goal of "finding a job" into four goals, each involving specific tasks. The goals included exploring employment options, developing a résumé, seeking employment, and interviewing for positions. The tasks within these goals laid out the types of steps that could be taken to achieve the goals; examples include attending Career Center workshops that addressed key topics related to employment, making an appointment with a career counselor who worked one-on-one with EHS families, attending the monthly job fair, reviewing job listings, and taking other steps to secure job interviews and follow up with the employer. To facilitate self-sufficiency discussions with parents, the programs also created brief forms that helped staff gather information about parents' employment and educational backgrounds, which could be used to identify and discuss goals with parents and to chart progress toward achieving them.

Staff still struggled with the task of setting self-sufficiency goals, and they expressed some reservation about requiring all families to have them. They did not see this as part of the core EHS program. Additionally, several staff said that they did not like to "push work" on parents, as they did not believe that this was always the best option for the family. Although

some of the training (discussed below) addressed such concerns, there were staff who remained unwilling to encourage all families to set self-sufficiency goals. 


\section{External Employment and Educational Resources}

The self-sufficiency specialists acted as "resource experts" to help the staff identify available employment and training-related resources. This allowed the programs to become knowledgeable about resources without overwhelming the frontline staff who worked directly with families. For example, home visitors could seek out the self-sufficiency specialist when they needed information to help address a specific issue or when they needed to access less commonly used resources or agencies.

The self-sufficiency staff were also in charge of establishing partnerships and referral mechanisms with the local agencies that provided EHS families with employment and educational services, such as job search assistance and General Educational Development (GED) classes. This allowed one staff person to establish community partnerships, increasing the likelihood of accountability and follow-up. That person met with service providers at One-Stop Career Centers, welfare agencies, and vocational rehabilitation services.

The programs differed in terms of how much focus they placed on working with outside service agencies. Youth in Need employed two self-sufficiency specialists, one of whom was responsible for developing community relationships and the other who worked more directly with staff and families. SEK-CAP had one staff person who was responsible for both areas.

Perhaps because Youth in Need had additional staff focused on self-sufficiency - and because it operated in three suburban counties that had more community resources than were available to SEK-CAP - it was more successful at forging relationships and documenting available resources. Youth in Need's achievements include successfully developing relationships with the workforce career centers, one of which agreed to dedicate a staff person to provide job search assistance to EHS families; providing information about external resources in the monthly Head Start newsletter to families; and attending community network meetings to learn about other opportunities for the families. In its rural county, which did not have GED classes for residents, Youth in Need developed a partnership with the school district to offer the classes at the EHS socialization center. The school district paid the instructor's salary, and the EHS home visitors took turns babysitting during class times so that parents could attend and not worry about child care. The same county also developed a relationship with the local YouthBuild program and had slots for a few teen parents in the program. ${ }^{6}$

Neither EHS program developed a close working relationship with the Temporary Assistance for Needy Families (TANF) program, perhaps because of the relatively low rates of

\footnotetext{
${ }^{6}$ YouthBuild is a program that helps teenagers work toward a GED certificate or high school diploma and learn a job skill, which, in this county, was in the construction industry.
} 
dual enrollment in both programs. At the start of the study program, about 29 percent of sample members received TANF assistance, but this declined to 17 percent by the end of the 18-month follow-up period, and some of the dual EHS and TANF recipients were not required to participate in the TANF work program because of the age of their child. ${ }^{7}$ The SEK-CAP program, which had a higher percentage of families receiving TANF when they enrolled in the study, developed a process with the TANF agency whereby EHS staff completed a form for families who were required to participate in TANF work activities and identified which monthly activities the families completed as part of the EHS program. ${ }^{8}$ These activities were used to fulfill part or all of the families' TANF work participation requirement. But staff from SEKCAP and TANF did not typically meet to discuss a family's case and how EHS could improve the family's self-sufficiency.

Both EHS programs developed binders to collect and organize information about community resources for staff to use and make referrals. The binders included additional information that the self-sufficiency specialists thought would be helpful to staff and parents, such as information about the interview process, developing a good résumé, and setting goals. Staff who were interviewed for this study appreciated such assistance, for the most part, although the rural counties had fewer available resources. Both programs also arranged for experts from a local bank or credit union to conduct sessions for the parents on budgeting and finances, using a national curriculum; Youth in Need used Money Smarts, and SEK-CAP used Money in Motion.

\section{Staff Training}

The two EHS programs instituted staff training to enhance the skills and competencies of frontline staff, so that they were better able to work with families on employment and selfsufficiency goals and needs. In addition, the research team provided technical assistance to help the self-sufficiency specialists enhance that component. This took the form of monthly check-in meetings with the coordinators and site visits early in the study that were designed to assess the changes being made to the program and provide feedback.

The Youth in Need coordinators conducted staff training on goal setting, on using the resource binder, on the challenges of helping parents who were ex-offenders find employment, and on budgeting and finances. They also conducted training on transitional benefits that were available to families who moved from welfare to employment, to address the concerns of some

\footnotetext{
${ }^{7}$ During the study period, TANF recipients with children under age 1 were exempted from the work participation requirements in both Kansas and Missouri.

${ }^{8}$ At random assignment, 33 percent of SEK-CAP families and 25 percent of Youth in Need families were receiving TANF.
} 
staff that families might not be better off financially after finding employment. In addition, early in the study, the coordinators invited a workforce development consultant to conduct an all-day training on helping families with employment barriers attain self-sufficiency. Initially, the Youth in Need trainings were conducted in all-staff settings (at annual or quarterly meetings), but, over time, the specialists found that it was more effective to work with staff individually or in small groups.

SEK-CAP conducted training on goal setting and using a tool kit developed by the selfsufficiency specialist. Like the Youth in Need staff, the SEK-CAP specialist also found it more effective to train staff individually. She accompanied them on home visits and modeled how they might talk with and help parents with self-sufficiency issues. Another method she used was to review the goals established for the families and provide feedback to staff on how they could help the families achieve or better define their goals. She also attended the monthly staff meetings and was allocated 30 minutes to discuss self-sufficiency and to "get staff excited" about assisting families in pursuing and achieving it.

\section{Direct Self-Sufficiency Assistance to Parents}

The EHS home visitors, teachers, and self-sufficiency specialists provided the selfsufficiency assistance to parents. For families receiving home-based services, home visitors were expected to review the family's goals during the weekly visits, to provide them with guidance on achieving their goals, and to make appropriate referrals. Field research revealed inconsistencies across staff in terms of how much time they focused on self-sufficiency issues during visits. Some frontline staff said that they brought up parental employment and selfsufficiency goals at every home visit, whereas others discussed them less frequently. For families receiving center-based services, the teachers might ask parents how their job was going when they came to drop off or pick up their children, but they were less likely to have a serious conversation about a parent's employment situation. Although they might discuss selfsufficiency issues during the parent education meetings, these occurred less often - monthly in SEK-CAP and quarterly in Youth in Need.

Frontline staff often relied on the specialists to provide the self-sufficiency assistance. They might ask the specialist to work with a parent who was interested in finding a job or going to school and who needed more one-on-one assistance. Some frontline staff felt they did not have the expertise and/or the time to work closely with the family.

The programs began to place a priority on the families who were most likely to benefit from the specialists' employment and self-sufficiency services, targeting (in descending order) parents who were unemployed and/or receiving cash assistance, who were not currently working full time or were underemployed, and who were employed but in unstable jobs or with irregular work schedules. Youth in Need tracked and monitored the progress of families in each 
category quarterly, compiling and sharing statistics in the staff management meetings. The selfsufficiency specialist focused more on checking in with parents who were unemployed. The SEK-CAP specialist used the priority scale to decide which families to visit with the home visitor and directly offer assistance, first meeting all families in which no one was employed and then meeting families who were employed part time or full time but who were not happy with their current job. Although the resulting effects of the targeting are not known, it did guide the specialists and helped them focus on the cases that they believed were most likely to benefit from assistance.

In addition, the specialists provided other assistance to families. Youth in Need specialists oversaw an initiative to collect and distribute professional clothing to parents, using a van that was stocked with work-appropriate clothes and was made available at many parent events. In both programs, the specialists presented information on self-sufficiency topics at parent committee meetings; popular topics included budgeting, networking, and job search.

\section{Barriers to Employment}

During field research visits, EHS staff were asked about parents' barriers to employment. The most common barriers reported centered on transportation and child care needs and a parent's lack of motivation to change the current situation. Public transportation was limited, especially in the rural counties, and not all parents had cars. Also, during this period, gas prices increased substantially, which caused hardships for those parents who did have cars. Regarding child care, although EHS offered it, it was not readily available in all counties. ${ }^{9}$ Staff reported that it was especially difficult to find child care for parents working evening and weekend shifts and for those who needed care for an infant. The lack of motivation that some staff reported as a barrier was an issue that some had the most difficulty addressing. Staff were unsure about how to motivate parents and about whether it was their place to tell parents what to do.

Other employment barriers that were mentioned by a handful of staff included helping undocumented parents who did not have work papers (expressed by staff in Missouri), a lack of jobs in the area, mental health and substance abuse issues, and low levels of education.

\footnotetext{
${ }^{9}$ Families who were receiving home-based services were not guaranteed center-based services when they found a job or enrolled in school. They had to wait until a spot opened up in the center and could enroll only if their priority scores were higher than other families' scores on the waiting list.
} 


\section{Participation in Early Head Start Services}

To supplement the field research, information in the parents' case files was reviewed, including the dates of participation, the screenings and assessments of their children, the referrals to outside agencies, the types of goals set by the families, and the topics discussed during home visits and meetings.

\section{Overall Engagement}

As shown in Table 2.1, about 81 percent of the families who were assigned to Enhanced EHS received at least one home visit or one day of center-based child care. The 19 percent of families who did not participate may have changed their minds about it after being randomly assigned to the EHS program group, or their circumstances may have changed (for example, they moved out of the county). Processes were changed during the study so that parents were contacted before the assignment was made, to reaffirm their interest, but even after that step was implemented, some parents agreed to participate but did not later enroll in the program. ${ }^{10}$ Among those who participated (that is, received at least one home visit or one day of center-based child care), the level of participation was high. Within the first 18 months following random assignment, participants received Enhanced EHS for about 11 months, on average.

Families who received home-based services for at least part of their time in Enhanced EHS were visited about 19 times during the 18-month follow-up period. This is fewer than four visits per month, given that families participated in Enhanced EHS for 11 months. In each month, an average of half (0.5) an appointment was canceled, either by the families themselves or by the home visitor. In addition, some families transitioned to the center-based service option during the follow-up period, and they received fewer visits as a result.

Families receiving Youth in Need center-based services received about 14 days of child care in a typical month. ${ }^{11}$ These families received about 13 home visits or parent education meetings during the 18-month follow-up period. While Youth in Need families were required to have only four parent education meetings per year, many of these families had been in the home-based service option before or were transitioning to center-based services, and this estimate includes those home visits and meetings.

\footnotetext{
${ }^{10}$ Participation increased slightly from 80 percent for an early cohort (randomly assigned before August 2005 ) to nearly 84 percent for the later cohort.

${ }^{11}$ Child-specific attendance records for center-based care were available only for Youth in Need.
} 


\section{The Enhanced Services for the Hard-to-Employ Demonstration}

Table 2.1

\section{Engagement in Enhanced EHS in 18 Months After Random Assignment Early Head Start with Enhanced Self-Sufficiency Services}

\begin{tabular}{lr}
\hline Outcome & $\begin{array}{r}\text { Program } \\
\text { Group }\end{array}$ \\
\hline Participated in Enhanced Early Head Start ${ }^{\mathrm{a}}$ (\%) & 80.7 \\
$\quad$ Length of participation (months) & 9.0 \\
Among participants, length of participation (months) & 11.1 \\
Ever received home-based services (\%) & 71.9 \\
Ever received center-based services (\%) & 43.7 \\
Among those who received home-based services: & \\
Average home visits per month & 1.04 \\
Length of participation (months) & 11.1 \\
Number of home visits in 18 months after random assignment & 18.8 \\
Number of cancellations in month & 0.5 \\
Number of calls between staff and parent in month & 0.5 \\
Among those who received center-based services: & \\
Average home visits per month & 0.71 \\
Length of participation (months) & 12.2 \\
Monthly child care attendance ${ }^{\mathrm{b}}$ (days) & 13.7 \\
Number of parent education meetings or home visits in 18 months after & 12.7 \\
$\quad$ random assignment & 270 \\
\hline Sample size &
\end{tabular}

SOURCES: Calculations from data gathered from a review of Enhanced Early Head Start participant case files.

NOTES: The number of home visits for both home-based and center-based services does not include visits with the self-sufficiency coordinator alone but may include instances when the self-sufficiency coordinator accompanied a home visitor.

aParticipation is defined as having received any home-based or center-based services during 18 months following random assignment.

${ }^{\mathrm{b}}$ This outcome reflects average attendance in months with attendance.

\section{Topics Discussed in Home Visits and Parent Education Meetings}

After conducting the home visits and parent education meetings, staff were required to document what had occurred during the visit by completing a short form and summarizing the activities that were conducted and the main discussions that took place. Presumably, staff would 
not document casual conversations, and their notes would include real issues of concern to the family or home visitor. The notes also do not include discussions that might have taken place at EHS events, when the parents were dropping off or picking up their children, and other less formal meetings. To some extent, staff had discretion about what to document, and the research team encountered different levels of detail in the case files.

Table 2.2 presents the topics that were discussed in meetings or mentioned in the notes. Most home visits (83 percent) focused some time on the child's development and on parenting education. About 18 percent of the visits included discussions of the family's basic social service needs, including issues related to transportation, child support, housing, electricity, food, WIC (the Women, Infants, and Children program), and public assistance. Home visitors discussed the parent's employment situation in about 15 percent of the visits, their child care needs in 11 percent of the visits, and the parent's progress with education or interest in enrolling in school in about 8 percent of the visits. As the table shows, the focus was generally on the child and not on self-sufficiency issues.

In about 86 percent of the quarterly parent education meetings that the teacher or area manager had with families in the Youth in Need center-based program (two meetings occurred in the home), staff discussed parenting education and the child's development . They discussed the family's social service needs in about 15 percent of the visits. They were less likely to discuss the parent's employment or education plans or child care needs during the quarterly parent meetings than during the weekly home visits. Parents in the center-based program were required to be employed or enrolled in school, so perhaps the staff felt that these parents were already pursuing their goals and needed no further assistance. Also, the center-based staff had fewer meetings with parents, so they may not have developed as strong a bond with parents as the home visitors had, which made it more difficult to discuss personal issues.

During the one-on-one meetings that the self-sufficiency specialist had with some parents in Youth in Need, the focus - not surprisingly - was on the parent's employment or education. Even so, 41 percent of the meetings also touched on the family's social service needs, and occasionally the family's child care needs and budget situation were discussed. ${ }^{12}$

Table 2.3 shows the percentage of parents who had any discussions of employment or education during the 18 months following random assignment. Among participating families, most parents (78 percent) had a discussion with staff of one topic or the other during a home visit, in a parent education meeting, or in a meeting with the self-sufficiency specialist. These

\footnotetext{
${ }^{12}$ The case files do not include information on visits conducted by the SEK-CAP specialist.
} 
The Enhanced Services for the Hard-to-Employ Demonstration

Table 2.2

Topics Addressed in Meetings with EHS Staff, by Type of Meeting

Early Head Start with Enhanced Self-Sufficiency Services

\begin{tabular}{lrrr}
\hline Outcome & $\begin{array}{r}\text { Home } \\
\text { Visit }\end{array}$ & $\begin{array}{r}\text { Parent Education } \\
\text { Meeting }\end{array}$ & $\begin{array}{r}\text { Self-Sufficiency } \\
\text { Meeting }^{\mathrm{a}}\end{array}$ \\
\hline Topics addressed by EHS staff (\% of meetings) & & & \\
$\quad$ Parenting education and child development & 82.9 & 85.5 & 0.0 \\
Family's social service needs & 17.5 & 15.4 & 40.9 \\
Parent's employment & 14.7 & 4.0 & 72.7 \\
Child care needs & 10.5 & 3.7 & 9.1 \\
Parent's education & 8.4 & 1.5 & 52.3 \\
Parent's health & 5.8 & 0.9 & 0.0 \\
Budget/finances & 2.2 & 0.9 & 13.6 \\
\hline Number of meetings & & 324 & 44 \\
\hline
\end{tabular}

SOURCES: Calculations from data gathered from a review of Enhanced Early Head Start participant case files.

NOTE: aThis table reflects one-on-one meetings that took place between the Youth-in-Need specialist and the parent. (The SEK-CAP case files do not include information on meetings with self-sufficiency specialists.)

The Enhanced Services for the Hard-to-Employ Demonstration

Table 2.3

Employment/Education Topics Addressed in Meetings with EHS Staff Early Head Start with Enhanced Self-Sufficiency Services

\begin{tabular}{lr}
\hline & Program \\
Outcome & Group \\
\hline & \\
Among participating parents ${ }^{\mathrm{a}}(\%)$ & 78.4 \\
Any discussion of self-sufficiency & 64.7 \\
Discussed self-sufficiency during home visit & 30.3 \\
Discussed self-sufficiency during parent education meeting & 39.5 \\
Had any contact with self-sufficiency specialist & 11.9 \\
Met with specialist during home visit (with home visitor present) & 218 \\
\hline Sample size & \\
\hline
\end{tabular}

SOURCES: Calculations from data gathered from a review of Enhanced Early Head Start participant case files.

NOTE: ${ }^{a}$ This table reflects discussions recorded in case files; since it is likely that discussions occurred that were not recorded in the case files, these estimates provide a lower-bound estimate. 
discussions were substantial enough to be recorded in the files and could center on the parents' job search, education plans or progress toward them, or current employment situation.

About 40 percent of the parents met with or spoke with the self-sufficiency specialist at some point during the 18 months following random assignment; about 12 percent of the parents met the specialist when the specialist accompanied the home visitor on a weekly visit.

\section{Setting Goals}

While the activity of establishing goals was in place before enhancements were made to the EHS programs - and included goals related to parenting, the child's development, and the family's health - the Enhanced EHS programs placed more emphasis on self-sufficiency goals as part of the intervention. Perhaps as a result, as Table 2.4 shows, the two most common goals focused on education and training (48 percent) and on employment (47 percent). Overall, 76 percent of participants had at least one of these self-sufficiency goals. Although 24 percent of the families did not have such a goal, some families had goals that are related to selfsufficiency, such as improving their housing situation, getting access to child care or transportation, developing a family budget, and addressing their health needs. Based on discussions with home visitors, staff noted that these related goals were often established because they were immediate needs that had to be addressed before focusing on employment or education. Also, the field research reveals that some home visitors did not feel comfortable assigning an employment or education goal if the parent was not interested in pursuing either avenue.

The parents often had a goal for their children, such as learning colors or letters. This type of goal is included in child education, and 36 percent of the parents expressed it. About 16 percent had the goal of improving some aspect of their parenting skills.

\section{Child Development and Health Screenings}

As shown in Table 2.5, among participating families, most children (95 percent) were screened at least once for child development or health issues. Health, nutrition, hearing, and vision screenings were commonly required at the beginning of enrollment, which explains the high percentage of children who received one of these (ranging from 87 percent to 94 percent). Some screenings that tracked the child's developmental progress - such as the Denver II, growth assessments, and Ages and Stages - were conducted at different points in time. The relatively low percentage of children who were screened with the Early Communication Indicator (ECI) - which is used to measure children's ability to express themselves through gestures, vocalizations, words, and sentences - reflects the fact that only SEK-CAP used this tool. 
The Enhanced Services for the Hard-to-Employ Demonstration

Table 2.4

Establishment of Family Goals

Early Head Start with Enhanced Self-Sufficiency Services

\begin{tabular}{lr}
\hline Outcome & Program \\
\hline Established at least one goal (\%) & Group \\
Among those who ever participated: & 70.7 \\
Established at least one goal (\%) & 86.7 \\
Among those who participated and established at least one goal (\%): & \\
Education or employment & 75.7 \\
Education/training & 48.2 \\
Employment & 47.1 \\
Child's education & 35.5 \\
Housing & 34.4 \\
Child care & 27.0 \\
Financial & 23.3 \\
Health & 15.9 \\
Parenting & 15.9 \\
Transportation & 13.8 \\
Nutrition/food & 5.8 \\
Public assistance & 3.7 \\
Mental health & 2.7 \\
\hline Sample size & 218 \\
\hline
\end{tabular}

SOURCES: Calculations from data gathered from a review of Enhanced Early Head Start participant case files.

\section{Referrals to Other Services}

When screenings identified issues or when home visits and parent education meetings indicated that a family could benefit from more specialized services, frontline staff would make referrals to other staff in the EHS program or to other programs and professionals in the community. Both EHS programs employed several staff specialists who were available for consultation on issues relating to disabilities, mental health, health, and nutrition. Most participating families ( 72 percent) were referred to services at least once. Just over half of all families were referred to a health professional (Table 2.5). Other common referrals were made for nutritional assistance (46 percent), social service or housing needs (33 percent), child development assistance (19 percent), dental appointments (10 percent), and employment or education 
The Enhanced Services for the Hard-to-Employ Demonstration

Table 2.5

Screenings and Referrals

Early Head Start with Enhanced Self-Sufficiency Services

\begin{tabular}{lr}
\hline Outcome & $\begin{array}{r}\text { Program } \\
\text { Group }\end{array}$ \\
\hline Received any screenings (\%) & 79.6 \\
Ever received referral (\%) & 58.9 \\
Among those who ever participated (\%): & \\
Any screening & 95.0 \\
Health & 93.6 \\
Nutrition & 86.7 \\
Hearing & 87.2 \\
Vision & 87.2 \\
Denver II & 87.2 \\
Growth & 83.0 \\
Ages and Stages & 78.0 \\
Dental & 64.7 \\
Lead-level screening & 56.0 \\
Hemoglobin screening & 47.7 \\
Early Communication Indicator (ECI) & 33.5 \\
Any referral & 72.0 \\
Health/physician & 52.8 \\
Nutrition & 45.9 \\
Social service/housing needs & 32.6 \\
Child development & 19.3 \\
Dental & 10.1 \\
Employment/education/self-sufficiency & 10.1 \\
Mental health & 6.4 \\
Prenatal & 3.7 \\
Birth to Three/Part C & 3.7 \\
Vision & 3.2 \\
\hline Sample size & 270 \\
\hline & \\
\hline
\end{tabular}

SOURCES: Calculations from data gathered from a review of Enhanced Early Head Start participant case files.

NOTE: Social service needs include housing and employment or self-sufficiency and education. 
assistance (10 percent). Less common were referrals to mental health services, prenatal services, early intervention services (such as Part C or Birth to Three), and vision-related appointments.

\section{Planned and Unplanned Exits from Enhanced EHS}

Table 2.6 shows that just over half the families who were assigned to the EHS program group exited Enhanced EHS within the first 18 months following random assignment. In onequarter of the exiting cases, the child transitioned to the Head Start program. Another onequarter exited the program due to lack of participation (either the child stopped attending the child care center or the home visitor could not schedule visits with the family. About 19 percent of the families were not interested in continuing to participate in the program and chose to withdraw; 12 percent of the families moved to another area; and 2 percent of the children in the families aged out, and there is no additional information about the subsequent services that children received. Finally, in about 16 percent of the cases, the reason for exit was not recorded in the case files.

\section{Participation Rates, by Age of Child}

The EHS programs recruited families with children up to age 3 as well as pregnant women. Families whose children were close to age 3 would be transitioned out of the program and possibly into the Head Start program when the child aged out. As a result, families with children who were approaching age 3 at random assignment might not receive the same level of services in the Enhanced EHS program. In addition, the age of the child could affect the mother's interest in employment and education services.

This section compares the participation in Enhanced EHS of families with children under 12 months (infants) at random assignment and the participation of families with children 12 months and older (toddlers). As Table 2.7 shows, the overall participation in EHS was higher among families with infants; about 91 percent of these families participated in EHS, compared with 73 percent of families with toddlers. Among those who participated (that is, received at least one home visit or one day of center-based child care), the level of participation was also higher among families with infants. Within the first 18 months following random assignment, they received about 13 months of EHS services, on average, compared with 9 months for families with toddlers.

Families with infants were more likely to receive home-based services; 83 percent of them received services at home at some point during the follow-up period, compared with 64 percent of families with toddlers. Similar shares of both groups received center-based services: 42 percent of families with infants, compared with 45 percent of families with toddlers. The families with infants who received center-based services participated longer (15 months, 
The Enhanced Services for the Hard-to-Employ Demonstration

Table 2.6

\section{Reasons for Exiting Early Head Start in 18 Months After Random Assignment}

Early Head Start with Enhanced Self-Sufficiency Services

\begin{tabular}{lr}
\hline & Program \\
Outcome & Group \\
\hline Percentage of cases that exited Enhanced Early Head Start in 18 months & 51.9 \\
Among those who exited, the reason for exit (\%): & 25.7 \\
Transition to Head Start & 25.0 \\
Lack of participation & 18.6 \\
Family chose to withdraw & 12.1 \\
Relocation of family & 2.1 \\
Child aged out & 15.7 \\
Unknown & 270 \\
\hline Sample size & \\
\hline
\end{tabular}

SOURCES: Calculations from data gathered from a review of Enhanced Early Head Start participant case files.

compared with 10 months for families with toddlers) and received more parent education meetings or home visits (18 meetings or visits, compared with 9 for families with toddlers).

Table 2.8 presents information on the types of goals that families set. While the proportion who set any goal is not statistically different ( 89 percent and 85 percent, respectively), families with infants were more likely to set a goal that focused on housing, child care, and health issues. A higher percentage of families with infants established an employment or education goal than of families with toddlers, although this difference is also not statistically significant.

Table 2.9 shows that families with infants were more likely to have had a discussion with program staff about self-sufficiency than families with toddlers ( 84 percent, compared with 74 percent). Families with infants were more likely to have the discussion during home visits rather than during parent education meetings, reflecting the higher percentage who received home-based services. The self-sufficiency specialist had contact with both types of families in similar proportions, but families with infants were more likely to see the specialist during a home visit. 


\section{The Enhanced Services for the Hard-to-Employ Demonstration}

Table 2.7

\section{Engagement in Enhanced Early Head Start in 18 Months After Random Assignment, by Age of Child at Random Assignment}

\section{Early Head Start with Enhanced Self-Sufficiency Services}

\begin{tabular}{|c|c|c|}
\hline Outcome & $\begin{array}{l}\text { Infant } \\
\text { Group }\end{array}$ & $\begin{array}{r}\text { Toddler } \\
\text { Group }\end{array}$ \\
\hline Participated in Enhanced Early Head Start ${ }^{\mathrm{a}}(\%)$ & 90.5 & $73.4 * * *$ \\
\hline Length of participation (months) & 12.0 & $6.8 * * *$ \\
\hline Among participants, length of participation (months) & 13.1 & $9.3 * * *$ \\
\hline Ever received home-based services (\%) & 82.8 & $63.6 * * *$ \\
\hline Ever received center-based services $(\%)$ & 42.2 & 44.8 \\
\hline \multicolumn{3}{|l|}{ Among those who received home-based services: } \\
\hline Length of participation (months) & 13.0 & $9.3 * * *$ \\
\hline Number of home visits in 18 months after random assignment & 20.1 & 17.6 \\
\hline Number of cancellations in month & 0.6 & $0.3 * * *$ \\
\hline Number of calls between staff and parent in month & 0.5 & 0.4 \\
\hline \multicolumn{3}{|l|}{ Among those who received center-based services: } \\
\hline Length of participation (months) & 15.2 & $10.1 * * *$ \\
\hline Monthly child care attendance ${ }^{\mathrm{b}}$ (days) & 13.7 & 13.7 \\
\hline $\begin{array}{l}\text { Number of parent education meetings or home visits in } \\
18 \text { months after random assignment }\end{array}$ & 18.3 & $8.8 * * *$ \\
\hline Sample size $($ total $=270)$ & 116 & 154 \\
\hline
\end{tabular}

SOURCES: Calculations from data gathered from a review of Enhanced Early Head Start participant case files.

NOTES: In order to assess differences in characteristics across research groups, chi-square tests were used for categorical variables, and t-tests were used for continuous variables. Statistical significance levels are indicated as follows: $* * *=1$ percent; $* *=5$ percent; $*=10$ percent. The significance level indicates the probability that one would be making an error in concluding that there is a difference between research groups for the variable in question.

The Infant Group is defined as families with children less than 12 months old at random assignment. The Toddler Group is defined as families with children 12 months or older at random assignment.

The number of home visits for both home-based and center-based services does not include visits with the self-sufficiency coordinator alone but may include instances when the self-sufficiency coordinator accompanied a home visitor.

aParticipation is defined as having received any home-based or center-based services during 18 months following random assignment.

${ }^{\mathrm{b}}$ This outcome reflects average attendance in months with attendance. 
The Enhanced Services for the Hard-to-Employ Demonstration

Table 2.8

Establishment of Family Goals in 18 Months After

Random Assignment, by Age of Child at Random Assignment

Early Head Start with Enhanced Self-Sufficiency Services

\begin{tabular}{lcc}
\hline Outcome & $\begin{array}{c}\text { Infant } \\
\text { Group }\end{array}$ & $\begin{array}{c}\text { Toddler } \\
\text { Group }\end{array}$ \\
\hline Among those who ever participated: & & \\
$\quad$ Established at least one goal (\%) & 88.6 & 85.0 \\
Among those who participated and established at least one goal (\%): & & 70.8 \\
Education or employment & 80.7 & 45.8 \\
$\quad$ Education/training & 50.5 & 43.8 \\
$\quad$ Employment & 50.5 & 38.5 \\
Child's education & 32.3 & $27.1 * *$ \\
Housing & 41.9 & $18.8 * * *$ \\
Child care & 35.5 & 21.9 \\
Financial & 24.7 & $10.4 * *$ \\
Health & 21.5 & 13.5 \\
Parenting & 18.3 & 11.5 \\
Transportation & 16.1 & 5.2 \\
Nutrition/food & 6.5 & 4.2 \\
Public assistance & 3.2 & 3.1 \\
Mental health & 2.2 & 113 \\
\hline Sample size (total =218) & & 105 \\
\hline
\end{tabular}

SOURCES: Calculations from data gathered from a review of Enhanced Early Head Start participant case files.

NOTES: In order to assess differences in characteristics across research groups, chi-square tests were used for categorical variables, and t-tests were used for continuous variables. Statistical significance levels are indicated as follows: $* * *=1$ percent; $* *=5$ percent; $*=10$ percent. The significance level indicates the probability that one would be making an error in concluding that there is a difference between research groups for the variable in question.

The Infant Group is defined as families with children less than 12 months old at random assignment. The Toddler Group is definded as families with children 12 months or older at random assignment.

\section{Challenges of Implementing Self-Sufficiency Enhancements}

Overall, although the specialists increased the focus on self-sufficiency in both programs, there were challenges in fully implementing the enhancements. The case file review found a lesser focus than was intended on self-sufficiency during home visits and parent education meetings. The results highlight the obstacles that can be difficult to overcome when 


\section{The Enhanced Services for the Hard-to-Employ Demonstration}

Table 2.9

\section{Topics Addressed in Meetings with EHS Staff in 18 Months After Random Assignment, by Age of Child at Random Assignment}

Early Head Start with Enhanced Self-Sufficiency Services

\begin{tabular}{lcc}
\hline Outcome & $\begin{array}{c}\text { Infant } \\
\text { Group }\end{array}$ & $\begin{array}{c}\text { Toddler } \\
\text { Group }\end{array}$ \\
\hline Among participating parents ${ }^{\mathrm{a}}(\%)$ : & & \\
Any discussion of self-sufficiency & 83.8 & $73.5 *$ \\
Discussed self-sufficiency during home visit & 73.3 & $56.6 * * *$ \\
Discussed self-sufficiency during parent education meeting & 23.8 & $36.3 * *$ \\
Any contact with self-sufficiency specialist & 37.1 & 41.6 \\
Met with specialist during home visit (with home visitor present) & 18.1 & $6.2 * * *$ \\
\hline Sample size (total =218) & 105 & 113 \\
\hline
\end{tabular}

SOURCES: Calculations from data gathered from a review of Enhanced Early Head Start participant case files.

NOTES: In order to assess differences in characteristics across research groups, chi-square tests were used for categorical variables, and t-tests were used for continuous variables. Statistical significance levels are indicated as follows: $* * *=1$ percent; $* *=5$ percent; $*=10$ percent. The significance level indicates the probability that one would be making an error in concluding that there is a difference between research groups for the variable in question.

The Infant Group is defined as families with children less than 12 months old at random assignment. The Toddler Group is defined as families with children 12 months or older at random assignment.

${ }^{a}$ This outcome reflects discussions recorded in case files; since it is likely that discussions occurred that were not recorded in the case files, these estimates provide a lower-bound estimate.

implementing such enhancements, particularly for programs that are traditionally defined as early childhood interventions. Some of these challenges are discussed below.

\section{Resistance and Lack of Expertise Among Some Staff}

The field research indicates that, initially, although EHS management supported the vision of enhancing the self-sufficiency component, frontline staff were not as quick to "buy in" to the changes involved. Some staff viewed the increased programmatic focus on employment and self-sufficiency as a burden that required additional time, which they felt they did not have. This difficulty was compounded because some staff were uncomfortable discussing employment and self-sufficiency issues with families; they were more comfortable discussing child development issues, which are generally aligned with their education, training, and interests. They felt that they lacked the expertise to help parents set and pursue education and employment goals. 
Several staff noted that they were uncomfortable encouraging work as a goal for families, believing that some families might not be better off after entering the workforce. Several staff who were interviewed pointed out that families lose public benefits when they take a job. Others noted that some mothers prefer to be at home with young children, and these staff were uncomfortable convincing the mothers to leave home for work.

Over time, with additional training, staff resistance lessened. The solution, however, lay partly in referring more families to the self-sufficiency specialists, rather than offering direct assistance themselves - which was the initial vision of how the self-sufficiency enhancements would be implemented. The field research also uncovered substantial variation in how frontline staff addressed self-sufficiency issues. Some home visitors discussed self-sufficiency during each visit, while others rarely mentioned it to parents.

\section{Diversity of Parents' Needs and Interests}

The parents in the study had a variety of reasons for enrolling in EHS. Many who applied for the home-visiting program did so because they were interested in its child development and parenting education services. And while many parents appreciated the employment and education assistance that was offered by frontline staff and the self-sufficiency specialists, others were not interested in either pursuit and, instead, preferred to stay home during their children's early years. Many of these parents were living with another adult who worked, and although they had low incomes, they were getting by from a mix of earnings and public benefits (such as WIC, food stamps, and housing assistance). For some families, the situation was compounded by concerns about placing their children in child care. A survey conducted by SEK-CAP to help staff understand parents' barriers and needs revealed that almost half the parents worried about placing their children in the care of others while they were away at work or school.

Parents who received center-based services were in a different situation. Most were getting child care because they were already employed or in school. When they lost their jobs, they might be quick to request assistance from the self-sufficiency specialist because they eventually would lose the child care services unless they found employment; while employed, however, they usually did not seek out or receive self-sufficiency assistance. Additionally, parents receiving Youth in Need center-based services met with staff individually only once a quarter, with either the teacher or the center manager. Most interactions with EHS occurred when parents were dropping off and picking up their children at the center, which was not as conducive to discussions about employment and education as might have occurred in home-based programs. In addition, as discussed above, the self-sufficiency specialists prioritized the families with whom they worked directly, and families who were already employed were considered a lower priority. 


\section{Implementation Delays}

It took some time to implement the enhancements to EHS because of staff turnover and the need to find and hire the self-sufficiency specialists. As a result, the programs delayed conducting many of the planned staff and parent training sessions that focused on employment and self-sufficiency. These delays likely contributed to gaps in staff knowledge about available community resources and to their reluctance early in the study to broach the topic of employment and self-sufficiency.

\section{Lack of Resources in Rural Areas}

While the EHS programs identified new employment and training resources available in the community, fewer resources were available in the rural counties. Child care - particularly care for infants - and public transportation were limited. The most rural Youth in Need county attempted to counter such problems by hosting a GED class on-site and by involving staff in the local YouthBuild program. But there were additional limitations. For example, this county did not have a One-Stop Career Center, a community college, or opportunities for training. The nearest services were located about 30 miles from the county center. Transportation was a serious barrier for many of the parents, especially in the more rural communities.

\section{Conclusion}

Enhanced EHS increased the focus on self-sufficiency but did not succeed in providing an intensive level of employment, education, and self-sufficiency assistance to most families. The programs struggled because staff were trained in child development and parenting issues and were asked to provide assistance on employment, education, and self-sufficiency, which were outside their knowledge base. Although further training helped them become more comfortable interacting with parents on self-sufficiency issues, many staff relied on the assistance of the self-sufficiency specialists to provide these services.

Future efforts to enhance early child development programs will need to recognize the diverse needs of the families enrolled in them. Some parents are interested only in the child care or child development services, while others want and could benefit from enhanced selfsufficiency services. 


\section{Chapter 3 \\ Impacts on Service Receipt}

Chapter 2 describes the implementation of formalized parental employment and educational services ("Enhanced Early Head Start" [EHS]) that were provided within two traditional EHS programs: the Southeast Kansas Community Action Program (SEK-CAP) Early Head Start program in Girard, Kansas, and the Youth in Need Early Head Start program in St. Charles, Missouri. Chapter 2 also provides information on the program group members' participation as recorded in the case files.

This chapter presents information on the receipt of early childhood development, parent education, social services, and self-sufficiency services as captured by a survey that was administered to program and control group members about 18 months after they entered the study. ${ }^{1}$ The control group members were not eligible for Enhanced EHS services at the two sites, but they were able to receive services from other programs in the community. Examining the differences between program group members' and control group members' participation is central to understanding the impacts of Enhanced EHS on the child and parent outcomes that are presented in Chapters 4, 5, and 6.

This chapter presents impacts for the full sample and by the age of the focal child. ${ }^{2}$ Appendix Tables D.1 to D.4 present impacts by program site and by the number of parents in the household. Box 3.1 explains how to interpret the estimated impacts shown in tables presented in the remainder of the report.

\section{Receipt of Family Development Services}

The 18-month survey of parents asked a series of questions intended to capture information about the receipt of family development and child development services. In particular, the survey asked whether the parent had had telephone contact or had met with a staff person who provided assistance or advice on (1) parenting, how to be a better parent, caring for kids, or

\footnotetext{
${ }^{1}$ This chapter includes information on the receipt of EHS child care services. Chapter 4 provides information on the overall receipt of child care.

${ }^{2}$ As is true with all applications to EHS, families identify a particular child who is up to age 3 or during the prenatal period and who will be enrolled in the program. In this study's 18-month parent survey and direct child assessments, this child is identified as the focal child who is the target of program services and is the focus of all questions related to child care and early educational experiences, parenting practices, and child development and well-being.
} 


\section{Box 3.1}

\section{How to Read the Estimated Impact Tables in This Report}

Most tables in this report use a similar format, illustrated below. Several participation outcomes are shown for the program group and the control group. For example, about 79 (78.6) percent of the program group and about 21 (21.2) percent of the control group ever participated in any EHS/HS-related activity.

The "Difference (Impact)" column shows the differences between the two research groups' participation rates - that is, the Enhanced EHS program's estimated impact on participation. For example, the estimated impact on participating in EHS/HS services can be calculated by subtracting 78.6 percent from 21.2 percent, yielding a difference of 57.5 percentage points.

Differences marked with asterisks are "statistically significant," meaning that it is quite unlikely that the differences arose by chance. The number of asterisks indicates whether the estimated impact is statistically significant at the 10 percent, 5 percent, or 1 percent level (the lower the level, the less likely that the impact is due to chance). For example, as shown below, the program group model had a statistically significant impact of 57.5 percentage points at the 1 percent level on participating in EHS/HS services. (One asterisk corresponds to the 10 percent level; two asterisks, the 5 percent level; and three asterisks, the 1 percent level.) The p-values show the exact levels of significance.

Impact estimates presented in this report are often referred to as "intent-to-treat" impact estimates. That is, the impacts are calculated by comparing all parents and children in the Enhanced EHS program group with all parents and children assigned to the non-Enhanced EHS control group, regardless of whether or how long they were engaged in Enhanced EHS services. The impact estimates are also regression-adjusted using background characteristics of the sample, including gender, age, race/ethnicity, prior employment, education, TANF receipt, number of children, child's age and gender, two-parent case status, site, random assignment cohort, and length of time between random assignment and the survey/assessment date.

\section{Impacts on Receipt of Family Development, Child-Focused, and Case Management Services}

\begin{tabular}{|c|c|c|c|c|c|}
\hline Outcome & $\begin{array}{r}\text { Program } \\
\text { Group }\end{array}$ & $\begin{array}{l}\text { Control } \\
\text { Group }\end{array}$ & $\begin{array}{r}\text { Difference } \\
\text { (Impact) }\end{array}$ & $\begin{array}{r}\text { Effect } \\
\text { Size }\end{array}$ & P-Value \\
\hline $\begin{array}{l}\text { Received any EHS/HS child care and/or family } \\
\text { development services since random assignment (\%) }\end{array}$ & 78.6 & 21.2 & $57.5 * * *$ & 1.15 & 0.000 \\
\hline $\begin{array}{l}\text { Received any EHS/HS family development services } \\
\text { since random assignment }(\%)\end{array}$ & 66.0 & 17.8 & $48.2 * * *$ & 0.98 & 0.000 \\
\hline \multicolumn{6}{|l|}{ Frequency of contact with EHS/HS (\%): } \\
\hline No contact & 34.0 & 82.2 & $-48.2 * * *$ & -0.98 & 0.000 \\
\hline Once or less than once a month & 9.1 & 6.0 & 3.1 & 0.12 & 0.204 \\
\hline At least once a month & 22.1 & 4.2 & $17.9 * * *$ & 0.53 & 0.000 \\
\hline At least once a week & 33.6 & 6.4 & $27.1 * * *$ & 0.68 & 0.000 \\
\hline Sample size $($ total $=491)$ & 242 & 249 & & & \\
\hline
\end{tabular}

SOURCE: MDRC calculations based on responses to the 18-month survey. 
understanding how kids develop; (2) activities that the parent could do with the child to help the child grow and learn; (3) the progress of the child; (4) budgeting and financial management; (5) arranging or paying for transportation; (6) finding or paying for good child care; (7) reading, math, or English skills or going to school; (8) prenatal care; (9) applying for government benefits; and (10) employment or job-related goals. This chapter refers to this collection of assistance as "family development services." Parents who answered "yes" to one of these questions were asked to identify where they had received these services, which could be through Early Head Start or Head Start (EHS/HS) or through other programs in the community. The survey also asked whether, since random assignment, the parents had received EHS/HS child care for at least 10 hours per week for a period that lasted two weeks or longer.

\section{Receipt of Early Head Start or Head Start}

This section presents impacts on the receipt of EHS/HS services and by the type of service provided.

- Given that control group members could not participate in EHS in the study counties, Enhanced EHS significantly increased participation in EHS/HS for the program group members.

As the first row of Table 3.1 shows, program group members were significantly more likely than control group members to have received EHS/HS services either from an EHS/HS child care center or through assistance from home visitors or other staff. About 79 percent of the program group received these services, compared with 21 percent of the control group. ${ }^{3}$ The low receipt of EHS/HS services by the control group members can be explained by the embargo that prevented them from enrolling in EHS during the first three years after joining the study. Some control group members may have enrolled in EHS/HS after moving to another community or may have enrolled in SEK-CAP HS after the child turned age 3. The Youth in Need program expanded the three-year embargo on control group members to prevent them from receiving HS services as well, resulting in low receipt of services by Youth in Need control group members. Appendix Table D.1 shows that the impact on the receipt of EHS/HS services in Youth in Need is 69 percentage points, compared with 46 percentage points in SEK-CAP. ${ }^{4}$

Among the full study sample, about 66 percent of the program group, compared with 18 percent of the control group, reported receiving family development services from EHS/HS

\footnotetext{
${ }^{3}$ The program group's participation rate is lower than the participation rate estimated from the case file and child care attendance records presented in Chapter 2, and the latter includes just EHS (not HS) participation. This implies that there may have been some recall error in parents' reporting of service receipt.

${ }^{4}$ Impacts are also larger for one-parent households than for two-parent households (Appendix Table D.3).
} 
The Enhanced Services for the Hard-to-Employ Demonstration

Table 3.1

Impacts on Receipt of Family Development, Child-Focused, and Case Management
Services 18 Months After Random Assignment, EHS/HS Providers Only

Early Head Start with Enhanced Self-Sufficiency Services

\begin{tabular}{|c|c|c|c|c|c|}
\hline Outcome & $\begin{array}{r}\text { Program } \\
\text { Group } \\
\end{array}$ & $\begin{array}{l}\text { Control } \\
\text { Group } \\
\end{array}$ & $\begin{array}{r}\text { Difference } \\
\text { (Impact) } \\
\end{array}$ & $\begin{array}{r}\text { Effect } \\
\text { Size }^{\mathrm{a}}\end{array}$ & P-Value \\
\hline $\begin{array}{l}\text { Received any EHS/HS child care and/or family } \\
\text { development services since random assignment (\%) }\end{array}$ & 78.6 & 21.2 & $57.5 * * *$ & 1.15 & 0.000 \\
\hline $\begin{array}{l}\text { Received any EHS/HS family development services } \\
\text { since random assignment }(\%)\end{array}$ & 66.0 & 17.8 & $48.2 * * *$ & 0.98 & 0.000 \\
\hline \multicolumn{6}{|l|}{ Frequency of contact with EHS/HS (\%): } \\
\hline No contact & 34.0 & 82.2 & $-48.2 * * *$ & -0.98 & 0.000 \\
\hline Once or less than once a month & 9.1 & 6.0 & 3.1 & 0.12 & 0.204 \\
\hline At least once a month & 22.1 & 4.2 & $17.9 * * *$ & 0.53 & 0.000 \\
\hline At least once a week & 33.6 & 6.4 & $27.1 * * *$ & 0.68 & 0.000 \\
\hline Length of engagement in EHS/HS (months) & 11.7 & 6.4 & 5.4 & & \\
\hline Sample size $($ total $=491)$ & 242 & 249 & & & \\
\hline
\end{tabular}

SOURCE: MDRC calculations based on responses to the 18-month survey.

NOTES: Statistical significance levels are indicated as follows: $* * *=1$ percent; $* *=5$ percent; $*=10$ percent. The significance level indicates the probability that one would incorrectly conclude that a difference exists between research groups for the corresponding variable.

Results in this table are regression-adjusted using ordinary least squares, controlling for pre-random assignment characteristics.

The measure shown in italic type is considered nonexperimental and is not tested for statistical significance.

aThe effect size is calculated by dividing the impact of the program (difference between program and control groups) by the observed variation for that outcome within the control group (the control group standard deviation).

staff — such as assistance on parenting, the child's development, accessing support services, and education or employment-related goals (Table 3.1). These percentages are slightly lower than those reported in the preceding paragraph because they do not include respondents who said that they received child care services from EHS/HS but did not report receiving family development services.

Approximately one-third of the program group reported having weekly contact with EHS/HS staff, compared with 6 percent of control group members. Among those who reported receiving the EHS/HS family development services, the program group received close to 12 months of services - substantially longer than the control group's 6.4 months. 


\section{Receipt of Any Family Development Services}

This section examines the overall receipt of family development services, regardless of the service provider, analyzed by the type of service.

- With the inclusion of services from non-EHS/HS programs, high proportions of both groups received family development services, reflecting the availability of these services in the community for control group members.

As shown in Table 3.2, about 91 percent of the program group and 80 percent of the control group received family development services either from EHS/HS or from other community programs. The difference of 11 percentage points is relatively small but is statistically significant. ${ }^{5}$

- Enhanced EHS increased the receipt of parenting and child development assistance.

The survey asked parents specifically about the types of services or topics addressed by the EHS/HS program or other programs in the community. Parenting education and child development services include helping parents with parenting skills (for example, how to be a better parent, how to help the child grow and learn, and how to chart the child's progress). About 84 percent of the program group reported that they received assistance or advice on parenting and child development, compared with 64 percent of the control group. This impact of 20 percentage points is statistically significant, although the high percentage of control group members who received parenting and child development assistance reflects the availability of services elsewhere in the community.

- Reflecting the enhancements offered by the EHS programs, Enhanced EHS also increased the receipt of assistance on self-sufficiency, although the impacts are modest.

For example, the parents who reported receiving help with education needs - which included advice on improving their literacy and math skills and on going to school — made up 23 percent of the program group and 15 percent of the control group, resulting in a statistically

\footnotetext{
${ }^{5}$ There were impacts on the receipt of family development services for one-parent households but not for two-parent households. That is, control group households with two parents were just as likely as program group households with two parents to receive these services. See Appendix Table D.4 for more information.
} 
The Enhanced Services for the Hard-to-Employ Demonstration

Table 3.2

\section{Impacts on Receipt of Family Development, Child-Focused, and Case Management Services 18 Months After Random Assignment, Both EHS/HS and Non-EHS/HS Providers}

\section{Early Head Start with Enhanced Self-Sufficiency Services}

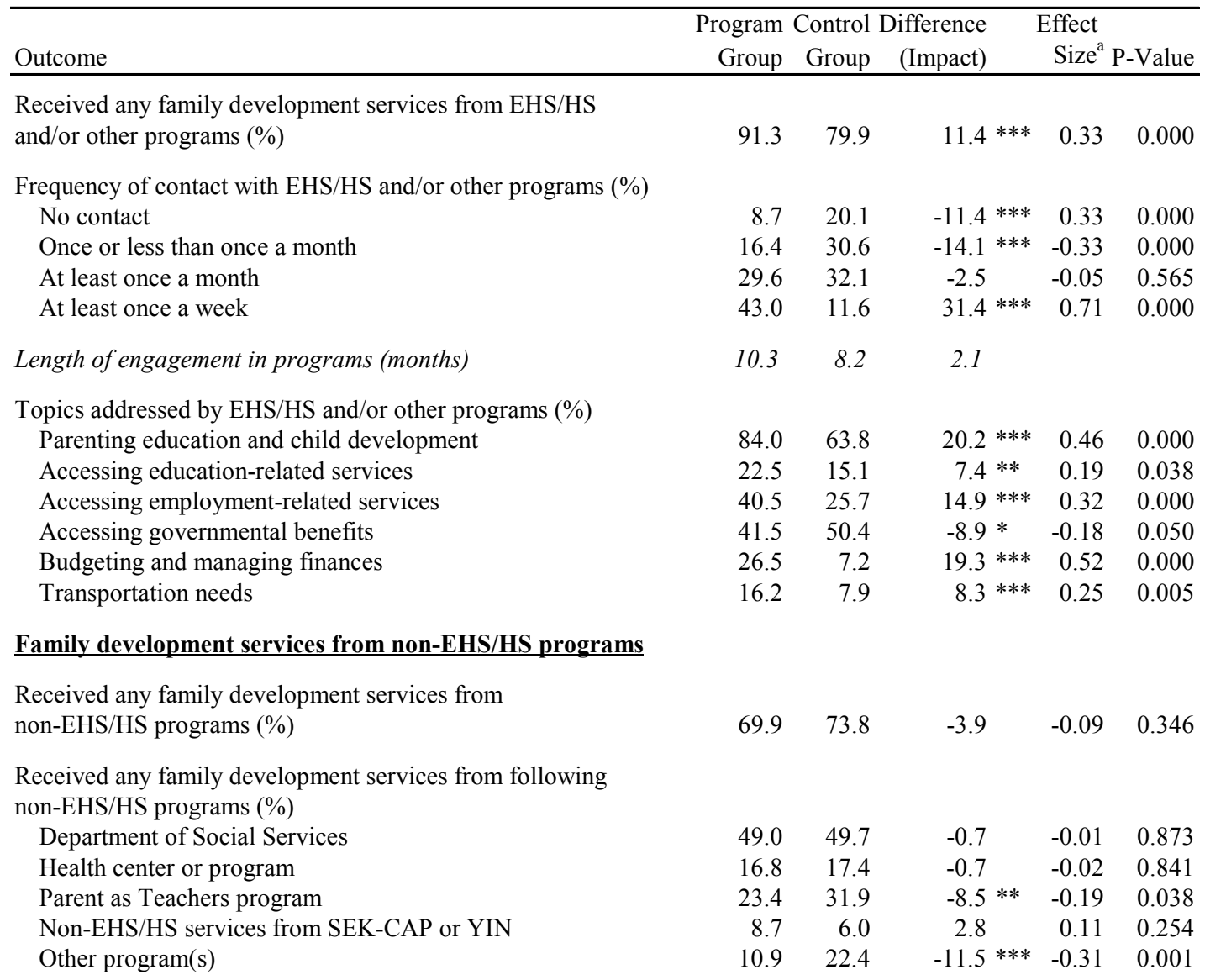

\section{Early intervention services}

Presence of physical, medical, learning, emotional, or mental health condition or disability (\%)

No child disability

Child disability and no early intervention services

Child disability and receipt of early intervention services

\begin{tabular}{rrrrr}
75.9 & 73.9 & 2.0 & 0.05 & 0.612 \\
1.6 & 2.1 & -0.5 & -0.04 & 0.690 \\
22.5 & 23.8 & -1.3 & -0.03 & 0.735 \\
& & & & \\
& & & & \\
94.9 & 93.2 & 1.7 & 0.07 & 0.439 \\
6.1 & 5.2 & $0.9 * *$ & 0.18 & 0.037 \\
92.6 & 92.9 & -0.3 & -0.01 & 0.905 \\
\hline 242 & 249 & & & \\
& & &
\end{tabular}


Table 3.2 (continued)

SOURCE: MDRC calculations based on responses to the 18-month survey.

NOTES: Statistical significance levels are indicated as follows: $* * *=1$ percent; $* *=5$ percent; $*=10$ percent. The significance level indicates the probability that one would incorrectly conclude that a difference exists between research groups for the corresponding variable.

Results in this table are regression-adjusted using ordinary least squares, controlling for pre-random assignment characteristics.

The measure shown in italic type is considered nonexperimental and is not tested for statistical significance.

${ }^{a}$ The effect size is calculated by dividing the impact of the program (difference between program and control groups) by the observed variation for that outcome within the control group (the control group standard deviation).

significant impact of just 7 percentage points. This impact was driven by an increase in assistance provided by the Youth in Need site. ${ }^{6}$ It supports the field research finding that Youth in Need placed a stronger emphasis than SEK-CAP on referring parents to education providers in the community (Chapter 2).

The program group was also more likely to get assistance or advice on finding a job or a job training program. Relative to the control group's participation, Enhanced EHS increased the receipt of employment-related services by 15 percentage points. It also increased the receipt of budgeting and financial management assistance by 19 percentage points.

There were impacts on the receipt of education- and employment-related services for households with one parent but not for households with two parents (Appendix Table D.4).

- The findings on accessing benefits and support services are mixed.

The survey asked about parents' receipt of assistance on accessing government benefits and support services. Interestingly, control group members were more likely than program group members to receive assistance on accessing government benefits (such as welfare, food stamps, and Medicaid). About 42 percent of program group members and 50 percent of control group members reported receiving assistance in this area, resulting in a negative impact of 9 percentage points for program group members. Enhanced EHS increased the receipt of transportation assistance by 8 percentage points.

- While Enhanced EHS increased participation in EHS/HS, control group members were more likely to receive services from other programs in the community.

\footnotetext{
${ }^{6}$ As shown in Appendix Table D.2, the Youth in Need program increased assistance on accessing education-related services by 19 percentage points; there was no statistically significant increase for SEK-CAP.
} 
The survey asked parents where they obtained the family development services discussed above. (Box 3.2 describes some of the community programs that sample members could have accessed.) As shown in the second panel of Table 3.2, the Parents as Teachers (PAT) program was one of the more common resources utilized by both groups, although control group members were more likely to do so. Almost one-third (32 percent) of control group members and one-quarter (23 percent) of program group members reported receiving services from PAT, resulting in a statistically significant negative impact of 9 percentage points for program group members. PAT is a home visiting program that provides services like those in EHS. In fact, both of the EHS sites used the PAT Born-to-Learn curriculum for the home visits during most of the study period, increasing the similarity of the child development services. A major difference between PAT and EHS is the frequency of interaction. PAT staff conduct monthly home visits, while EHS staff conduct weekly home visits.

While both program and control group members received equivalent levels of services from the Department of Social Services, health centers or programs, and non-EHS services offered by Youth in Need and SEK-CAP, the control group was more likely to receive services from other programs in the community (Table 3.2). These other programs include a mix of early intervention programs for children with disabilities, other home visiting and parenting education programs, employment programs, and family preservation services. About 11 percent of program group members and 22 percent of control group members received services from other programs. This decrease of 11 percentage points is statistically significant.

While many control group members received other services in the community, the services provided by Enhanced EHS may have been more comprehensive and more intensive than the services in many of these other programs. For example, families receiving Enhanced EHS home-based services met more frequently with their home visitors than families enrolled in other home-based programs; families receiving Enhanced EHS center-based services likely received higher-quality child care than those who received center-based care from other community providers, since EHS center-based care is required to meet revised Head Start Program Performance Standards; and EHS families had access to specialized services (for example, a nurse, disability specialist, nutrition specialist, and mental health specialist). The breadth of services offered by Enhanced EHS - excluding the costs associated with implementing the enhanced employment, educational, and self-sufficiency services - is reflected in the relatively high cost of $\$ 6,775$ per child (averaged across the two sites). This is higher than the per child cost estimated for other community programs that offered similar but less intensive services. Appendix $\mathrm{C}$ analyzes the costs of services provided to program group and control group members. 
Box 3.2

\section{Other Community Programs Providing Family Development Services}

Parents as Teachers (PAT). This home visiting program serves families and children from pregnancy through age 5 . In the study counties, PAT conducted monthly home visits of about 60 minutes each. In addition, the program conducts health, hearing, vision, and developmental screenings of children; has group meetings for parents; and refers parents to community resources, depending on their needs.

PAT is similar to the EHS home-based programs, which use the PAT Born-to-Learn curriculum that was also used in the EHS study sites until 2007. The primary difference between the two programs is the intensity of services: PAT participants meet monthly with home visitors - rather than weekly, as in EHS - and do not have access to the same level of specialists that are available to EHS participants.

Early Intervention Programs. These programs provide services to children under age 3 who have special needs. The early intervention program operating in southeast Kansas is called "Birth to Three," and the one operating in Missouri is called "First Steps." In both, an initial assessment is conducted to determine whether the child demonstrates a developmental delay or disability that meets the eligibility criteria. If so, a service coordinator is assigned to the family and, with them, develops an Individualized Family Service Plan (IFSP) that outlines the services to be provided to the child. The coordinator then works with the family to ensure that the IFSP is implemented and that the family and child receive the services and supports they need.

Stay at Home Parent Program (Missouri). This program is funded by the Missouri Early Childhood Development, Education, and Care Fund through grants to community organizations. It provides home visiting services to low-income families with children younger than 3, to help parents develop effective parenting skills and ensure the health and development of children. The program operated in Lincoln and Montgomery Counties during the study period.

Healthy Start. This program is designed to help parents improve their parenting skills and to provide guidance to expectant and new mothers who have questions about having a healthy pregnancy and caring for their baby. Providing health education is a primary component of the program. Home visitors also act as case managers and try to connect parents with other community resources. Healthy Start staff in Crawford County (Kansas) report that the frequency of home visits depends on the intensity of the issues that the family is facing. Families with intense needs receive weekly visits - or even twice weekly - while other families meet with the case manager monthly. In Crawford, after a child turns age 2, the family is referred to PAT, or Birth to Three (if necessary), or other community programs. 
- Enhanced EHS did not increase the receipt of early intervention services for children with disabilities, but it did increase the receipt of routine health care visits.

In terms of other child-focused services, Enhanced EHS conducted assessments of children soon after they enrolled in the program. And when staff suspected a child of having a disability, they made a referral to the local early intervention agency designated by the state Part $\mathrm{C}$ plan, to determine eligibility for Part $\mathrm{C}$ services and coordinate the development of an Individualized Family Service Plan (IFSP). ${ }^{7}$ The family might also be referred by other programs, the child's physician, or the parent. Control group members might also be referred by these other sources.

About one-quarter of both groups reported having a child with a disability. Most children who had a disability were receiving early intervention services. There was no difference in the receipt of early intervention services between the two research groups.

In terms of the receipt of health care services, most respondents reported the child's immunizations were up-to-date and most children had access to health insurance. Enhanced EHS did increase the number of routine health care visits by about one visit a year.

\section{Participation in Job Search, Education, and Training}

\section{- Enhanced EHS did not increase participation in any formal job search or education and training activity.}

As Table 3.3 shows, about 59 percent of program group members and 55 percent of control group members participated in any job search, education, or training activity. The difference is not statistically significant.

About one-quarter of sample members participated in a job search activity, with over 15 percent participating in group job search (such as group job-readiness classes or meetings) and about 15 percent participating in individual job search, which required them to bring a list of the employers that they had contacted to someone who worked at an agency. Both types of job search activities are often mandated by welfare agencies as a requirement for receiving benefits from the Temporary Assistance for Needy Families (TANF) program. It is unlikely that program group members who had received assistance with job search as part of Enhanced EHS would have responded that they had participated in such activities, because they were not

\footnotetext{
${ }^{7}$ The federal Individuals with Disabilities Education Act (IDEA) Part C provides funding to states and public agencies for early intervention services for infants and toddlers with disabilities and for their families.
} 


\section{The Enhanced Services for the Hard-to-Employ Demonstration}

Table 3.3

\section{Impacts on Participation in Job Search, Education, and Training Activities} Early Head Start with Enhanced Self-Sufficiency Services

\begin{tabular}{|c|c|c|c|c|c|}
\hline Outcome & $\begin{array}{r}\text { Program } \\
\text { Group } \\
\end{array}$ & $\begin{array}{r}\text { Control } \\
\text { Group }\end{array}$ & $\begin{array}{r}\text { Difference } \\
\text { (Impact) } \\
\end{array}$ & $\begin{array}{r}\text { Effect } \\
\text { Size }^{\mathrm{a}}\end{array}$ & P-Value \\
\hline $\begin{array}{l}\text { Ever participated in any job search, education, and/or } \\
\text { training activity }(\%)\end{array}$ & 59.1 & 54.6 & 4.5 & 0.09 & 0.318 \\
\hline Participated in job search activity (\%) & 26.3 & 23.8 & 2.5 & 0.06 & 0.519 \\
\hline Group job search/job club (\%) & 18.9 & 15.8 & 3.1 & 0.08 & 0.363 \\
\hline Individual job search (\%) & 15.9 & 14.3 & 1.6 & 0.04 & 0.625 \\
\hline Participated in education/training activity (\%) & 48.1 & 44.4 & 3.6 & 0.07 & 0.417 \\
\hline Adult basic education/GED classes $(\%)$ & 11.6 & 8.0 & 3.5 & 0.12 & 0.135 \\
\hline College courses $(\%)$ & 29.1 & 27.1 & 2.0 & 0.04 & 0.611 \\
\hline English as a Second Language (ESL) classes (\%) & 2.2 & 1.1 & 1.1 & 0.08 & 0.357 \\
\hline Vocational training $(\%)$ & 12.8 & 10.0 & 2.8 & 0.09 & 0.329 \\
\hline Other education or training activity $(\%)$ & 1.9 & 3.9 & -2.0 & -0.12 & 0.199 \\
\hline $\begin{array}{l}\text { Obtained degree or diploma/GED certificate since } \\
\text { random assignment }(\%)\end{array}$ & 6.4 & 7.4 & -0.9 & -0.04 & 0.668 \\
\hline \multicolumn{6}{|l|}{ Average number of weeks participating in: } \\
\hline Job search activities & 2.9 & 1.8 & 1.1 & 0.12 & 0.177 \\
\hline Education/training activities & 13.8 & 12.3 & 1.4 & 0.06 & 0.493 \\
\hline \multicolumn{6}{|l|}{$\begin{array}{l}\text { Among those who participated, average number } \\
\text { of weeks in: }\end{array}$} \\
\hline Job search activities & 11.8 & 6.8 & 5.0 & & \\
\hline Education/training activities & 29.5 & 26.9 & 2.6 & & \\
\hline Sample size $($ total $=491)$ & 242 & 249 & & & \\
\hline
\end{tabular}

SOURCES: MDRC calculations based on responses to the 18-month survey.

NOTES: Statistical significance levels are indicated as follows: $* * *=1$ percent $* *=5$ percent; $*=10$ percent. The significance level indicates the probability that one would incorrectly conclude that a difference exists between research groups for the corresponding variable.

Results in this table are regression-adjusted using ordinary least squares, controlling for pre-random assignment characteristics.

The measures shown in italic type are considered nonexperimental and are not tested for statistical significance.

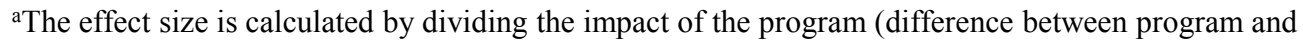
control groups) by the observed variation for that outcome within the control group (the control group standard deviation). 
mandated to $\log$ their contacts with employers and report them to the home visitor or selfsufficiency specialist. ${ }^{8}$ For the full sample, there also was no impact on the number of weeks of participation in these services.

Enhanced EHS was intended to increase participation in education and training activities, but this did not occur. About 48 percent of the program group and 44 percent of the control group participated in an education or training activity - a difference that is not statistically significant. The most common type of education or training activity was participation in college courses; 29 percent of program group members and 27 percent of control group members took college courses. In addition, 12 percent of the program group and 8 percent of the control group took adult basic education or General Educational Development (GED) courses, and 13 percent of the program group and 10 percent of the control group participated in vocational training. Program group members were no more likely than control group members to have obtained a degree or diploma since random assignment.

A separate analysis, by site (Appendix Table D.5), shows that the Youth in Need program group was more likely than its control group to participate in adult basic education or GED classes. The Youth in Need Enhanced EHS program increased adult basic education or GED participation by 8 percentage points. In addition to emphasizing the referral of parents to education providers in the community more than the SEK-CAP program did, the Youth in Need program also offered GED classes on-site in one rural county because these services were not available elsewhere in the county. A separate analysis of one-parent and two-parent households did not find impacts for either subgroup (Appendix Table D.6).

\section{Participation Rates, by Child's Age}

This section presents the programs' impacts on the receipt of EHS/HS and other services as analyzed by the age of the focal child at study entry. Although Chapter 2 reports that families with infants (younger than 12 months) participated in EHS at a higher level than families with toddlers (12 months or older), this does not imply that the impact on service receipt is larger for the subgroup with infants. Control group families with infants could have participated at a higher level than control group families with toddlers.

- The impact on the receipt of EHS/HS child care or family development services is larger for families with infants than for families with toddlers.

\footnotetext{
${ }^{8}$ Discussions that program group members might have had with EHS staff about their job search are more likely reflected in the topics addressed by staff, reported in Table 3.2.
} 
As shown in Table 3.4, Enhanced EHS increased participation in EHS/HS by 65 percentage points for the infant subgroup and by 51 percentage points for the toddler subgroup. Examining the percentage who reported receiving family development services from EHS/HS staff, the impact is also larger for the infant subgroup. Finally, the impact on the percentage who received weekly contacts with EHS/HS is also larger for the families with infants than for those with toddlers.

\section{- Considering assistance provided by EHS/HS and other programs in the community, the findings are mixed when analyzed by child's age.}

Similar to the results for the full sample, Table 3.5 shows that the impacts on the receipt of any family development services by program group members are modest for both of the subgroups defined by child's age - 10 and 12 percentage points, respectively. High percentages of program group and control group members in both subgroups reported receiving family development services in the community.

Enhanced EHS increased the percentage who received assistance on parenting education and child development, by 27 percentage points for families with infants and by 13 percentage points for families with toddlers. In contrast, there are impacts on the receipt of education- and employment-related assistance for the toddler subgroup but not for the infant subgroup. ${ }^{9}$ For families with toddlers, Enhanced EHS increased the participation in education-related services by 11 percentage points and in employment-related services by 21 percentage points. The program increased the percentage of program group members in both subgroups who received assistance with budgeting and managing their finances and with transportation needs.

For the full sample, the negative impact on assistance accessing government benefits and support services is driven by the negative impact for the subgroup of families with infants. It is unclear why these program group families were less likely than control group families with infants to receive assistance in this area. Perhaps the other programs that provided services to control group members placed a stronger emphasis on accessing benefits than the EHS program did.

\footnotetext{
${ }^{9}$ Table 3.5 shows higher receipt of employment- and education-related assistance by program group families with toddlers than by program group families with infants at study entry, which differs from patterns presented in Chapter 2. As noted in Chapter 2, program group families with infants were more likely than families with toddlers to have had a discussion on self-sufficiency. However, program group families with toddlers at study entry were less likely to ever receive any Enhanced EHS services, were engaged in Enhanced EHS for shorter periods of time, and were more likely to age out of the program over the course of the followup period. It could be that the program group families with toddlers at study entry were more likely than pregnant women and families with infants to receive assistance on employment, educational, and selfsufficiency issues from other community programs, which is not captured in the participation data alone.
} 


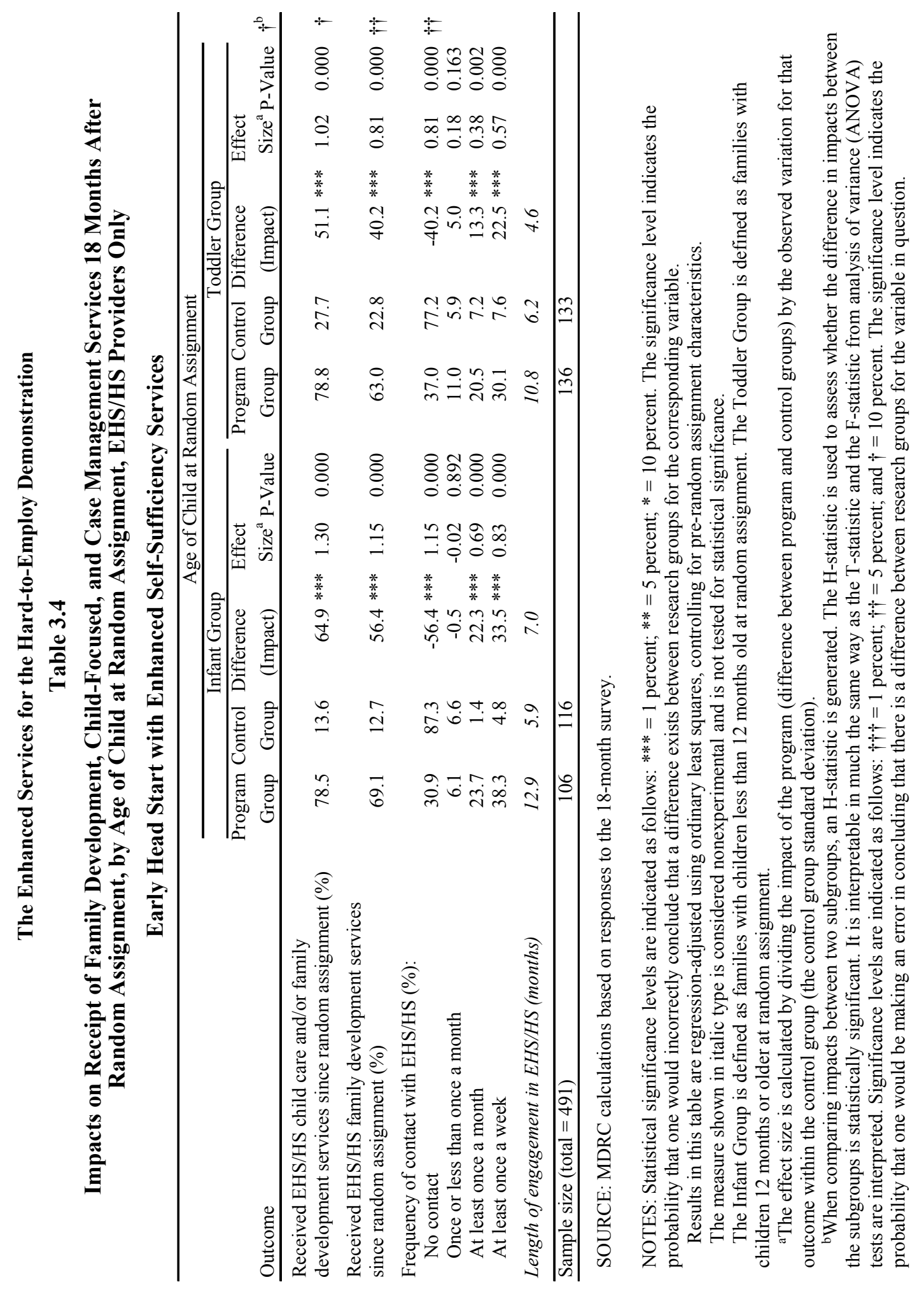




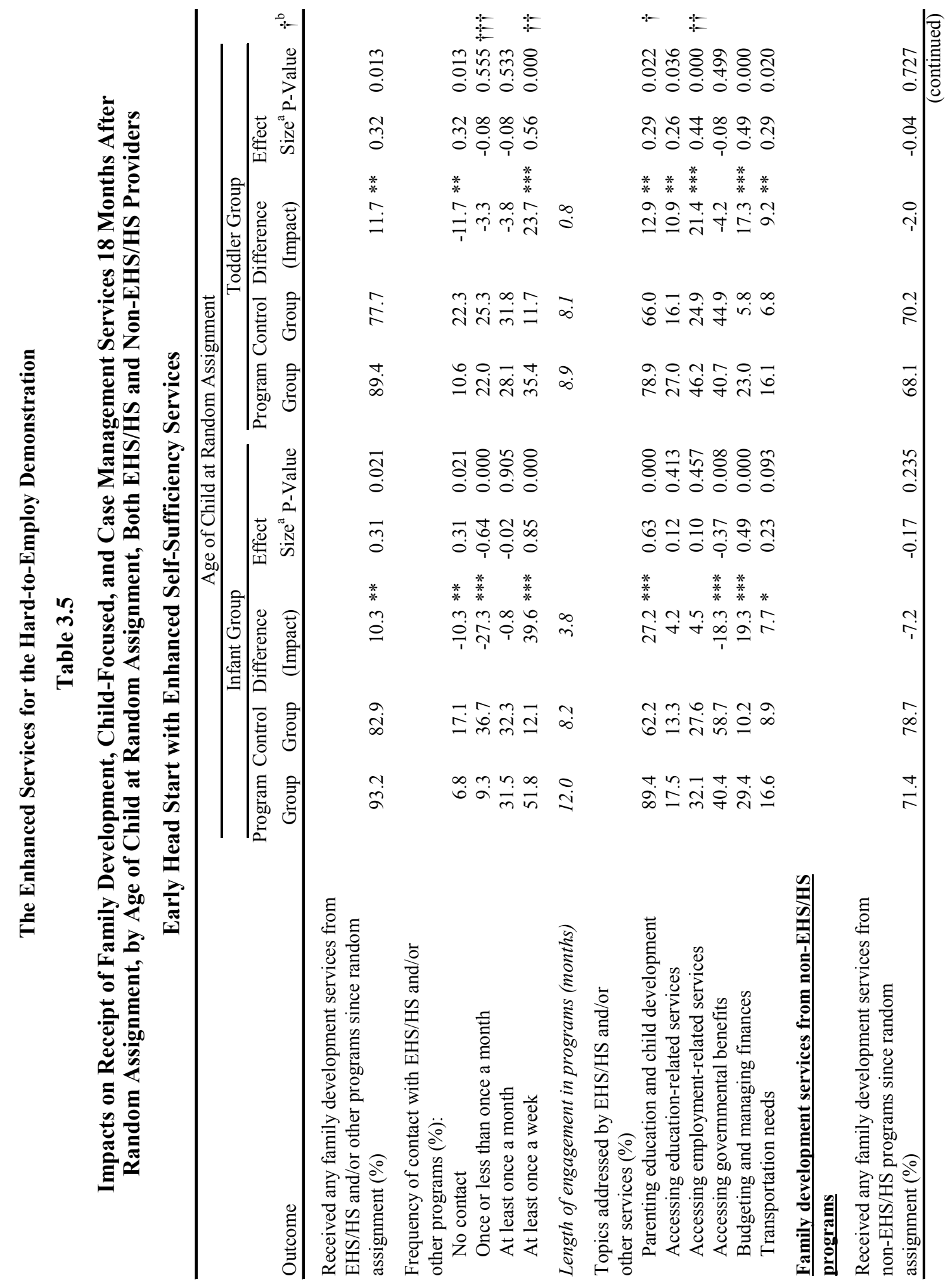




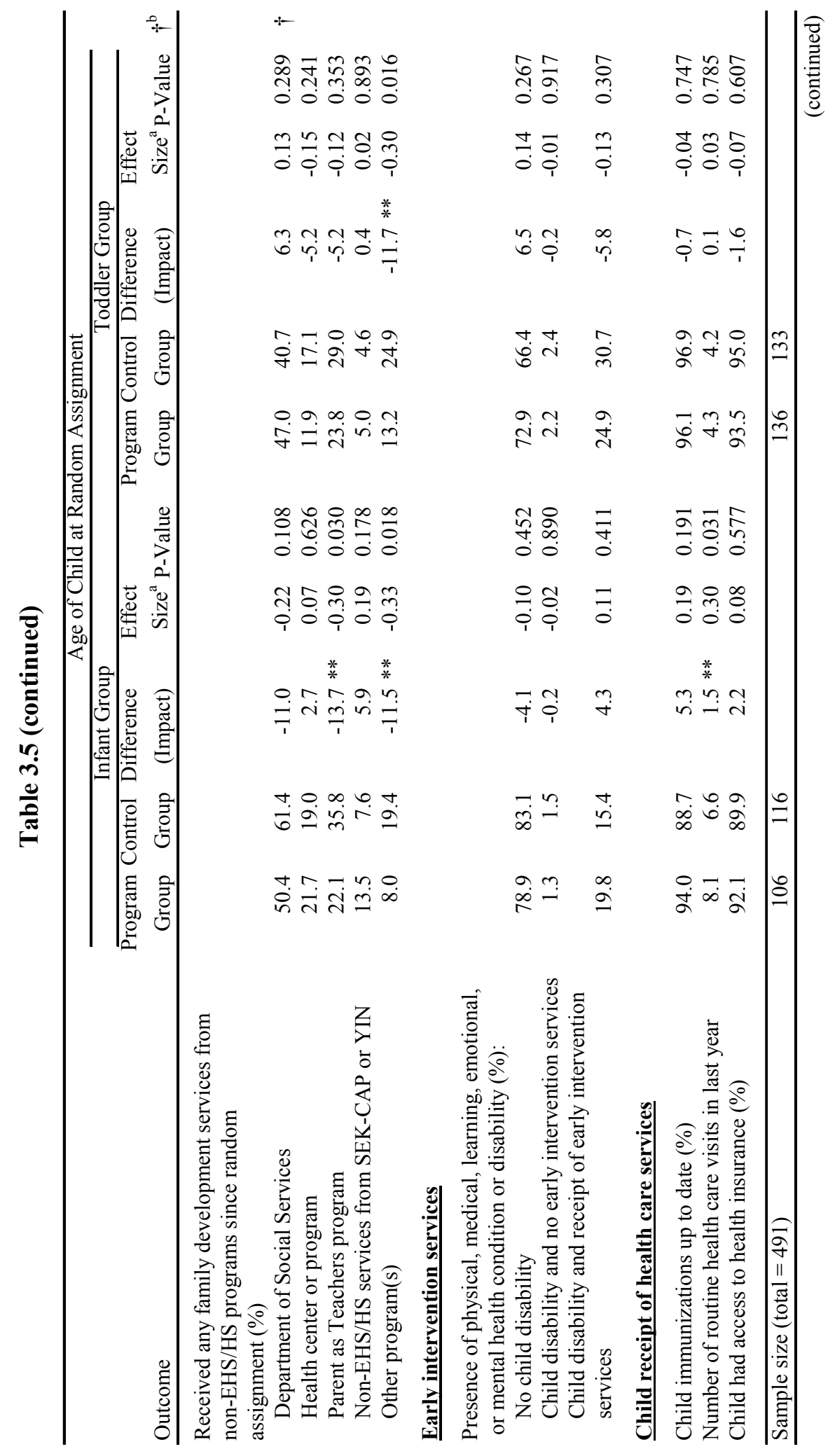




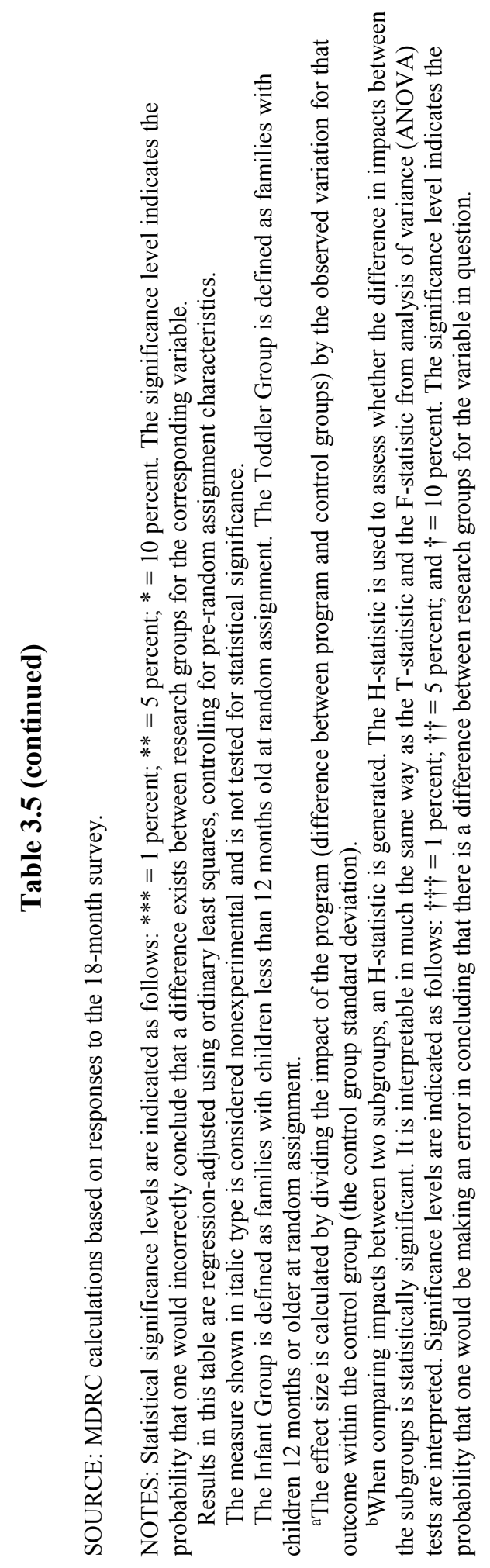


Control group members were more likely than program group members to receive other services in the community. About 22 percent of program group members with infants and 36 percent of control group members with infants received PAT services, resulting in a negative impact of 14 percentage points. For the toddler subgroup, 24 percent of program group members participated, compared with 29 percent of control group members; the difference is not statistically significant. As Table 3.5 indicates, the control group members in both subgroups were more likely to receive services from other community programs, including early intervention programs for children with disabilities, other parenting education programs, employment programs, and family preservation services. Enhanced EHS reduced participation in these other programs by 12 percentage points for both groups.

Enhanced EHS increased the number of routine health care visits by about 1.5 visits per year for the infant group; it did not increase the number of visits for the toddler group.

- Enhanced EHS did not increase participation in any formal job search or education and training activity for either subgroup defined by the child's age.

As Table 3.6 shows, there are no impacts on participation in job search, education and training, or the receipt of a high school diploma or college degree for families with infants or for families with toddlers at study entry.

\section{Summary of Impacts on Service Receipt}

Enhanced EHS increased program group members' participation in EHS/HS, although control group members were able to find programs that offered parenting and child development assistance in the community. Enhanced EHS also increased the receipt of education- and employment-related assistance, although the impacts are rather modest. The program did not increase participation in formal job search and education programs.

There are larger impacts on the receipt of EHS/HS and on the receipt of parenting and child development assistance among families with infants at study entry. Conversely, there are impacts on the receipt of education- and employment-related assistance among the families with toddlers but not among the families with infants. 


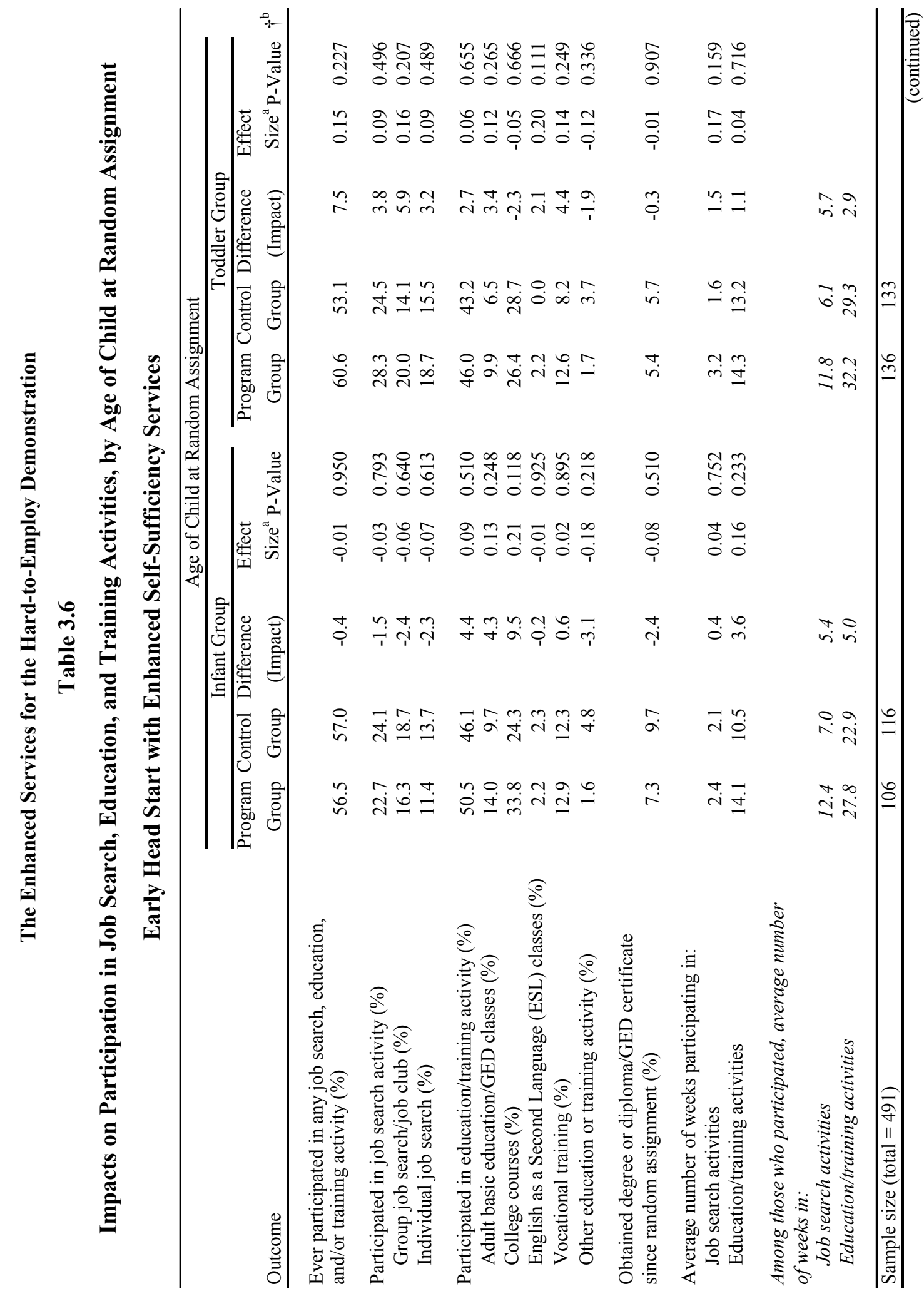




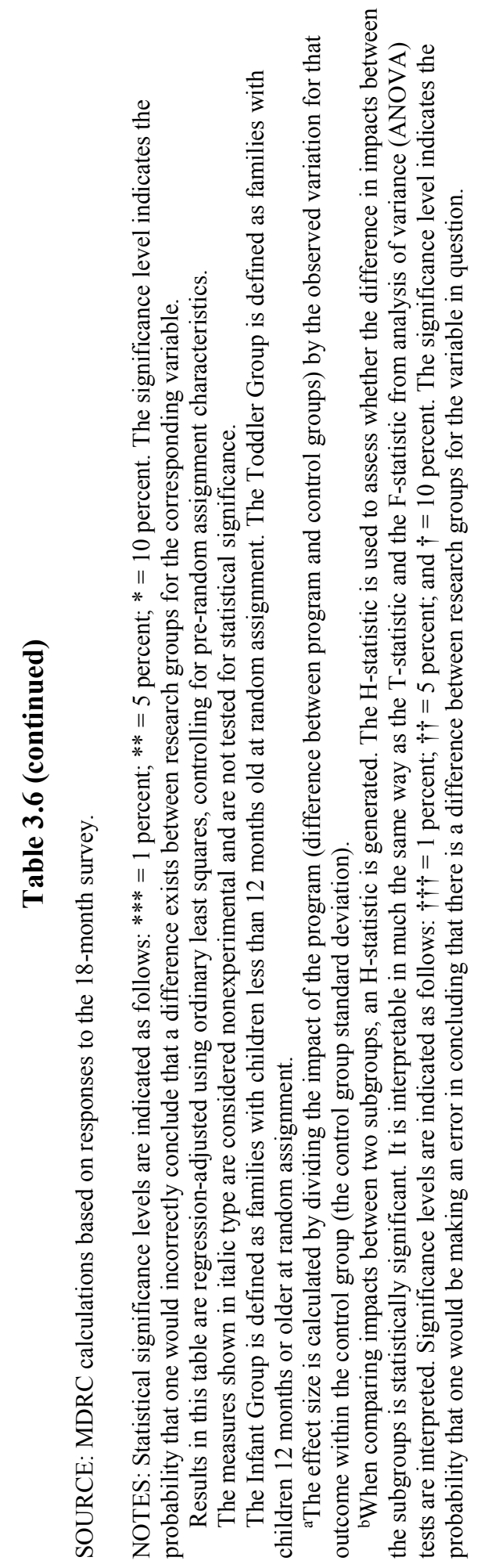




\section{Chapter 4 \\ Impacts on Child Care and Early Educational Experiences}

The Enhanced Services for the Hard-to-Employ Demonstration and Evaluation Project is studying the effectiveness of offering parents employment and educational services within two traditional Early Head Start (EHS) programs: one offered by the Southeast Kansas Community Action Program (SEK-CAP) in Girard, Kansas, and one offered by the Youth in Need program in St. Charles, Missouri. These "Enhanced EHS" programs aimed to improve families' economic circumstances and self-sufficiency and, thus, also to improve their children's development. Families in the study were randomly assigned either to the Enhanced EHS program group (and could receive either home-based or center-based services) or to the control group, whose members could not access Enhanced EHS or traditional EHS from these two programs but could seek alternative services available in the community.

Enhanced EHS may have changed children's child care and early educational experiences. Changes in these experiences are expected to be among the primary ways by which the program supports children's cognitive, social, and emotional development as well as parents' abilities to maintain stable employment. This chapter presents the impacts of Enhanced EHS on children's receipt of child care, the types of child care that they received, and the amount of time that they spent in different care arrangements. In addition, the program's impacts on child care stability are explored. These outcomes are measured using information from a survey administered to parents approximately 18 months after random assignment. (See Box 4.1.) The final section of the chapter considers how Enhanced EHS might have differentially affected the child care experiences of infants and toddlers, by examining subgroups of families defined by the age of the focal child at random assignment. ${ }^{1}$

\section{Full-Sample Impacts on the Use of Child Care}

By providing subsidized Early Head Start or Head Start (EHS/HS) center-based care, Enhanced EHS may be an effective strategy for encouraging parents to use higher-quality child care options (such as formal care) rather than other forms of informal and home-based care

\footnotetext{
${ }^{1}$ As is true with all applications to EHS, families identify a particular child who is up to age 3 or during the prenatal period and who will be enrolled in the program. In this study's 18-month parent survey and direct child assessments, this child is identified as the focal child who is the target of program services and is the focus of all questions related to child care and early educational experiences, parenting practices, and child development and well-being.
} 


\section{Box 4.1 \\ Measures of Child Care Outcomes}

Data about children's experiences with child care were collected by the 18-month survey of parents.

Child care use. The survey collected information from parents (primarily mothers) about different forms of child care that might have been used for at least 10 hours per week and for at least two weeks since random assignment. A composite measure of whether the child was ever placed in any form of care since random assignment was created using this information. In addition, different forms of child care were categorized into formal and home-based care. These categories are not mutually exclusive; that is, parents who reported placing their children in formal care may also have relied on home-based care at some point during the follow-up period.

- Formal child care includes Early Head Start (EHS) or Head Start (HS) center-based care and structured center-based or group child care provided outside the home in preschool, nursery school, summer daycare, or extended day programs.

- Home-based child care includes care provided by nonrelatives in another person's home (such as a babysitter not related to the child or family); daycare in the home; and care provided by siblings, grandparents, or other relatives.

In addition, because of the child development services delivered through EHS/HS care, impacts are presented separately on the use of EHS/HS care and other forms of formal care described above. Impacts are also presented separately for home-based care provided by relatives and by nonrelatives.

Children's time spent in child care. In addition to general information about the types of child care used since random assignment, parents were asked to report how many months since random assignment the focal child spent in each form of care. Parents were also asked to report on how many hours per week in the past month the focal child spent in all forms of care arrangements. This information was used to calculate the average number of months that a child spent in formal or home-based care, the average number of months in each form of care during the follow-up period, and the total hours in any care in a typical week in the past month.

Child care stability. Parents reported on three aspects of child care stability: (1) the total number of care arrangements used in the last month prior to the interview, (2) difficulties in arranging for care for the focal child, and (3) the extent to which the number of hours that the child spent in care (across all arrangements) changed from week to week in the month prior to the interview. For the last two indicators of child care stability, responses were recorded on a 4-point scale ranging from "hardly at all or rarely" to "always." 
arrangements (such as relatives, friends, and neighbors). Examining impacts for the full research sample, this section first explores whether the program had an overall impact on the percentage of children who were ever placed in nonparental care at some point after random assignment. This is followed by an analysis of whether the program encouraged parents to shift their use of different types of child care during the follow-up period. Lastly, the section discusses whether Enhanced EHS affected the amount of time that children spent in nonparental care over the follow-up period for the full research sample.

The first and second panels of Table 4.1 show the program's impacts on these outcomes. Enhanced EHS did not have a significant impact on use of nonparental care; about 80 percent of children in the program group and 77 percent of children in the control group were in nonparental care at some point during the follow-up period. This is not surprising, because the program did not have an overall impact on rates of parental employment, education, or training (Chapters 3 and 5), which are thought to be primary drivers of parents' needs for nonparental child care.

\section{- Enhanced EHS increased the use of formal child care - a shift driven primarily by an increase in the use of EHS/HS care - and it decreased the use of nonrelative home-based care.}

Although the program did not change the percentage of children who were ever in nonparental care at some point during the follow-up period, there is evidence that it was effective at changing parents' use of different types of child care arrangements. Most notably, 57 percent of children in program group families were ever placed in formal care, compared with only 37 percent of children in control group families (Table 4.1).

This impact appears to be driven by an increase in the use of EHS/HS care. Parents reported that 42 percent of children in program group families, compared with 9 percent of children in control group families, received EHS/HS care over the follow-up period. ${ }^{2}$

To a lesser extent, the program also appears to have shifted parents away from the use of home-based child care. According to parents in the survey, 55 percent of children in program group families, compared with 64 percent of children in control group families, were ever in a home-based care arrangement at some time during the follow-up period. However, there is evidence that the program had differential effects on the use of home-based care provided by relatives and unrelated caregivers. Enhanced EHS did not reduce whether children were in relative home-based care; about 45 percent of children in both the program and the control group

\footnotetext{
${ }^{2}$ The control group rate of EHS/HS child care receipt largely reflects that study participants in SEK-CAP were not prevented from receiving HS when the child turned 3 years old and that the control group in Youth in Need was not permitted to receive EHS/HS services for a period of three years after random assignment.
} 
The Enhanced Services for the Hard-to-Employ Demonstration

Table 4.1

Impacts on Child Care Outcomes

Early Head Start with Enhanced Self-Sufficiency Services

\begin{tabular}{|c|c|c|c|c|c|}
\hline Outcome & $\begin{array}{r}\text { Program } \\
\text { Group } \\
\end{array}$ & $\begin{array}{l}\text { Control } \\
\text { Group }\end{array}$ & $\begin{array}{r}\text { Difference } \\
\text { (Impact) } \\
\end{array}$ & $\begin{array}{r}\text { Effect } \\
\text { Size }^{\mathrm{a}}\end{array}$ & P-Value \\
\hline \multicolumn{6}{|l|}{ Child care use since random assignment (\%) } \\
\hline Any nonparental child care & 79.5 & 76.9 & 2.6 & 0.06 & 0.472 \\
\hline Any formal care & 57.2 & 37.1 & $20.1 * * *$ & 0.40 & 0.000 \\
\hline Early Head Start/Head Start care & 42.1 & 8.7 & $33.4 * * *$ & 0.77 & 0.000 \\
\hline Other formal care & 21.3 & 30.5 & $-9.2 * *$ & -0.21 & 0.018 \\
\hline Any home-based care & 54.7 & 63.6 & $-8.9 * *$ & -0.18 & 0.044 \\
\hline Care provided by relative & 42.9 & 47.3 & -4.4 & -0.09 & 0.333 \\
\hline Care provided by nonrelative & 24.1 & 38.4 & $-14.3 * * *$ & -0.31 & 0.001 \\
\hline \multicolumn{6}{|l|}{ Children's time spent in child care } \\
\hline Hours in any nonparental care per week in past month & 25.2 & 24.5 & 0.7 & 0.03 & 0.740 \\
\hline $\begin{array}{l}\text { Since random assignment, number of months spent in } \\
\text { any nonparental child care }\end{array}$ & 11.0 & 8.8 & $2.2 * * *$ & 0.24 & 0.005 \\
\hline Any formal care (months) & 6.0 & 3.1 & $2.9 * * *$ & 0.45 & 0.000 \\
\hline Early Head Start/Head Start care & 4.7 & 0.5 & $4.1 * * *$ & 0.75 & 0.000 \\
\hline Other formal care & 1.8 & 2.7 & $-0.9 * *$ & -0.18 & 0.036 \\
\hline Any home-based care (months) & 5.1 & 5.8 & -0.7 & -0.11 & 0.243 \\
\hline Care provided by relative & 4.4 & 4.1 & 0.3 & 0.04 & 0.655 \\
\hline Care provided by nonrelative & 1.8 & 3.3 & $-1.5 * * *$ & -0.29 & 0.001 \\
\hline \multicolumn{6}{|l|}{ Child care stability } \\
\hline Number of child care providers used in past month & 1.4 & 1.4 & 0.0 & 0.02 & 0.784 \\
\hline $\begin{array}{l}\text { Hours in child care hardly or rarely change from } \\
\text { week to week }(\%)\end{array}$ & 51.1 & 47.6 & 3.6 & 0.07 & 0.447 \\
\hline $\begin{array}{l}\text { Difficulties in arranging for child care hardly } \\
\text { or rarely occur }(\%)\end{array}$ & 64.6 & 58.6 & 5.9 & 0.12 & 0.189 \\
\hline Sample size $($ total $=481)$ & 237 & 244 & & & \\
\hline
\end{tabular}

SOURCES: MDRC calculations based on responses to the 18-month survey.

NOTES: Statistical significance levels are indicated as follows: $* * *=1$ percent; $* *=5$ percent; $*=10$ percent. The significance level indicates the probability that one would incorrectly conclude that a difference exists between research groups for the corresponding variable.

Outcomes in this table are defined in Box 4.1.

Results in this table are regression-adjusted using ordinary least squares, controlling for pre-random assignment characteristics.

aThe effect size is calculated by dividing the impact of the program (difference between program and control groups) by the observed variation for that outcome within the control group (the control group standard deviation). 
were ever cared for by relatives. However, the program appears to have decreased the use of home-base care provided by adults unrelated to the focal children; 24 percent of program group children were ever in nonrelative care, compared with 38 percent of control group children.

\section{Full-Sample Impacts on Time Spent in Child Care}

This section considers how Enhanced EHS might have changed the amount of time that children spent in nonparental child care over the follow-up period for the full research sample. This interest stems from the primary concern that when children are very young, being placed in nonparental care for extended periods of time - such as the total number of months and hours per day of nonparental care - can have some negative consequences. ${ }^{3}$ To explore these issues, first the section examines the impacts of Enhanced EHS on the number of hours that children spent in any form of nonparental care. Second, it examines the impacts of Enhanced EHS on the total number of months that children spent in particular types of care over the follow-up period, since Enhanced EHS would more likely affect the use of formal and center-based care, in particular, given the nature of the services offered.

- Enhanced EHS did not have an overall impact on the number of hours that children were placed in nonparental care.

The second panel of Table 4.1 shows that the program did not have a significant impact on the number of hours that children in the full research sample were in nonparental care during a typical week in the month prior to the follow-up survey date; on average, parents reported that children in program and control group families spent about 25 hours per week in nonparental care.

- Enhanced EHS increased the number of months that children were placed in any nonparental care over the follow-up period and, especially, the number of months in formal care and EHS/HS care.

Although the program did not change the percentage of children who were ever in nonparental care at some time during the follow-up period (the first panel of Table 4.1), Enhanced EHS significantly increased the number of months that children spent in any nonparental care, by an average of 2.2 months.

In line with the impacts reported above, Enhanced EHS increased the amount of time that children spent in formal care overall and EHS/HS care in particular since random assignment. Children in program group families spent, on average, 2.9 more months in any formal care than their counterparts in control group families. In addition, program group children spent

\footnotetext{
${ }^{3}$ NICHD Early Child Care Research Network (2005).
} 
an average of 4.7 months in EHS/HS center-based care, compared with 0.5 month for control group children over the follow-up period.

- Enhanced EHS slightly reduced the number of months that children spent in non-EHS/HS formal care. However, the program had no overall impact on the number of months spent in home-based care.

The program also slightly reduced the time that children spent in other non-EHS/HS formal care; during the follow-up period, children in the program group spent, on average, 0.9 month less in other non-EHS/HS formal care than children in the control group. Altogether, the results suggest that the increase in time that program group children spent in formal care is driven primarily by an increase in the use of EHS/HS care.

As with the results above, there are no significant differences in the time that children spent in home-based child care; on average, children across the program and control groups spent a little less than six months in home-based care since random assignment. The program also had no significant impact on the time that children spent being cared for by relatives; across the program and control groups, children were in relative care for an average of about six months over the course of the follow-up period. Yet the program produced a modest reduction in the amount of time that children were cared for by unrelated adults in home-based arrangements, by about 1.5 months over the follow-up period.

Encouraging parents to pursue employment and educational opportunities and also providing subsidized EHS/HS care could affect the age at which children are first placed in nonparental care. Nonexperimental analyses were used to explore differences between the program and control group families in the ages at which children were first placed in various types of care arrangements. The results suggest that children in families with access to Enhanced EHS were likely to be placed in nonparental care and in formal care at younger ages than children in the control group (not shown). This may be one reason why the program affected the amount of time that children spent in nonparental care and in formal care overall and $\mathrm{EHS} / \mathrm{HS}$ care in particular.

Taken together, Enhanced EHS did not affect the degree to which children were ever placed in nonparental care since random assignment, though it did increase the amount of time over the follow-up period that children were placed in nonparental care. However, it appears that the program was effective at encouraging parents to use formal care arrangements overall and, notably, EHS/HS care. Interestingly, the greater reliance on EHS/HS care did not coincide with a reduction of the same magnitude in the use of home-based care; the program decreased the use of home-based care provided by nonrelatives but had no discernable impact on the use of home-based care provided by relatives. This pattern of impacts suggests that Enhanced EHS 
should have positive impacts on child development and well-being, inasmuch as prior research has generally identified EHS/HS care as being high quality.

\section{Full-Sample Impacts on Child Care Stability}

This section summarizes the impacts of Enhanced EHS on several aspects of child care stability. While some changes in children's care experiences are expected, frequent and unexpected changes in child care arrangements can disrupt family routines, challenge parents' abilities to stay employed, and undermine children's development. ${ }^{4}$ The available measures of child care stability from the 18-month parent-reported follow-up survey provide limited insights into how Enhanced EHS might influence child care stability, but they can generate hypotheses to explore in future research. These measures include the number of child care providers used in the month prior to the date of the follow-up survey as well as parents' perceptions of whether the hours that their children were in care changed from one week to the next and whether they had difficulties arranging for their children's care.

The third panel of Table 4.1 shows the impacts on the available indicators of child care stability. The findings suggest that Enhanced EHS did not have an impact on the number of child care providers that parents relied on; both program and control group families used, on average, 1.4 child care providers in the prior month. When considered in conjunction with the pattern of findings on the incidence and duration of care use over the follow-up period, the cumulative findings appear to suggest that families in the program group may have been relying on the same number of child care providers as their counterparts in the control group but for longer durations of time over the follow-up period. Furthermore, there are no statistically significant impacts on parental perceptions of weekly changes in the hours that their children were in nonparental care or on their difficulties in arranging for child care, suggesting that Enhanced EHS had limited impacts on the stability of children's child care experiences.

\section{Subgroup Impacts on Child Care Experiences, by Child's Age}

This section presents impacts on the child care outcomes discussed above, analyzed by the age of the child at random assignment. ${ }^{5}$ These analyses assess program impacts for families

\footnotetext{
${ }^{4}$ Knox, London, and Scott (2003); Lowe, Weisner, Geis, and Huston (2005); Shonkoff and Phillips (2000).

${ }^{5}$ To explore these impacts for the full sample and by child's age at random assignment, the research team examined whether impacts of Enhanced EHS on children's care experiences also varied by program site and household structure (that is, one-parent and two-parent households). Subgroup impacts by program site and by one- and two-parent households are shown in Appendix E. The subgroup analyses suggest that Youth in Need increased the use of EHS/HS care by a greater magnitude than SEK-CAP. As discussed in preceding chapters, SEK-CAP did not provide EHS/HS center-based care until 2007, and the pattern of impacts likely reflect this. Furthermore, the program decreased the extent to which single parents relied on other non-EHS/HS formal care, whereas no comparable impact among two-parent families was found. And the program increased the time that children in one-parent households spent in EHS/HS care by a greater magnitude than in two-parent households, even though the program increased the use of EHS/HS care for both types of families.
} 
with infants (defined as families who were expecting a child or had a child younger than 12 months old) and for families with toddlers (children 12 months or older at study entry) and whether the magnitude and direction of these impacts differ for these subgroups. Differential impacts on child care use between subgroups of families with infants and those with toddlers might occur for a variety of reasons. For example, it might be that the differential effects of Enhanced EHS on parental work hours and wages for subgroups of families defined by the age of the focal child (Chapter 5) are tied to effects of the program on children's child care experiences. It may also be that nonparental care more broadly - and center-based care, in particular — is less normative for very young infants than for toddlers, ${ }^{6}$ which might result in differential impacts of Enhanced EHS on child care experiences by child's age at random assignment. Although such possibilities are explored in this section, the results should be interpreted with caution because of the small size of the subgroup samples.

The first panel of Table 4.2 shows program impacts on the incidence of child care use when analyzed by the child's age at random assignment. Analyses indicate that the program's impacts among infants and among toddlers are generally similar in pattern: the program had no overall impact on the use of nonparental care for infants or toddlers, but it decreased the use of any nonrelative care. However, the impacts do differ from one another in two key ways. The program significantly increased the use of formal child care among families with infants, but it had no discernable impact on the use of formal care among families with toddlers. About 52 percent of infants in the program group were enrolled in formal care at some point during the follow-up period, compared with only 18 percent of infants in the control group families. This represents nearly a 35 percentage point increase in the use of formal care among families with infants in the program group. The program may not have produced significant impacts on the use of formal child care use among toddlers. This may be, in part, because formal care is fairly common among children in this age range; in the control group, 54 percent of toddlers were ever in formal care at some point over the follow-up period. At the same time, it appears that the program encouraged more parents of toddlers to rely on EHS/HS care in place of other forms of formal care. The program reduced the percentage of toddlers who were placed in nonEHS/HS formal care by 22 percentage points, whereas no such impact is evident among families with infants.

- Enhanced EHS had a greater impact on receipt of formal child care among infants than among toddlers. In addition, the program encouraged a greater proportion of families with toddlers to use EHS/HS care instead of other non-EHS/HS formal care options.

Similar patterns emerge when the duration of child care use over the follow-up period is examined by child's age (the second panel of Table 4.2). For infants, the program increased the total hours spent in nonparental care in the week prior to the date of the follow-up survey and

\footnotetext{
${ }^{6}$ Capizzano and Adams (2003).
} 


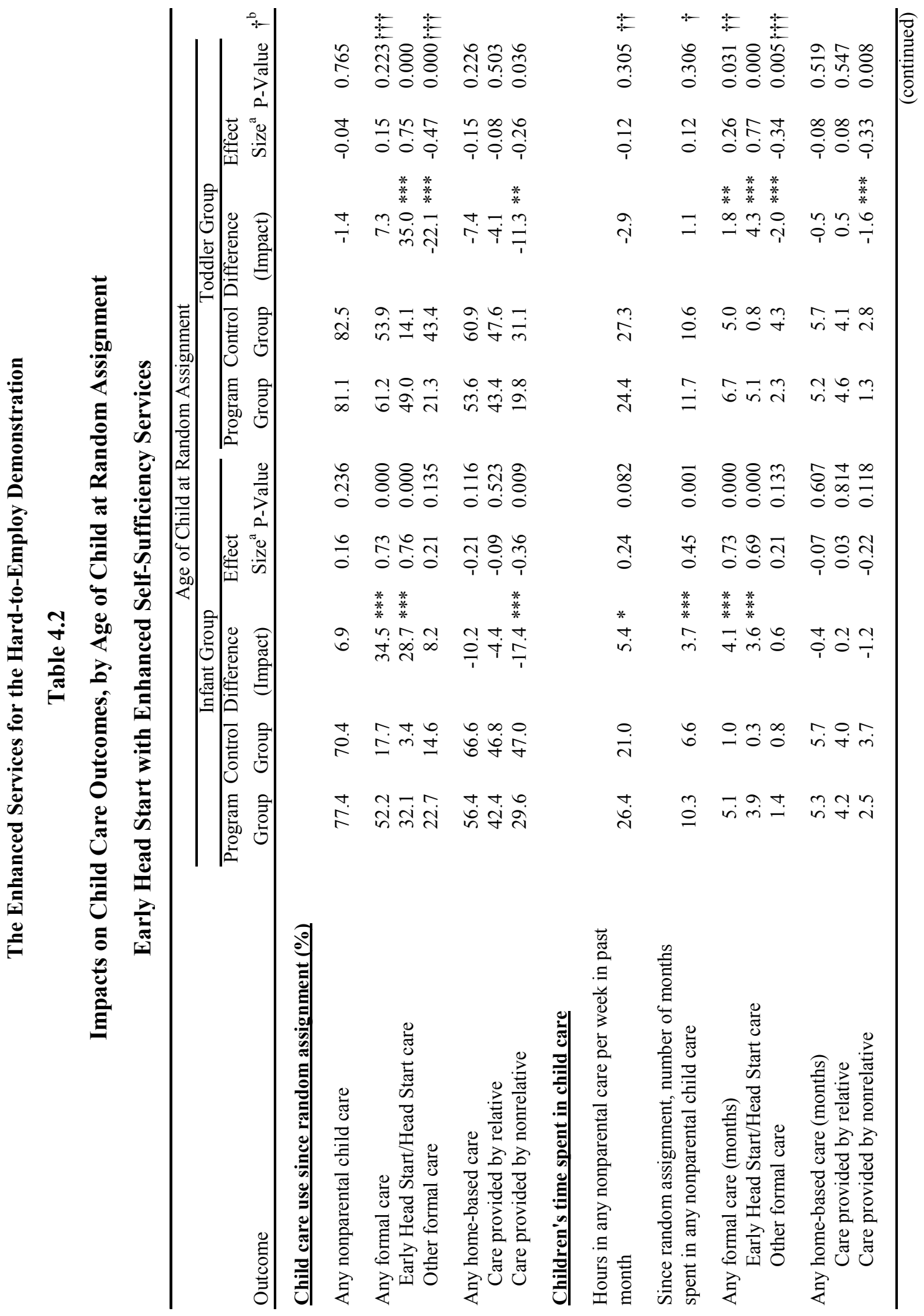




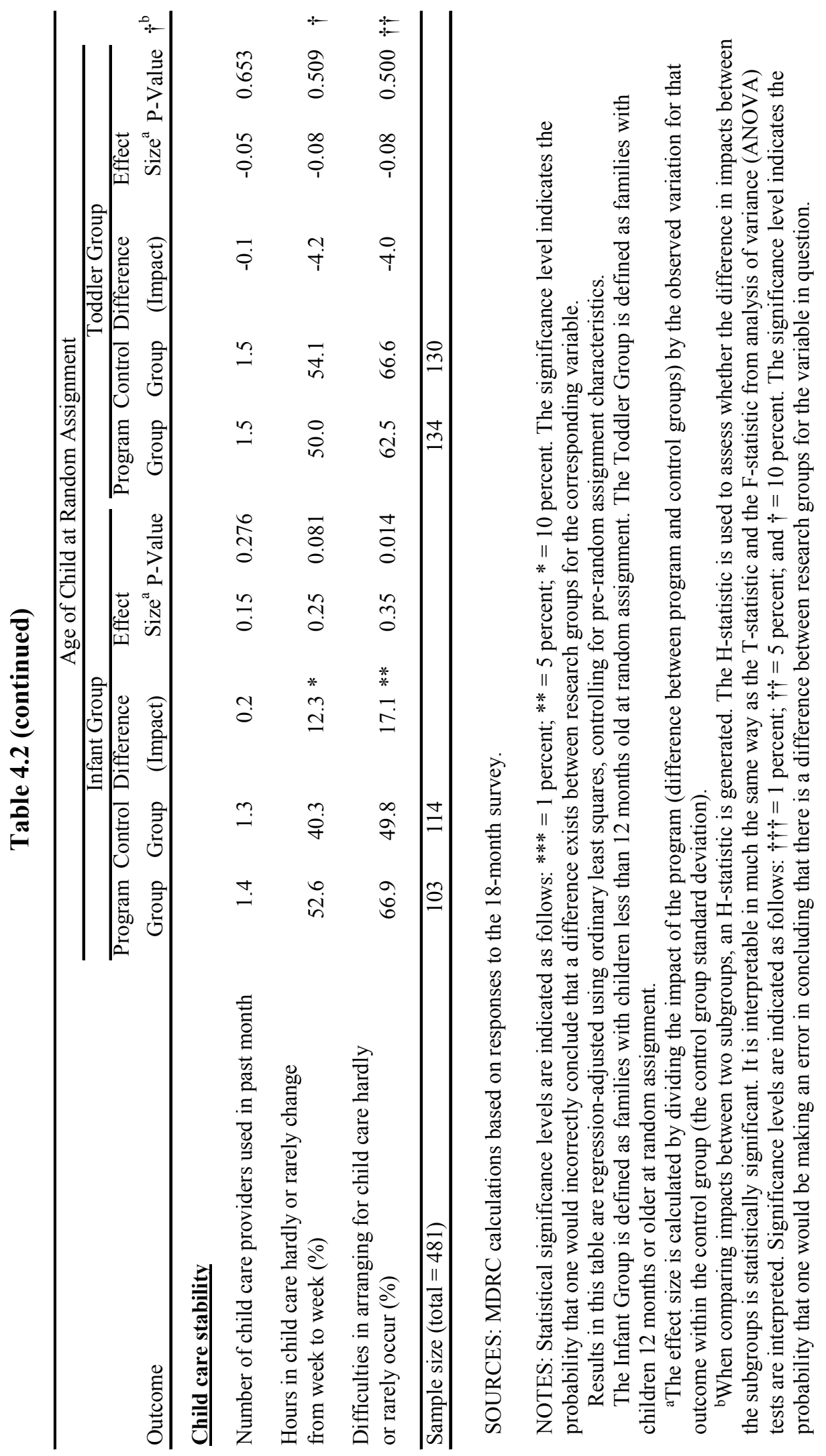


the number of months spent in any nonparental care since random assignment. For toddlers, the program did not affect the amount of time spent in any nonparental care. However, the program did increase the amount of time that infants and toddlers spent in formal care over the follow-up period, though this impact is greater in magnitude among infants. Infants in program group families spent almost four times as much time in formal care (5.2 months, compared with 1.0 month for infants in the control group), whereas the program only modestly increased the amount of time that toddlers spent in formal care (6.7 months, compared with 5.0 months for toddlers in the control group). The program uniformly increased the amount of time that infants and toddlers spent in EHS/HS care. And the program did not affect the amount of time that infants spent in non-EHS/HS formal care, but it did decrease the amount of time that toddlers spent in non-EHS/HS formal care over the follow-up period.

Lastly, the program did not affect the number of months that infants and toddlers spent in home-based care - particularly, in home-based care provided by relatives (the second panel of Table 4.2). However, the program did decrease the number of months that toddlers spent in home-based care provided by unrelated caregivers, even though the direction and magnitude of this effect do not differ between infants and toddlers.

- Enhanced EHS increased parents' perceptions of child care stability for infants but did not affect these perceptions among parents with toddlers.

In terms of indicators of child care stability (the last panel of Table 4.2), Enhanced EHS reduced fluctuations in child care hours and difficulties in arranging care for their infants according to parental reports, whereas the program did not affect parents' perceptions of these outcomes in families with toddlers. For families with infants, 53 percent of parents reported that the hours of care rarely or hardly ever changed from week to week, compared with 40 percent of parents in the control group. In addition, 67 percent of parents of infants in the program group reported hardly or rarely having difficulties arranging for child care, compared with 50 percent of parents of infants in the control group. These findings are in line with the field research suggesting that there was limited availability of infant care options, particularly in rural areas (Chapter 2). Thus, it is possible that the provision of EHS/HS center-based care helped to address these constraints faced by many parents of infants.

\section{Summary of Impacts on Child Care}

Enhanced EHS increased parents' reliance on EHS/HS care and, in turn, their reliance on formal care, even though it did not increase the rate at which children were placed in nonparental care at some point over the follow-up period. This pattern of impacts is evident for both infants and toddlers, though the magnitude of the impacts is greater among families with 
infants. In contrast, the program encouraged parents of toddlers to switch from other forms of formal care to EHS/HS formal care.

Nevertheless, the program did not altogether reduce parental reliance on home-based care. Rather, the program reduced reliance on care provided by unrelated caregivers but not on care provided by relatives. There are reasons why it may be more difficult to shift parental reliance on care arrangements by relatives than reliance on other forms of child care. Parents tend to place more trust in relatives to care for their children, especially when children are very young. ${ }^{7}$ Furthermore, given that a substantial proportion of parents in both the program and control group worked over the follow-up period, it may be that parents required child care outside the hours that formal care was available; therefore, they turned to relatives as a low-cost option to cover their child care needs.

There is limited evidence to suggest that Enhanced EHS improved child care stability overall, but it appears to have helped parents of infants to secure reliable child care, whereas they might otherwise have had difficulties doing so.

\footnotetext{
${ }^{7}$ Knox, London, and Scott (2003); Lowe, Weisner, Geis, and Huston (2005).
} 


\section{Chapter 5}

\section{Impacts on Employment, Earnings, and Household Income}

The Enhanced Services for the Hard-to-Employ Demonstration and Evaluation Project is studying two traditional Early Head Start (EHS) programs in Kansas and Missouri that enhanced their services by offering parents employment and education assistance. Examining whether improving families' economic circumstances and self-sufficiency would improve children's development, the study assigned families, at random, to the Enhanced EHS program group, whose members could receive either home-based or center-based services, or to the control group, whose members could not access Enhanced EHS or traditional EHS from these two programs, although they could seek alternative services available in the community.

This chapter presents the impacts of Enhanced EHS on employment and earnings, job characteristics, and household income. The analysis uses unemployment insurance data from the National Directory of New Hires (NDNH) database to estimate the proportion of parents who were employed and their average earnings in each of the six quarters following random assignment and over the six-quarter follow-up period as a whole. In addition, data from the 18month survey of parents are used to estimate impacts on self-reported employment, job characteristics, and household income. The chapter first presents impacts for the full study sample and then presents subgroup impacts by the age of the focal child at random assignment. ${ }^{1}$

The results indicate that Enhanced EHS had little effect on employment, earnings, or job characteristics for the full sample. The lack of impacts may also reflect the challenges of program implementation, which led to lesser focus on self-sufficiency enhancements than had been expected (Chapter 2). The subgroup analysis indicates that there may have been more positive impacts among families who had infants (younger than 12 months) at baseline than among families who had toddlers (12 months or older) at baseline. These subgroup results should be interpreted with caution, however, because of the small size of the samples.

\footnotetext{
${ }^{1}$ As is true with all applications to EHS, families identify a particular child who is up to age 3 or during the prenatal period and who will be enrolled in the program. In this study's 18-month parent survey and direct child assessments, this child is identified as the focal child who is the target of program services and is the focus of all questions related to child care and early educational experiences, parenting practices, and child development and well-being.
} 


\section{Full-Sample Impacts on Employment, Earnings, and Income}

\section{Quarterly Employment and Earnings}

This section presents impacts on mothers' quarterly employment and earnings outcomes from an analysis of NDNH unemployment insurance data. Data are available for two parents in cases where two parents are included on the program's Baseline Information Form, but the analysis focuses on the mother or female guardian, for two reasons. ${ }^{2}$ First, a review of Enhanced EHS case files shows that the mother is the parent most likely to have had contact with the program; ${ }^{3}$ therefore, the program was most likely to affect maternal employment outcomes. Second, an analysis of mothers' employment outcomes is more comparable to the analysis of survey-reported outcomes, since nearly all survey respondents (97 percent) are female. ${ }^{4}$

- Among the full sample, Enhanced EHS had no statistically significant impacts on maternal employment or earnings in any of the six quarters following random assignment or for the entire six-quarter period.

Table 5.1 shows quarterly employment and earnings impacts for the mothers. There were no significant program impacts on maternal employment or earnings in any of the six quarters after random assignment or for the six-quarter follow-up period as a whole. ${ }^{5}$ For both the Enhanced EHS group and the control group, the rate of maternal employment remained fairly steady over the course of the follow-up period, with about 65 percent of sample members in both groups being employed in each quarter. Overall, about 85 percent of mothers were ever employed during the six-quarter follow-up period. For both the program and the control group, earnings increased from Quarter 1, in which mothers earned about \$1,700, to Quarter 6, in which they earned about $\$ 2,200 .^{6}$ Both program and control group mothers earned about $\$ 12,000$, on average, over the follow-up period.

The lack of full-sample impacts on employment and earnings is not entirely surprising, given the findings from the implementation research (Chapter 2); even though the programs

\footnotetext{
${ }^{2}$ In the NDNH analysis, the sample that is referred to in the text as "the mothers" includes males who were the only parent in the household (1.5 percent of the sample).

${ }^{3}$ In 90 percent of cases, the first parent listed on the EHS baseline application is female. The case file review shows that only 26 percent of Enhanced EHS cases include any recorded contact between the program and the secondary parent.

${ }^{4}$ Although the primary parent — that is, the first parent listed on the baseline form — is male in 10 percent of cases, the survey focused on the female parent or guardian, if one was listed at baseline. Therefore, while 90 percent of primary parents are female, a higher percentage of survey respondents are female (97 percent).

${ }^{5}$ There were also no significant, full-sample impacts on employment or earnings for the mother and father combined (Appendix Table F.1) or for the father alone (not shown). Employment and earnings impacts did not differ depending on whether the family had a second parent (Appendix Table F.7).

${ }^{6}$ Dollar values include zeroes for sample members who were not employed.
} 
The Enhanced Services for the Hard-to-Employ Demonstration

Table 5.1

Impacts on Mothers' Quarterly Employment and Earnings

Early Head Start with Enhanced Self-Sufficiency Services

\begin{tabular}{|c|c|c|c|c|c|}
\hline Outcome & $\begin{array}{r}\text { Program } \\
\text { Group }\end{array}$ & $\begin{array}{r}\text { Control } \\
\text { Group }\end{array}$ & $\begin{array}{r}\text { Difference } \\
\text { (Impact) }\end{array}$ & $\begin{array}{l}\text { Effect } \\
\text { Size }^{\text {a }}\end{array}$ & P-Value \\
\hline \multicolumn{6}{|l|}{ Employment (\%) } \\
\hline Quarter 1 (quarter of random assignment) & 63.5 & 58.2 & 5.3 & 0.11 & 0.177 \\
\hline Quarter 2 & 63.0 & 60.6 & 2.4 & 0.05 & 0.533 \\
\hline Quarter 3 & 64.9 & 62.8 & 2.1 & 0.04 & 0.584 \\
\hline Quarter 4 & 65.4 & 62.2 & 3.2 & 0.07 & 0.400 \\
\hline Quarter 5 & 63.1 & 66.3 & -3.2 & -0.07 & 0.397 \\
\hline Quarter 6 & 64.0 & 69.3 & -5.3 & -0.11 & 0.159 \\
\hline Ever employed, Quarters 1-6 & 86.2 & 84.0 & 2.3 & 0.06 & 0.422 \\
\hline \multicolumn{6}{|l|}{ Earnings (\$) } \\
\hline Quarter 1 (quarter of random assignment) & 1,805 & 1,603 & 202 & 0.08 & 0.296 \\
\hline Quarter 2 & 1,940 & 1,860 & 80 & 0.03 & 0.689 \\
\hline Quarter 3 & 1,961 & 1,931 & 30 & 0.01 & 0.884 \\
\hline Quarter 4 & 2,137 & 1,992 & 145 & 0.06 & 0.472 \\
\hline Quarter 5 & 2,159 & 2,168 & -9 & 0.00 & 0.967 \\
\hline Quarter 6 & 2,167 & 2,252 & -85 & -0.03 & 0.685 \\
\hline Total earnings, Quarters 1-6 & 12,024 & 11,705 & 319 & 0.02 & 0.759 \\
\hline Sample size $($ total $=597)$ & 300 & 297 & & & \\
\hline
\end{tabular}

SOURCE: MDRC calculations from the National Directory of New Hires database.

NOTES: Statistical significance levels are indicated as follows: $* * *=1$ percent, $* *=5$ percent, and $*=10$ percent. The significance level indicates the probability that one would be making an error in concluding that there is a difference between research groups for the variable in question.

Dollar values include zeroes for sample members who were not employed, unless otherwise noted.

The sample used in this analysis includes females from two-parent cases (41.3 percent), females from oneparent cases ( 57.1 percent), and males from one-parent cases ( 1.5 percent). Due to missing baseline information, employment data are not available for 13 sample members.

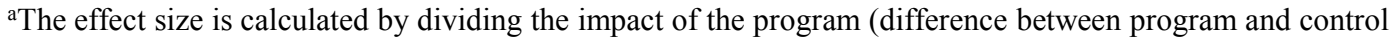
groups) by the observed variation for that outcome within the control group (the control group standard deviation).

increased their focus on parental employment, the programmatic enhancements remained peripheral service components of Enhanced EHS and may not have been strong enough to affect employment.

In addition, given high rates of employment among the control group, it may have been difficult to produce an increase in employment among the program group. In the control group, 
85 percent of mothers were employed, and about 90 percent of households had either a mother or a father employed during the follow-up period (Appendix Table F.1). These rates are somewhat higher than anticipated, given that the program was intended to target families who had employment needs. However, Enhanced EHS was designed both to help parents who were not employed find employment and to help parents who were employed retain their positions and find higher-quality jobs. Indeed, the center-based program specifically targeted low-income, working parents, as employment was a requirement for the program, and many families in the home-based program were two-parent families in which one parent was working. ${ }^{7}$

\section{Survey-Reported Employment, Job Characteristics, and Income}

\section{- Among the full sample, Enhanced EHS had almost no statistically sig- nificant impacts on mothers' self-reported employment and job charac- teristics.}

Table 5.2 presents the impacts of Enhanced EHS on mothers' self-reported employment, fathers' employment (as reported by the mothers), and mothers' job characteristics as captured by the 18-month survey. ${ }^{8}$ These results closely match the NDNH unemployment insurance data reported above. The survey data show no significant impacts on employment; about 87 percent of mothers in both groups indicated that they had been employed since random assignment, and about 65 percent were working at the time of the survey. For both groups, the longest amount of time that the mothers spent continuously working in one job was about 10 months, on average. There were also no significant impacts on fathers' employment; about half the mothers reported that they had a spouse or partner who had worked since random assignment, and just over 40 percent had a spouse or partner who was working at the time of the survey. ${ }^{9}$

Although there were no overall impacts on employment, it was hypothesized that since the self-sufficiency enhancements were designed not just to help unemployed parents become employed but also to help employed parents gain better employment, Enhanced EHS might improve the job characteristics of participants. For example, some parents may have worked in jobs that did not have health insurance or that had work hours that changed from week to week. Self-sufficiency coordinators and frontline staff may have helped those parents obtain positions

\footnotetext{
${ }^{7}$ To be eligible for Enhanced EHS in these two program sites, families had to have an income that was at or below the federal poverty level, except that up to 10 percent of cases could be included if the child or family had special needs. To apply for and keep a center-based slot, families had to have at least one working parent.

${ }^{8}$ The survey was conducted with only one parent from each family. In two-parent cases, the mother was targeted as the survey respondent; 97 percent of respondents are the mother or female guardian.

${ }^{9}$ At the time of the survey, 54 percent of program group mothers and 53 percent of control group mothers (not a statistically significant difference) reported that they were living with a spouse or partner. This person may not be the same spouse or partner who was identified at baseline as the second parent. The analysis of fathers' employment includes zeroes for those who did not have a spouse or partner.
} 
The Enhanced Services for the Hard-to-Employ Demonstration

Table 5.2

Impacts on Characteristics of Current Job

Early Head Start with Enhanced Self-Sufficiency Services

\begin{tabular}{|c|c|c|c|c|c|}
\hline Outcome & $\begin{array}{r}\text { Program } \\
\text { Group } \\
\end{array}$ & $\begin{array}{r}\text { Control } \\
\text { Group }\end{array}$ & $\begin{array}{r}\text { Difference } \\
\text { (Impact) }\end{array}$ & $\begin{array}{r}\text { Effect } \\
\text { Size }^{\text {a }} \\
\end{array}$ & P-Value \\
\hline \multicolumn{6}{|l|}{ Mothers' employment $^{\text {b }}$} \\
\hline Ever worked for pay since random assignment (\%) & 87.5 & 86.8 & 0.7 & 0.02 & 0.821 \\
\hline Working for pay at time of survey (\%) & 63.4 & 64.4 & -1.0 & -0.02 & 0.814 \\
\hline Longest job spell since random assignment (months) & 10.1 & 10.9 & -0.8 & -0.11 & 0.203 \\
\hline \multicolumn{6}{|l|}{ Fathers' employment ${ }^{\mathrm{c}}(\%)$} \\
\hline Ever worked for pay since random assignment & 49.9 & 49.0 & 0.9 & 0.02 & 0.830 \\
\hline Working for pay at time of survey & 41.7 & 41.0 & 0.7 & 0.01 & 0.861 \\
\hline \multicolumn{6}{|l|}{${\text { Characteristics of mothers' } \text { job }^{b}}^{b}$} \\
\hline Hours worked per week $^{\mathrm{d}}$ & 20.9 & 21.8 & -0.9 & -0.05 & 0.572 \\
\hline Not working $(\%)$ & 36.6 & 35.6 & 1.0 & 0.02 & 0.814 \\
\hline Working part time $(\%)$ & 16.5 & 17.0 & -0.5 & -0.01 & 0.890 \\
\hline Working full time (\%) & 46.9 & 47.2 & -0.4 & -0.01 & 0.937 \\
\hline Earnings per week $(\$)$ & 178 & 207 & -29 & -0.14 & 0.104 \\
\hline Hourly wage (\$) & 5.41 & 5.99 & -0.58 & -0.11 & 0.209 \\
\hline Average hourly wage, among those employed (\$) & 8.54 & 9.44 & -0.90 & & \\
\hline Receiving any benefits (\%) & 38.3 & 43.7 & -5.4 & -0.11 & 0.220 \\
\hline Sick days with full pay (\%) & 21.1 & 25.8 & -4.7 & -0.11 & 0.216 \\
\hline Paid vacation $(\%)$ & 26.9 & 30.6 & -3.7 & -0.08 & 0.364 \\
\hline Receiving or offered health care coverage (\%) & 35.0 & 39.4 & -4.4 & -0.09 & 0.313 \\
\hline \multicolumn{6}{|l|}{ Work and family interference (scale of 1-5) } \\
\hline Perceived spillover from family to work & 2.0 & 2.4 & $-0.4 * *$ & -0.20 & 0.036 \\
\hline Perceived workplace flexibility & 8.6 & 8.2 & 0.4 & 0.10 & 0.287 \\
\hline Sample size $($ total $=491)$ & 242 & 249 & & & \\
\hline
\end{tabular}


Table 5.2 (continued)

SOURCE: MDRC calculations from responses to the 18-month survey.

NOTES: Statistical significance levels are indicated as follows: $* * *=1$ percent; $* *=5$ percent; and $*=10$ percent. The significance level indicates the probability that one would be making an error in concluding that there is a difference between research groups for the variable in question.

Results in this table are regression-adjusted using ordinary least squares, controlling for pre-random assignment characteristics.

The measure shown in italic type is considered nonexperimental and is not tested for statistical significance.

Dollar values include zeroes for sample members who were not employed, unless otherwise noted.

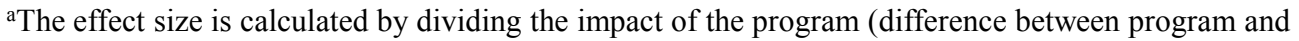
control groups) by the observed variation for that outcome within the control group (the control group standard deviation).

${ }^{b}$ About 97 percent of survey respondents are female. This measure includes responses for some males $(2.6$ percent of cases) and may include responses from female guardians who were not the child's biological mother.

${ }^{\mathrm{c}}$ About 54 percent of program group mothers and 53 percent of control group mothers (not a statistically significant difference) reported that they lived with a spouse of partner at the time of the survey. This spouse or partner may not be the same person identified at baseline as the second parent. Two-parent cases (those with a second parent at baseline) may not have a spouse or a partner present at the time of the survey, and one-parent cases (those with only one parent at baseline) may have a spouse or partner present at the time of the survey.

The analysis of fathers' employment includes zeros if there is no spouse or partner present.

${ }^{\mathrm{d}}$ This is based on the number of hours worked per week. Fewer than 30 hours is considered part time, and 30 hours or more is considered full time.

with fringe benefits or with consistent work hours. Thus, even though there were no impacts on employment, Enhanced EHS could have led to impacts on job characteristics.

The third panel of Table 5.2 shows impacts on mothers' job characteristics at the time of the survey. ${ }^{10}$ The results indicate that Enhanced EHS had little effect on mothers' job characteristics. There were no significant impacts on hours worked per week (about 21 hours) or on working full time versus part time; about 50 percent of mothers in both groups were working full time, defined as at least 30 hours per week, while about 17 percent were working part time. The program also does not appear to have affected mothers' hourly wages. Yet it may have helped mothers better balance the responsibilities of family and work, as the program group mothers reported having fewer problems with family responsibilities affecting their work, ${ }^{11}$

\footnotetext{
${ }^{10}$ An analysis (not shown) of impacts on job characteristics that includes both the current job and the most recent job - for those not currently working — shows a similar pattern of results. Zeroes are included for those who were not employed at the time of the survey.

${ }^{11}$ The perceived spillover scale includes three items, ranging from 0 ("never") to 4 ("always"), which asked respondents (1) how often family life disrupted their ability to go to work, (2) how often the availability of affordable or reliable transportation interfered with their ability to go to work, and (3) how often the availability of affordable or reliable child care interfered with their ability to go to work. The scale is a sum of the three items.
} 
though the number of significant impacts identified here is also few enough that this one significant impact could be a product of chance.

- Among the full sample, Enhanced EHS had no statistically significant impacts on sources of household income, amount of individual or household income, or poverty.

Table 5.3 shows other measures of families' economic well-being, including income, income source, and poverty outcomes captured by the 18-month survey. Not surprisingly, given that there were no impacts on employment or earnings, there were no impacts on any of these measures. For both groups, nearly 90 percent of mothers reported having income from either their own earnings or the earnings of someone else in their household in the month prior to the survey. During that time, however, about 50 percent of households were in poverty, ${ }^{12}$ and over 60 percent received public assistance, mostly as food stamp payments. Total household monthly income was less than $\$ 2,000$ for both groups, with mothers earning about 58 percent of their household's income, on average.

\section{Subgroup Impacts on Employment, Earnings, and Income, by Child's Age}

The impacts of Enhanced EHS on parental employment and job characteristics may vary by the age of the focal child when families entered the study. Mothers may make different employment decisions while their children are infants (younger than 12 months) than they do when their children are toddlers (12 months or older), and results presented in preceding chapters - showing subgroup differences in impacts on program participation, service receipt, and child care - suggest that employment impacts may also differ by the child's age at random assignment.

This section presents the results of a subgroup analysis examining employment-related impacts by the age of the focal child at random assignment. ${ }^{13}$ The impacts of Enhanced EHS among families with infants are compared with the impacts among families with toddlers. Again, these subgroup results should be taken with caution because the sample sizes are small; the NDNH analysis includes 270 families with infants and 327 families with toddlers, and the survey analysis includes 222 respondents with infants and 269 respondents with toddlers.

\footnotetext{
${ }^{12}$ This estimate of poverty is not an official measure but is based on available data. It was calculated only for those respondents $($ total $=467)$ who reported a household income as well as the number of people in the household.

${ }^{13}$ Two other subgroup analyses were conducted: impacts examined by program site and by whether the family had two parents or one at random assignment. Neither analysis shows a pattern of subgroup differences (Appendix F).
} 


\section{The Enhanced Services for the Hard-to-Employ Demonstration}

Table 5.3

Impacts on Household Income and Poverty Status

Early Head Start with Enhanced Self-Sufficiency Services

\begin{tabular}{|c|c|c|c|c|c|}
\hline Outcome & $\begin{array}{r}\text { Program } \\
\text { Group }\end{array}$ & $\begin{array}{r}\text { Control } \\
\text { Group }\end{array}$ & $\begin{array}{r}\text { Difference } \\
\text { (Impact) }\end{array}$ & $\begin{array}{r}\text { Effect } \\
\text { Size }^{\mathrm{a}}\end{array}$ & P-Value \\
\hline \multicolumn{6}{|l|}{ Household income } \\
\hline \multicolumn{6}{|l|}{ Income source (\%): } \\
\hline Earnings & 89.0 & 88.6 & 0.4 & 0.01 & 0.880 \\
\hline Child support & 21.6 & 20.3 & 1.3 & 0.03 & 0.721 \\
\hline Public assistance & 63.5 & 58.0 & 5.4 & 0.11 & 0.217 \\
\hline Cash assistance & 17.5 & 18.4 & -0.9 & -0.02 & 0.791 \\
\hline Food stamps & 56.5 & 51.1 & 5.4 & 0.11 & 0.226 \\
\hline $\begin{array}{l}\text { Supplemental Security Income (SSI) or } \\
\text { disability income }\end{array}$ & 15.8 & 18.8 & -3.0 & -0.08 & 0.391 \\
\hline Total maternal income in prior month ${ }^{\mathrm{b}}(\$)$ & 950 & 977 & -27 & -0.04 & 0.673 \\
\hline Total household income in prior month $(\$)$ & 1,924 & 1,983 & -60 & -0.05 & 0.606 \\
\hline Percentage of household income from mother ${ }^{b}$ & 58.4 & 56.6 & 1.8 & 0.05 & 0.576 \\
\hline Does not know household income (\%) & 3.9 & 5.8 & -1.9 & -0.09 & 0.350 \\
\hline \multicolumn{6}{|l|}{ Poverty status } \\
\hline Below federal poverty level (\%) & 50.2 & 50.9 & -0.7 & -0.01 & 0.873 \\
\hline Sample size (total $=178)$ & 242 & 249 & & & \\
\hline
\end{tabular}

SOURCE: MDRC calculations from responses to the 18-month survey.

NOTES: Statistical significance levels are indicated as follows: $* * *=1$ percent; $* *=5$ percent; and $*$ $=10$ percent. The significance level indicates the probability that one would be making an error in concluding that there is a difference between research groups for the variable in question.

Results in this table are regression-adjusted using ordinary least squares, controlling for pre-random assignment characteristics.

Dollar values include zeroes for sample members who had no income, were not employed, or were not receiving child support or public assistance.

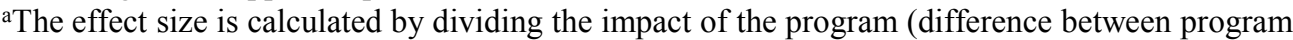
and control groups) by the observed variation for that outcome within the control group (the control group standard deviation).

bAbout 97 percent of survey respondents are female. This measure includes responses for some males (2.6 percent of cases) and may include responses from female guardians who were not the child's biological mother.

${ }^{\mathrm{c}}$ The poverty measure was calculated only for those respondents who reported a household income and the number of people in their household (total =467). This is an estimate of poverty based on available data; it is not an official poverty measure. 
- The positive impacts of Enhanced EHS on earnings and job characteristics may be more evident among families with infants than among families with toddlers.

The results of the subgroup analysis by child's age suggest that the positive impacts of Enhanced EHS on earnings and job characteristics may be more evident among families with infants. First, as shown in Table 5.4, although there were no impacts on mothers' employment, the program may have increased earnings late in the follow-up period among families with infants. In Quarter 6, program group mothers with infants earned about \$500 more than their control group counterparts. Similarly, the positive impacts of the program on job characteristics may be more evident for the infant group. The third panel of Table 5.5 shows a positive impact of about 5 hours of work per week and an increase of about 14 percentage points on working full time among mothers with infants. In addition, program group mothers with infants were more likely to be receiving or to have been offered health care coverage with their jobs (44 percent, compared with 31 percent). Finally, Table 5.6 shows that there may have been a positive impact on the receipt of income from earnings.

In contrast to the impacts among families with infants, the impacts among families with toddlers appear to be less positive. As shown in Table 5.4, late in the follow-up period, the impact on earnings was negative among families with toddlers (and significantly different from the impact among families with infants). The impacts on job characteristics may also have been less positive among families with toddlers. The third panel of Table 5.5 shows a negative impact on hours of work per week and a negative impact on working full time among mothers with toddlers, compared with the positive impacts among mothers with infants. In addition, program group mothers with toddlers were less likely to receive health care or other benefits than their control group counterparts. In each of these cases, the impacts are significantly different between the two subgroups defined by child's age.

It is not entirely clear why Enhanced EHS might be more positive for families with infants than for families with toddlers. Given the small size of the subgroups, it may be that these significant differences arose by chance, and so caution should be used when interpreting these results. It is possible that the positive impacts on employment and job characteristics are more evident among families with infants because these families were engaged in Enhanced EHS for longer periods of time than families with toddlers (Chapter 2). Program group families with infants and pregnant women at study entry were also more likely than program group families with toddlers to receive home-based services, which provided more frequent opportunities for program staff to discuss employment, educational, and self-sufficiency issues with parents.

Furthermore, because families with toddlers at study entry were more likely to age out of their eligibility for Enhanced EHS over the course of the 18-month follow-up period than 


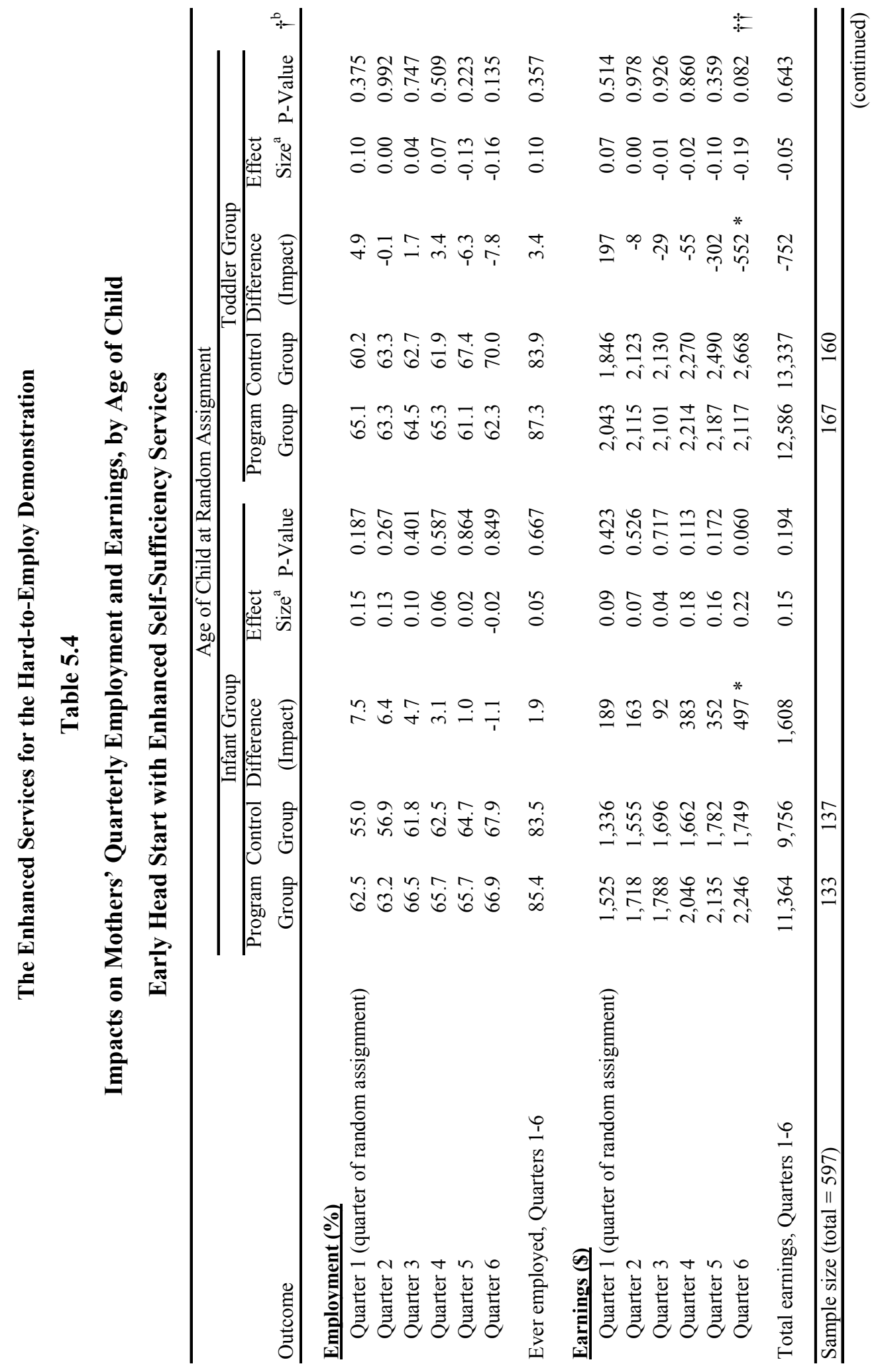




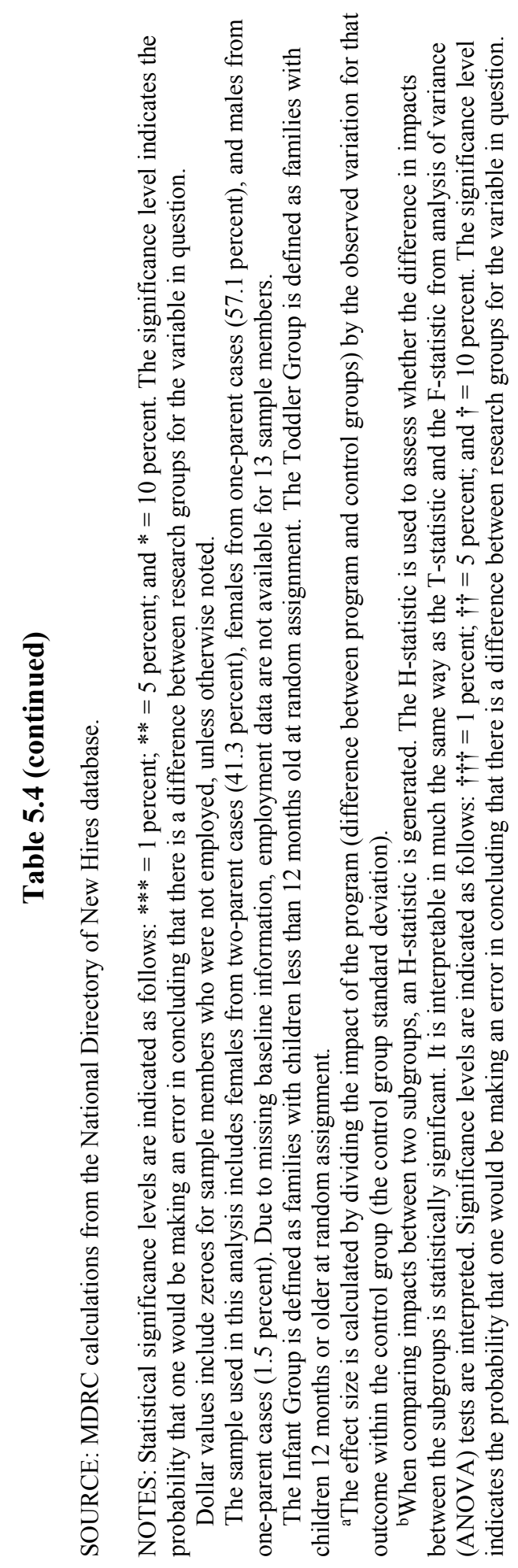




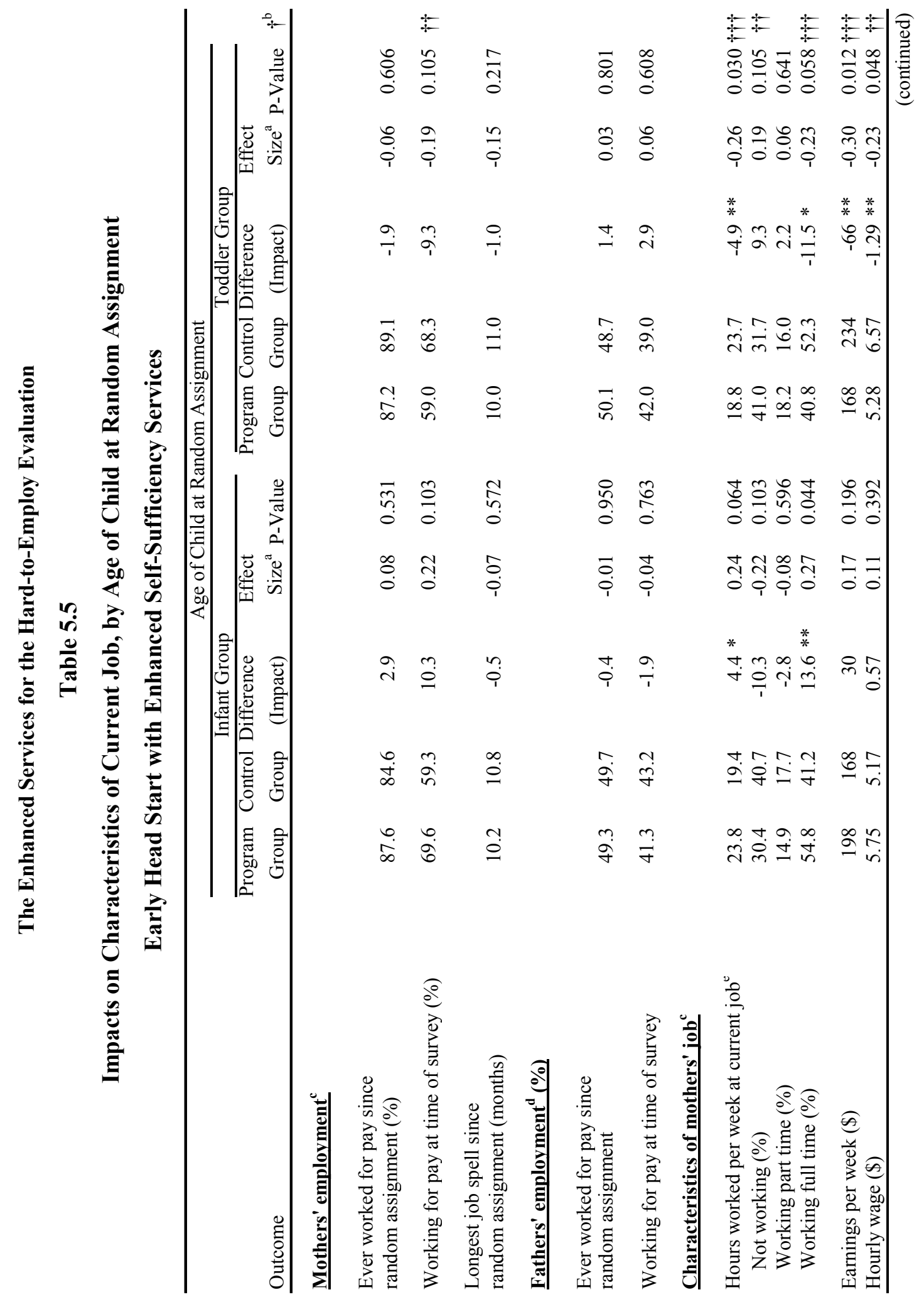




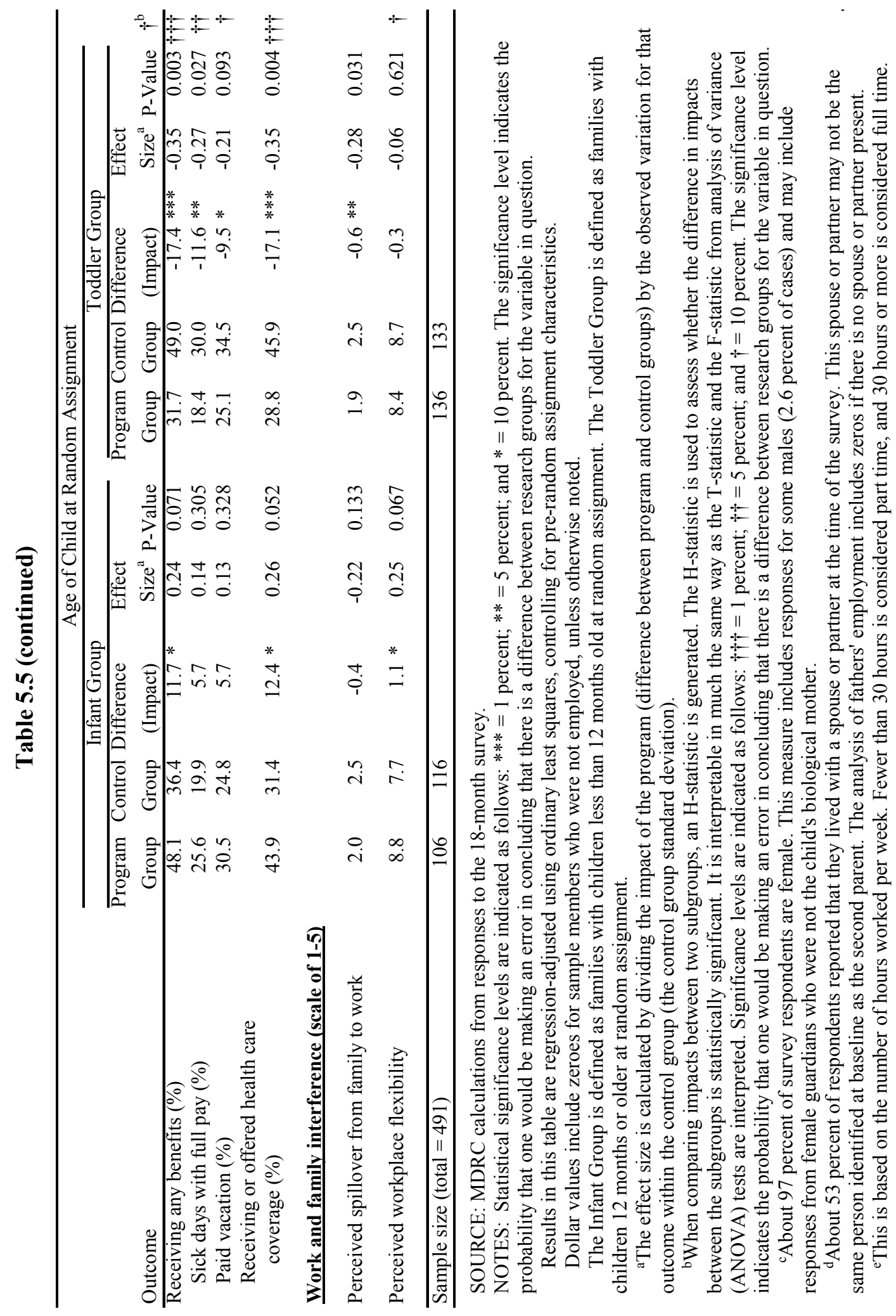




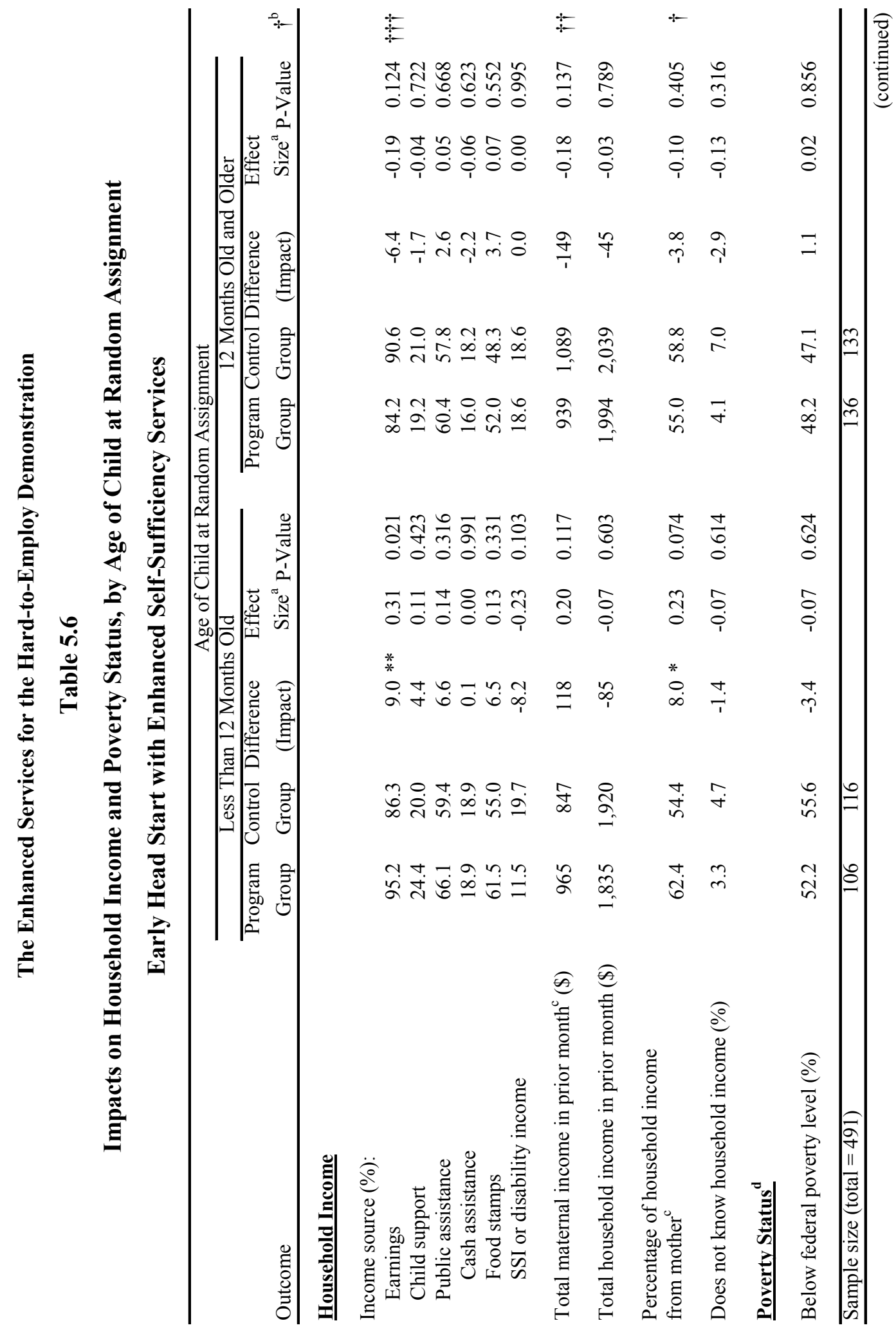




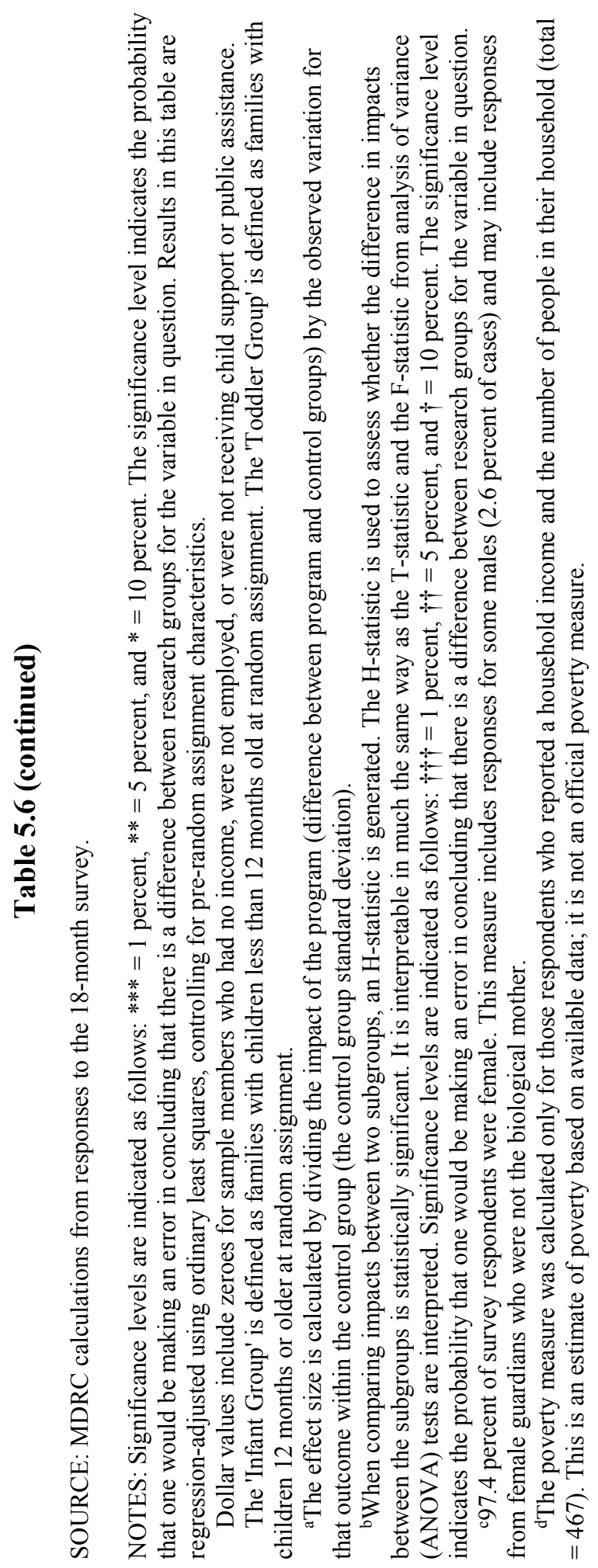


families with infants and pregnant women at study entry, ${ }^{14}$ it is possible that recent or upcoming transitions out of Enhanced EHS for families with toddlers might drive the negative impacts of the program on parental earnings for this subgroup. For example, parents might make adjustments in their work behaviors by cutting back the work hours or taking jobs that are less demanding (and have fewer benefits) but offer greater work-family flexibility to accommodate the use of a new child care arrangement when children transition out of Enhanced EHS. These findings are in line with recent ethnographic research, which suggests that some low-income parents - particularly those who are single parents - seek out low-paying jobs with part-time or flexible work hours because such jobs allow them to tend to family emergencies and responsibilities as needed. ${ }^{15}$

Lastly, it could be that the provision of EHS care, as a free or low-cost child care option, has differential implications for mothers' work decisions and behaviors, depending on the age of the focal child. As described in Chapter 4, Enhanced EHS led to differential impacts on infants' and toddlers' child care experiences, with an increase in the use of formal care among families with infants and a shift from other formal care to Early Head Start or Head Start (EHS/HS) care among families with toddlers. This suggests that, for families with infants, Enhanced EHS increased access to formal care, which may have made it easier for mothers to work more hours or to seek full-time employment with benefits. For families with toddlers, Enhanced EHS may have lowered the cost of child care, since EHS care is free or low-cost. If so, this may have made it easier for mothers to reduce their work hours or to make employment decisions that were based on factors other than pay, such as flexibility of hours or proximity to home. In the end, however, it is not entirely clear why these results were found.

\section{Summary of Impacts on Employment, Earnings, and Income}

Among the full study sample, Enhanced EHS produced almost no significant impacts on measures of employment, earnings, job characteristics, or income. There are several possible explanations for the lack of employment impacts for the full sample. First, due to several implementation challenges, there was a lesser focus on the self-sufficiency components of the

\footnotetext{
${ }^{14}$ As discussed in Chapter 2, just over half the families who were assigned to the program group exited Enhanced EHS within the first 18 months following random assignment. In one-quarter of these cases, the families transitioned to the Head Start (HS) program. The remaining cases exited the program for a variety of reasons, including lack of participation, the family's choosing to withdraw, moving to an area outside the program's coverage area, and unknown reasons. These cases were more likely to be influenced by disruptions in child care as a consequence of the child's transitioning out of Enhanced EHS. In contrast, the transition from Enhanced EHS to HS was fairly seamless from the perspective of families and children participating in Enhanced EHS; children typically did not experience a change in home visitors or in EHS/HS center-based care providers when they transitioned to traditional Head Start provided by the two participating programs.

${ }^{15}$ Yoshikawa, Weisner, and Lowe (2006).
} 
two programs than had been expected, and they may not have been strong enough to produce impacts. Second, given that the rate of employment was already high among the study sample, it is possible that the programs did not serve a population with a sufficiently strong need for or interest in employment services, making it difficult to produce an impact. Yet it was expected that at least some parents would be working, though low-income, especially since those using EHS center-based child care services were required to be working or furthering their education and the programs were designed not only to help participants obtain jobs but also to improve the employment circumstances and job retention of those who were working. This result also is not reflected in the impacts. Finally, these programs may have been operating in a relatively service-rich environment, in which control group members were able to access similar services elsewhere. As shown in Chapter 3, nearly three-quarters of the control group received family development or child-focused services in the community, and there were no significant impacts on participation in employment- and education-related activities.

There is some evidence that Enhanced EHS may have led to a different pattern of impacts among families with infants than among families with toddlers, although these findings should be taken with caution because of the small size of the subgroup samples. The program appears to have had more positive impacts on earnings and job characteristics among parents with an infant or who were still pregnant at baseline than among parents with toddlers at baseline. The reasons for these results are not entirely clear. This story is still unfolding, and it is important to examine impacts over the full follow-up period, which is 12 quarters. 



\section{Chapter 6}

\section{Impacts on Parenting Practices, Parental Psychological Well-Being, and Child Outcomes}

Two Early Head Start (EHS) programs in Kansas and Missouri enhanced their traditional services by offering employment and education assistance to parents, with the goal of improving families' economic circumstances and self-sufficiency in order to improve children's development. Part of the Hard-to-Employ Demonstration and Evaluation Project, this study randomly assigned families in these two sites either to the Enhanced EHS program group, which could receive home-based or center-based services, or to the control group, which could not access Enhanced EHS or traditional EHS from the two programs but could seek alternative services available in the community.

This chapter focuses on the impacts of Enhanced EHS on parenting practices, parental psychological well-being, and outcomes measuring child development. Enhanced EHS was designed to benefit children's physical health and cognitive, language, social, and behavioral development directly and indirectly through changes in parenting practices and parental psychological well-being, as well as through the provision of EHS child care. As such, the program could result in both psychological benefits for parents and more positive parenting, such as use of more effective disciplinary strategies, more emotionally supportive parent-child relations, and increased engagement in more social play and cognitively stimulating activities with the child at home.

This chapter first presents the impacts of Enhanced EHS on parenting practices and on parental psychological well-being. That is followed by the program's impacts on measures of child development and well-being. For each domain of outcomes, first the impacts for the full research sample are presented, followed by how the impacts of might differ for subgroups of families with infants (younger than 12 months) and families with toddlers (12 months or older) at the time they entered the study. These subgroup results should be interpreted with caution, however, because of the small size of the research samples.

\section{Full-Sample Impacts on Parenting Practices and Parental Psychological Well-Being}

Box 6.1 describes the measures of parenting practices and parental psychological wellbeing that were collected by the 18-month survey of parents. 


\section{Box 6.1}

\section{Measures of Parenting Practices and Parental Psychological Well-Being}

Data about parenting practices and parental psychological well-being were collected by the 18-month survey of parents.

Parenting warmth. A single item on the 18-month survey asked parents how often they showed physical affection to, hugged, or kissed the focal child in the past month. Responses were recorded on a 6-point scale ranging from "more than once a day" to "not at all" and were used to create a measure of whether parents reported showing physical affection, on average, at least once a day or less frequently.

Social play and cognitive stimulation. Parental engagement in activities that can stimulate children's cognitive and language development was measured using a composite scale of six items. Parents were asked how often they engaged in the following cognitivestimulating and social play activities with the focal child: playing with toys, singing songs or nursery rhymes, dancing, reading or telling stories, and going to the park. Responses were recorded on a 6-point scale ranging from "more than once a day" to "not at all" and were used to create a measure of whether parents reported engaging in these activities, on average, at least once a day or less frequently.

Discipline strategies. To assess the severity of parents' disciplinary strategies, the survey asked them how they would handle two common situations involving child misbehavior: throwing a temper tantrum in public and playing with breakable things. Parents provided open-ended responses that were coded for the degree of harshness of the disciplinary strategy, on a scale from 1 ("mild") to 5 ("harsh"). These data were then used to create a binary outcome indicating whether parents used only mild disciplinary techniques (for example, preventing the situation, distracting the child, removing the child or object, talking to the child or explaining the issue, ignoring the behavior, putting the child in a timeout, sending the child to his or her room, threatening to take away treats or threatening a time-out, or telling the child "no"). ${ }^{\dagger}$

Spanked child in past week. Parents were asked whether they had spanked the focal child in the past week because the child was misbehaving or acting up.

Parenting stress. Parenting-specific stress was measured by a composite scale of the average of seven items assessing the degree of difficulty they experienced in caring for the focal child. Examples of these items include "feeling trapped by your responsibilities as a parent" and "having focal child has caused more problems than you expected in your interpersonal relationship." Responses were coded on a 5-point scale ranging from "strongly agree" to "strongly disagree." The internal consistency for the composite scale is 0.65 . $^{\ddagger}$

(continued) 


\section{Box 6.1 (continued)}

Parental psychological distress. To assess parental psychological distress, the K6 Mental Health Screening Tool was used to ask parents about how often they experienced symptoms of depression and anxiety during the month prior to the interview. Responses were coded on a 5-point scale ranging from "none of the time" to "all of the time" and were summed to create a composite measure of parental psychological distress on a scale from 1 to 25 . The internal consistency for the composite scale is $0.78 .^{\S}$

NOTES: "Early Head Start Research and Evaluation Project (U.S. Department of Health and Human Services, Administration for Children and Families, 2002).

'Infant Health and Development Project (Brooks-Gunn, Klebanov, Liaw, and Spiker, 1993).

${ }^{\ddagger}$ Parenting Stress Index — Short Form (Abidin, 1995).

${ }^{\S}$ K6 Mental Health Screening Tool (Kessler et al., 2003).

\section{Impacts on Parenting Practices}

In general, low-income parents have been found to provide home environments that are less cognitively stimulating than those provided by more economically advantaged parents. ${ }^{1}$ Low-income parents also tend to exhibit lower levels of emotional support for their children and more punitive and inconsistent discipline than higher-income parents. ${ }^{2}$ Enhanced EHS is expected to improve a broad range of parenting practices through education aimed at modeling and teaching parents developmentally appropriate practices and providing parents with information about young children's developmental norms and milestones (Chapter 2).

- Among the full sample, Enhanced EHS had no significant impacts on parents' warmth, engagement in social play and cognitively stimulating activities, or use of punitive disciplinary strategies with their children. ${ }^{3}$

The first panel of Table 6.1 shows the impacts of the program on parents' involvement and engagement with their children - that is, the frequency of parenting warmth and engagement in social play and cognitively stimulating activities - among the full research sample.

\footnotetext{
${ }^{1}$ Brooks-Gunn, Klebanov, and Liaw (1995); Watson, Kirby, Kelleher, and Bradley (1996).

${ }^{2}$ McLoyd (1990).

${ }^{3}$ As is true with all applications to EHS, families identify a particular child who is up to age 3 or during the prenatal period and who will be enrolled in the program. In this study's 18-month parent survey and direct child assessments, this child is identified as the focal child who is the target of program services and is the focus of all questions related to child care and early educational experiences, parenting practices, and child development and well-being.
} 
The Enhanced Services for the Hard-to-Employ Demonstration

Table 6.1

Impacts on Parenting Practices and Parental Psychological Well-being Early Head Start with Enhanced Self-Sufficiency Services

\begin{tabular}{|c|c|c|c|c|c|}
\hline Outcome & $\begin{array}{r}\text { Program } \\
\text { Group }\end{array}$ & Gontrol & $\begin{array}{r}\text { Difference } \\
\text { (Impact) }\end{array}$ & $\begin{array}{r}\text { Effect } \\
\text { Size }^{\mathrm{a}}\end{array}$ & P-Value \\
\hline \multicolumn{6}{|l|}{ Parental involvement and engagement (\%) } \\
\hline \multicolumn{6}{|l|}{ Frequency of parenting warmth: } \\
\hline $\begin{array}{l}\text { Frequency of social play and cognitive stimulation: } \\
\text { At least once a day }\end{array}$ & 59.4 & 54.2 & 5.2 & 0.11 & 0.245 \\
\hline \multicolumn{6}{|l|}{ Disciplinary strategies } \\
\hline $\begin{array}{l}\text { Percentage of parents who suggest using only mild } \\
\text { disciplinary strategies in hypothetical situations }\end{array}$ & 86.4 & 82.4 & 4.0 & 0.11 & 0.240 \\
\hline Percentage of parents who spanked their child in past week & 33.9 & 31.8 & 2.0 & 0.04 & 0.639 \\
\hline \multicolumn{6}{|l|}{ Parental psychological well-being } \\
\hline Parenting stress and aggravation & 1.5 & 1.5 & 0.0 & -0.02 & 0.851 \\
\hline Parental psychological distress & 5.1 & 4.6 & 0.5 & 0.13 & 0.146 \\
\hline Sample size $($ total $=491)$ & 242 & 249 & & & \\
\hline
\end{tabular}

SOURCE: MDRC calculations based on responses to the 18-month survey.

NOTES: Statistical significance levels are indicated as follows: $* * *=1$ percent; $* *=5$ percent; $*=10$ percent. The significance level indicates the probability that one would incorrectly conclude that a difference exists between research groups for the corresponding variable.

Results in this table are regression-adjusted using ordinary least squares, controlling for pre-random assignment characteristics.

Outcomes in this table are defined in Box 6.1.

aThe effect size is calculated by dividing the impact of the program (difference between program and control groups) by the observed variation for that outcome within the control group (the control group standard deviation).

Analyses indicate that the program had no overall impact on the extent to which parents showed warmth or engaged in social play and cognitively stimulating activities with their children. Over 98 percent of parents in both the program and the control group families reported being warm and affectionate with their child at least once a day. Yet there was no impact on this outcome, even though the program was hypothesized to positively affect the degree to which parents engaged in social play and cognitively stimulating activities with their children. A little 
over half the parents in program and control group families reported engaging in social play and cognitively stimulating activities with their children on a daily basis.

The second panel of Table 6.1 shows the full-sample impacts of Enhanced EHS on parents' disciplinary strategies. Continuing the pattern of statistically nonsignificant impacts for the full research sample, the program did not have an overall impact on disciplinary strategies. It did not affect the types of strategies that parents offered when asked to describe how they would discipline their child in a hypothetical situation when the child is misbehaving (for example, throwing a temper tantrum or playing with a breakable object), and it did not reduce whether parents ever reported spanking their child in the week prior to the 18-month follow-up interview. Roughly 32 percent of control group parents said that they had spanked their child in the past week, and this percentage is similar (34 percent) among parents in the program group. This rate of spanking is not especially high among low-income parents with very young children, and it is in line with prior research. ${ }^{4}$

\section{Impacts on Parental Psychological Well-Being}

As discussed above, the expectation was that Enhanced EHS would benefit parents psychologically by directly supporting them and by providing EHS mental health services (described in Chapter 2).

- Among the full sample, Enhanced EHS had no discernable impact on parenting-specific stress or on overall parental psychological distress.

The bottom panel of Table 6.1 shows the impacts on two key indicators of parental psychological well-being. The program had no discernable impact on parenting-specific stress or on parental psychological distress. Overall, among the full research sample, it appears that the program had no reliable impacts on parenting practices or parental psychological well-being.

\section{Subgroup Impacts on Parenting Practices and Parental Psychological Well-Being, by Child's Age ${ }^{5}$}

Although Enhanced EHS appears to have had limited effects on parenting and related outcomes among the full research sample, it is important to examine whether the impacts of the program might have varied for families with children of different ages, for a number of reasons. First, it may be that families who enrolled in Enhanced EHS when mothers were pregnant or

\footnotetext{
${ }^{4}$ U.S. Department of Health and Human Services, Administration for Children and Families (2002).

${ }^{5}$ The impacts on parenting practices and parental psychological well-being for subgroups defined by program site and by the number of parents in the household at random assignment were also explored and are shown in Appendix G.
} 
when their children were infants (younger than 12 months) may have been enrolled in the program for longer periods of time than families who enrolled when their children were toddlers (12 months or older). Second, prior evaluations of family development and child-focused programs suggest that early intervention can be better than later intervention and might maximize a program's effectiveness for changing parenting behaviors. ${ }^{6}$ Lastly, as shown in preceding chapters, it appears that Enhanced EHS had differential patterns of impacts on a spectrum of parental employment and child care outcomes for subgroups defined by the child's age. This suggests that there might be evidence of differential effects on parenting practices and parental psychological well-being for families with infants and for those with toddlers at study entry. Again, however, subgroup results should be interpreted with caution because of the small size of the samples.

- Among families with infants, the program had a cluster of positive impacts on parenting warmth and parenting-specific stress. In contrast, it increased parental psychological distress among families with toddlers.

Table 6.2 shows the program's impacts on these outcomes separately for families with infants and for families with toddlers. In general, the results suggest that the program had fairly limited effects on measures of parenting practices and parental psychological well-being. However, the analyses indicate a clustering of positive effects across several of these parenting outcomes among families with infants at baseline. These findings are in line with expectations that it might be more advantageous to enroll families in family- and child-focused services while mothers are pregnant or soon after their children are born. This pattern of findings may also reflect that the programs were more successful at engaging the families who had infants and pregnant women at study entry; they participated in Enhanced EHS at higher rates and for longer periods of time - particularly in home-based services - than families who had toddlers at study entry.

As shown in the first panel of Table 6.2, the program had a small positive impact on parental warmth among families with infants, whereas it had no significant impact on this aspect of parent-child interactions among families with toddlers. Among the control group families with infants, 97 percent of parents reported being warm and affectionate with their child on a daily basis, compared with 100 percent of parents in the program group. The effect size of this impact is modest in magnitude. For the subgroups of families defined by the child's age, however, the program had no significant impact on the frequency of parents' engagement in social play and cognitively stimulating activities with their children.

${ }^{6}$ U.S. Department of Health and Human Services, Administration for Children and Families (2002); Brooks-Gunn, Klebanov, Liaw, and Spiker (1993). 


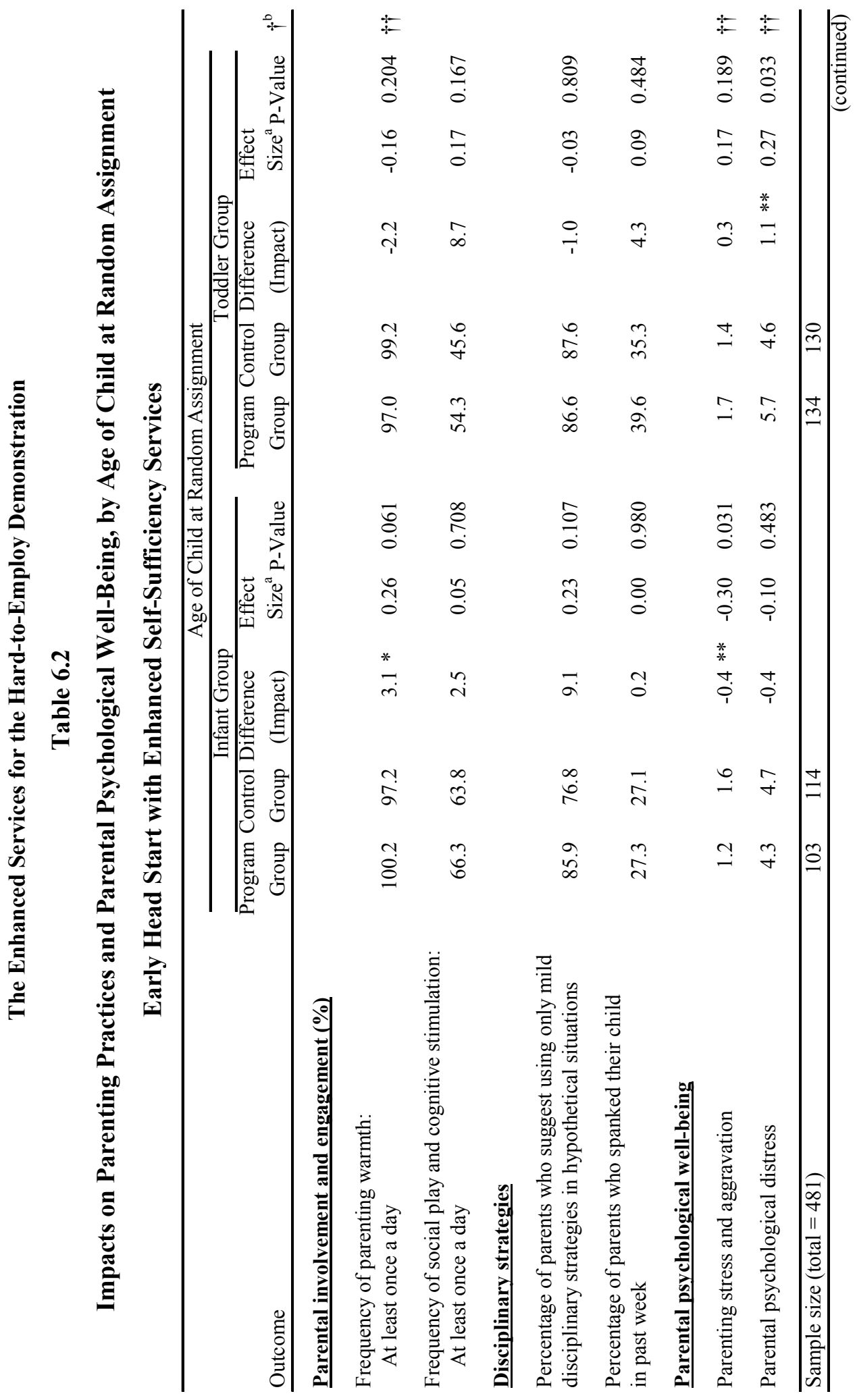




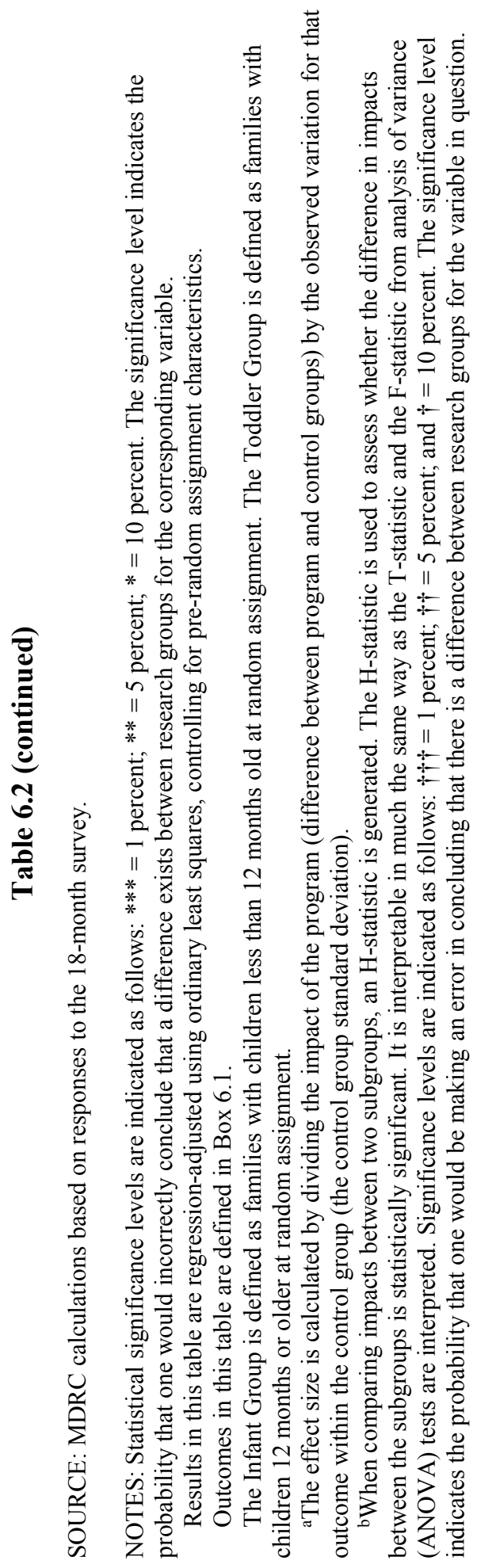


Similarly, the program appears to have slightly increased the percentage of parents with infants who reported using only mild disciplinary strategies, though this impact falls just below significance levels (Table 6.2). In the control group, 77 percent of parents with infants reported using mild disciplinary strategies when their child might be misbehaving, compared with 86 percent of program group parents with infants. At the same time, there were no significant impacts on the percentage of parents who reported spanking their children, whether infants or toddlers.

The bottom panel of Table 6.2 shows the program's impacts on parenting-specific stress and parental psychological distress. The findings highlight a contrasting pattern of effects on indicators of parental psychological well-being, depending on the age of the child at study entry. It appears that the program modestly reduced parenting stress among families with infants, whereas it had no impact on this outcome among families with toddlers. In contrast, the program had no impacts on the levels of parenting-specific stress, but it led to modest increases in parental psychological distress among families with toddlers.

Taken together, the findings suggest that, overall, Enhanced EHS has limited effects on parenting practices and parental psychological well-being. Yet the pattern of impacts also suggests that the program's scattered beneficial effects on these outcomes may be more evident among families who enter the program when their children are infants or the mothers are pregnant.

\section{Summary of Impacts on Parenting Practices and Parental Psychological Well-Being}

Though the Enhanced EHS program's theory of change envisions broader impacts on parenting, parent-child relations, and parental psychological well-being - regardless of the child's age - these positive impacts are not evident among the full sample in this study. The clustering of significant impacts among parents with infants at random assignment could have occurred because these families were engaged in the program for longer periods of time than families who had toddlers at random assignment, in part because they were less likely to age out of eligibility for Enhanced EHS over the study's follow-up period. Compared with program group families with toddlers at study entry, families with infants and pregnant women in the program group were also more likely to be engaged in Enhanced EHS home-based services, which tended to provide more opportunities than center-based services did for program staff to discuss parenting issues with participating families.

The pattern of findings might also suggest that there may be salient points of intervention either before or immediately after the birth of the child when the program's beneficial impacts on family functioning and parenting practices are most likely to be realized. It may be 
that once parenting practices are established, it can be difficult to alter patterns in parent-child interactions. ${ }^{7}$ Thus, intervening and teaching parents developmentally appropriate parenting strategies and addressing their mental health needs while their children are still newborns and infants appears to be an important component of setting a positive path for family functioning and parent-child relations.

At the same time, it may be that the clustering of positive program impacts on parenting and parental psychological outcomes among families with infants at study entry is linked to the impacts on parents' work hours, earnings, and securing stable child care and jobs with benefits and more flexible environments (Chapters 4 and 5). To the extent that programs are able to assist pregnant women and parents with newborns or infants in achieving stable, high-quality employment and child care, this may confer psychological benefits for parents, in turn enabling them to engage in warm and nurturing interactions with their children and to use less harsh disciplinary techniques. ${ }^{8}$

In contrast, the impacts on employment may have contributed to the negative impacts on parental psychological distress among families with toddlers at study entry. The pattern of impacts on employment and job characteristics (Chapter 5) indicates that program group parents with toddlers might have opted to take jobs that required fewer hours, were lower paying, and offered fewer benefits. At the same time, program group parents with toddlers perceived to a lesser degree that their family lives interfered with their ability to work. Recent ethnographic research suggests that some low-income parents - particularly single parents — seek out jobs with part-time or flexible work hours, which tend to pay less, in part because such jobs allow them to tend to family emergencies and responsibilities as needed. ${ }^{9}$ Thus, one could posit that the parents with toddlers were making an effort to balance the demands of work and family life by opting to take jobs that were less demanding and, consequently, less rewarding. Even so, there is evidence to suggest that this kind of low-wage work can be psychologically stressful ${ }^{10}$ and may be one reason why the program appears to have increased parental psychological distress among families with toddlers at study entry.

\section{Full-Sample Impacts on Child Outcomes}

This section presents impacts on children's language, cognitive, and social and emotional development, as well as health and disability outcomes. Box 6.2 describes these outcomes,

\footnotetext{
${ }^{7}$ Patterson (1982).

${ }^{8}$ Downey and Coyne (1990).

${ }^{9}$ Yoshikawa, Weisner, and Lowe (2006).

${ }^{10}$ Menaghan and Parcel (1995).
} 


\section{Box 6.2 \\ Measures of Child Outcomes}

Data about children's language, cognitive, social and emotional development, and health and disability outcomes were collected primarily at the 18-month follow-up through direct assessments of children's functioning. This information was supplemented by parent reports of children's development and well-being on the 18-month follow-up survey.

Verbal comprehension was measured for focal children who were 24 months old or older at the 18-month follow-up, using the receptive language subscale of the Reynell Developmental Language Scales. ${ }^{*}$ For the impact analysis, children's raw scores are converted into percentile scores, which were created by comparing the focal child's score with norms for his or her chronological age group.

Early reading and math skills were measured for focal children who were 24 months old or older at the 18-month follow-up, using the Letter-Word Identification and Applied Problems subtests of the Woodcock-Johnson III-R, respectively. Because standardized norms on scores are not available for children younger than age 3, impacts are examined using children's raw scores on each of these subtests.

Behavioral regulation was measured by two direct child assessments for focal children who were 24 months or older at the 18-month follow-up. From the scores of the tasks described below, a composite measure of behavioral regulation was created, based on whether the child successfully slowed down during none, one, or two of the tasks. These direct child assessments and measurement methods have been commonly used in prior research. ${ }^{\dagger}$

- Drawing circles task. The child was asked to draw circles at varying speeds. The measurement method is the difference in seconds between the child's slow and fast trials.

- Walk-a-line task. The child was asked to walk a line once and then was directed to walk the same line two more times, slowly. The measurement method is the difference in seconds between the child's slow and regular or baseline trials.

Delay of gratification/impulse control was measured with a single direct assessment: the gift wrap task asked the child to wait and not to peek while the interviewer noisily pretended to wrap a "gift." The measurement method is latency to first peek, in seconds, during the waiting period. This measurement approach has been used in prior research using self-regulation tasks."

Total social and emotional problems and competencies of children who were younger than 36 months at the 18-month follow-up were measured via parent reports, using the subscales of the Brief Infant and Toddler Social and Emotional Assessment (BITSEA). ${ }^{\S}$

(continued) 


\section{Box 6.2 (continued)}

Children's general health was assessed by a single item on the 18-month follow-up survey. Parents were asked to rate the focal child's health on a 4-point scale ranging from "excellent" to "poor."

NOTES: *The receptive language subscale of the Reynell Developmental Language Scales was administered to children who were between the ages of 12 and 24 months as well. However, due to difficulties in administration, the scores for these children are not valid and, therefore, are not included in the impact analysis.

${ }^{\dagger}$ McCabe, Hernandez, Lara, and Brooks-Gunn (2000); Murray and Kochanska (2002); SmithDonald, Raver, Hayes, and Richardson (2007).

'Smith-Donald, Raver, Hayes, and Richardson (2007).

${ }^{\S}$ Briggs-Gowan et al. (2004).

which were measured through direct assessments of children's functioning at the 18-month follow-up and by parent reports of children's development and well-being as captured by the 18-month survey.

Given the findings that Enhanced EHS generally had limited impacts on parents' employment, engagement in educational activities, parenting, and psychological well-being but that it was effective at promoting the use of formal child care overall - and of Early Head Start or Head Start (EHS/HS) care in particular - it is unclear whether the program will have notable impacts on the well-being of children in the full research sample at the 18-month follow-up. It might be that the provision of EHS care benefits children's development. In contrast, the lack of significant findings on aspects of parenting and related outcomes and on employment, education, and economic outcomes could diminish the program's potential positive impacts on children's development and well-being. These possibilities are explored in this section.

- Among the full research sample, Enhanced EHS had limited impacts on children's cognitive, language, social and emotional, and physical health, except that the program increased children's abilities to regulate their behaviors.

The top panel of Table 6.3 summarizes the full-sample impacts of Enhanced EHS on children's language, cognitive, and social and emotional outcomes. There is limited evidence to suggest that the program affected children's development across these domains, except for one significant impact in the area of behavioral regulation. The program increased children's abilities to regulate their behaviors. The magnitude of this impact is small: an effect size of 0.20 standard deviation. 
The Enhanced Services for the Hard-to-Employ Demonstration

Table 6.3

Impacts on Child Outcomes

Early Head Start with Enhanced Self-Sufficiency Services

\begin{tabular}{|c|c|c|c|c|c|}
\hline Outcome & $\begin{array}{r}\text { Program } \\
\text { Group } \\
\end{array}$ & $\begin{array}{r}\text { Control } \\
\text { Group }\end{array}$ & $\begin{array}{r}\text { Difference } \\
\text { (Impact) }\end{array}$ & $\begin{array}{r}\text { Effect } \\
\text { Size }^{\text {a }}\end{array}$ & P-Value \\
\hline \multicolumn{6}{|l|}{ Child social and emotional outcomes } \\
\hline \multicolumn{6}{|l|}{ Self-regulation } \\
\hline Behavioral regulation & 0.9 & 0.7 & $0.2 * *$ & 0.22 & 0.026 \\
\hline Delay of gratification/impulse control & 15.7 & 17.5 & -1.8 & -0.09 & 0.374 \\
\hline Total social and emotional problems & 11.6 & 11.8 & -0.2 & -0.03 & 0.754 \\
\hline Total social and emotional competencies & 17.6 & 17.4 & 0.2 & 0.09 & 0.321 \\
\hline \multicolumn{6}{|l|}{ Child language and cognitive outcomes } \\
\hline Verbal comprehension & 26.9 & 29.5 & -2.6 & -0.09 & 0.382 \\
\hline Early reading skills & 2.7 & 2.5 & 0.1 & 0.05 & 0.565 \\
\hline Early math skills & 4.0 & 3.5 & 0.4 & 0.10 & 0.246 \\
\hline \multicolumn{6}{|l|}{ Child health outcomes } \\
\hline \multicolumn{6}{|l|}{ General health status: } \\
\hline Excellent $(\%)$ & 42.3 & 43.1 & -0.8 & -0.02 & 0.866 \\
\hline Sample size $($ total $=481)$ & 237 & 244 & & & \\
\hline
\end{tabular}

SOURCES: MDRC calculations based on responses to the 18 -month survey and direct child assessments.

NOTES: Statistical significance levels are indicated as follows: $* * *=1$ percent; $* *=5$ percent; $*=10$ percent. The significance level indicates the probability that one would incorrectly conclude that a difference exists between research groups for the corresponding variable.

Results in this table are regression-adjusted using ordinary least squares, controlling for pre-random assignment characteristics.

Child language, cognitive, and social and emotional outcomes in this table are defined in Box 6.2.

aThe effect size is calculated by dividing the impact of the program (difference between program and control groups) by the observed variation for that outcome within the control group (the control group standard deviation).

These collective impacts suggest that, at the time of the 18-month follow-up, the program had little or no significant impact on developmental and well-being outcomes among children in the full research sample. It may be that increasing families' use of formal care overall and EHS/HS care without corresponding improvements in parents' outcomes is not sufficient to generate positive impacts on the domains of child outcomes that were examined. Additionally, it may take time for the program's impacts on children's developmental outcomes to unfold, making it important to examine the impacts on these outcomes at a later follow-up. 


\section{Subgroup Impacts on Child Outcomes, by Child's Age}

This section explores the impacts of Enhanced EHS on children's development and well-being among two subgroups defined by the child's age at random assignment: infants (younger than 12 months) and toddlers (12 months or older). Caution in interpreting subgroup differences is again advised because there is a lack of comparability in several of the child outcome measures across subgroups, making it impossible to examine whether impacts differ significantly for infants and toddlers. The small size of the research subgroups also makes this discussion exploratory in nature. It is thus important to continue investigating hypotheses generated by this 18-month impact analysis using child outcome data collected at a later follow-up point.

Table 6.4 presents the impacts on children's development and well-being, in subgroups defined by the child's age at study entry. There is some evidence of positive impacts on social, emotional, and self-regulation outcomes, though varying impacts by child's age are also evident. The program enhanced toddlers' self-regulatory abilities and reduced infants' social and emotional problems as reported by parents in the 18-month survey. The effect sizes for both impacts are small and are consistent with findings from an earlier evaluation of EHS. ${ }^{11}$ As discussed above and in Chapters 4 and 5, the clustering of positive impacts on parents' work hours, use of EHS/HS care, parenting warmth, and parenting stress may be beneficial for younger children's social and emotional adjustment, and the positive impacts on the use of EHS/HS care may improve older children's self-regulation.

The program did not significantly affect cognitive and language outcomes at the 18month follow-up for children who were toddlers when they entered the study. However, it is difficult to draw conclusions about the extent to which impacts in these areas varied by child's age, because measures of cognitive and language outcomes were not available for infants when they entered the study. These findings differ somewhat from the earlier evaluation's findings, which show that EHS improved young children's language and cognitive development. ${ }^{12}$ That study sample, however, includes only families with infants and pregnant women at study entry, making it difficult to generalize the earlier findings to this evaluation's subgroup of families with toddlers.

Even though access to high-quality center-based child care - like the center-based care provided by Enhanced EHS - is expected to enhance young children's cognitive and language development, the effects may take time to evolve and may become evident at a later follow-up point. Also, as discussed in Chapter 4, although the program increased the overall use of EHS/HS care regardless of the child's age at study entry, it appears to have encouraged the

\footnotetext{
${ }^{11}$ U.S. Department of Health and Human Services, Administration for Children and Families (2002).

${ }^{12}$ U.S. Department of Health and Human Services, Administration for Children and Families (2002).
} 


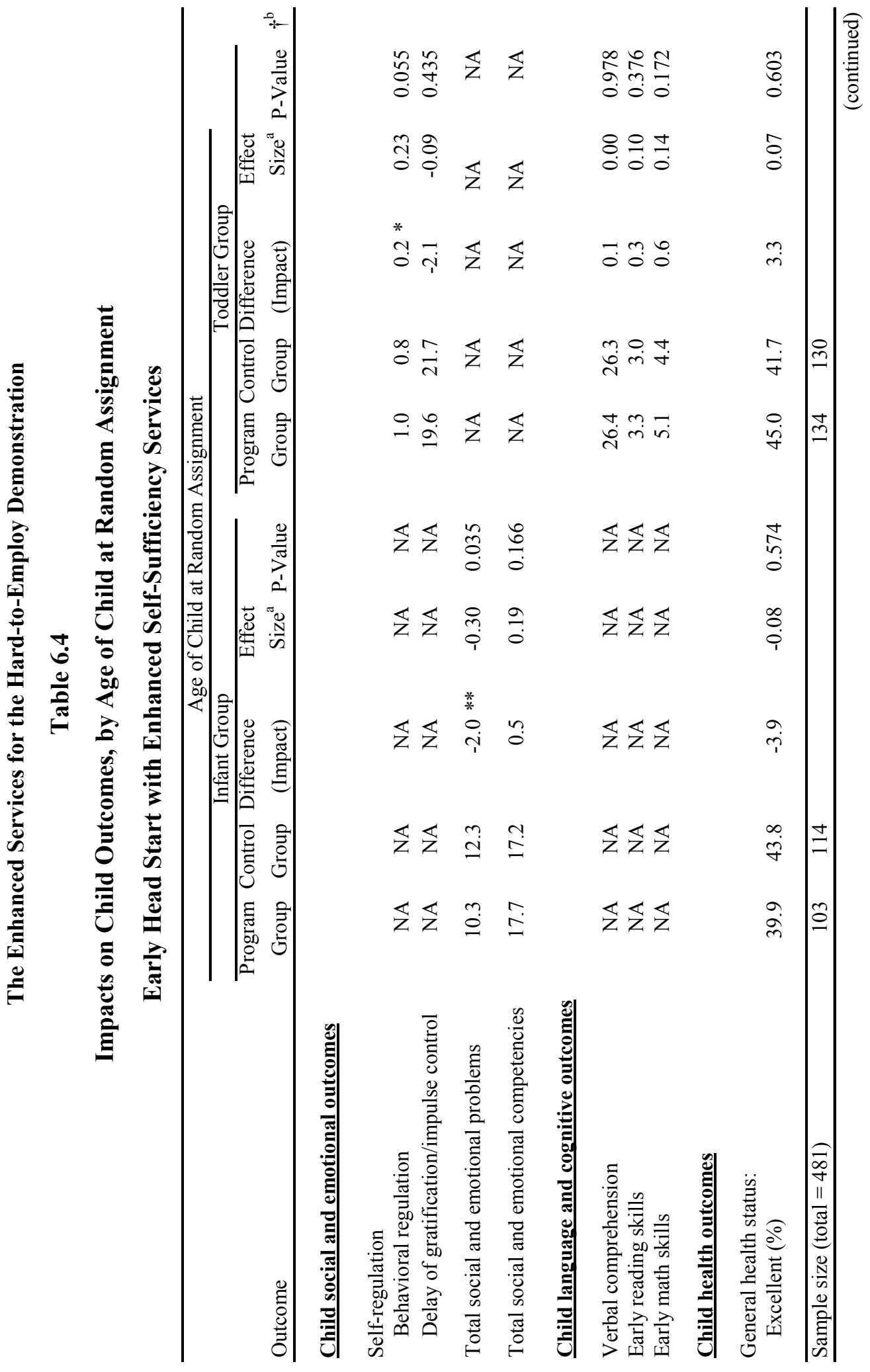




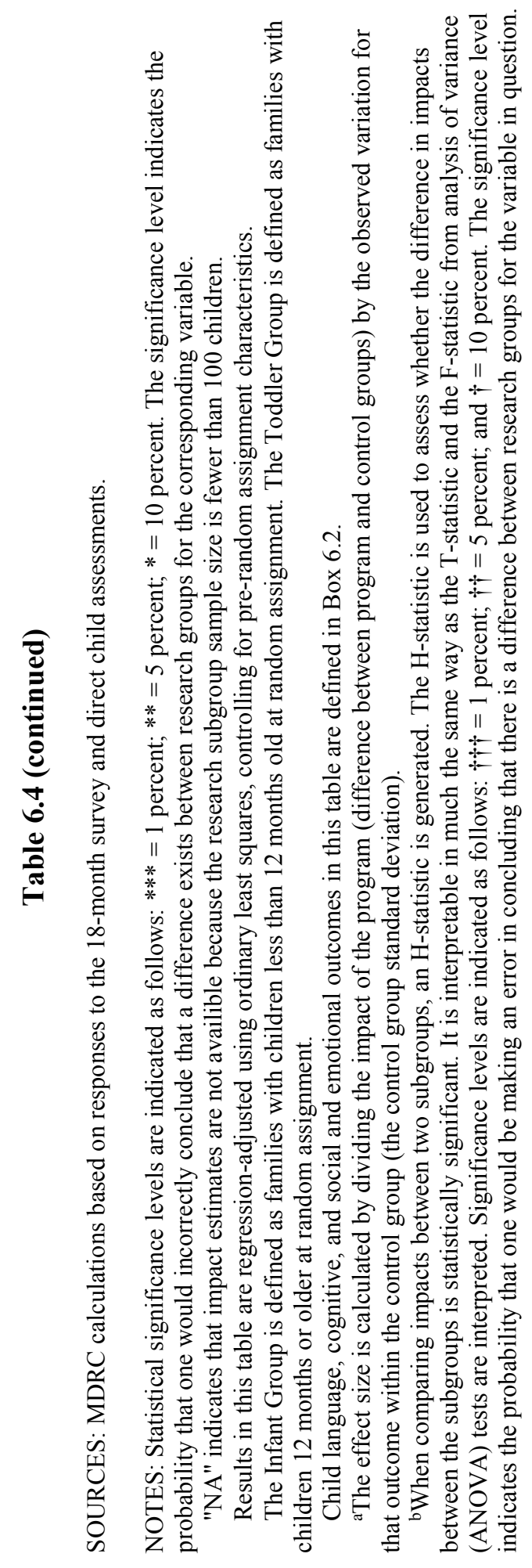


families with toddlers to trade other forms of formal care for EHS/HS care without increasing the overall take-up rate of formal child care for this subgroup. It could be that the type of child care - notably, formal versus home-based - is the more salient dimension of children's care experiences that shapes their early development of cognitive and language skills. ${ }^{13}$ It may also be that the measures used to assess toddlers' language and cognitive development may not be sensitive enough to detect the impacts of Enhanced EHS for this subgroup. Furthermore, any positive developmental benefits for children that are conferred by EHS care may be offset by the program-driven increases in parental psychological distress and by the negative impacts on employment and job quality (Chapter 5) among families with toddlers.

Lastly, the program did not affect the physical health outcomes for children who were either infants or toddlers when they entered the study. As discussed in Chapter 3, high levels of children in the study sample received health care services and health insurance coverage, perhaps due in part to other policy initiatives affecting children's health, such as the expansions of State Child Health Insurance Programs since 1997. There may have been less opportunity for the program to enhance children's receipt of health care services and their physical health outcomes.

\section{Summary of Impacts on Child Outcomes}

The pattern of impacts for the full sample and for subgroups defined by the child's age suggests that the services of Enhanced EHS have fairly limited short-term impacts on children's development and well-being. The program appears to have improved some aspects of children's self-regulation and social and emotional adjustment, but these effects might vary somewhat by age. Undoubtedly, the effects of Enhanced EHS on children's development and well-being will continue to unfold, making it important to assess longer-term impacts using data from a later follow-up point.

\footnotetext{
${ }^{13}$ NICHD Early Child Care Research Network (2002a, 2002b).
} 

Appendix A

Response Bias Analysis:

18-Month Survey of Parents and

Direct Child Assessments 

To examine the possibility of improving children's development by improving families' economic circumstances and self-sufficiency, the Hard-to-Employ Demonstration and Evaluation Project is studying two traditional Early Head Start (EHS) programs in Kansas and Missouri that enhanced their services by offering parents assistance with employment and education. Families in the study were randomly assigned either to the Enhanced EHS program group and could receive home-based or center-based services or to the control group and could not access services from these two programs but could seek services available in the community.

Appendix A assesses the reliability of the impact results from the 18-month follow-up data collection activities, which include a survey of parents and direct child assessments. The appendix examines whether the impacts for the survey respondents and for the child assessment respondents can be generalized to the impacts for the full research sample - all the families who were randomly assigned during the sample intake period. (Box A.1 describes the research samples that are used in the analysis.)

The appendix first describes the components of the 18-month data collection and how the fielded samples were selected. Then it discusses the overall response rates for the parent survey and the child assessments and how these rates might differ by research group. Next, it compares the two research groups (the program group and the control group) among respondents to the parent survey and the child assessments. That is followed by a comparison of differences between respondents and nonrespondents to each of the data collection activities. The appendix then compares the impacts on employment and earnings - as calculated using administrative records - for the various respondent samples and for the fielded sample and/or the full research sample. Finally, data from the parent survey and direct child assessments are used to analyze the sensitivity of the impact results to nonresponse bias - the possibility of differences in baseline characteristics between the respondent samples and the nonrespondent samples.

This appendix concludes, with some caution, that the impact analysis for outcomes assessed with the parent survey and direct child assessments is reliable and that the results for these respondent samples can be generalized to the full research sample. Despite some significant differences in baseline characteristics between respondents and nonrespondents and some differences in baseline characteristics among respondents in the two research groups, the impacts on administrative measures of employment are similar for the full research sample and for the respondent samples. In addition, the analysis weighting for nonresponse shows that the impact estimates from the parent survey and direct child assessments are not highly sensitive to weighting for nonresponse, suggesting that the impact estimates from the respondent data can be generalized to the full research sample. 


\section{Box A.1}

\section{Key Analysis Samples}

Research sample: All individuals in the study who were randomly assigned during the sample intake period, which extended from July 2004 through December 2006.

Parent survey fielded sample: All the sample members in the research sample, inasmuch as all were selected for the parent survey field interview.

Parent survey respondent sample: Sample members in the fielded sample who completed the 18-month parent survey.

Parent survey nonrespondent sample: Sample members in the fielded sample who were not interviewed for the parent survey because they were not located, refused to be interviewed, or had other reasons for not participating.

Child assessment fielded sample: Sample members in the research sample whose children were at least 6 months old at random assignment.

Child assessment respondent sample: Members of the child assessment fielded sample who completed at least one child assessment.

Child assessment nonrespondent sample: Members of the child assessment fielded sample who did not complete a child assessment because the child was not available or they were not located, refused to be interviewed, or had other reasons for not participating.

\section{Components of the 18-Month Data Collection}

The 18-month data collection effort includes two components: a survey of parents and direct child assessments. The survey was used to measure service receipt, the use of child care, parents' psychological well-being, parenting practices, parents' employment and job characteristics, household income, and parent-reported measures of children's social, emotional, and cognitive development.

The same interviewer conducted the child assessments directly with the focal children. ${ }^{1}$ In most cases, the assessments occurred immediately after the parent's survey interview, but, in

\footnotetext{
${ }^{1}$ As is true with all applications to EHS, families identify a particular child who is up to age 3 or during the prenatal period and who will be enrolled in the program. In this study's 18-month parent survey and direct child assessments, this child is identified as the focal child who is the target of program services and is the focus of all questions related to child care and early educational experiences, parenting practices, and child development and well-being.
} 
some cases - because of time constraints, children's availability, or a child's inability to participate because of tiredness or sickness - the assessments were conducted at a later date or not at all. The assessments included self-regulation tasks, such as a drawing circles task, a walkthe-line task, and a gift wrap activity; the broad math and reading subtests of the WoodcockJohnson III-R; and a subscale of the Reynell Developmental Language Scales. For a detailed description of these assessments, see Box 6.2 in Chapter 6.

\section{Selection of the Fielded Sample}

The full research sample for this study includes 610 families who were randomly assigned in equal numbers to the program and control groups from July 2004 to December 2006. The parent survey fielded sample - those who were selected to be interviewed - reflects the entire research sample.

Child assessments were conducted only of children who were 24 months old or older. Only those who were at least 6 months old at random assignment (and, therefore, were at least 24 months old at the follow-up 18 months later) could be included in the child assessment fielded sample, which includes 434 children.

\section{Response Rates}

From the parent survey fielded sample, parents who were interviewed for the 18month survey are referred to as "parent survey respondents," or the parent survey respondent sample, while parents who were not interviewed are referred to as "parent survey nonrespondents," or the parent survey nonrespondent sample. A total of 491 sample members, or 81 percent of the parent survey fielded sample, completed the parent survey. Seventy-nine percent of the program group fielded sample (total $=242$ ) and 82 percent of the control group fielded sample (total $=249$ ) completed the survey. These response rates do not differ significantly across the research groups.

From the child assessment fielded sample, children who completed at least one child assessment are referred to as "child assessment respondents," or the child assessment respondent sample, while families with children who were not interviewed are referred to as "child assessment nonrespondents," or the child assessment nonrespondent sample. All families who completed a child assessment also responded to the parent survey. A total of 315 families, or 73 percent of the child assessment fielded sample, had focal children who completed a direct child assessment. Seventy-one percent of the program group fielded sample (total $=160$ ) and 76 percent of the control group fielded sample (total $=155)$ completed the survey. These response rates do not differ significantly across the research groups. 
Overall, of the parent survey nonrespondent sample, 45 percent (54 out of 119) could not be located for the interview; 23 percent (27 out of 119) were located, but the interview was not completed; and 19 percent (23 out of 119) refused to participate in the interview. ${ }^{2}$ Information on the frequency of reasons why some families completed a questionnaire but did not have a completed child assessment was not available. Whenever the response rate is lower than 100 percent, nonresponse bias may occur. That is, differences may exist between the respondent sample and the larger, fielded sample, owing to differences between those sample members who completed the survey and those who did not. Furthermore, the impact estimates may be biased if the background characteristics of the research groups differ.

\section{Comparison of the Research Groups Within the Respondent Samples}

Random assignment research designs minimize potential bias. There is the possibility in this case, however, that the characteristics of the research groups differed due to the selective nature of the response process for each of the 18-month data collection components. If so, the reliability of impact estimates for the respondent samples may be affected.

Appendix Table A.1 shows selected characteristics of the parent survey respondents at baseline, analyzed by research group. In general, differences between the program group and control group are relatively small and not statistically significant, but some differences are significant. The research groups differ on child's age, percentage Hispanic, and employment history during the three years prior to random assignment. A test of the joint significance of all baseline variables was conducted by running a regression predicting program group status versus control group status among parent survey respondents. It showed no significant difference between the two groups in baseline characteristics as a whole.

Appendix Table A.2 shows selected characteristics of the child assessment respondents at baseline, again by research group. As with the parent survey groups, the differences between these program and control groups are generally small and not statistically significant. However, the research groups do differ on the percentage Hispanic and the percentage who were teen parents at random assignment. A test of the joint significance of all baseline variables was conducted by running a regression predicting program group status versus control group status among child assessment respondents. It showed no significant difference between the two groups in baseline characteristics as a whole.

\footnotetext{
${ }^{2}$ Other members of the fielded sample were not included in the parent survey respondent sample because they moved far away, could not complete the interview because of a language barrier, were incapacitated, or were deceased.
} 
The Enhanced Services for the Hard-to-Employ Demonstration

Appendix Table A.1

Baseline Characteristics of Parent Survey Respondents, by Research Group

Early Head Start with Enhanced Self-Sufficiency Services

\begin{tabular}{|c|c|c|c|}
\hline Characteristic & Enhanced EHS & Non-EHS & Total \\
\hline \multicolumn{4}{|l|}{ Primary parent } \\
\hline Female $(\%)$ & 90.5 & 91.9 & 91.2 \\
\hline Average age (in years) & 25.8 & 26.1 & 26.0 \\
\hline $\begin{array}{l}\text { Marital status }(\%) \\
\text { Single, never married } \\
\text { Married } \\
\text { Separated, divorced, or widowed }\end{array}$ & $\begin{array}{l}52.7 \\
29.3 \\
18.0\end{array}$ & $\begin{array}{l}53.7 \\
32.0 \\
14.3\end{array}$ & $\begin{array}{l}53.2 \\
30.6 \\
16.1\end{array}$ \\
\hline Spanish/Hispanic/Latino(a) (\%) & 2.5 & 6.1 & $4.3 *$ \\
\hline $\begin{array}{l}\text { Race/ethnicity }{ }^{\mathrm{a}}(\%) \\
\text { White } \\
\text { Black or African-American } \\
\text { Other }\end{array}$ & $\begin{array}{r}89.5 \\
6.7 \\
3.8\end{array}$ & $\begin{array}{r}0.0 \\
85.7 \\
10.2 \\
4.1\end{array}$ & $\begin{array}{r}87.6 \\
8.5 \\
3.9\end{array}$ \\
\hline $\begin{array}{l}\text { Primary parent employed during the past } 3 \text { years }(\%) \\
\text { Did not work at all } \\
\text { Worked } 1 \text { year or less } \\
\text { Worked more than } 1 \text { year }\end{array}$ & $\begin{array}{l}16.5 \\
27.8 \\
55.7\end{array}$ & $\begin{array}{r}0.0 \\
15.5 \\
37.0 \\
47.5\end{array}$ & $\begin{array}{l}16.0 \\
32.4 \\
51.6\end{array}$ \\
\hline Prenatal $^{\mathrm{b}}(\%)$ & 12.0 & 10.8 & 11.4 \\
\hline Teen parent $(\%)$ & 10.3 & 13.7 & 12.0 \\
\hline Two-parent household (\%) & 39.3 & 45.0 & 42.2 \\
\hline Currently on $\mathrm{TANF}^{\mathrm{c}}(\%)$ & 29.3 & 29.4 & 29.4 \\
\hline Ever on $\mathrm{TANF}^{\mathrm{c}}(\%)$ & 47.5 & 45.2 & 46.3 \\
\hline \multicolumn{4}{|l|}{$\underline{\text { Child }}^{d}$} \\
\hline $\begin{array}{c}\text { Gender }(\%) \\
\text { Female } \\
\text { Male }\end{array}$ & $\begin{array}{l}46.8 \\
53.2\end{array}$ & $\begin{array}{l}44.8 \\
55.2\end{array}$ & $\begin{array}{l}45.7 \\
54.3\end{array}$ \\
\hline Average age (in months) & 18.0 & 16.2 & $17.1 *$ \\
\hline Sample size & 242 & 249.0 & 491 \\
\hline
\end{tabular}




\section{Appendix Table A.1 (continued)}

SOURCE: MDRC calculations from Early Head Start (EHS) Program Information Forms (PIFs).

NOTES: In order to assess differences in characteristics across research groups, chi-square tests were used for categorical variables, and t-tests were used for continuous variables.

Statistical significance levels are indicated as follows: $* * *=1$ percent; $* *=5$ percent; $*=10$ percent.

The significance level indicates the probability that one would be making an error in concluding that there is a difference between research groups for the variable in question.

a"Other" race/ethnicity was self-identified by the parent and may include biracial or multiracial individuals or a race/ethnicity category other than white, black, American Indian, or Asian/Pacific Islander.

bPrenatal status indicates whether the mother was currently pregnant at random assignment.

${ }^{c}$ Current TANF receipt indicates whether the family was currently receiving TANF at random assignment. "Ever on TANF" indicates whether the family had ever received TANF prior to random assignment.

dPrenatal cases are not included in this computation. 
The Enhanced Services for the Hard-to-Employ Demonstration

Appendix Table A.2

Baseline Characteristics of Child Assessment Respondents, by Research Group

Early Head Start with Enhanced Self-Sufficiency Services

\begin{tabular}{|c|c|c|c|}
\hline Characteristic & Program Group & Control Group & Total \\
\hline \multicolumn{4}{|l|}{ Primary parent } \\
\hline Female $(\%)$ & 90.0 & 90.3 & 90.2 \\
\hline Average age (in years) & 26.7 & 27.0 & 26.9 \\
\hline Marital status (\%) & 0.0 & 0.0 & \\
\hline Single, never married & 49.0 & 52.9 & 51.0 \\
\hline Married & 32.5 & 32.0 & 32.3 \\
\hline Separated, divorced, or widowed & 18.5 & 15.0 & 16.8 \\
\hline Spanish/Hispanic/Latino(a) (\%) & 1.9 & 5.9 & 3.8 \\
\hline Race/ethnicity ${ }^{\mathrm{a}}(\%)$ & 0.0 & 0.0 & \\
\hline White & 89.9 & 84.2 & 87.1 \\
\hline Black or African-American & 7.0 & 11.8 & 9.4 \\
\hline Other & 3.2 & 3.9 & 3.5 \\
\hline Primary parent employed during the past 3 years $(\%)$ & 0.0 & 0.0 & \\
\hline Did not work at all & 12.2 & 14.4 & 13.2 \\
\hline Worked 1 year or less & 26.9 & 34.2 & 30.5 \\
\hline Worked more than 1 year & 60.9 & 51.4 & 56.3 \\
\hline Teen parent $(\%)$ & 5.0 & 11.0 & 7.9 \\
\hline Two-parent household (\%) & 39.4 & 42.6 & 41.0 \\
\hline Currently on $\mathrm{TANF}^{\mathrm{b}}(\%)$ & 31.3 & 31.8 & 31.5 \\
\hline Ever on $\mathrm{TANF}^{\mathrm{b}}(\%)$ & 48.8 & 46.8 & 47.8 \\
\hline \multicolumn{4}{|l|}{$\underline{\text { Child }}^{\mathrm{c}}$} \\
\hline \multicolumn{4}{|l|}{ Gender $(\%)$} \\
\hline Female & 47.1 & 45.3 & 46.2 \\
\hline Male & 52.9 & 54.7 & 53.8 \\
\hline Average age (in months) & 21.5 & 20.6 & 21.0 \\
\hline Sample size & 160.0 & 155.0 & 315 \\
\hline
\end{tabular}




\section{Appendix Table A.2 (continued)}

SOURCES: MDRC calculations from Early Head Start (EHS) Program Information Forms (PIFs).

NOTES: In order to assess differences in characteristics across research groups, chi-square tests were used for categorical variables, and t-tests were used for continuous variables.

Statistical significance levels are indicated as follows: $* * *=1$ percent; $* *=5$ percent; $*=10$ percent. The significance level indicates the probability that one would be making an error in concluding that there is a difference between research groups for the variable in question.

Open brackets [ ] indicate that 20 percent or more of the categories for the variable in question have cell sizes less than 5 .

The child assessment fielded sample includes only children who were 6 months old or older at random assignment.

a"Other" race/ethnicity was self-identified by the parent and may include biracial or multiracial individuals or a race/ethnicity category other than white, black, American Indian, or Asian/Pacific Islander.

${ }^{b}$ Current TANF receipt indicates whether the family was currently receiving TANF at random assignment. "Ever on TANF" indicates whether the family had ever received TANF prior to random assignment.

cPrenatal cases are not included in this computation.

\section{Comparison of Respondents and Nonrespondents Within the Fielded Samples for the Parent Survey and the Direct Child Assessments}

This section examines whether there are any systematic differences between those who responded to the parent survey and child assessments and those who did not.

Appendix Table A.3 shows selected characteristics of parent survey respondents and nonrespondents at baseline, and the two groups did have some differences. Respondents are more likely to be female, more likely to be white, and less likely to be Hispanic. A test of the joint significance of all baseline variables was conducted by running a regression predicting survey response that included all baseline variables in the model. The model shows that the baseline coefficients as a group are significantly different from zero, indicating that there are systematic differences between parent survey respondents and nonrespondents.

Appendix Table A.4 shows selected characteristics of the child assessment respondents and nonrespondents at baseline, and the same types of differences are seen as with the parent survey. This is not surprising, given that child assessments were conducted only after parents had completed the parent survey. Child assessment respondent families are more likely to have a female primary parent and are more likely to be white and less likely to be Hispanic. A test of the joint significance of all baseline variables was conducted by running a regression predicting survey response that included all baseline variables in the model. The model shows that the baseline coefficients as a group are significantly different from zero, indicating that there are systematic differences between child assessment respondents and nonrespondents. 
The Enhanced Services for the Hard-to-Employ Demonstration

Appendix Table A.3

Baseline Characteristics of Parent Survey Respondents and Nonrespondents

Early Head Start with Enhanced Self-Sufficiency Services

\begin{tabular}{|c|c|c|c|c|}
\hline Characteristic & $\begin{array}{r}\text { Respondent } \\
\text { Group }\end{array}$ & $\begin{array}{r}\text { Nonrespondent } \\
\text { Group } \\
\end{array}$ & Total & \\
\hline \multicolumn{5}{|l|}{ Primary parent } \\
\hline Female $(\%)$ & 91.2 & 83.1 & 89.6 & $* * *$ \\
\hline Average age (in years) & 26.0 & 25.3 & 25.8 & \\
\hline $\begin{array}{l}\text { Marital status }(\%) \\
\text { Single, never married } \\
\text { Married } \\
\text { Separated, divorced, or widowed }\end{array}$ & $\begin{array}{l}53.2 \\
30.6 \\
16.1\end{array}$ & $\begin{array}{l}58.1 \\
21.4 \\
20.5\end{array}$ & $\begin{array}{l}54.2 \\
28.8 \\
17.0\end{array}$ & \\
\hline Spanish/Hispanic/Latino(a) (\%) & 4.3 & 8.5 & 5.1 & $*$ \\
\hline $\begin{array}{l}\text { Race/ethnicity }{ }^{\mathrm{a}}(\%) \\
\text { White } \\
\text { Black or African-American } \\
\text { Other }\end{array}$ & $\begin{array}{r}87.6 \\
8.5 \\
3.9\end{array}$ & $\begin{array}{r}79.5 \\
7.7 \\
12.8\end{array}$ & $\begin{array}{r}86.0 \\
8.3 \\
5.7\end{array}$ & $* * *$ \\
\hline $\begin{array}{l}\text { Primary parent employed during the } \\
\text { Did not work at all } \\
\text { Worked } 1 \text { year or less } \\
\text { Worked more than } 1 \text { year }\end{array}$ & $\begin{array}{l}16.0 \\
32.4 \\
51.6\end{array}$ & $\begin{array}{l}12.0 \\
35.9 \\
52.1\end{array}$ & $\begin{array}{l}15.2 \\
33.1 \\
51.7\end{array}$ & \\
\hline Prenatal $^{\mathrm{b}}(\%)$ & 11.4 & 7.6 & 10.7 & \\
\hline Teen parent $(\%)$ & 12.0 & 11.8 & 12.0 & \\
\hline Two-parent household (\%) & 42.2 & 41.2 & 42.0 & \\
\hline Currently on $\mathrm{TANF}^{\mathrm{c}}(\%)$ & 29.4 & 27.7 & 29.1 & \\
\hline Ever on $\mathrm{TANF}^{\mathrm{c}}(\%)$ & 46.3 & 47.9 & 46.6 & \\
\hline \multicolumn{5}{|l|}{ Child $^{\mathrm{d}}$} \\
\hline $\begin{array}{l}\text { Gender }(\%) \\
\text { Female } \\
\text { Male }\end{array}$ & $\begin{array}{l}45.7 \\
54.3\end{array}$ & $\begin{array}{l}51.9 \\
48.1\end{array}$ & $\begin{array}{l}47.0 \\
53.0\end{array}$ & \\
\hline Average age (in months) & 17.1 & 16.8 & 17.0 & \\
\hline Sample size & 491 & 119 & 610 & \\
\hline
\end{tabular}




\section{Appendix Table A.3 (continued)}

SOURCE: MDRC calculations from Early Head Start (EHS) Program Information Forms (PIFs).

NOTES: In order to assess differences in characteristics across research groups, chi-square tests were used for categorical variables, and t-tests were used for continuous variables.

Statistical significance levels are indicated as follows: $* * *=1$ percent; $* *=5$ percent; $*=10$ percent. The significance level indicates the probability that one would be making an error in concluding that there is a difference between research groups for the variable in question.

a"Other" race/ethnicity was self-identified by the parent and may include biracial or multiracial individuals or a race/ethnicity category other than white, black, American Indian, or Asian/Pacific Islander.

bPrenatal status indicates whether the mother was currently pregnant at random assignment.

${ }^{c}$ Current TANF receipt indicates whether the family was currently receiving TANF at random assignment. "Ever on TANF" indicates whether the family had ever received TANF prior to random assignment.

dPrenatal cases are not included in this computation. 
The Enhanced Services for the Hard-to-Employ Demonstration

Appendix Table A.4

Baseline Characteristics of Child Assessment Respondents and Nonrespondents Early Head Start with Enhanced Self-Sufficiency Services

\begin{tabular}{|c|c|c|c|c|}
\hline Characteristic & $\begin{array}{r}\text { Respondent } \\
\text { Group }\end{array}$ & $\begin{array}{r}\text { Nonrespondent } \\
\text { Group }\end{array}$ & Total & \\
\hline \multicolumn{5}{|l|}{$\underline{\text { Primary parent }}$} \\
\hline Female $(\%)$ & 90.2 & 81.4 & 87.8 & $* *$ \\
\hline Average age (in years) & 26.9 & 26.3 & 26.7 & \\
\hline $\begin{array}{l}\text { Marital status }(\%) \\
\text { Single, never married } \\
\text { Married } \\
\text { Separated, divorced, or widowed }\end{array}$ & $\begin{array}{l}51.0 \\
32.3 \\
16.8\end{array}$ & $\begin{array}{l}50.8 \\
24.6 \\
24.6\end{array}$ & $\begin{array}{l}50.9 \\
30.1 \\
18.9\end{array}$ & \\
\hline Spanish/Hispanic/Latino(a) (\%) & 3.8 & 11.0 & 5.8 & $* * *$ \\
\hline $\begin{array}{l}\text { Race/ethnicity }{ }^{\mathrm{a}}(\%) \\
\text { White } \\
\text { Black or African-American } \\
\text { Other }\end{array}$ & $\begin{array}{r}87.1 \\
9.4 \\
3.5\end{array}$ & $\begin{array}{r}76.9 \\
8.5 \\
14.5\end{array}$ & $\begin{array}{r}84.3 \\
9.1 \\
6.6\end{array}$ & $* * *$ \\
\hline $\begin{array}{l}\text { Primary parent employed during the } \\
\text { Did not work at all } \\
\text { Worked } 1 \text { year or less } \\
\text { Worked more than } 1 \text { year }\end{array}$ & $\begin{array}{l}13.2 \\
30.5 \\
56.3\end{array}$ & $\begin{array}{l}15.3 \\
31.4 \\
53.4\end{array}$ & $\begin{array}{l}13.8 \\
30.7 \\
55.5\end{array}$ & \\
\hline Teen parent $(\%)$ & 7.9 & 8.4 & 8.1 & \\
\hline Two-parent household (\%) & 41.0 & 40.3 & 40.8 & \\
\hline Currently on TANF ${ }^{\mathrm{b}}(\%)$ & 31.5 & 27.7 & 30.5 & \\
\hline Ever on $\mathrm{TANF}^{\mathrm{b}}(\%)$ & 47.8 & 48.7 & 48.0 & \\
\hline \multicolumn{5}{|l|}{$\underline{\text { Child }}^{\mathrm{c}}$} \\
\hline $\begin{array}{l}\text { Gender }(\%) \\
\text { Female } \\
\text { Male }\end{array}$ & $\begin{array}{l}46.2 \\
53.8\end{array}$ & $\begin{array}{l}46.2 \\
53.8\end{array}$ & $\begin{array}{l}46.2 \\
53.8\end{array}$ & \\
\hline Average age (in months) & 21.0 & 19.7 & 20.7 & \\
\hline Sample size & 315 & 119 & 434 & \\
\hline
\end{tabular}




\section{Appendix Table A.4 (continued)}

SOURCE: MDRC calculations from Early Head Start (EHS) Program Information Forms (PIFs).

NOTES: In order to assess differences in characteristics across research groups, chi-square tests were used for categorical variables, and t-tests were used for continuous variables.

Statistical significance levels are indicated as follows: $* * *=1$ percent; $* *=5$ percent; $*=10$ percent. The significance level indicates the probability that one would be making an error in concluding that there is a difference between research groups for the variable in question.

The child assessment fielded sample includes only children who were 6 months old or older at random assignment

a“Other" race/ethnicity was self-identified by the parent and may include biracial or multiracial individuals or a race/ethnicity category other than white, black, American Indian, or Asian/Pacific Islander.

${ }^{b}$ Current TANF receipt indicates whether the family was currently receiving TANF at random assignment. "Ever on TANF" indicates whether the family had ever received TANF prior to random assignment.

cPrenatal cases are not included in this computation.

\section{Comparison of Impacts Among the Respondent Samples and the Fielded and Full Research Samples}

This section discusses whether the impacts among the respondents to the parent survey and the direct child assessments can be generalized to the parent survey fielded sample (the full research sample) and the direct child assessment fielded sample. Consistency of impact findings among the samples is considered to be the best result, suggesting that impacts on measures calculated from respondent samples can be generalized to the full research sample. When impacts for the parent survey or direct child assessment respondent samples that are calculated using administrative data differ in size and direction from results for all other samples, the results using the respondent samples may be considered unreliable because of response bias. An unlucky sample draw, or "sampling bias," may be inferred when impacts for the respondent sample resemble results for the fielded sample but findings for both samples vary from findings for the research sample, from which the other samples were drawn.

Appendix Table A.5 shows the adjusted means and impacts on employment and earnings using administrative data for the parent survey fielded sample (the full research sample),

parent survey respondent sample, parent survey nonrespondent sample, child assessment fielded sample, child assessment respondent sample, and child assessment nonrespondent sample. These comparisons are useful in assessing whether the pattern of impacts change when using different samples.

For both the parent survey respondent sample and the child assessment respondent sample, the impacts look similar to the impacts for the fielded and full research samples (Appendix Table A.5). For those two respondent samples as well, there are no impacts on 
The Enhanced Services for the Hard-to-Employ Demonstration

Appendix Table A.5

\section{Six-Quarter Impacts for the Research Sample, Parent Survey Respondent and Nonrespondent Samples, and Child Assessment Respondent and Nonrespondent Samples}

Early Head Start with Enhanced Self-Sufficiency Services

\begin{tabular}{|c|c|c|c|c|c|}
\hline \multirow{2}{*}{$\begin{array}{l}\text { Outcome } \\
\text { Mother's total employment (\%) }\end{array}$} & \multicolumn{2}{|c|}{ Program Control } & \multirow[t]{2}{*}{$\begin{array}{r}\text { Difference } \\
\text { (Impact) }\end{array}$} & \multicolumn{2}{|c|}{$\begin{array}{l}\text { Effect } \\
\text { Size }^{\mathrm{a}} \mathrm{P} \text {-Value }\end{array}$} \\
\hline & & & & & \\
\hline Research sample/parent survey fielded sample & 86.2 & 84.0 & 2.3 & 0.06 & 0.422 \\
\hline Parent survey respondent sample & 84.1 & 84.4 & -0.2 & -0.01 & 0.940 \\
\hline Parent survey nonrespondent sample & 95.1 & 81.4 & $13.7^{* *}$ & 0.43 & 0.020 \\
\hline Child assessment fielded sample & 86.0 & 85.2 & 0.8 & 0.02 & 0.811 \\
\hline Child assessment respondent sample & 82.4 & 85.5 & -3.1 & -0.08 & 0.433 \\
\hline Child assessment nonrespondent sample & 95.0 & 84.6 & $10.4 *$ & 0.35 & 0.067 \\
\hline \multicolumn{6}{|l|}{ Mother's total earnings $(\$)$} \\
\hline Research sample/parent survey fielded sample & 12,024 & 11,705 & 319 & 0.02 & 0.759 \\
\hline Parent survey respondent sample & 11,394 & 11,840 & -446 & -0.03 & 0.698 \\
\hline Parent survey nonrespondent sample & 14,523 & 11,123 & 3,399 & 0.25 & 0.222 \\
\hline Child assessment fielded sample & 11,880 & 12,657 & -777 & -0.05 & 0.559 \\
\hline Child assessment respondent sample & 11,141 & 13,237 & $-2,096$ & -0.14 & 0.179 \\
\hline Child assessment nonrespondent sample & 13,616 & 11,117 & 2,500 & 0.18 & 0.351 \\
\hline \multicolumn{6}{|l|}{ Sample size } \\
\hline Research sample/parent survey fielded sample $($ total $=597)$ & 300 & 297 & & & \\
\hline Parent survey respondent sample $($ total $=483)$ & 240 & 243 & & & \\
\hline Parent survey nonrespondent sample $($ total $=114)$ & 60 & 54 & & & \\
\hline Child assessment fielded sample (total = 425) & 223 & 202 & & & \\
\hline Child assessment respondent sample (total $=311)$ & 160 & 151 & & & \\
\hline Child assessment nonrespondent sample $($ total $=114)$ & 63 & 51 & & & \\
\hline
\end{tabular}

SOURCE: MDRC calculations from the National Directory of New Hires database.

NOTES: Statistical significance levels are indicated as follows: $* * *=1$ percent; $* *=5$ percent; and $*=10$ percent. The significance level indicates the probability that one would be making an error in concluding that there is a difference between research groups for the variable in question.

Dollar values include zeroes for sample members who were not employed, unless otherwise noted.

The sample used in this analysis includes females from two-parent cases (41.3 percent), females from one-parent cases (57.1 percent), and males from one-parent cases (1.5 percent). Due to missing baseline information, employment data are not available for 13 sample members,

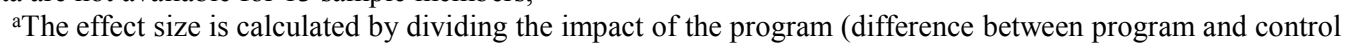
groups) by the observed variation for that outcome within the control group (the control group standard deviation). 
employment or earnings for the six-quarter follow-up period. This suggests that the respondent samples are not substantially different from the full research sample.

Appendix Table A.5 also shows, however, that the pattern of impacts for both the parent survey nonrespondent sample and the child assessment nonrespondent sample differs from the pattern for respondent samples for each of these data collection activities. For these nonrespondent samples, there are significant impacts of between 10 and 14 percentage points on employment over the follow-up period. This suggests that the nonrespondents - and, therefore, the respondents - to the parent survey and the direct child assessments may not be representative of the fielded or full research samples. If this is the case, impact results using outcomes from the parent survey or the direct child assessments may be affected by nonresponse bias. Given this possibility, the next section conducts a sensitivity test to determine whether the impact results for the respondent samples can be generalized to the full research sample.

\section{Sensitivity Test: Weighting for Nonresponse Bias}

Given that the employment impacts - calculated using administrative records - for the nonrespondents to the parent survey and the direct child assessments are dissimilar to the impacts for the fielded or full research and respondent samples, and some evidence suggests that there are differences in baseline characteristics between the respondent and nonrespondent samples, the sensitivity of the impact results using the data drawn from the parent survey and the direct child assessments were assessed by reweighting the respondent samples to better match the full research sample. In this analysis, separately for the parent survey and for the child assessment samples, the probability of response for the full research sample was regressed on a range of baseline characteristics, including site, child's age, parent's age, parent's gender, race/ethnicity, employment history, number of parents in the household, and receipt of Temporary Assistance for Needy Families (TANF). Nonresponse weights were constructed as the inverse of the predicted probability of response.

Appendix Table A.6 shows weighted impact estimates for selected outcomes for the respondent samples, compared with the unweighted estimates presented in the main body of the report. Appendix Table A.7 shows the same comparison of impacts for respondent subgroups defined by the child's age. Overall, for the full sample and by subgroup, the impact estimates do not appear to be highly sensitive to weighting. For example, compared with the unweighted results, the weighted results show similar impacts on child care use, employment, parenting, and child outcomes in both the respondent sample and the subgroup impact analysis. Given the similarly of results across the wide range of outcomes presented in this report, weighting the data does not alter the general conclusions about the impacts of Enhanced EHS. Therefore, the impact results presented in this report do not appear to be biased by nonresponse to the parent

survey or direct child assessments and can be, with some caution, generalized to the full research sample. 
The Enhanced Services for the Hard-to-Employ Demonstration

Appendix Table A.6

Impacts on Selected Outcomes for the Full Research Sample

18 Months After Random Assignment, Unweighted and Weighted for Nonresponse

Early Head Start with Enhanced Self-Sufficiency Services

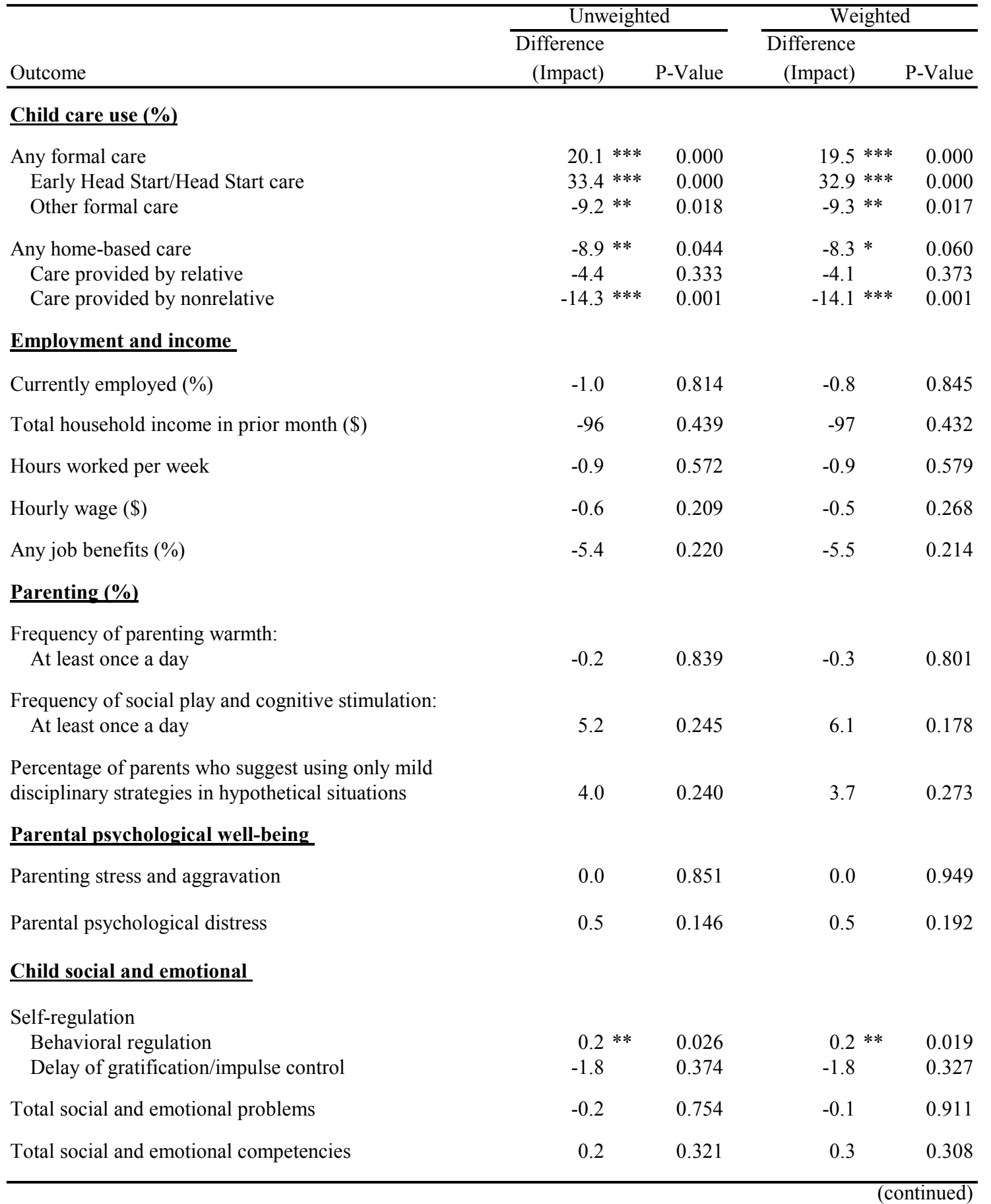




\section{Appendix Table A.6 (continued)}

SOURCES: MDRC calculations based on responses to the 18-month survey and direct child assessments of children's self-regulation outcomes.

NOTES: Statistical significance levels are indicated as follows: $* * *=1$ percent; $* *=5$ percent; $*=10$ percent. The significance level indicates the probability that one would incorrectly conclude that a difference exists between research groups for the corresponding variable.

Results in this table are regression-adjusted using ordinary least squares, controlling for pre-random assignment characteristics.

Outcomes in this table are defined in Boxes 6.1 and 6.2. 


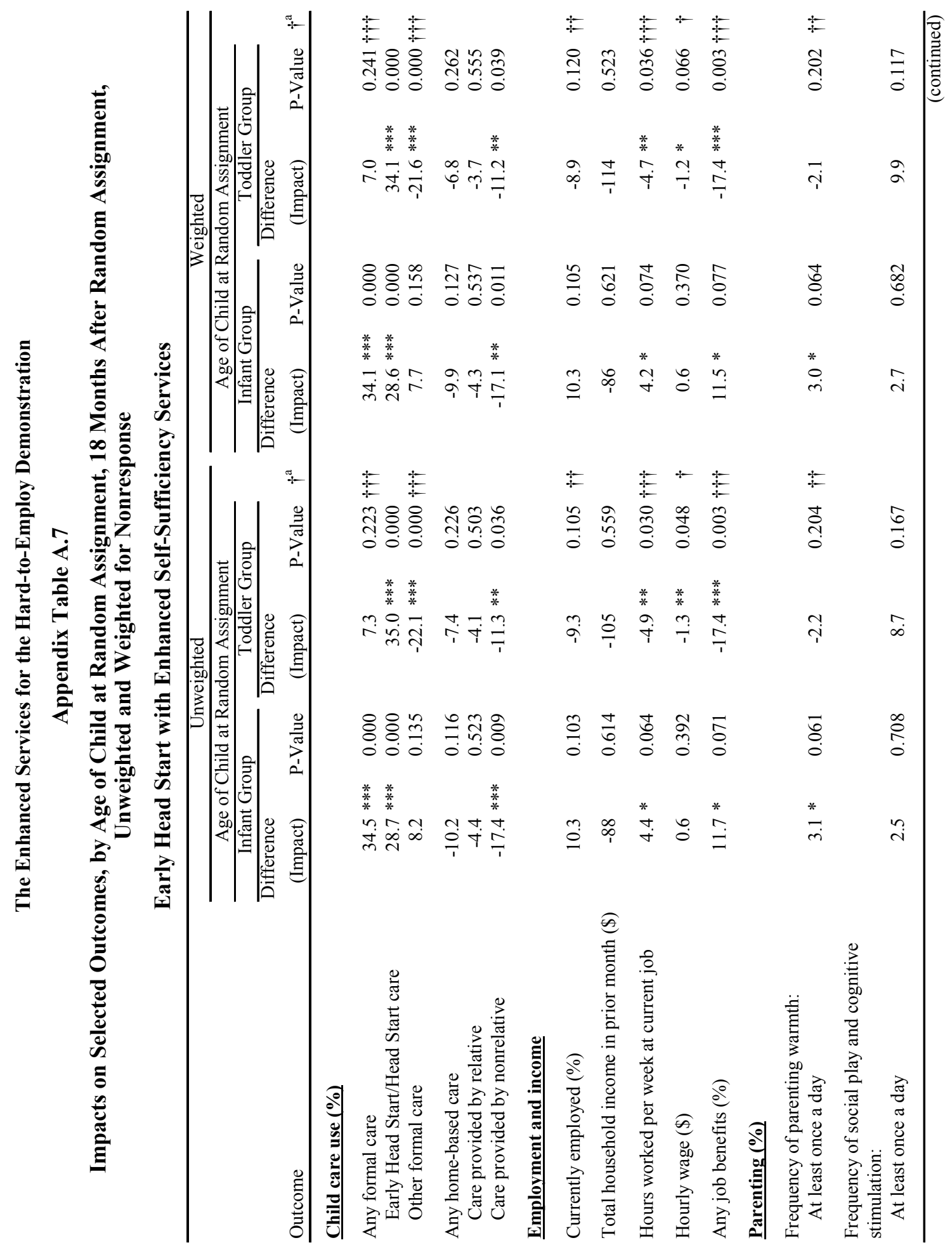




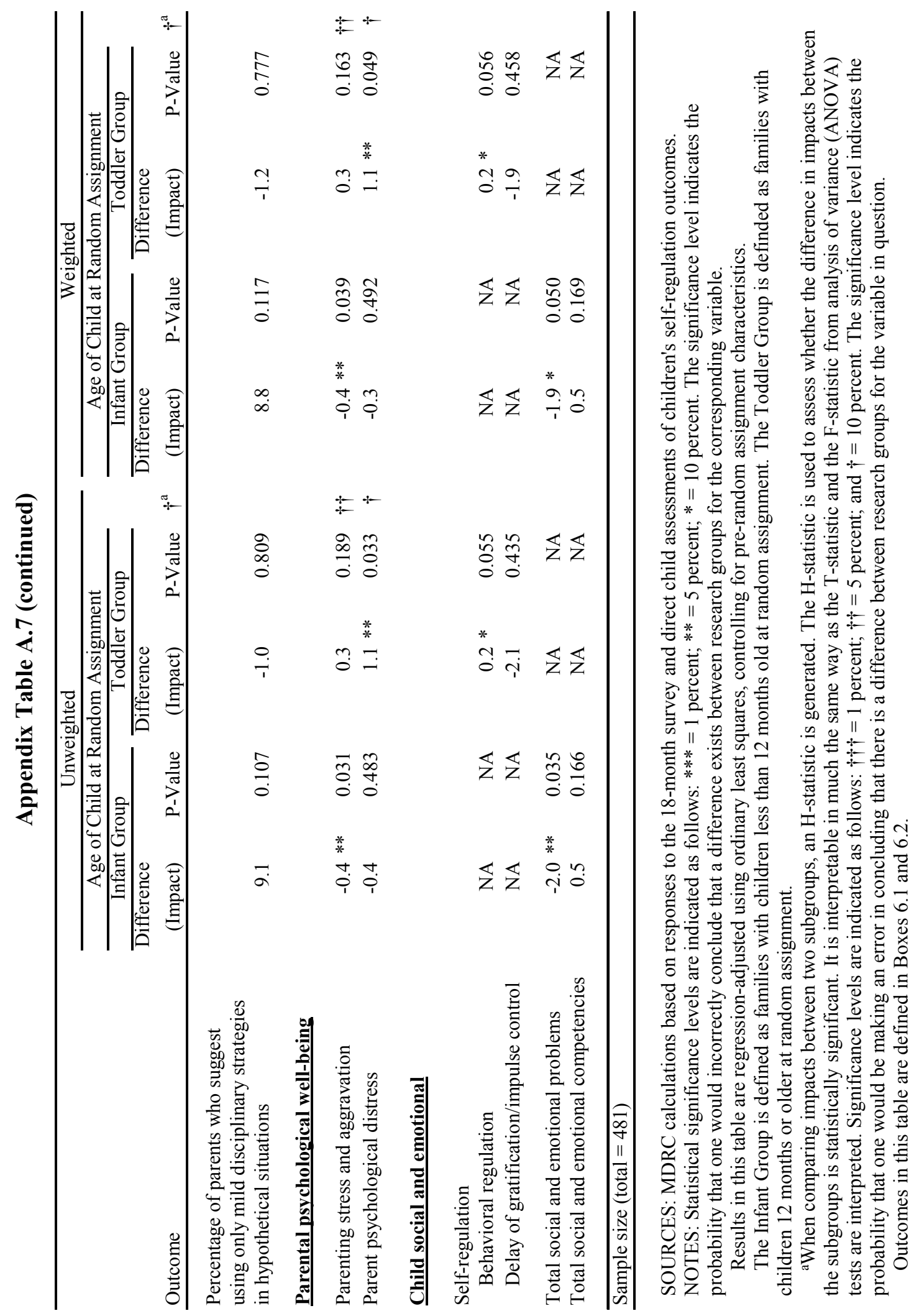


Appendix B

Characteristics of Sample Members at Baseline, by Child's Age 

The Enhanced Services for the Hard-to-Employ Demonstration

Appendix Table B.1

Characteristics of Sample Members at Baseline, by Age of Child at Random Assignment

\section{Early Head Start with Enhanced Self-Sufficiency Services}

\begin{tabular}{|c|c|c|c|c|}
\hline Characteristic & Infant & Toddler & Total & \\
\hline \multicolumn{5}{|l|}{ Primary parent } \\
\hline Female $(\%)$ & 92.3 & 87.3 & 89.6 & $* *$ \\
\hline Average age (in years) & 24.6 & 26.9 & 25.8 & $* * *$ \\
\hline $\begin{array}{l}\text { Marital status }(\%) \\
\text { Single, never married } \\
\text { Married } \\
\text { Separated, divorced, or widowed }\end{array}$ & $\begin{array}{l}59.4 \\
24.9 \\
15.7\end{array}$ & $\begin{array}{l}49.5 \\
32.3 \\
18.2\end{array}$ & $\begin{array}{l}54.2 \\
28.8 \\
17.0\end{array}$ & $* *$ \\
\hline Spanish/Hispanic/Latino(a) (\%) & 3.9 & 6.3 & 5.1 & \\
\hline $\begin{array}{l}\text { Race/ethnicity }{ }^{\mathrm{a}}(\%) \\
\text { White } \\
\text { Black or African-American } \\
\text { Other }\end{array}$ & $\begin{array}{r}87.3 \\
8.1 \\
4.6\end{array}$ & $\begin{array}{r}84.8 \\
8.5 \\
6.6\end{array}$ & $\begin{array}{r}86.0 \\
8.3 \\
5.7\end{array}$ & \\
\hline $\begin{array}{l}\text { Highest education }^{\mathrm{b}}(\%) \\
\text { GED certificate/high school diploma } \\
\text { Postsecondary degree } \\
\text { None of the above }\end{array}$ & $\begin{array}{r}68.0 \\
6.1 \\
26.0\end{array}$ & $\begin{array}{r}66.5 \\
8.8 \\
24.6\end{array}$ & $\begin{array}{r}67.2 \\
7.5 \\
25.3\end{array}$ & \\
\hline $\begin{array}{l}\text { Primary parent employed during the past } 3 \text { years }(\%) \\
\text { Did not work at all } \\
\text { Worked } 1 \text { year or less } \\
\text { Worked more than } 1 \text { year }\end{array}$ & $\begin{array}{l}16.3 \\
36.9 \\
46.8\end{array}$ & $\begin{array}{l}14.2 \\
29.7 \\
56.1\end{array}$ & $\begin{array}{l}15.2 \\
33.1 \\
51.7\end{array}$ & {$[*]$} \\
\hline Prenatal $^{\mathrm{c}}(\%)$ & 22.6 & 0.0 & 10.7 & \\
\hline Teen parent $(\%)$ & 18.5 & 6.2 & 12.0 & \\
\hline Two-parent household (\%) & 44.3 & 39.9 & 42.0 & \\
\hline Currently on $\mathrm{TANF}^{\mathrm{d}}(\%)$ & 26.5 & 31.4 & 29.1 & \\
\hline Ever on $\mathrm{TANF}^{\mathrm{d}}(\%)$ & 44.9 & 48.1 & 46.6 & \\
\hline \multicolumn{5}{|l|}{$\underline{\text { Child }}^{\mathrm{e}}$} \\
\hline $\begin{array}{l}\text { Gender }(\%) \\
\text { Female } \\
\text { Male }\end{array}$ & $\begin{array}{l}48.6 \\
51.4\end{array}$ & $\begin{array}{l}45.9 \\
54.1\end{array}$ & $\begin{array}{l}47.0 \\
53.0\end{array}$ & \\
\hline Average age (in months) & 5.7 & 24.8 & 17.0 & $* * *$ \\
\hline Sample size & 323 & 287 & 610 & \\
\hline
\end{tabular}




\section{Appendix Table B.1 (continued)}

SOURCE: MDRC calculations from Early Head Start (EHS) Program Information Forms (PIFs).

NOTES: In order to assess differences in characteristics across research groups, chi-square tests were used for categorical variables, and t-tests were used for continuous variables.

Statistical significance levels are indicated as follows: $* * *=1$ percent; $* *=5$ percent; $*=10$ percent. The significance level indicates the probability that one would be making an error in concluding that there is a difference between research groups for the variable in question.

Open brackets [ ] indicate that 20 percent or more of the categories for the variable in question have cell sizes less than 5 .

The Infant Group is defined as families with children less than 12 months old at random assignment. The Toddler Group is definded as families with children 12 months or older at random assignment.

a"Other" race/ethnicity was self-identified by the parent and may include biracial or multiracial individuals or a race/ethnicity category other than white, black, American Indian, or Asian/Pacific Islander.

${ }^{\mathrm{b} C a l c u l a t i o n s}$ of highest education at baseline are based on responses to the 18-month survey and are available only for the survey sample. At the 18-month follow-up, respondents were asked about their highest credential - a GED certificate, high school diploma, associate's degree, bachelor's degree, or graduate degree - and, if any, when they received it. The highest credential at baseline includes only those that were obtained prior to random assignment. "Postsecondary degree" is defined as an associate's, bachelor's, or other graduate degree.

'Prenatal status indicates whether the mother was currently pregnant at random assignment.

${ }^{\mathrm{d} C}$ Current TANF receipt indicates whether the family was currently receiving TANF at random assignment. "Ever on TANF" indicates whether the family had ever received TANF prior to random assignment.

ePrenatal cases are not included in this computation. 
Appendix C

Cost Analysis of the Programs in the Study Sites 

Appendix C estimates the costs of operating Enhanced Early Head Start (EHS) in the two program sites in Kansas and Missouri that added self-sufficiency enhancements to their core services by offering parents assistance with employment and education. The analysis identifies the costs of the enhancements separately from the costs of the core services. The costs are presented for the 18-month period following sample members' random assignment into either the Enhanced EHS program group, which could receive home-based or center-based services, or the control group, which could not access services from these two programs but could seek alternative services that were available in the community.

The analysis also estimates the costs of services that sample members received outside the EHS/HS programs; this is required in order to estimate the average net cost of providing Enhanced EHS to program group members. The net cost is the difference between the average cost per program group member and the average cost per control group member of the relevant services that were used during the 18-month follow-up period. The overall net costs provide another perspective for interpreting the program's impacts on key outcomes, presented in Chapters 3 through 6.

The appendix begins with an overview of the major components of the cost analysis. It then discusses in detail the cost estimates for the program group and the control group. Finally, it presents cost estimates for program and control group members analyzed by the child's age at random assignment, comparing the costs of providing services to families whose focal child is an infant (younger than 12 months) and to families whose focal child is a toddler (12 months or older). ${ }^{1}$

\section{The Analytic Approach}

\section{Cost Components}

Appendix Figure C.1 illustrates the cost components for the program and control groups in the EHS/HS programs operated by the Southeast Kansas Community Action Program (SEKCAP) and Youth in Need. The gross costs for each program group member (Box D) consist of three main categories: expenditures on family development and child-focused services, which include EHS/HS and other services available in the community that focus on families' and

\footnotetext{
${ }^{1}$ As is true with all applications to EHS, families identify a particular child who is up to age 3 or during the prenatal period and who will be enrolled in the program. In this study's 18-month parent survey and direct child assessments, this child is identified as the focal child who is the target of program services and is the focus of all questions related to child care and early educational experiences, parenting practices, and child development and well-being.
} 
The Enhanced Services for the Hard-to-Employ Demonstration

\section{Appendix Figure C.1}

\section{Simplified Diagram of Major Cost Components}

Early Head Start with Enhanced Self-Sufficiency Services

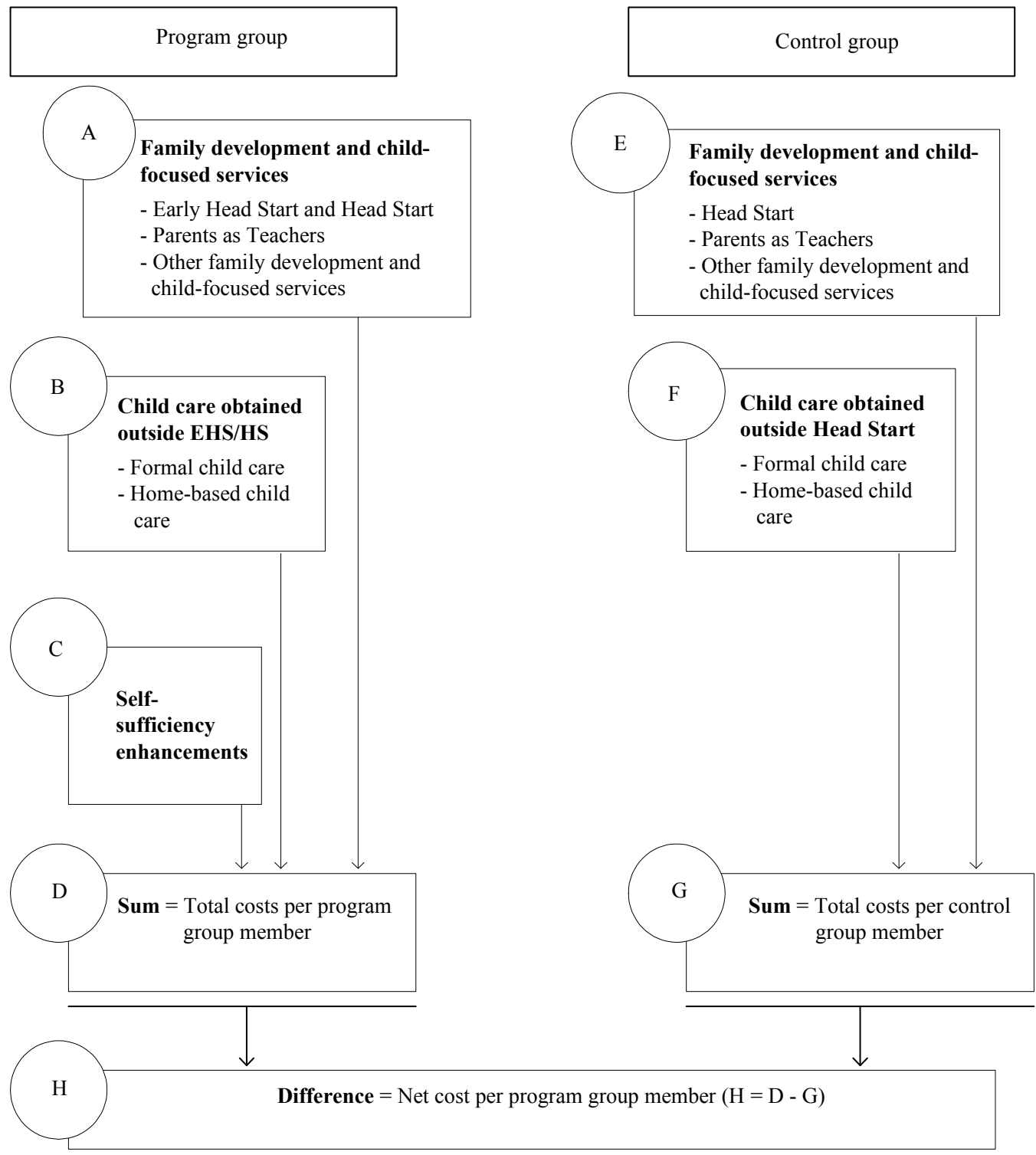


children's development (Box A); expenditures on child care received outside the programs (Box B); and the self-sufficiency enhancements provided to assist program group members with their education and employment needs (Box C).

The gross cost for each control group member (Box G) equals the costs of the family development and child-focused services (Box E) and the costs of non-HS child care (Box F). As discussed in Chapter 3, the control group members were not eligible for EHS during the first three years after random assignment and, thus, were also not eligible for the enhanced selfsufficiency services provided to EHS participants. They were, however, eligible for other family development and child-focused services available in the community.

The net cost is shown in Box $\mathrm{H}$ and is the difference between the average cost per program group member and the average cost per control group member. Net cost estimates were calculated separately for the Youth in Need and the SEK-CAP programs.

\section{Methodology}

\section{Early Head Start and Head Start}

To estimate the cost spent on EHS and HS services, the research team collected expenditure and participation data from SEK-CAP and Youth in Need for a steady-state period (a oneor two-year period when the program group members were receiving EHS services). They used these data to estimate the unit costs for each site, which are the costs of serving one person in the EHS and HS program for one month. To estimate unit costs, expenditures during the steadystate period were divided by the number of children who were enrolled in EHS/HS each month, summed across the steady-state period. To determine the average cost incurred per program or control group member during the 18-month follow-up period, the unit cost for each site was multiplied by the average number of months that program group and control group members were enrolled in the program, as reported in the survey.

Expenditure and survey data did not distinguish between EHS and HS expenditures and participation. Thus, separate cost estimates could not be estimated for each program.

\section{Parents as Teachers and Other Family and Child Development Services}

Separate unit costs were calculated for the Parents as Teachers (PAT) program because the survey reported relatively high levels of participation in it among sample members. To estimate the cost of one month of PAT services, the research team reviewed studies on PAT costs in the past, which ranged from $\$ 131$ to $\$ 233$ monthly (inflation-adjusted to 2008). The 
present analysis used an estimate of $\$ 137$, based on a cost reported by the Parents as Teachers National Center. ${ }^{2}$

The survey asked about participation in other programs that provided assistance on parenting or child development. Those respondents who said that they had received such services were asked where they had received them. The programs in this category that were reported by respondents include a mix of early intervention programs for special needs children, services offered by the welfare agency or career center, programs for children in foster care, and services offered by other community-based and faith-based organizations that offered support to families. The most common assistance of this type that respondents received from other programs was early intervention services. Therefore, the analysis used a cost estimate of a program in Missouri called "First Steps"; its estimate of \$383 per month for early intervention services fell within the range of other studies reviewed. ${ }^{3}$ A similar estimate could not be obtained for the Birth-to-Three program in Kansas, and so the Missouri estimate was used for the monthly cost of early intervention services in both sites.

\section{Child Care}

To estimate the costs of child care services provided by agencies or programs other than the EHS/HS programs in this study, state-level cost estimates for child care, by age of child, were collected from the National Association of Child Care Resource \& Referral Agencies (NACCRRA). These costs were reported separately for center-based and home-based care.

\section{The EHS Cost per Program Group Member}

This section examines expenditures for the program group's family development and child-focused services, non-child care services, and self-sufficiency enhancements (described in Chapter 2).

\section{Family Development and Child-Focused Services}

SEK-CAP and Youth in Need spent similar amounts to provide EHS/HS services to sample members: $\$ 730$ and $\$ 751$ per person, respectively. SEK-CAP program group members

\footnotetext{
${ }^{2}$ The PAT costs are reported in Aos et al. (2004), which estimated the cost to be $\$ 3,500$ over the full 2.5year program period (estimated to be $\$ 117$ per month, inflation-adjusted to $\$ 137$ ).

${ }^{3}$ Cost estimates from other studies ranged from about $\$ 160$ to $\$ 1,362$. The higher estimate is for the Infant Health and Development Program, an eight-site clinical trial implemented in 1997 that provided early intervention services for premature, low-birth-weight infants. Its higher cost reflects the intensity of the intervention and the greater needs of the families it targeted. (For more information, see Aos et al., 2004.) The lower estimate is for the Birth-to-Three program in Wisconsin.
} 
spent 8.4 months in EHS/HS, on average, and Youth in Need program group members spent an average of 8.8 months in the programs. This resulted in average costs of $\$ 6,100$ and $\$ 6,624$ per program group member, respectively, for EHS/HS services provided by SEK-CAP and Youth in Need. This is less than the national cost estimate of \$7,209 per child for Head Start services. ${ }^{4}$

Some program group members also reported receiving services from the PAT program, which operated in both the areas served by SEK-CAP and Youth in Need. With a cost estimated to be about $\$ 137$ per person per month, PAT was less expensive to operate than EHS/HS. And though it provided services similar to the EHS home visiting model, it was less comprehensive, and its staff met less frequently with parents than EHS home visitors did. Program group members, in SEK-CAP received an average of 1.9 months of PAT services, while those in Youth in Need received an average of 2.7 months of services; the resulting costs of PAT per program group member were $\$ 265$ and $\$ 364$, respectively,

In addition, SEK-CAP program group members reported receiving 1 month of other child and family development services, and Youth in Need program group members reported receiving 2 months of such services. The cost analysis estimated this to be about $\$ 399$ and $\$ 775$ per person, respectively.

\section{Child Care Services}

The EHS/HS costs presented above include the costs of EHS and HS child care to the Head Start programs. They do not include the costs of non-EHS child care that EHS participants received in the community. As mentioned above, to estimate the non-EHS child care costs, the analysis used state-level cost estimates for child care, by age of child and type of care, reported by NACCRRA.

The estimated monthly costs of child care services are included in Appendix Table C.1. Monthly costs of care are higher for infants than for older children; a weighted average was calculated based on the proportion of program and control group children in each category. Also, center-based care is more expensive than home-based care. Finally, during this period, child care was more expensive, on average, in Kansas than in Missouri.

SEK-CAP program group members received 1.8 months of formal non-EHS centerbased child care and 2.5 months of home-based child care. This resulted in a total cost for nonEHS care of \$2,192 per program group member. SEK-CAP could have reimbursed parents for some of this child care if the family was enrolled in EHS/HS when receiving it. Alternatively,

\footnotetext{
${ }^{4}$ For more information, see U.S. Department of Health and Human Services, Administration for Children and Families (2007).
} 


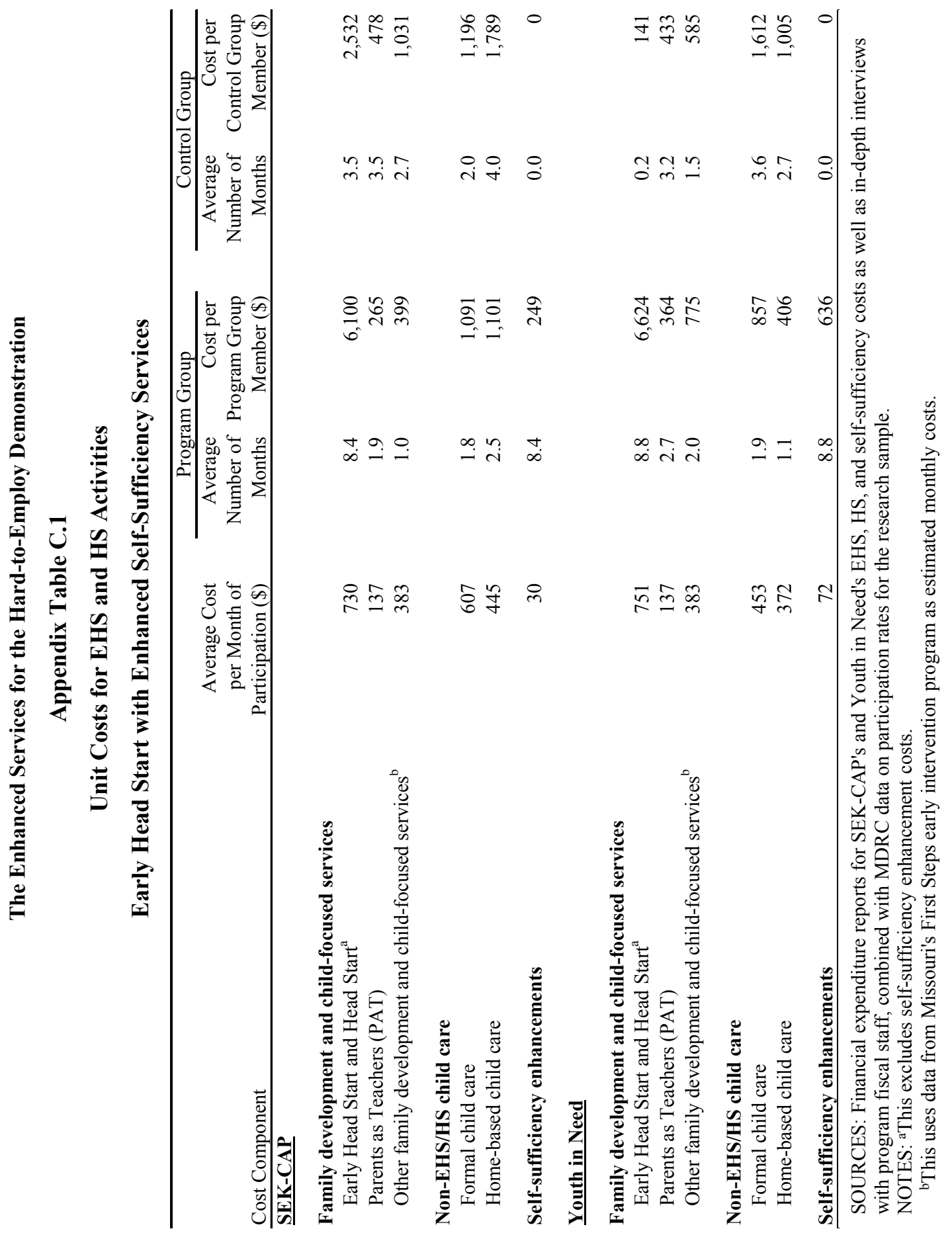


parents might have received a subsidy from the state if they were participating in the TANF program or another state program. Finally, some families may have paid for the care themselves.

Youth in Need program group members received 1.9 months of formal center-based child care and 1.1 months of home-based child care, resulting in an overall cost of $\$ 1,263$ per program group member. As with SEK-CAP, the child care costs might have been paid by the Youth in Need program, by the state welfare agency, or by the families themselves.

\section{Self-Sufficiency Enhancements}

As discussed in Chapter 1, the sites received funding to enhance the self-sufficiency component of their programs. This funding was used to hire one staff person in each site. In addition, Youth in Need contributed additional funding to hire another staff person to focus on self-sufficiency during the study period. The sites also used the funding for expenses related to purchasing materials, paying for travel-related expenses for the self-sufficiency staff, and paying for overhead expenses. Estimates were also made for time spent by home visitors to assist families with their self-sufficiency needs, and the cost of their time is included in these estimates.

The monthly cost of providing the self-sufficiency enhancements was $\$ 30$ per person in SEK-CAP and $\$ 72$ per person in Youth in Need; the higher cost for the latter reflects the additional staff person who focused on self-sufficiency at that site. The SEK-CAP selfsufficiency specialist also spent some of her time assisting with recruitment activities, and the analysis excludes the cost of that time. Inasmuch as the program group members averaged about 8.4 months in SEK-CAP and about 8.8 months in Youth in Need over the 18-month follow-up period, the per person costs of the enhancements were $\$ 249$ and $\$ 636$, respectively.

\section{The Gross Cost per Program Group Member}

The gross cost per program group member (Box D in Appendix Figure C.1) was determined by adding the family development and child-focused services (Box A), the non-EHS/HS child care (Box B), and the self-sufficiency enhancements (Box C). This estimate is important because it represents the costs of all services, including those that were provided apart from the EHS and HS programs that have the potential to improve the parents' and children's outcomes. This total investment must be compared with the total gross cost per control group in order to determine the net investment per program group member.

The estimated gross cost per program group member was $\$ 9,205$ in SEK-CAP and $\$ 9,661$ in Youth in Need. While the overall cost estimates were similar across the two sites, a higher share of the total gross costs in Youth in Need were for the self-sufficiency enhancements (7 percent in Youth in Need, compared with 3 percent in SEK-CAP), while a higher 
share of the SEK-CAP gross costs were for non-EHS/HS child care services (24 percent in SEK-CAP, compared with 13 percent in Youth in Need).

\section{The EHS Cost per Control Group Member}

The same unit cost estimates as those reported above were used to estimate the cost of services received by the control group. The difference in costs across the two groups is driven by the differences in their levels of participation. In addition, because the control group members were not eligible for the program's self-sufficiency enhancements, no costs were assigned for these services.

\section{Family Development and Child-Focused Services}

Control group members were not allowed to enroll in Early Head Start at SEK-CAP or Youth in Need for the three-year period following their random assignment. Youth in Need extended the embargo to include the Head Start program as well, while SEK-CAP control group families could enroll their children in Head Start after their children turned age 3. As a result, SEK-CAP control group members reported higher levels of participation in EHS/HS on the survey than were reported by Youth in Need control group members. On average, control group members in SEK-CAP received about 3.5 months of Head Start, and those in Youth in Need received about 0.2 month. Families may have received these services either from SEK-CAP and Youth in Need or, if a family moved, from programs in another county. The embargo did not apply to programs operating outside the research counties, which might explain the participation, albeit low participation, reported by Youth in Need control group members.

As a result of the higher levels of participation, the control group costs for EHS/HS were significantly higher in SEK-CAP — an average of \$2,532, compared with \$141 in Youth in Need.

Control group members in both sites received just over 3 months of PAT services, on average, which exceeded the program group members' average participation. The cost of PAT services per control group member was $\$ 478$ in SEK-CAP and \$433 in Youth in Need. In addition, control group members received 2.7 months of other family development and childfocused programs in SEK-CAP and 1.5 months in Youth in Need, resulting in costs per control group member of \$1,031 in SEK-CAP and \$585 in Youth in Need.

\section{Child Care Services}

Compared with the program group members, the control group members were more likely to receive non-HS child care services, which is attributed primarily to the embargo on their using EHS child care. They averaged 6.0 months of non-HS child care services in SEK- 
CAP and 6.3 months in Youth in Need, resulting in costs of $\$ 2,985$ and $\$ 2,618$, respectively. While Youth in Need control group members were more likely to be enrolled in the more expensive center-based care than home-based care, the slightly higher overall costs for SEKCAP reflect the higher cost of child care in Kansas, as reported by NACCRRA.

\section{The Gross Cost per Control Group Member}

Appendix Table C. 2 shows that the estimated gross cost per control group member was $\$ 7,049$ in SEK-CAP and \$3,776 in Youth in Need. The SEK-CAP control group reported higher levels of participation in family development and child-focused services, especially in the Head Start program, which increased the costs for SEK-CAP relative to Youth in Need.

\section{The Net Cost per Program Group Member}

The estimated net cost per program group member represents the additional costs of services for the program group compared with the control group. Appendix Table C.2 shows that the net cost per program group member was $\$ 2,179$ in SEK-CAP and $\$ 5,885$ in Youth in Need. The lower net cost per program group member in SEK-CAP was driven by higher participation levels among control group members, which led to higher control group costs.

\section{Subgroups Defined by Age of Child}

The report identifies differences in impacts on key outcomes as measured by the age of the child. This section presents the differences in costs analyzed by site and by age of child. Specifically, it distinguishes between the costs for families with infants at baseline (children younger than 12 months old, including prenatal cases) and the costs for families with toddlers at baseline (children 12 months or older).

The differences in costs for families with infants and for families with toddlers are due to differences in levels of participation. Appendix Table C.3 shows that, in SEK-CAP, the gross costs per program group member were higher for families with toddlers than for the families with infants; the program group families with toddlers spent more time in the non-EHS/HS child care programs. In Youth in Need, the gross costs were equivalent for both subgroups.

Among the control group, the costs for families in SEK-CAP were higher for the families with toddlers. The difference is due, in part, to the higher level of participation in EHS/HS programs by control group families with toddlers. Families were not eligible for EHS but became eligible for HS when the child turned age 3. Some toddlers did that during the 18month follow-up period and were enrolled in HS. As discussed in Chapter 3, control group 
The Enhanced Services for the Hard-to-Employ Demonstration Appendix Table C.2

Estimated Gross and Net Costs per Sample Member Within 18 Months After Random Assignment (in 2008 Dollars)

\section{Early Head Start with Enhanced Self-Sufficiency Services}

\begin{tabular}{|c|c|c|c|}
\hline Site and Component & $\begin{array}{c}\text { Total Gross Cost } \\
\text { per Program } \\
\text { Group Member (\$) }\end{array}$ & $\begin{array}{r}\text { Total Gross Cost } \\
\text { per Control } \\
\text { Group Member }(\$) \\
\end{array}$ & $\begin{array}{r}\text { Net Cost } \\
\text { per Program } \\
\text { Group Member (\$) } \\
\end{array}$ \\
\hline \multicolumn{4}{|l|}{ SEK-CAP } \\
\hline \multicolumn{4}{|c|}{ Family development and child-focused services } \\
\hline Early Head Start and Head Start ${ }^{\mathrm{a}}$ & 6,100 & 2,532 & 3,567 \\
\hline Parents as Teachers (PAT) & 265 & 478 & -213 \\
\hline $\begin{array}{l}\text { Other family development and } \\
\text { child-focused services }{ }^{\mathrm{b}}\end{array}$ & 399 & 1,031 & -632 \\
\hline Subtotal & 6,764 & 4,041 & 2,722 \\
\hline \multicolumn{4}{|l|}{ Non-EHS/HS child Care } \\
\hline Formal child care & 1,091 & 1,196 & -105 \\
\hline Home-based child care & 1,101 & 1,789 & -688 \\
\hline Subtotal & 2,192 & 2,985 & -792 \\
\hline Self-sufficiency enhancements & 249 & 0 & 249 \\
\hline Total & 9,205 & 7,026 & 2,179 \\
\hline \multicolumn{4}{|l|}{ Youth in Need } \\
\hline \multicolumn{4}{|c|}{ Family development and child-focused services } \\
\hline Early Head Start and Head Start ${ }^{\mathrm{a}}$ & 6,624 & 141 & 6,483 \\
\hline Parents as Teachers (PAT) & 364 & 433 & -69 \\
\hline $\begin{array}{l}\text { Other family development and } \\
\text { child-focused services }\end{array}$ & 775 & 585 & 190 \\
\hline Subtotal & 7,762 & 1,159 & 6,604 \\
\hline \multicolumn{4}{|l|}{ Non-EHS/HS child care } \\
\hline Formal child care & 857 & 1,612 & -756 \\
\hline Home-based child care & 406 & 1,005 & -599 \\
\hline Subtotal & 1,263 & 2,618 & $-1,355$ \\
\hline Self-sufficiency enhancements & 636 & 0 & 636 \\
\hline Total & 9,661 & 3,776 & 5,885 \\
\hline
\end{tabular}

SOURCES: Financial expenditure reports for SEK-CAP's and Youth in Need's EHS, HS, and selfsufficiency costs as well as in-depth interviews with program fiscal staff, combined with MDRC data on participation rates for the research sample.

NOTES: ${ }^{\text {This }}$ excludes self-sufficiency enhancement costs.

${ }^{\mathrm{b}}$ This uses data from Missouri's First Steps early intervention program as estimated monthly costs. 


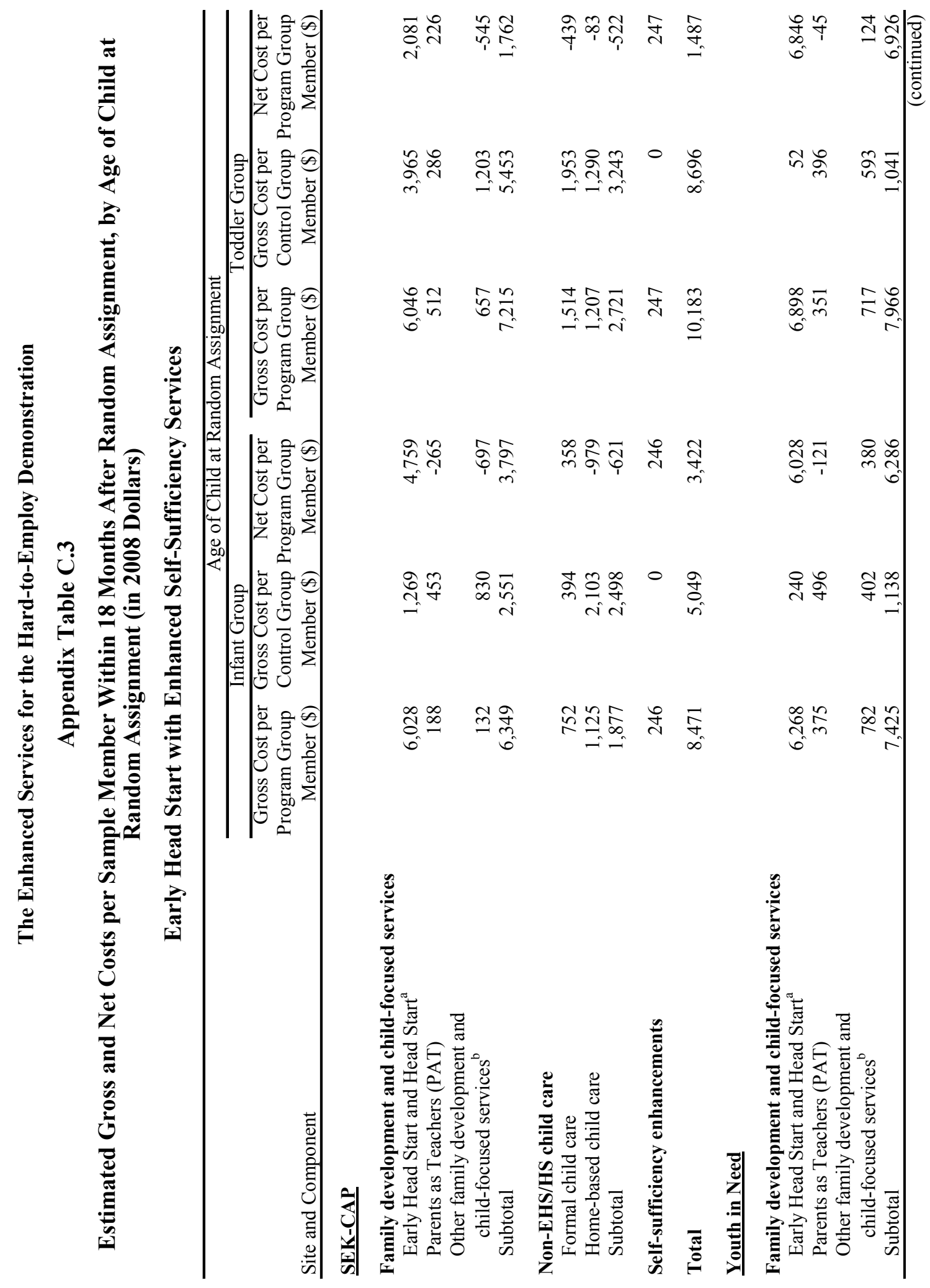




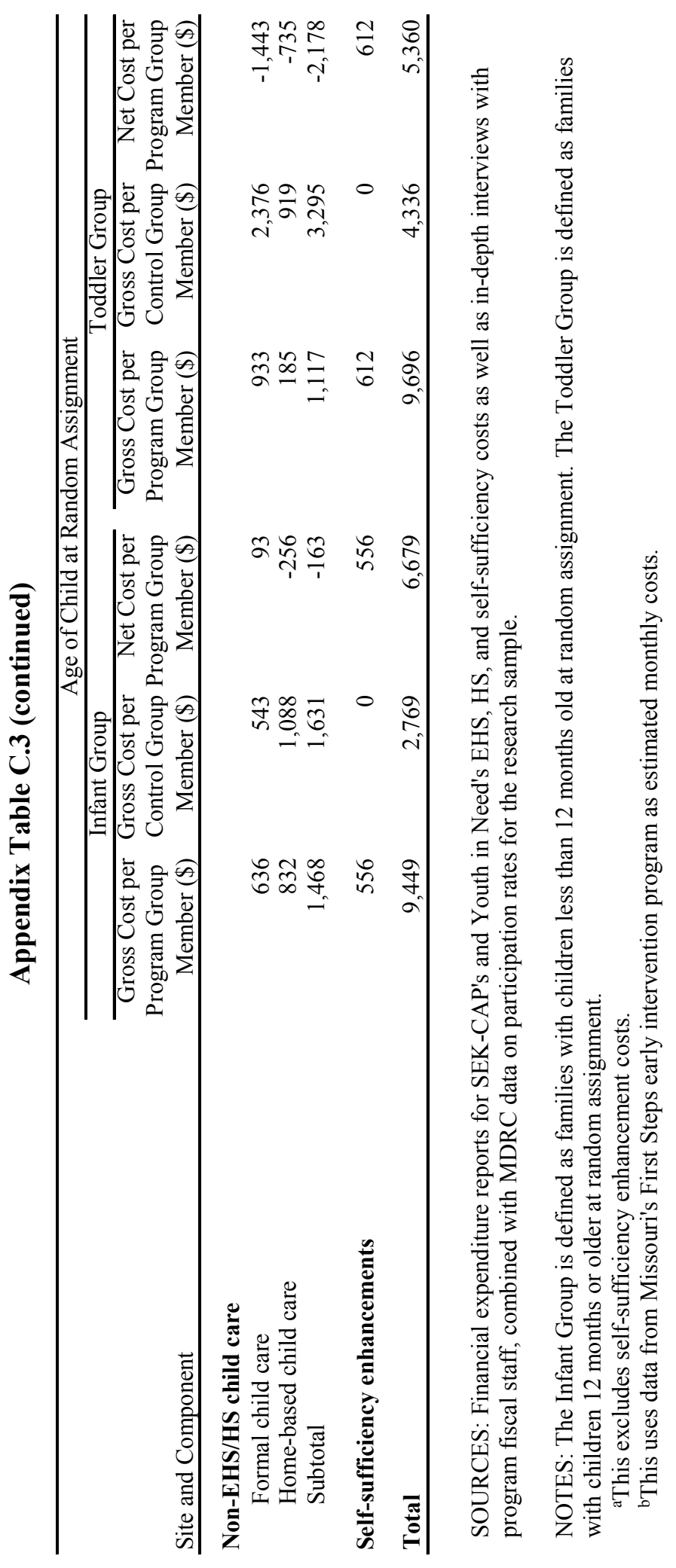


families in Youth in Need could not participate in EHS/HS for three years after random assignment. Thus, the cost differences between infants and toddlers in Youth in Need are not as large as in SEK-CAP. The Youth in Need families with toddlers had a higher cost per family than families with infants because their level of participation in formal non-EHS/HS child care was greater.

Overall, the net cost per program group member was over $\$ 6,000$ for both Youth in Need subgroups. The net cost per program group member was substantially less for both SEKCAP subgroups due to higher levels of participation by the SEK-CAP control group members.

\section{Conclusion}

Early Head Start and Head Start are relatively expensive programs to operate, compared with other early child development programs, reflecting their comprehensive services, as discussed in Chapter 2. The sites in this study employed home visitors, center-based staff, and a cadre of staff who were available to provide expertise and make referrals to address issues relating to health, nutrition, mental health, and disabilities. The home visiting program also provides a more intensive level of services than other programs, such as the PAT program, with home visits taking place weekly rather than monthly. These additional services increased the cost of the program relative to other programs offered in the community.

The control group received services from other organizations in the community, although these services were less comprehensive and less expensive. As a result, the net cost per program group member was relatively high.

The self-sufficiency enhancements to the programs were relatively inexpensive when spread across all participants, averaging about $\$ 50$ per month across the two sites. The intervention did not provide an intensive level of services, which is reflected in the low cost. 

Appendix D

Impacts on Service Receipt 



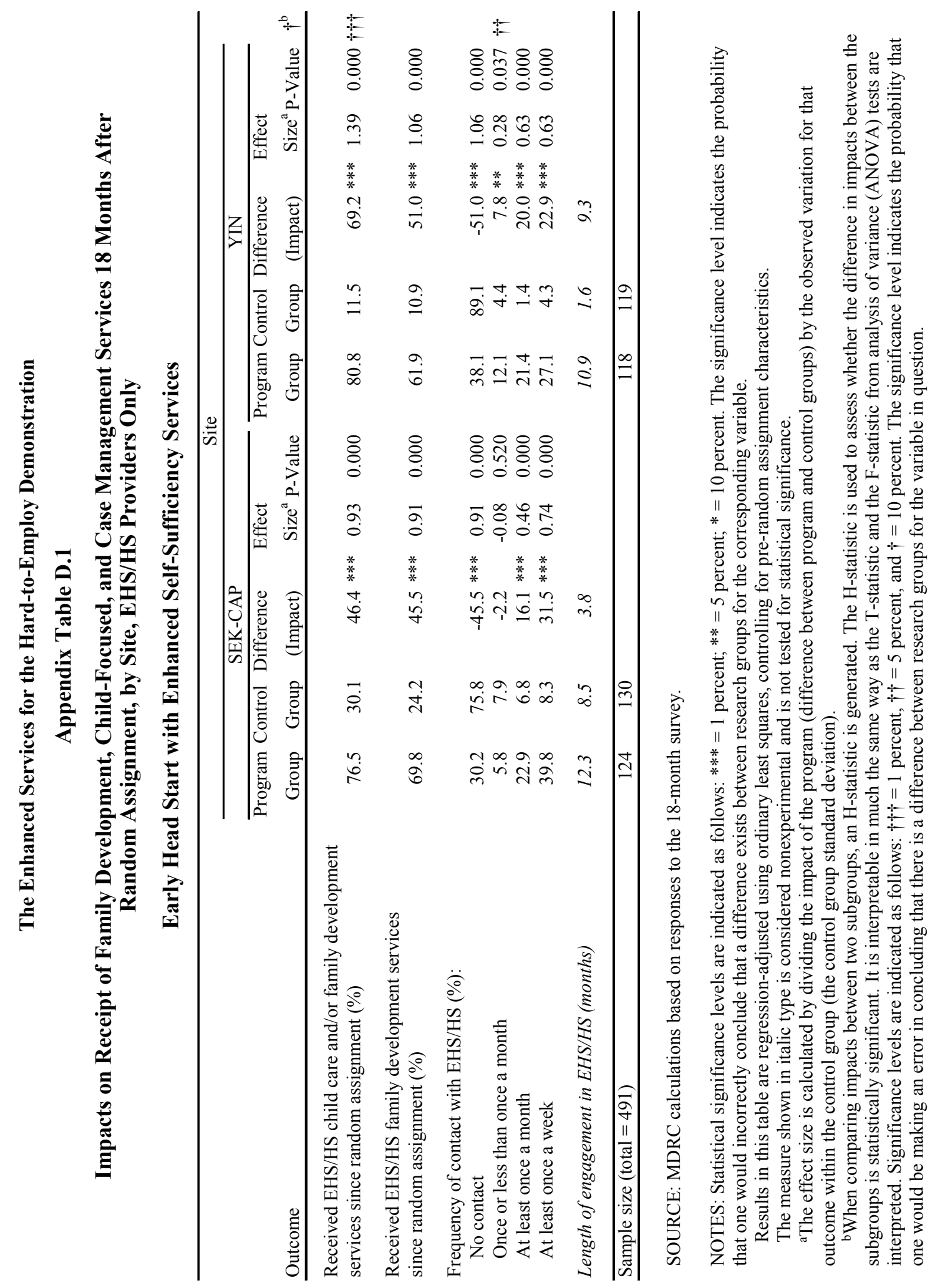




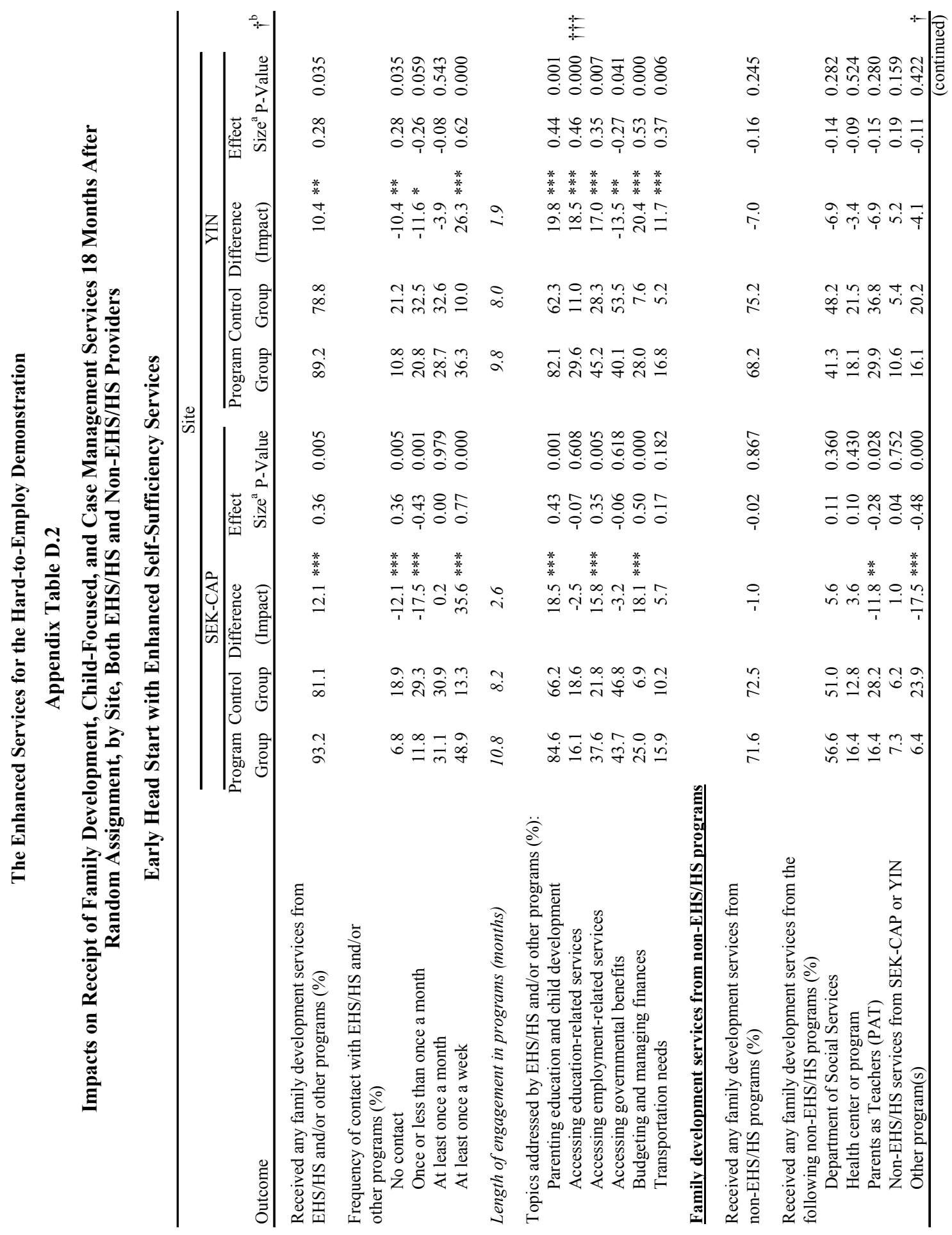




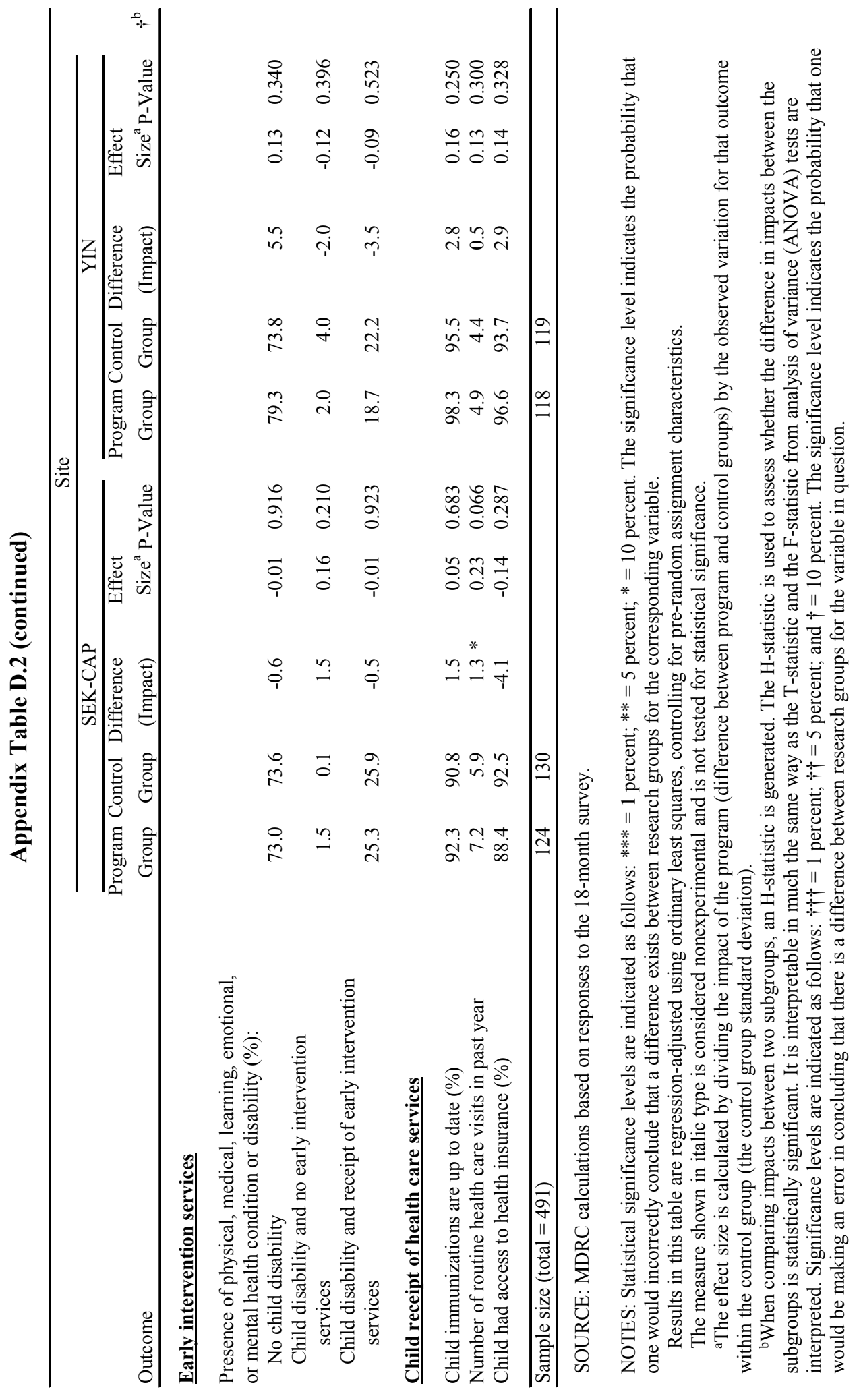




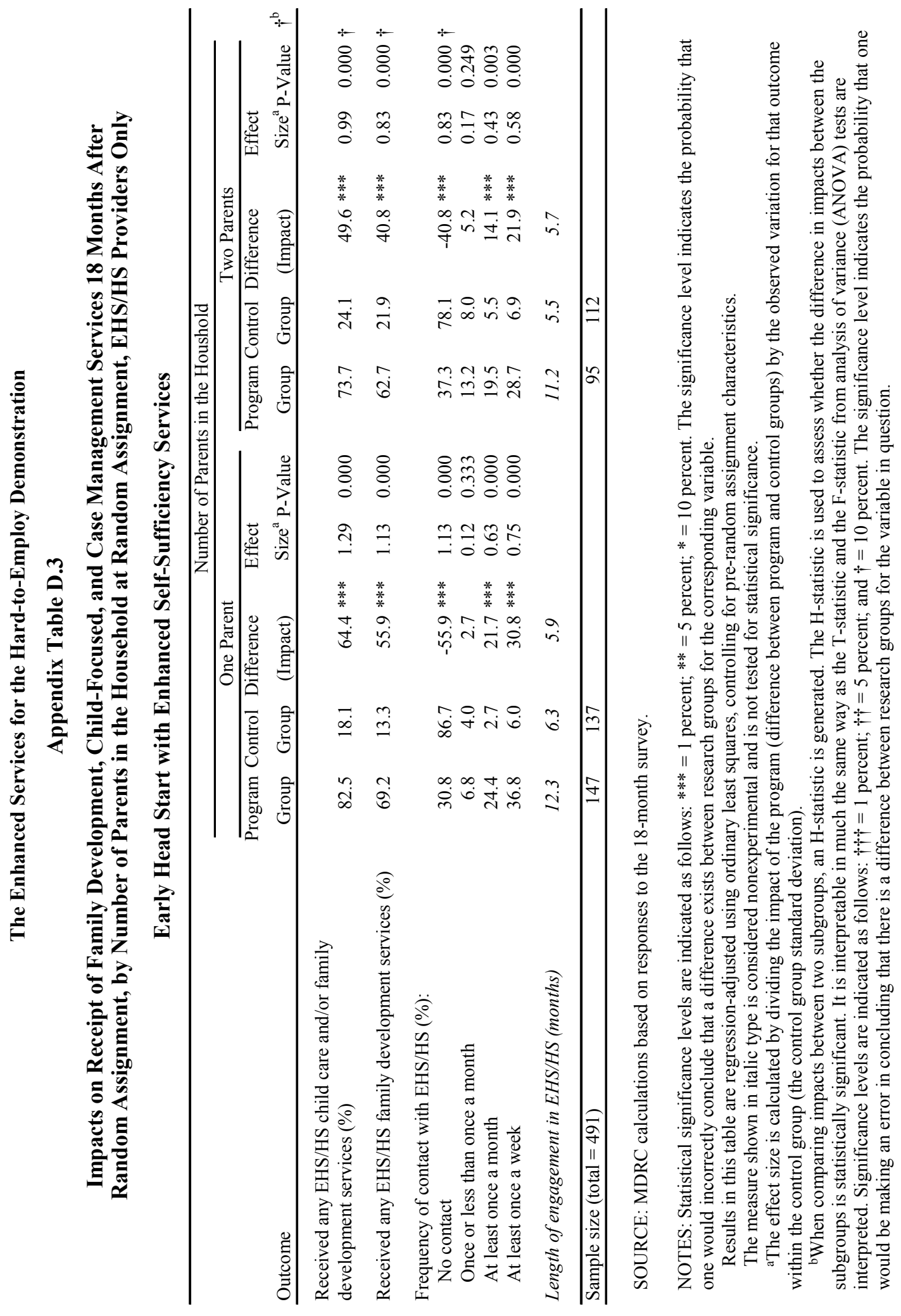




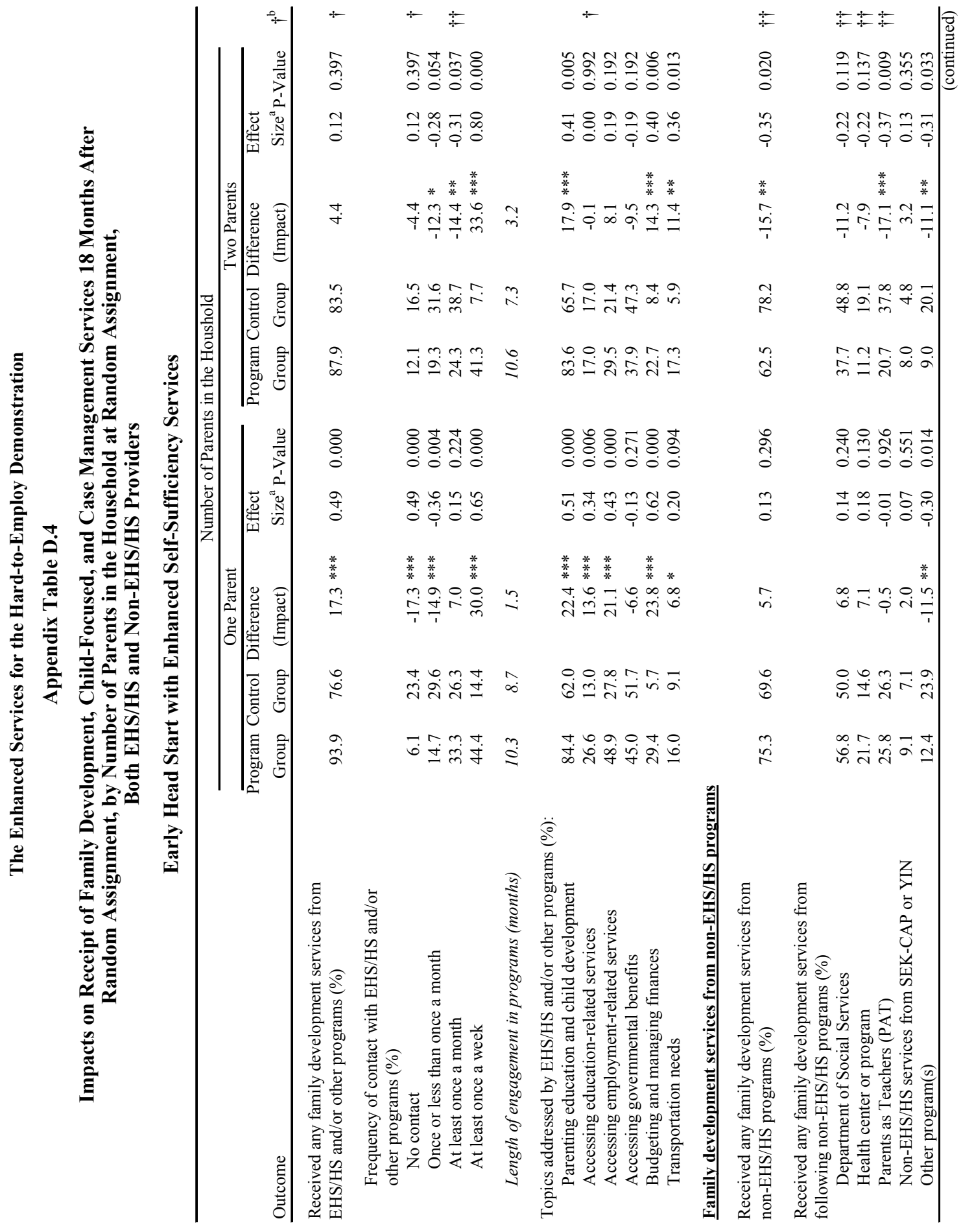




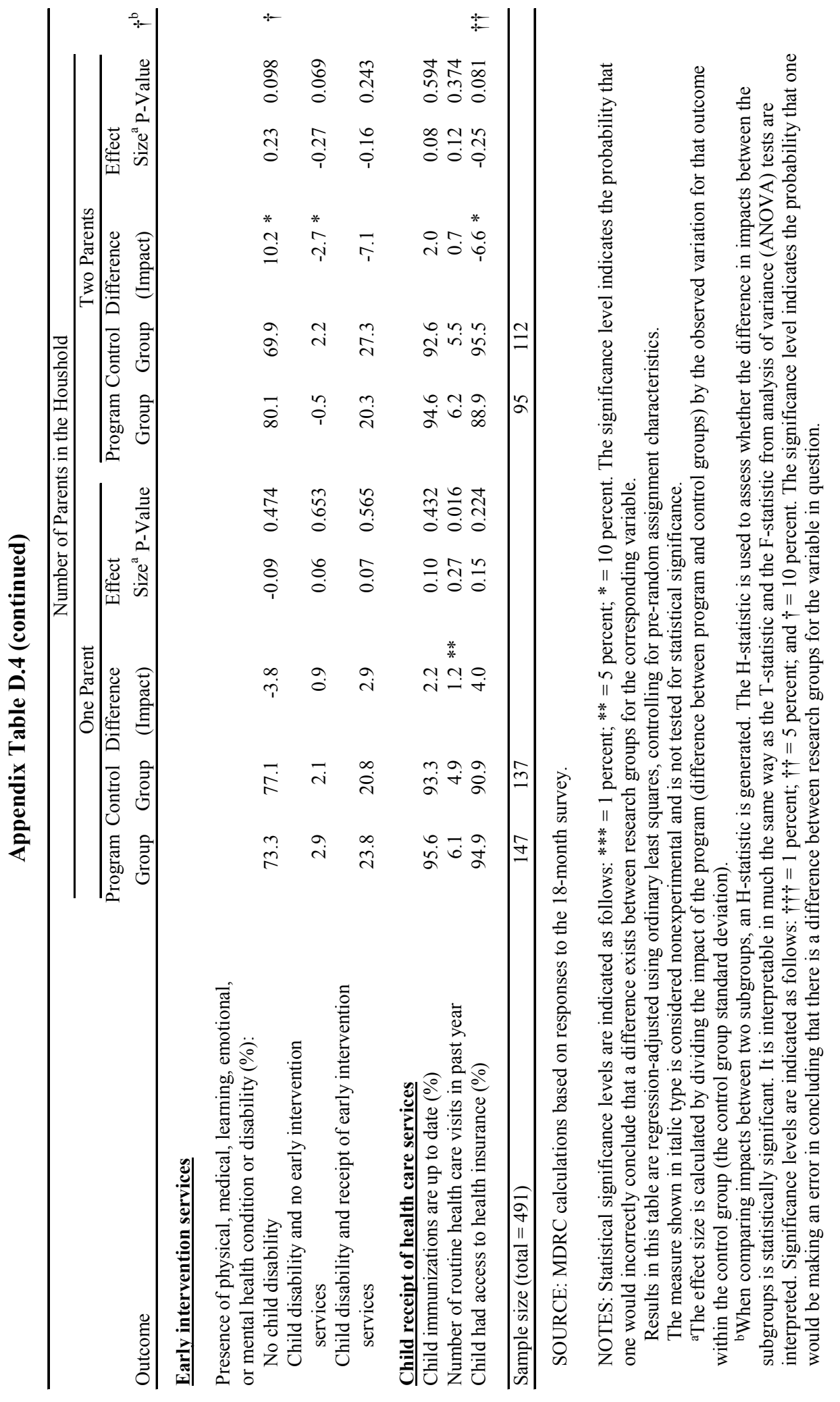




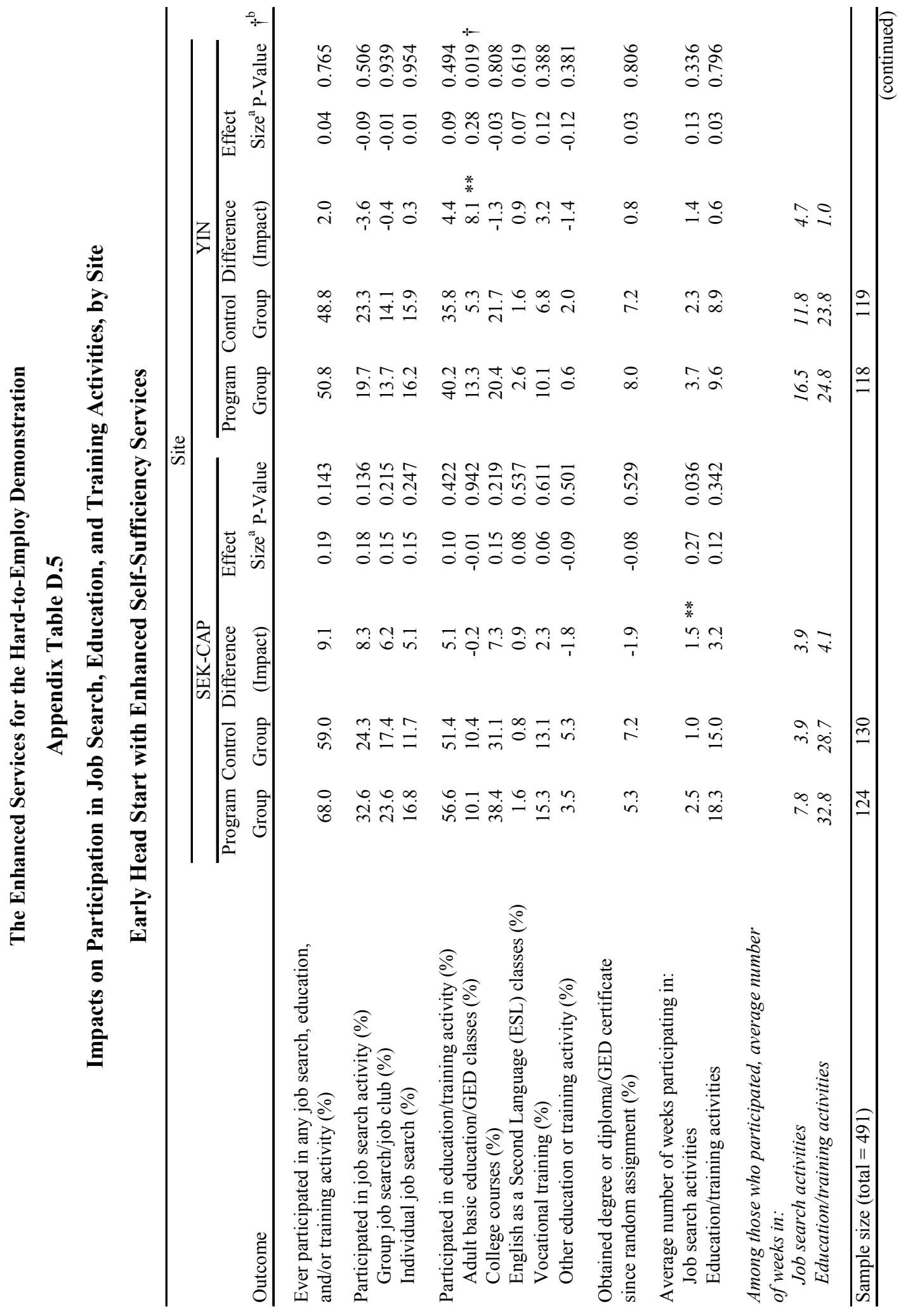




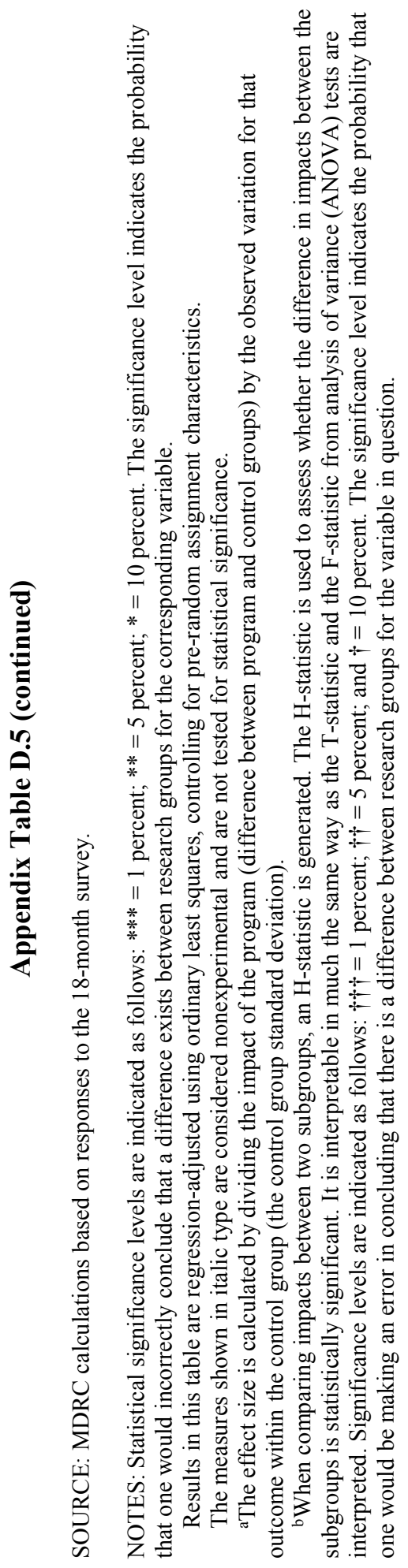




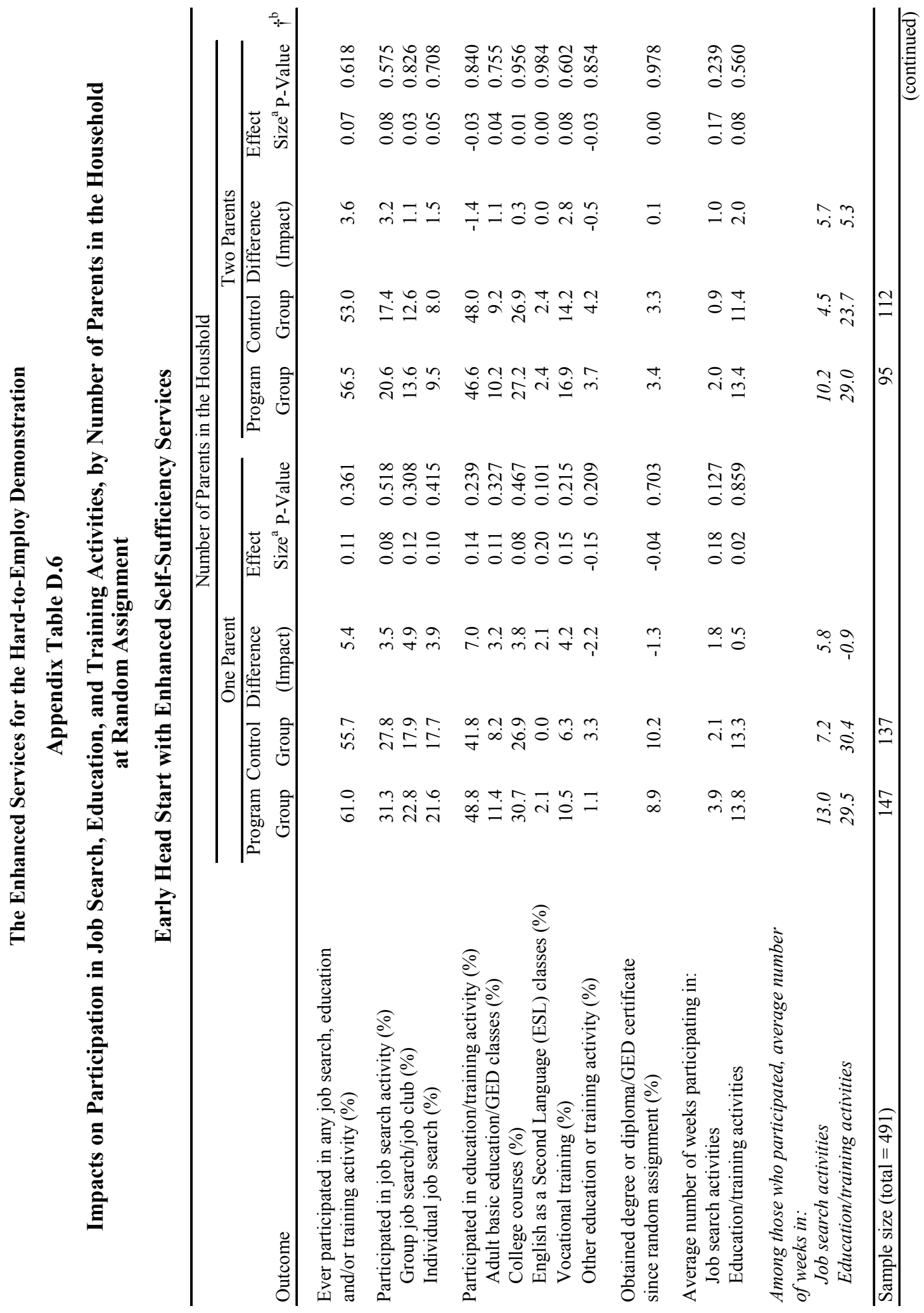




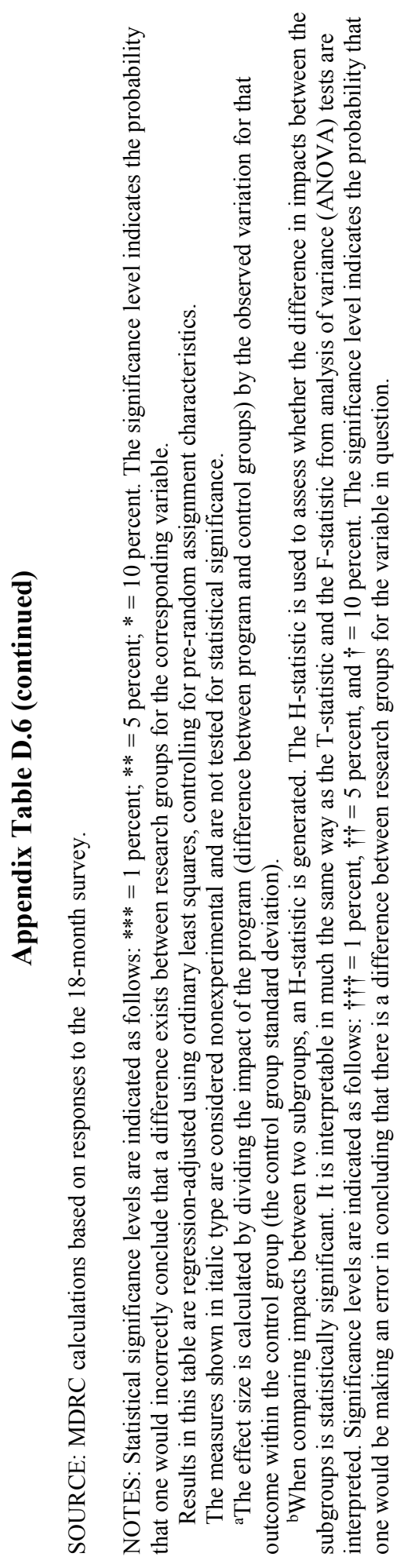


Appendix E

Impacts on Child Care 



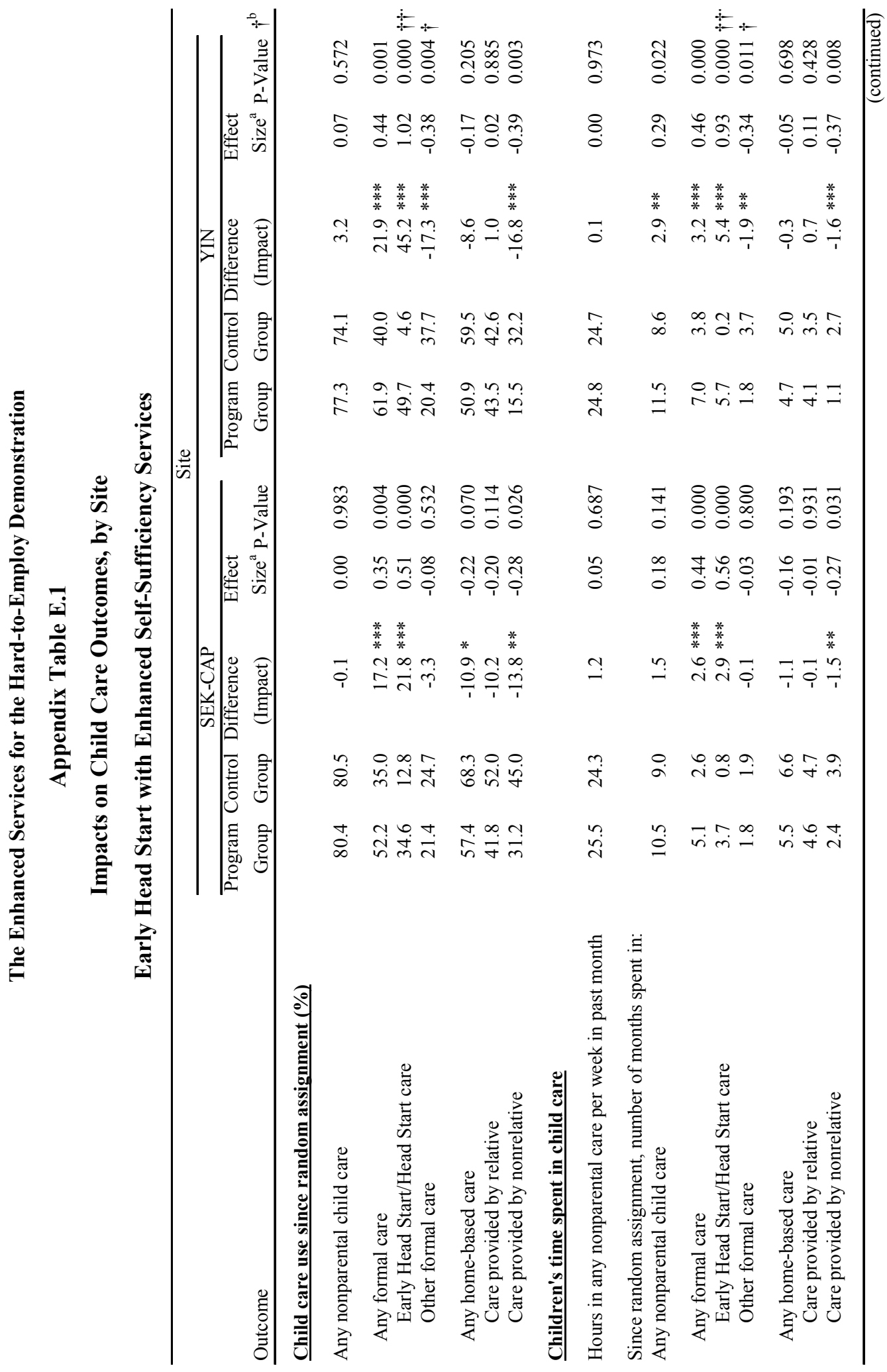




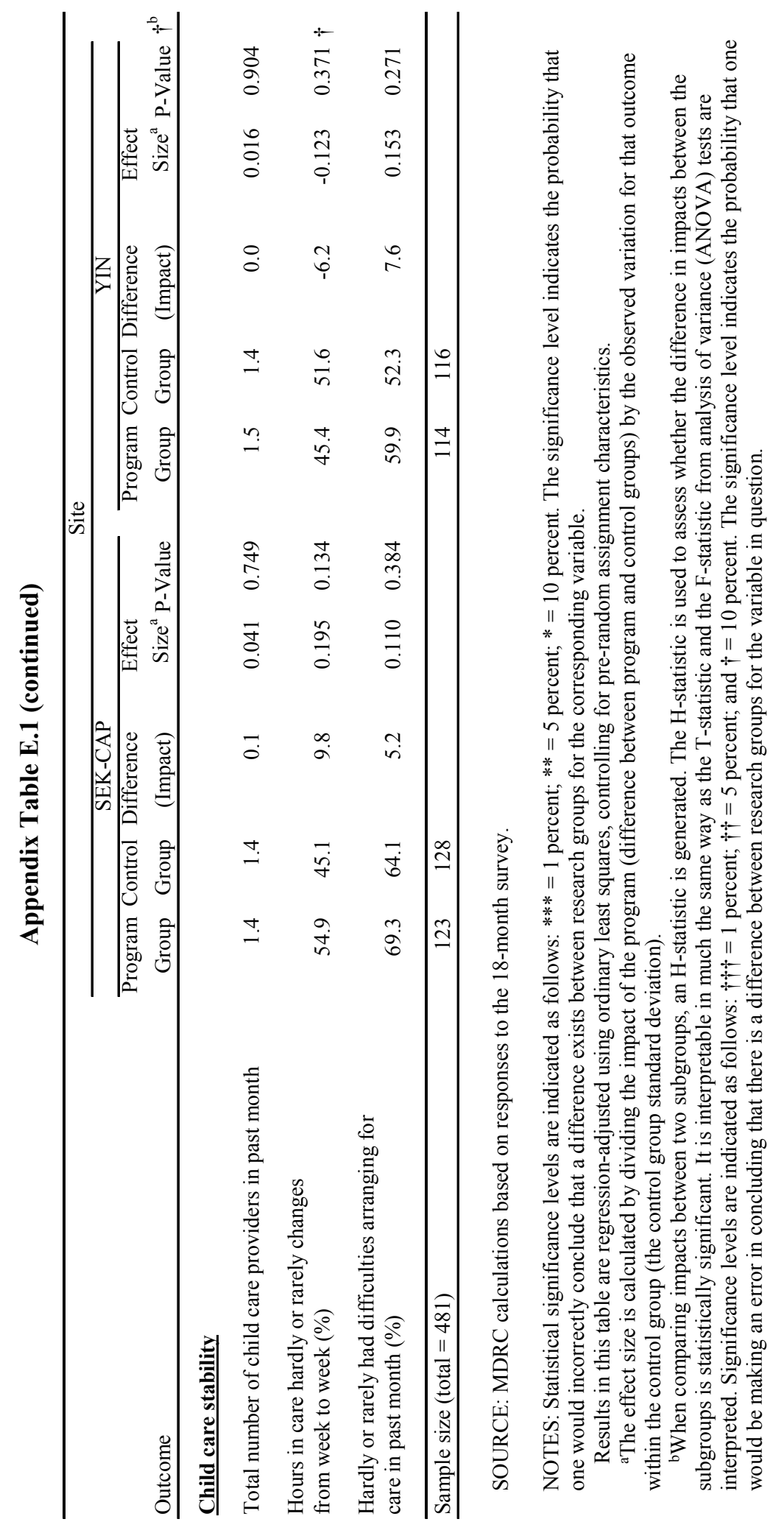




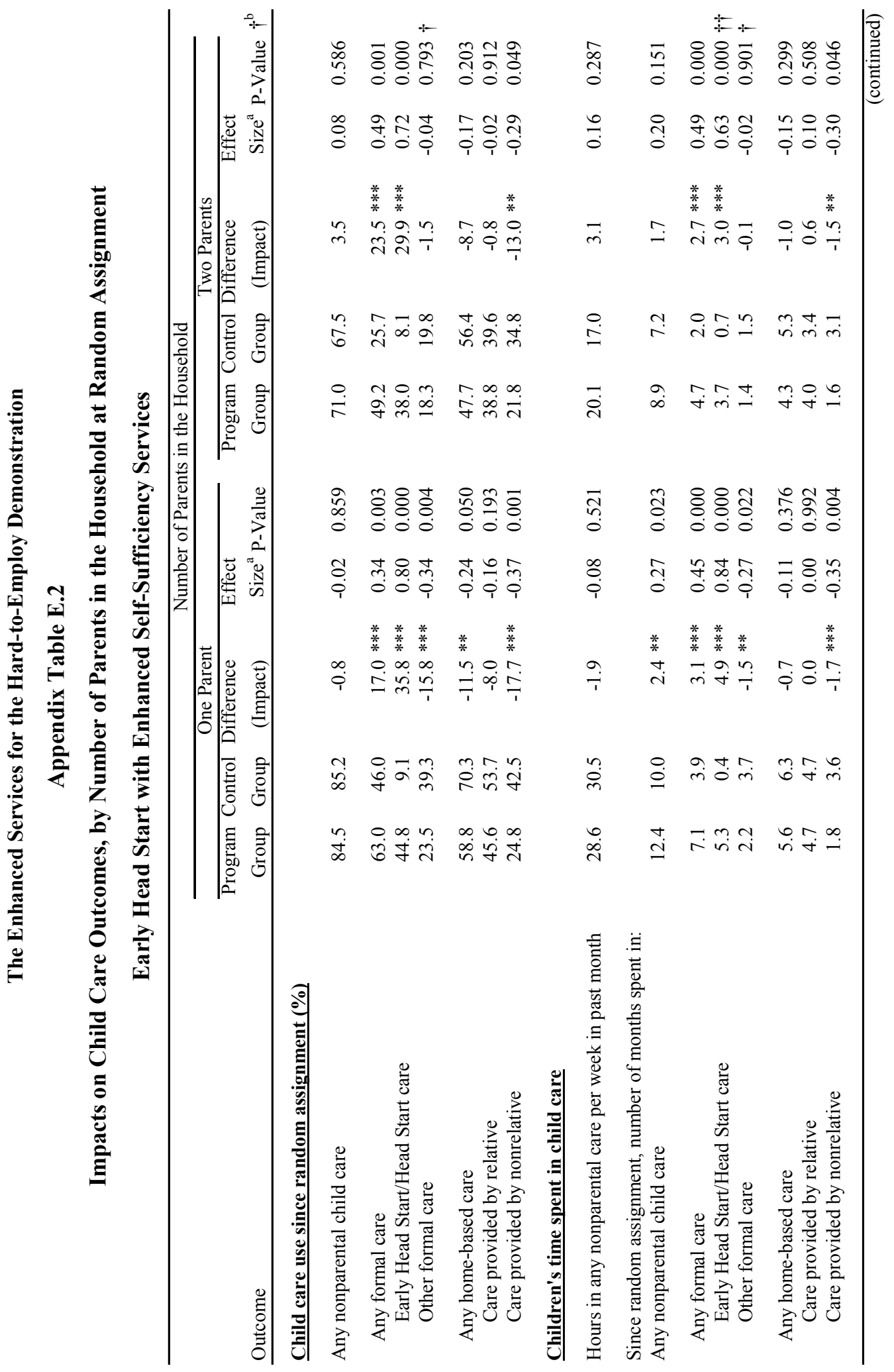




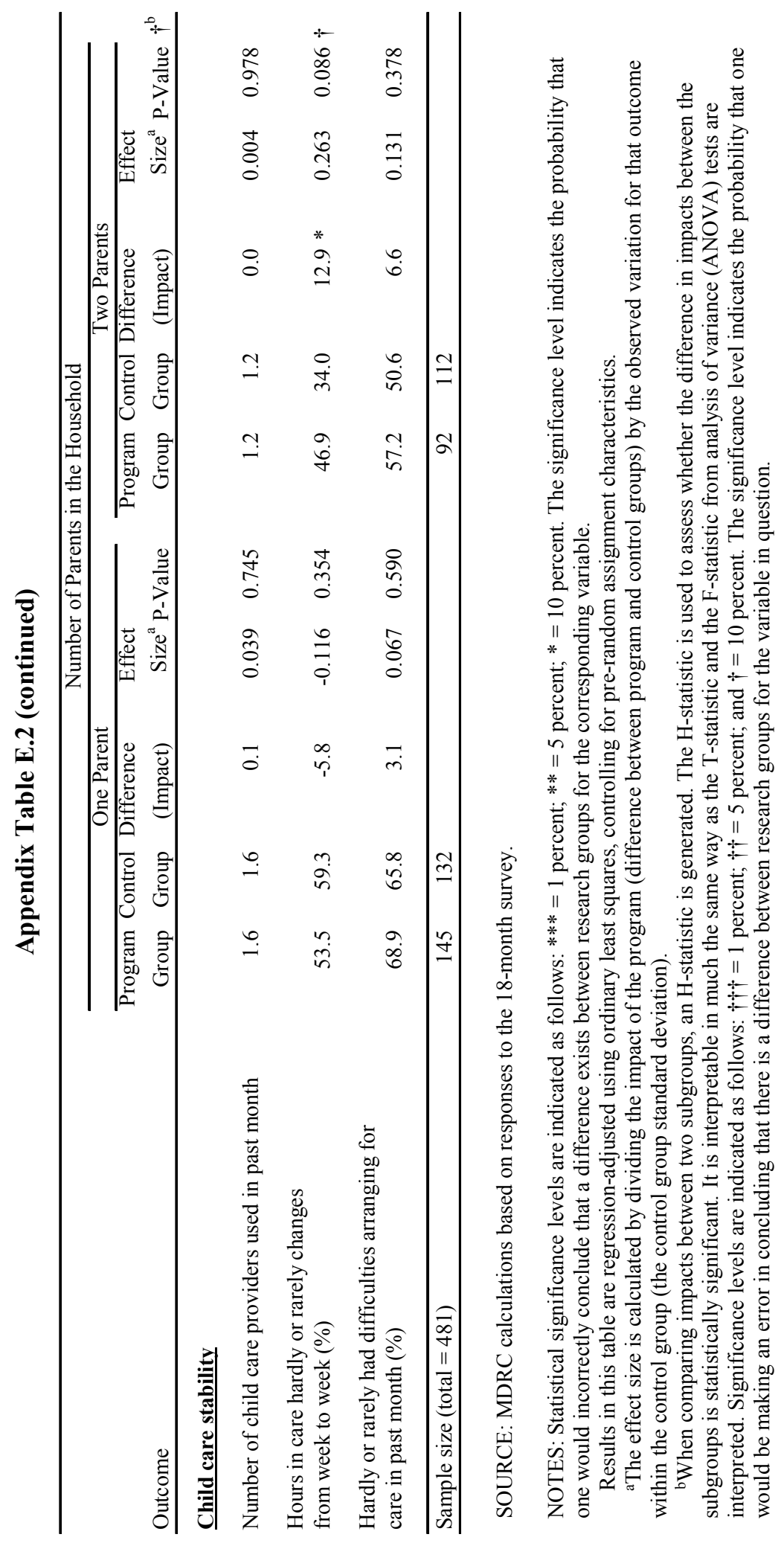


Appendix F

\section{Impacts on Employment}



The Enhanced Services for the Hard-to-Employ Demonstration

\section{Appendix Table F.1}

\section{Impacts on Quarterly Employment and Earnings for the Household}

Early Head Start with Enhanced Self-Sufficiency Services

\begin{tabular}{|c|c|c|c|c|c|}
\hline Outcome & $\begin{array}{r}\text { Program } \\
\text { Group }\end{array}$ & $\begin{array}{l}\text { Control } \\
\text { Group }\end{array}$ & $\begin{array}{r}\text { Difference } \\
\text { (Impact) }\end{array}$ & $\begin{array}{l}\text { Effect } \\
\text { Size }^{a}\end{array}$ & P-Value \\
\hline \multicolumn{6}{|l|}{ Employment (\%) } \\
\hline Quarter 1 (quarter of random assignment) & 76.1 & 72.6 & 3.6 & 0.08 & 0.297 \\
\hline Quarter 2 & 74.1 & 71.7 & 2.4 & 0.05 & 0.470 \\
\hline Quarter 3 & 75.3 & 73.7 & 1.6 & 0.04 & 0.638 \\
\hline Quarter 4 & 75.1 & 73.0 & 2.1 & 0.05 & 0.536 \\
\hline Quarter 5 & 73.2 & 75.9 & -2.8 & -0.06 & 0.417 \\
\hline Quarter 6 & 74.2 & 76.9 & -2.6 & -0.06 & 0.431 \\
\hline Ever employed, Quarters 1-6 & 91.9 & 89.0 & 3.0 & 0.10 & 0.195 \\
\hline \multicolumn{6}{|l|}{ Earnings (\$) } \\
\hline Quarter 1 (quarter of random assignment) & 3,535 & 3,112 & 423 & 0.10 & 0.155 \\
\hline Quarter 2 & 3,587 & 3,552 & 35 & 0.01 & 0.907 \\
\hline Quarter 3 & 3,617 & 3,646 & -29 & -0.01 & 0.928 \\
\hline Quarter 4 & 3,829 & 3,715 & 114 & 0.02 & 0.724 \\
\hline Quarter 5 & 3,914 & 3,840 & 74 & 0.02 & 0.828 \\
\hline Quarter 6 & 4,022 & 3,855 & 167 & 0.04 & 0.623 \\
\hline Total earnings, Quarters 1-6 & 22,207 & 21,540 & 666 & 0.03 & 0.695 \\
\hline Sample size $($ total $=597)$ & 300 & 297 & & & \\
\hline
\end{tabular}

SOURCE: MDRC calculations from the National Directory of New Hires database.

NOTES: Statistical significance levels are indicated as follows: $* * *=1$ percent; $* *=5$ percent; and $*=10$ percent. The significance level indicates the probability that one would be making an error in concluding that there is a difference between research groups for the variable in question.

Dollar values include zeroes for sample members who were not employed, unless otherwise noted.

The sample used in this analysis includes females from two-parent cases (41.3 percent), females from one-parent cases (57.1 percent), and males from one-parent cases ( 1.5 percent). Due to missing baseline information, employment data are not available for 13 sample members. 


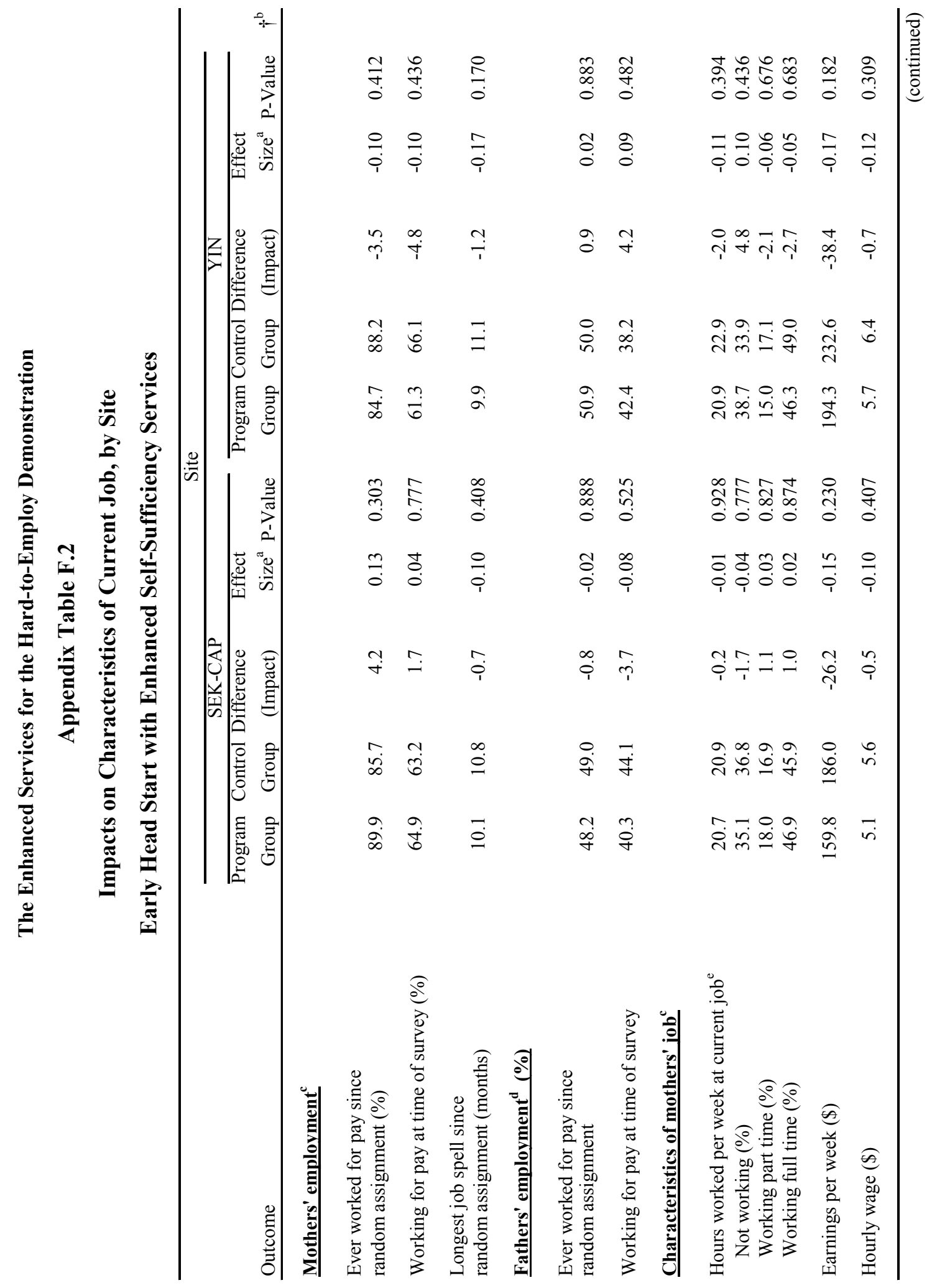




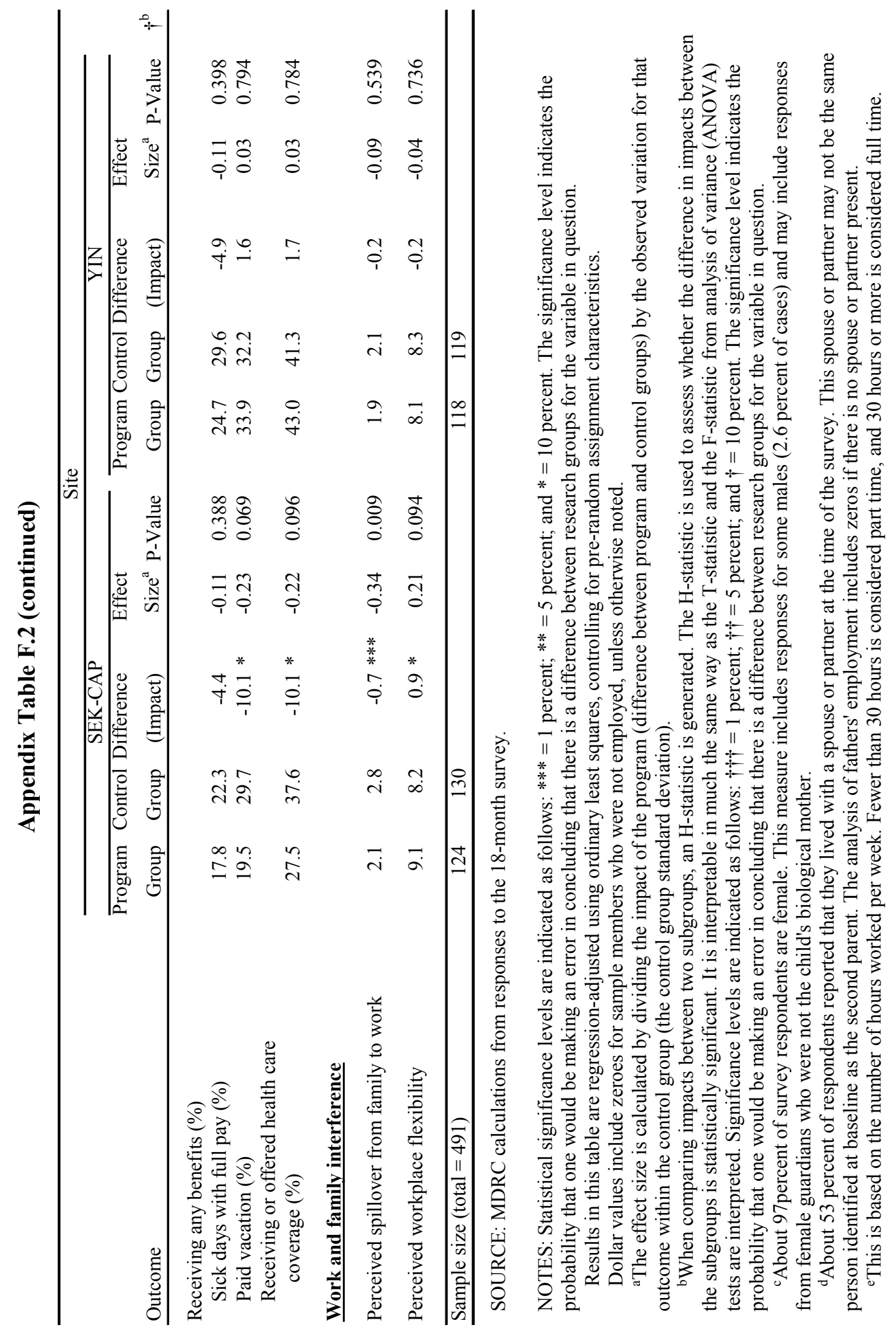




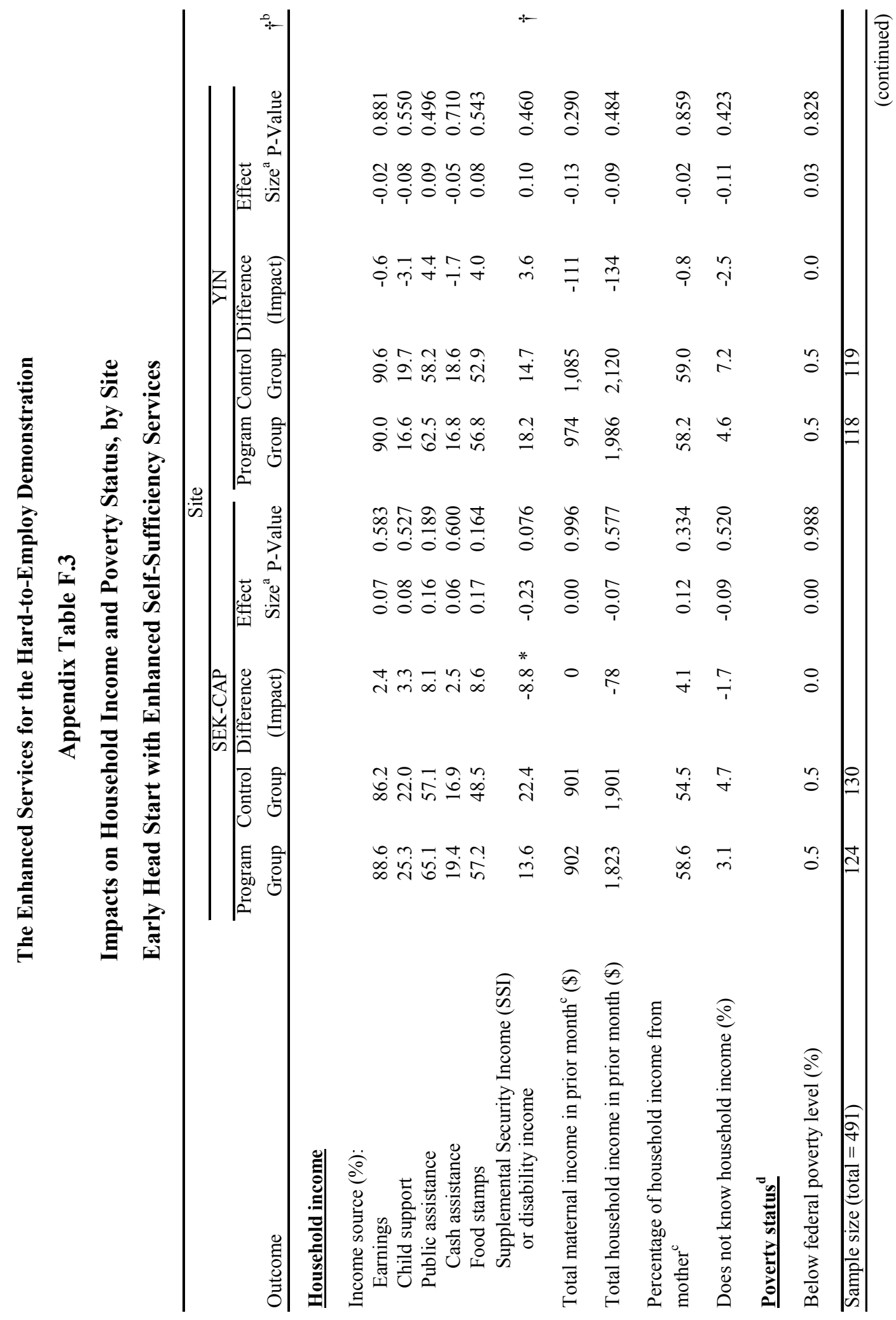




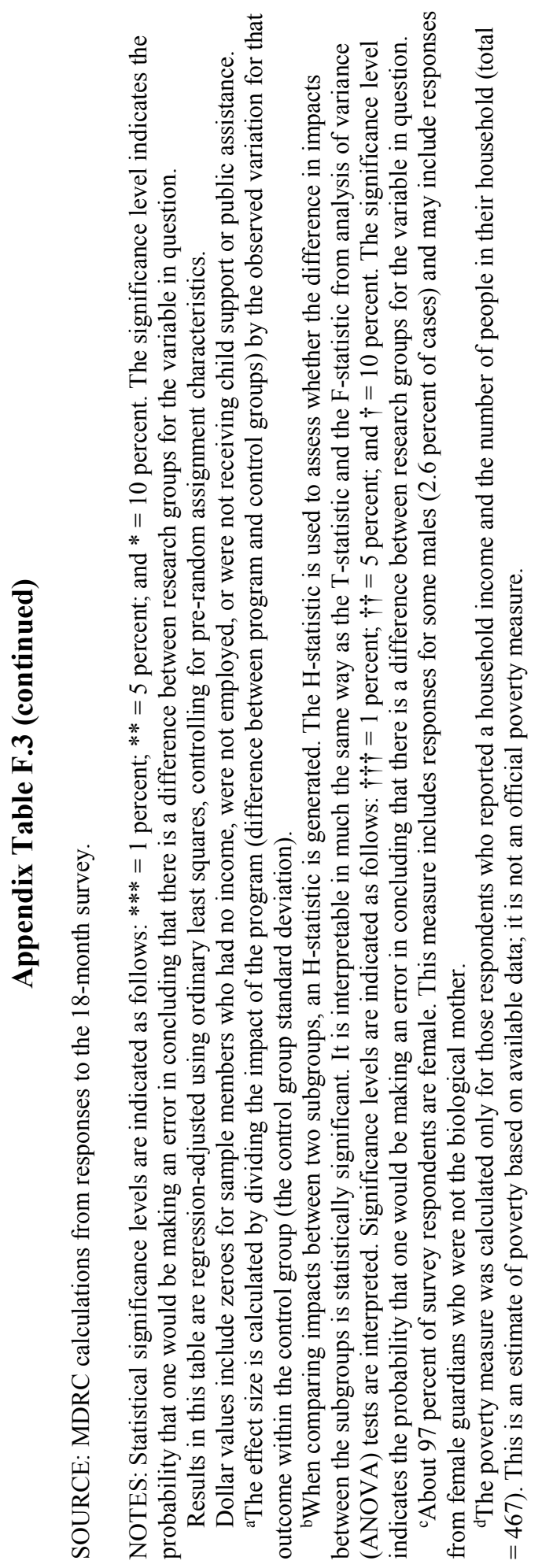




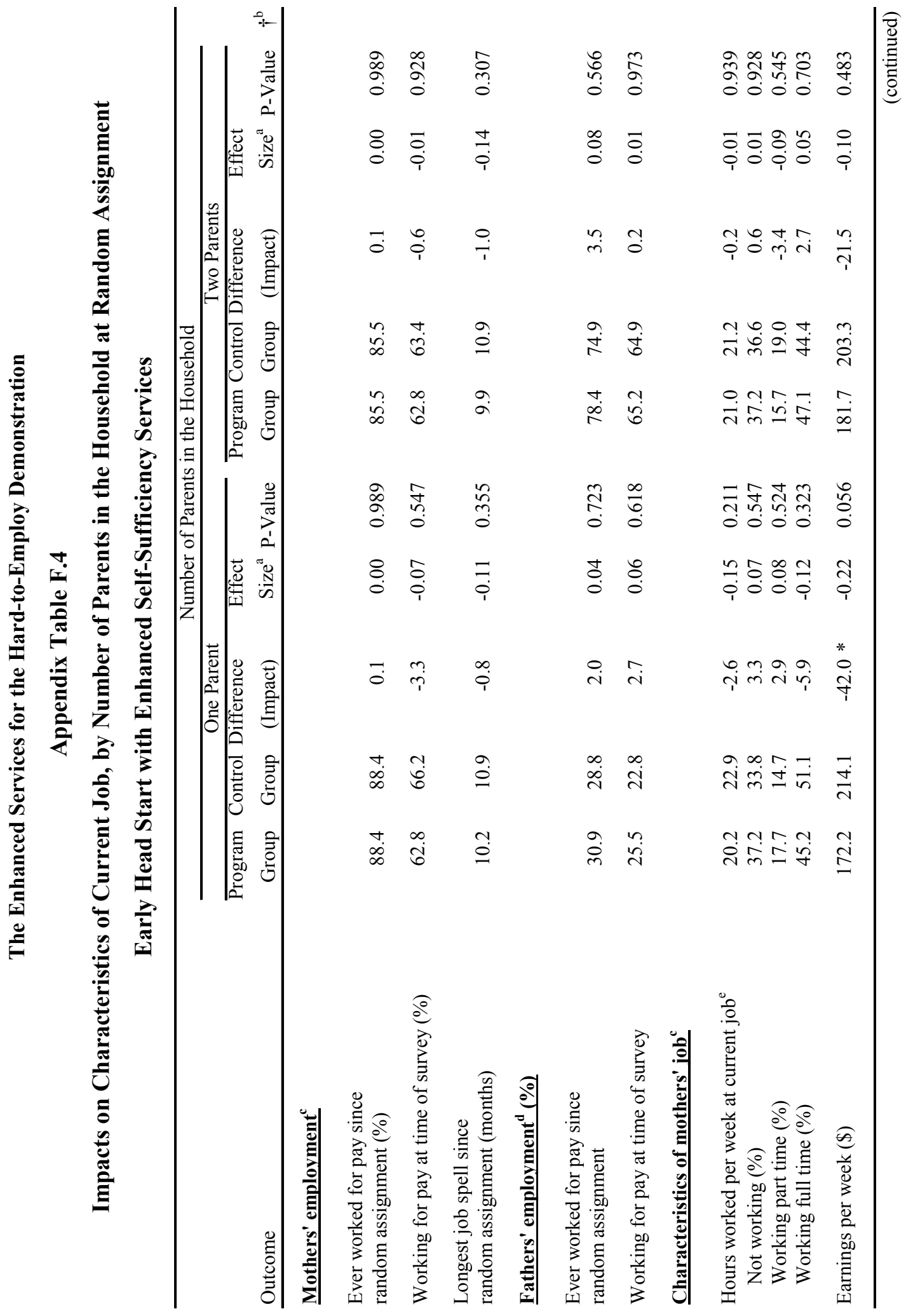




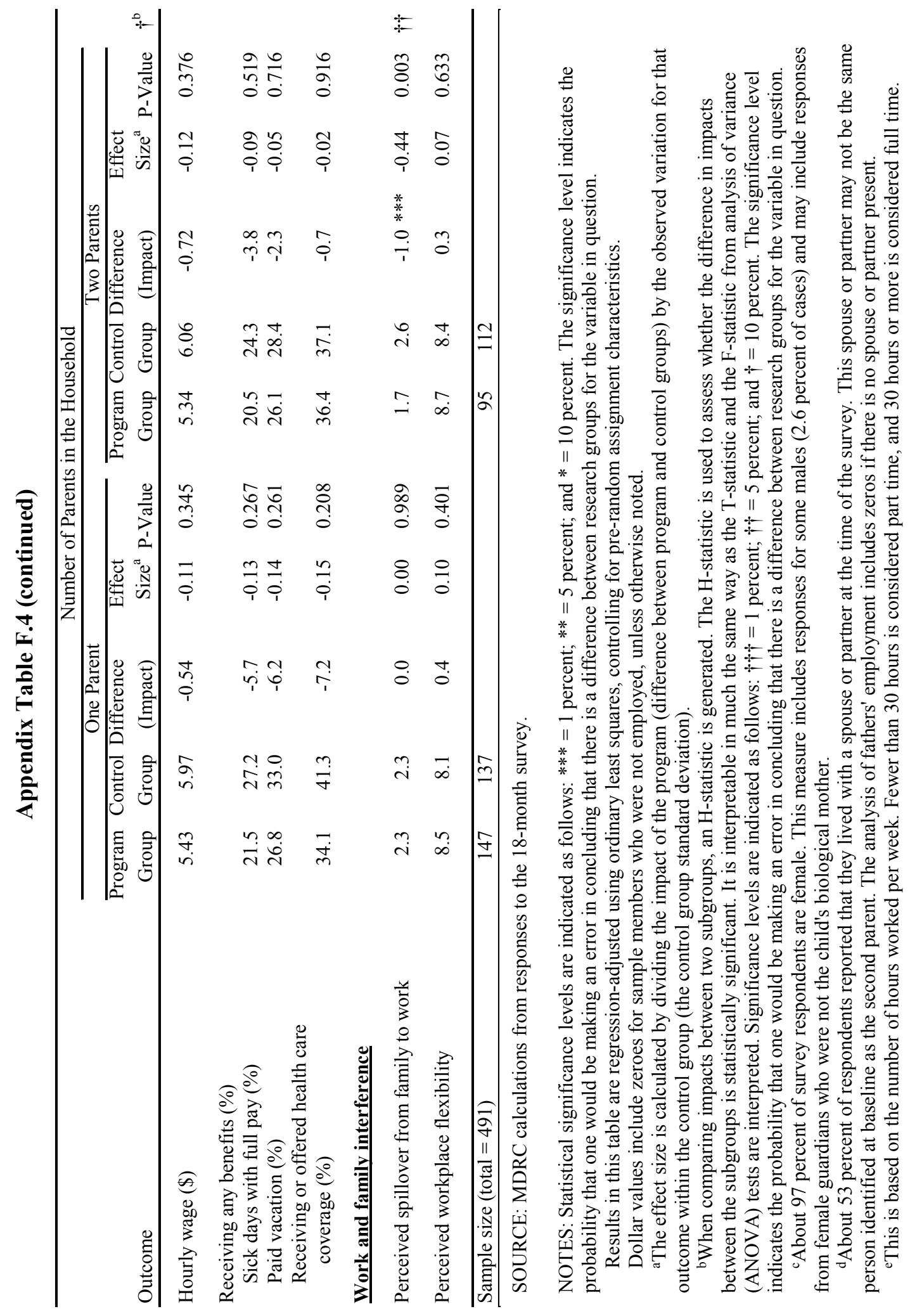




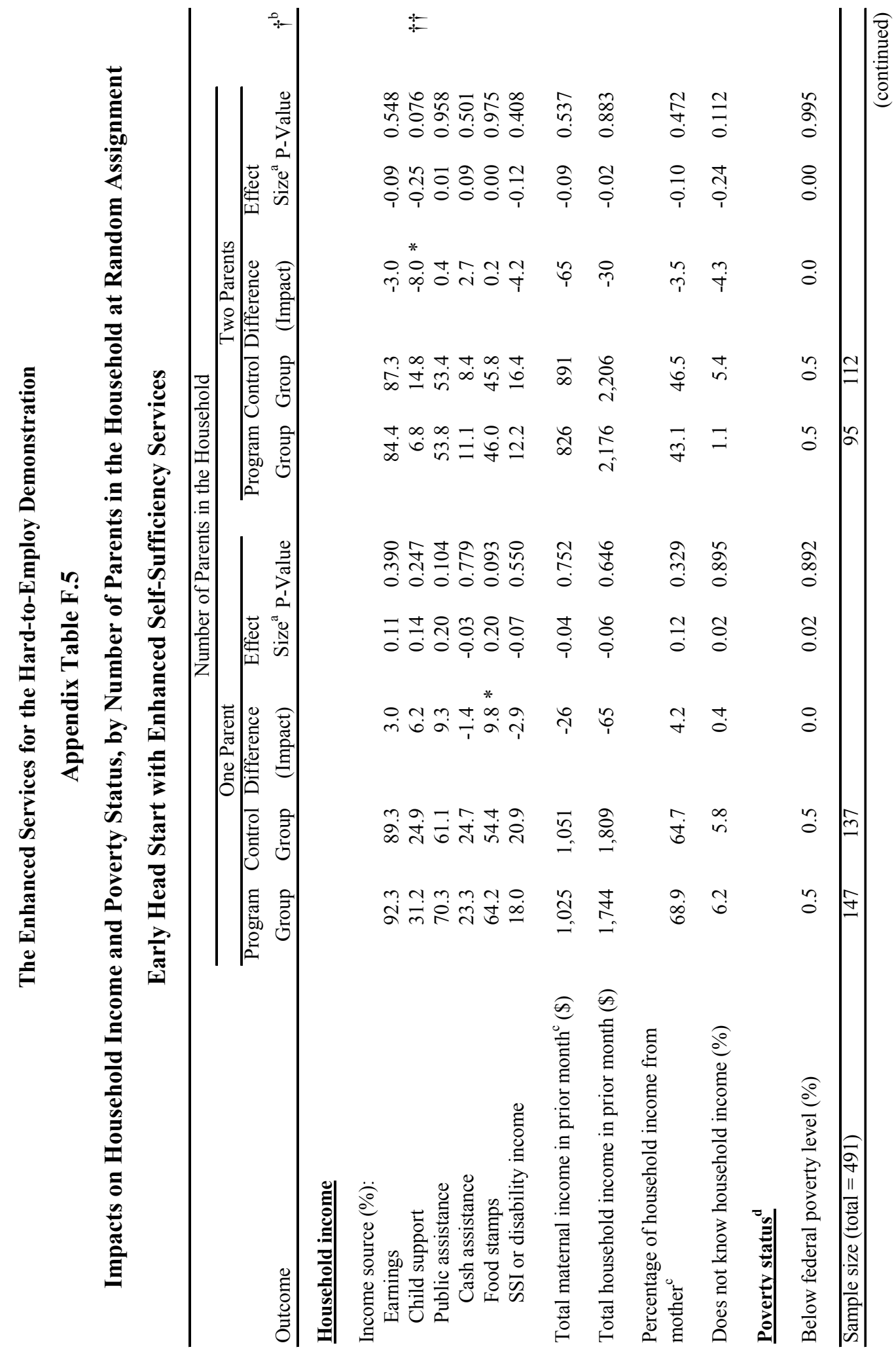




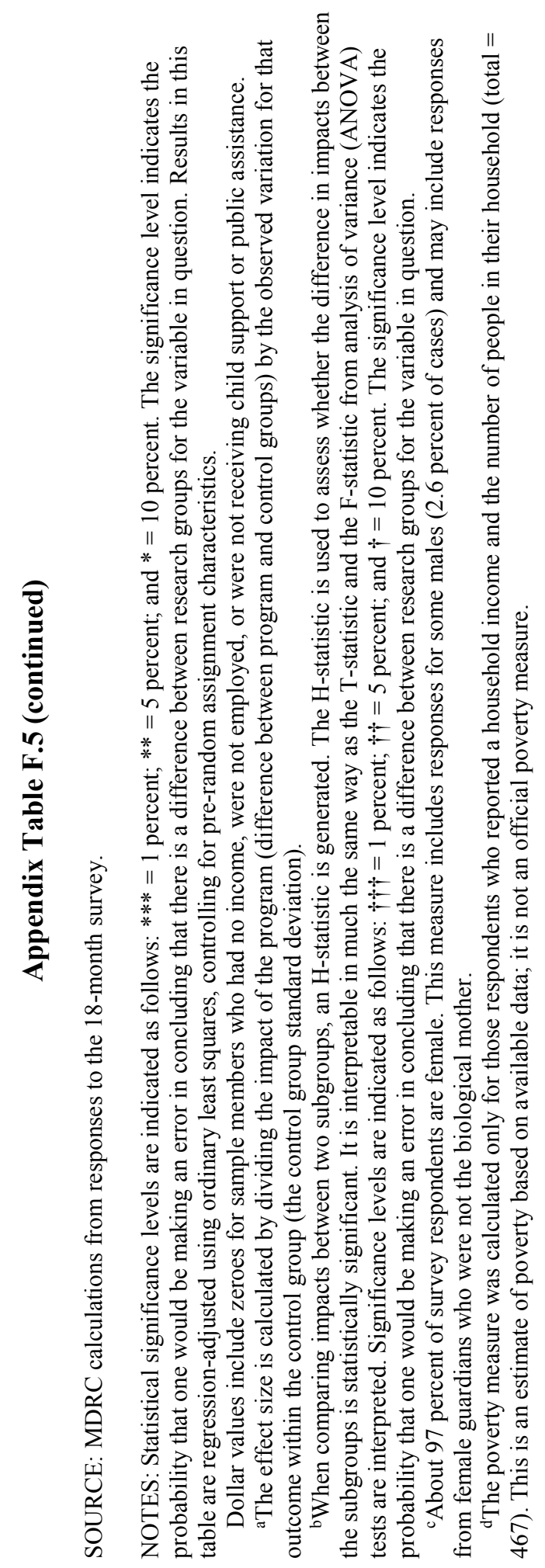




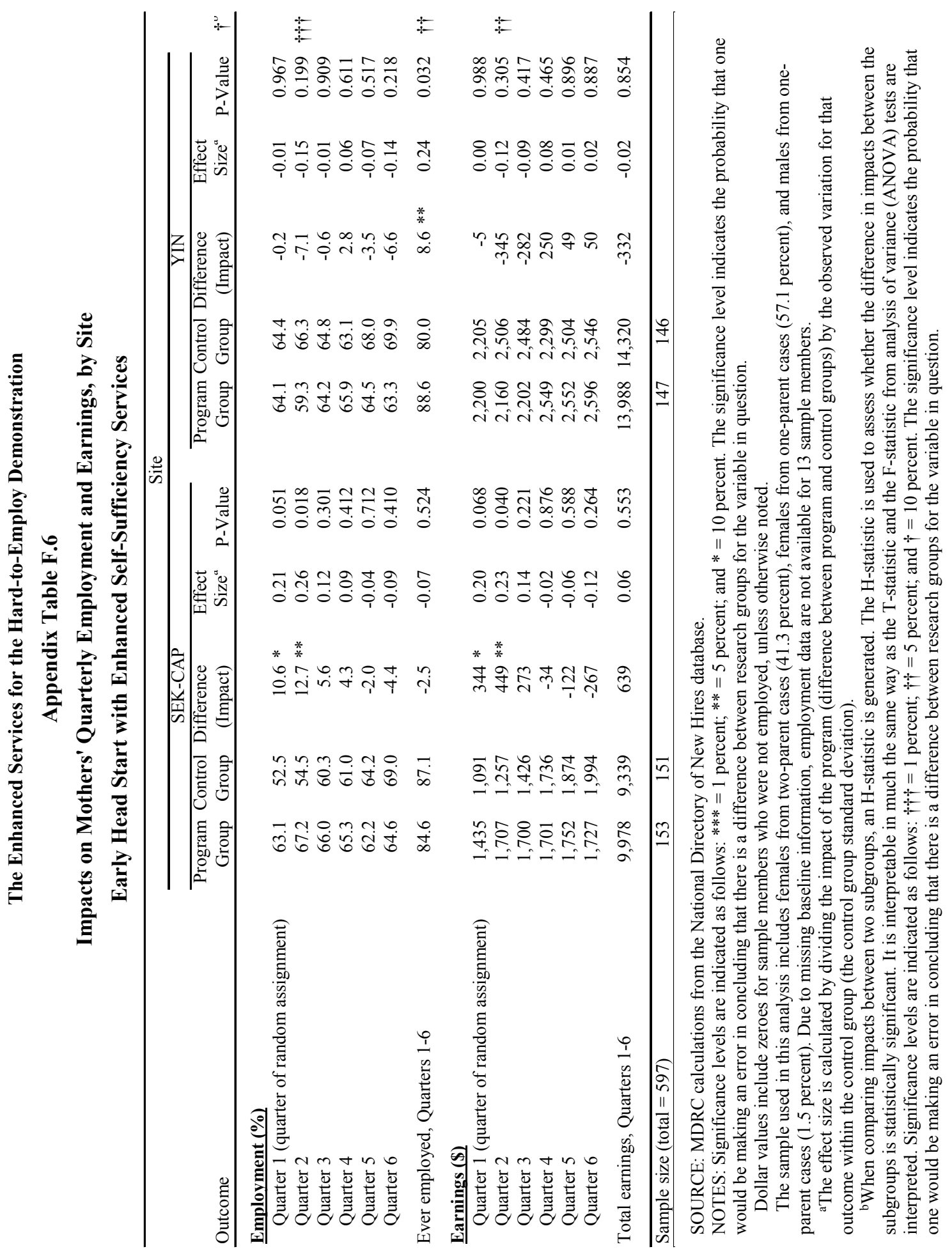




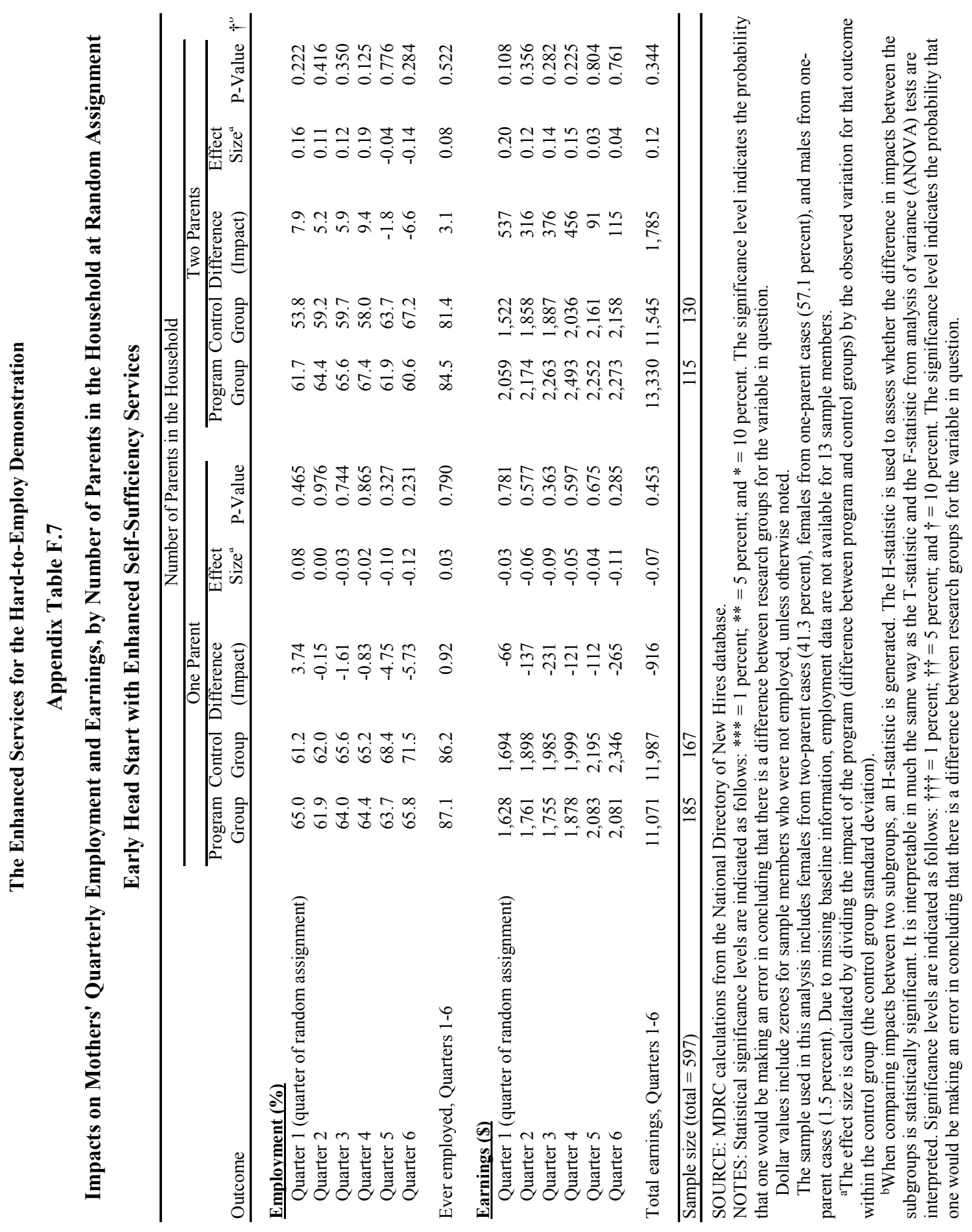



Appendix G

Impacts on Parent and Child Outcomes 



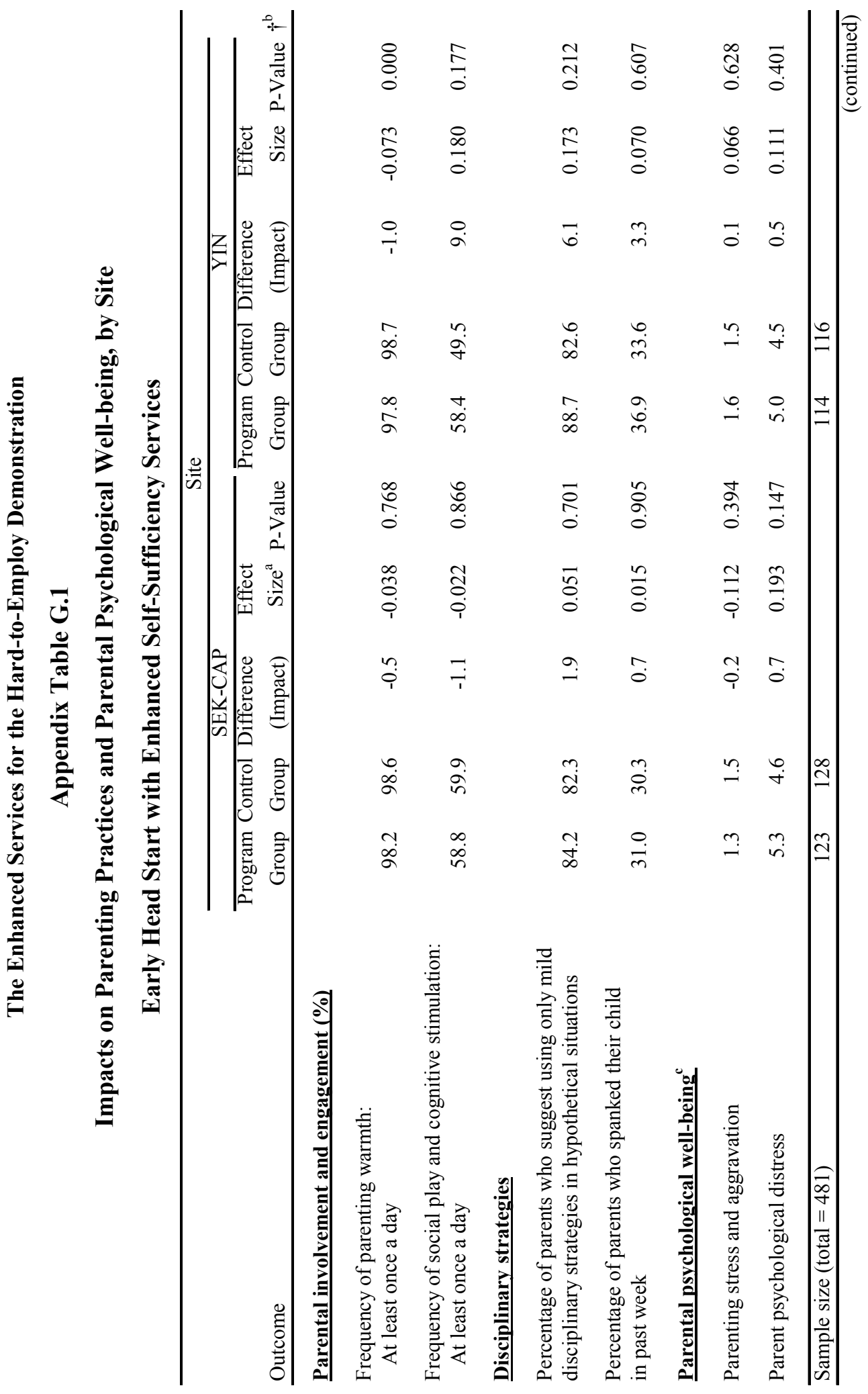




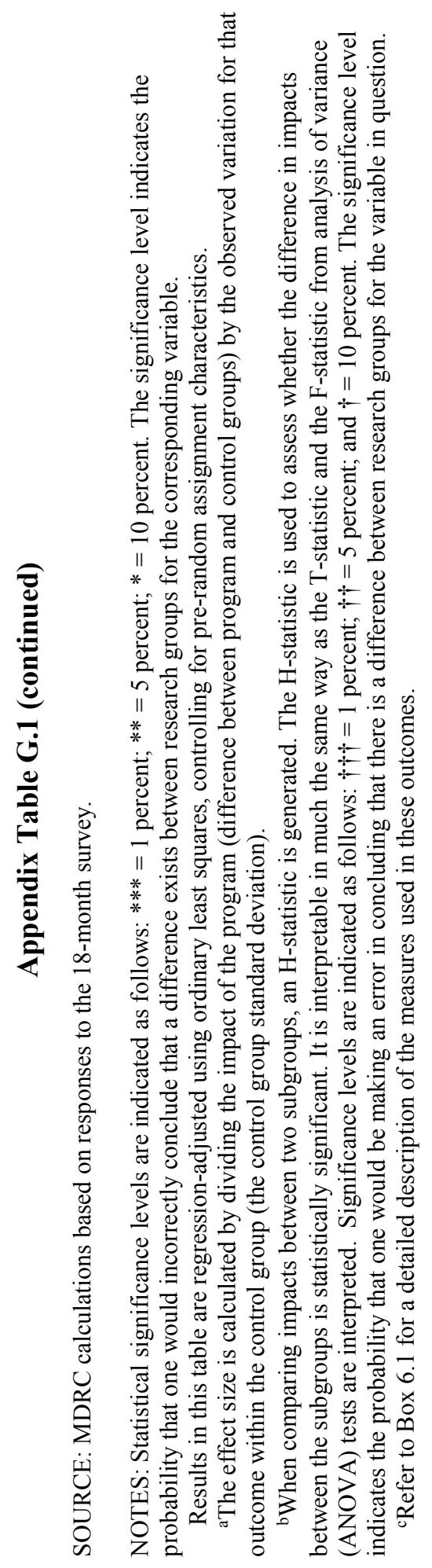




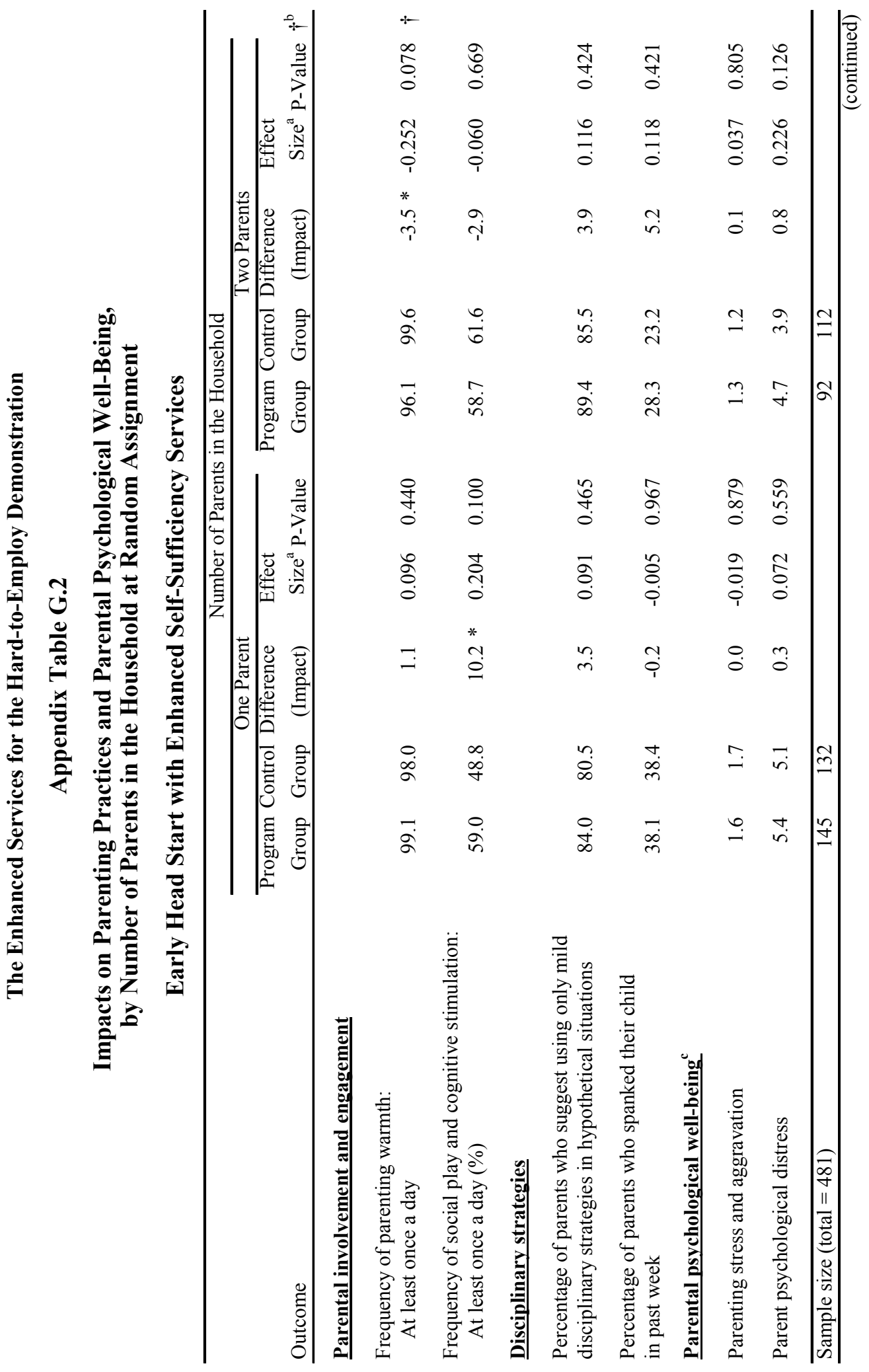




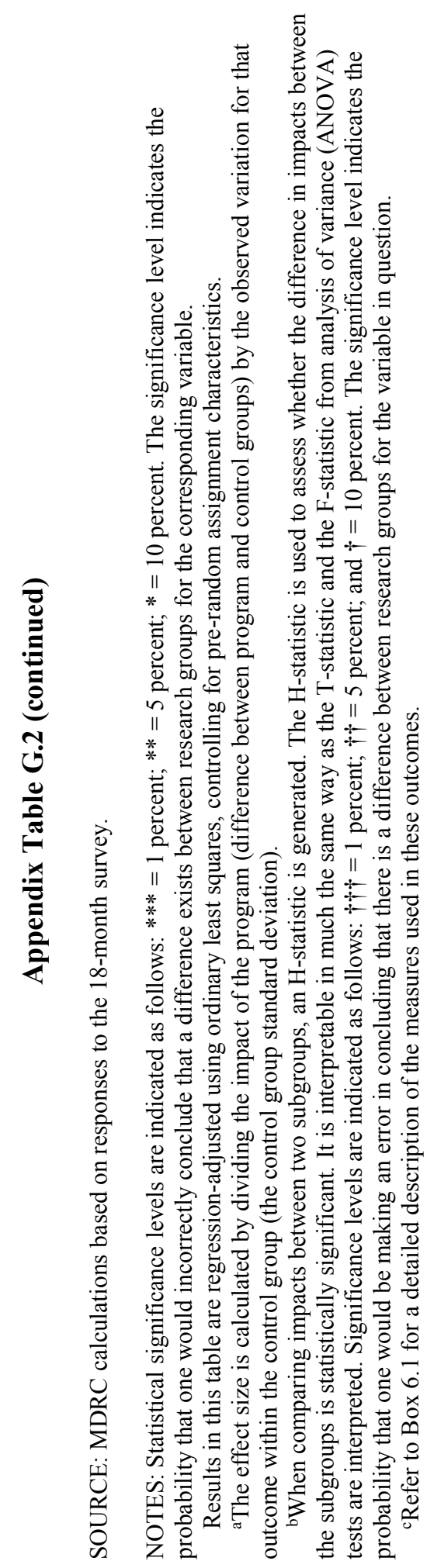




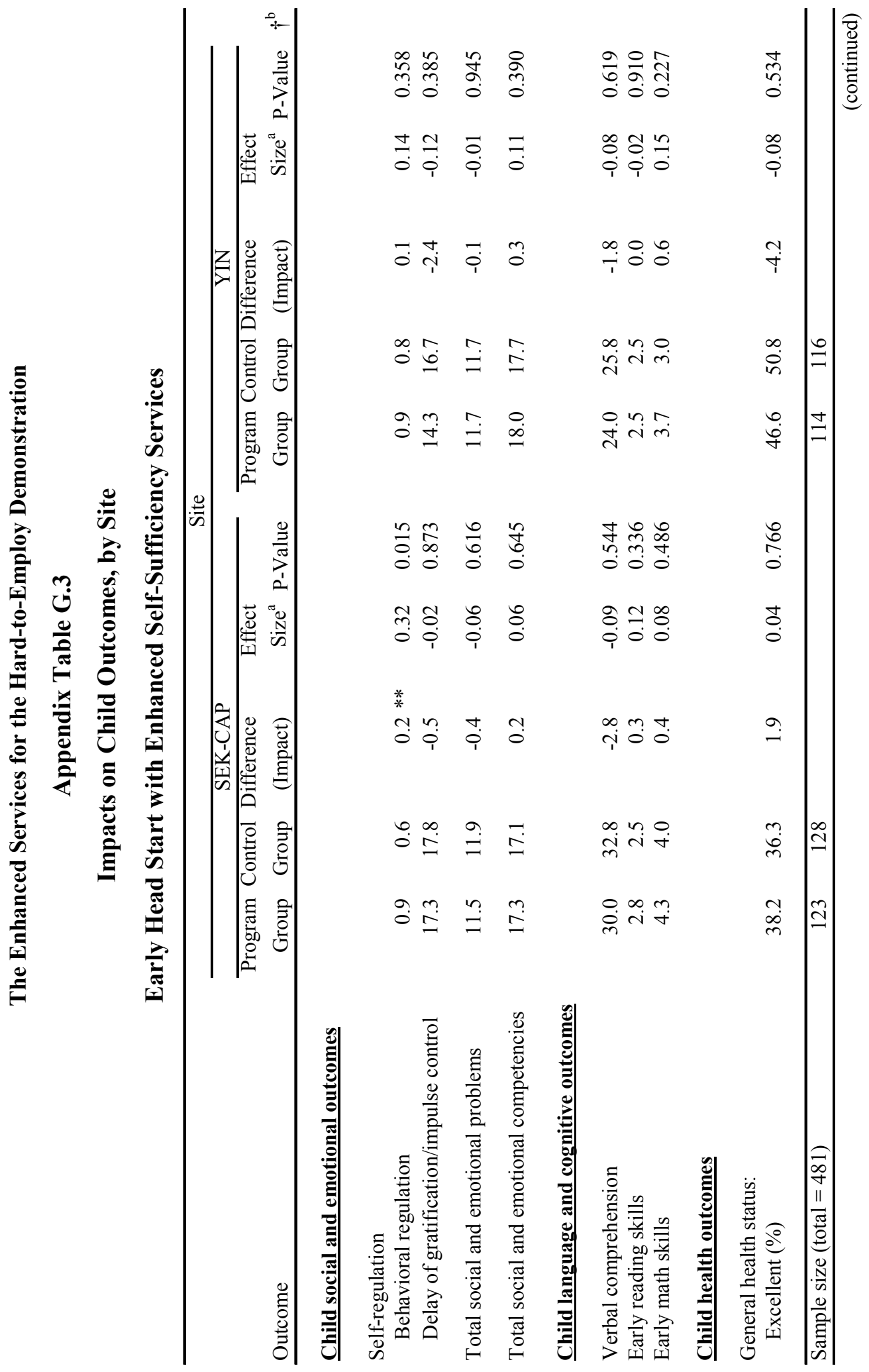




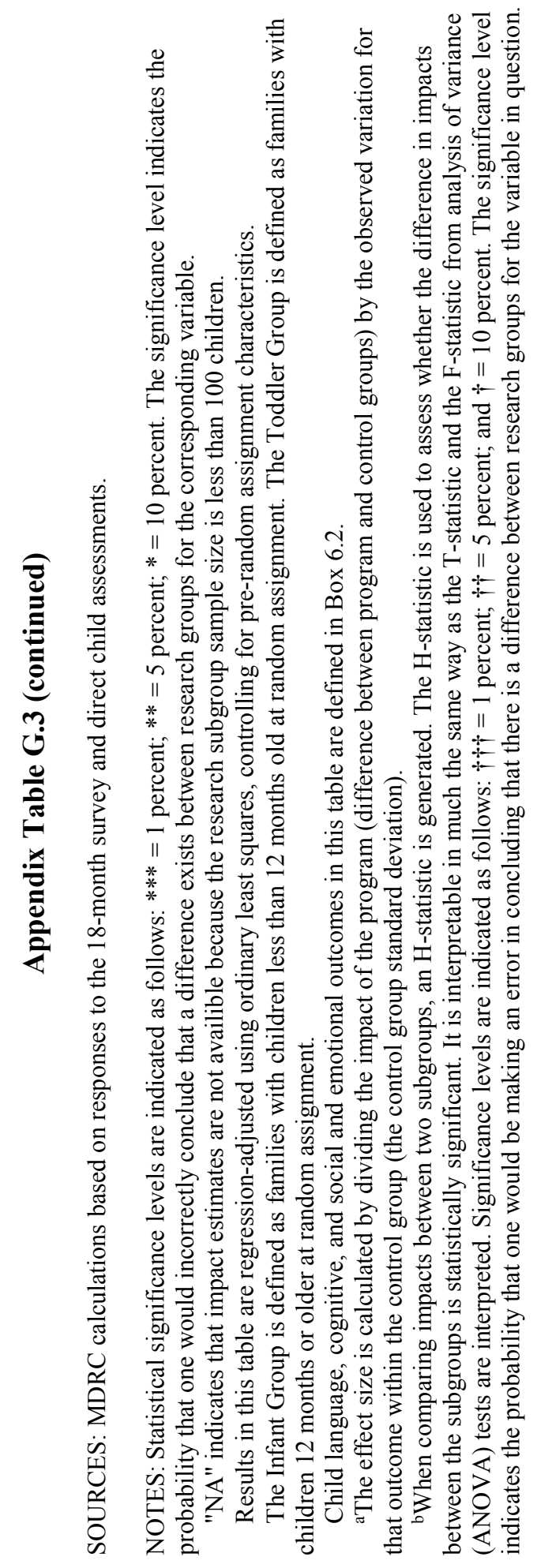




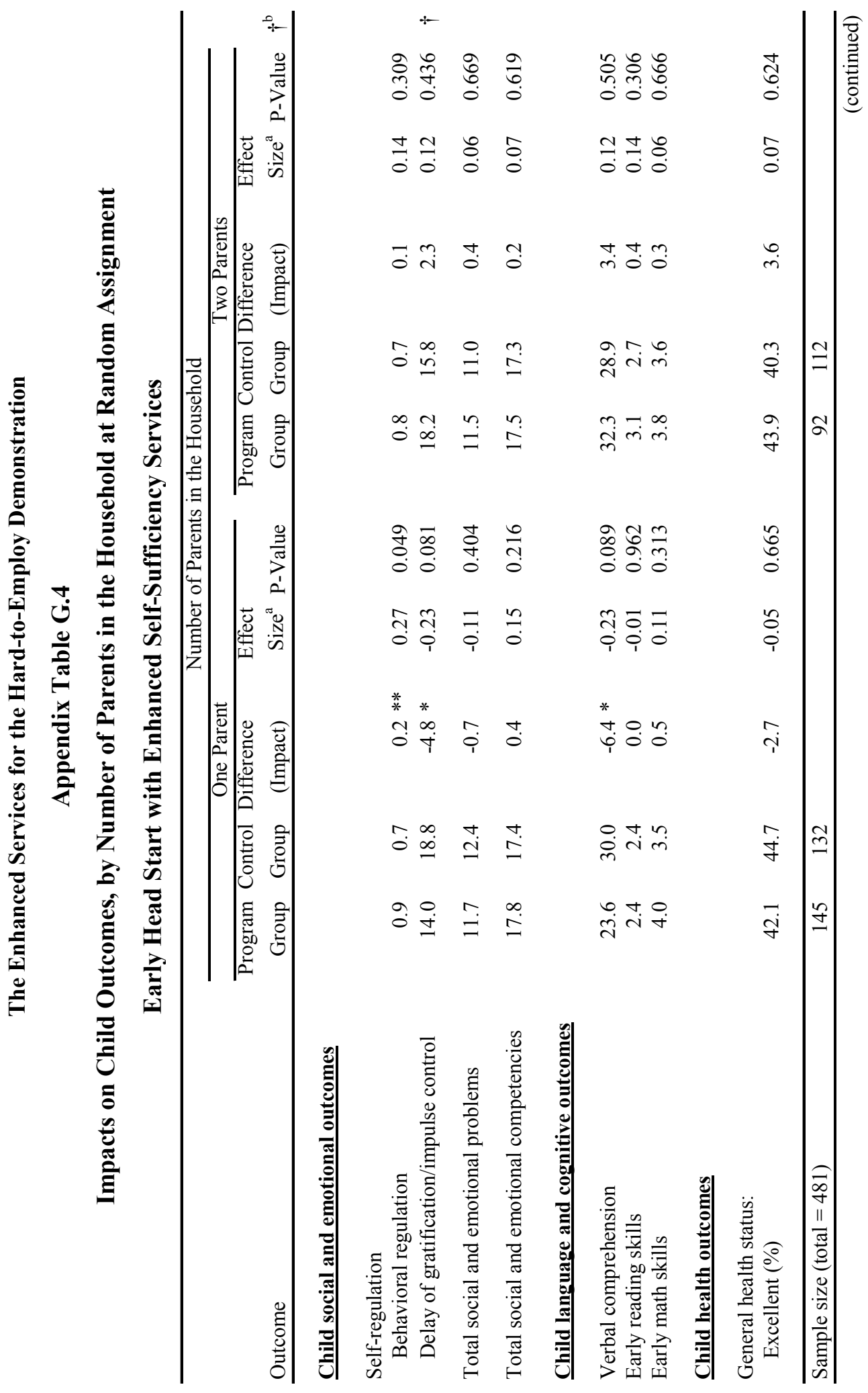




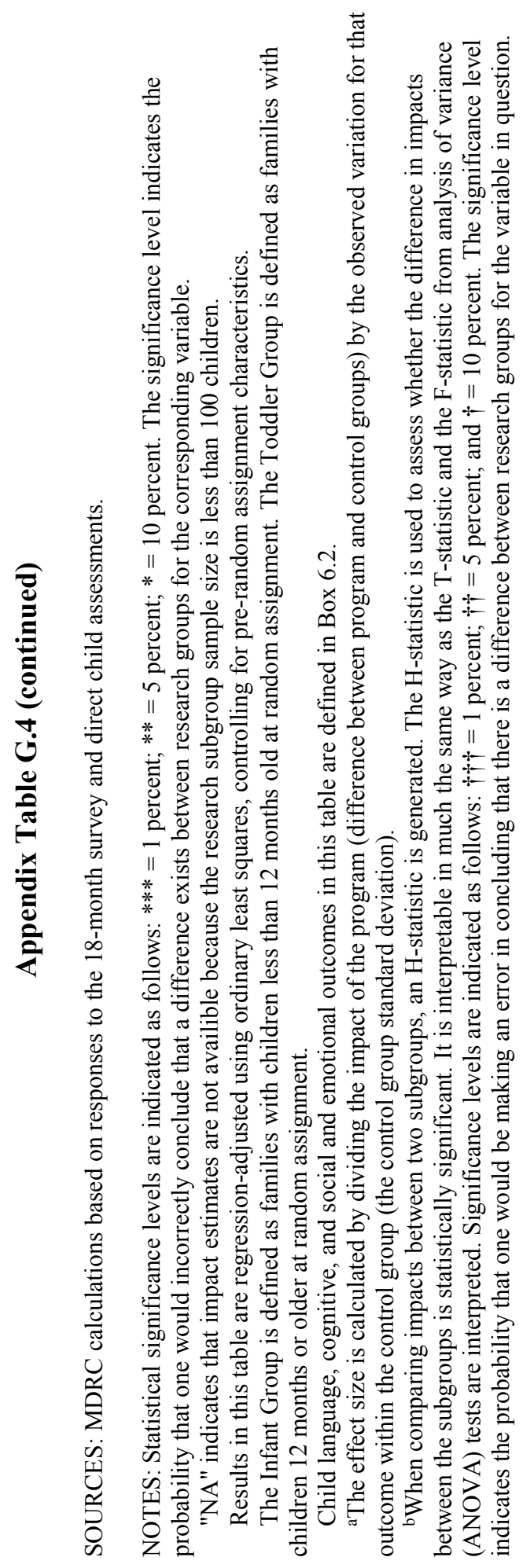




\section{References}

Abidin, R. Richard. 1995. "Parenting Stress Index: Professional Manual" (3rd ed.). Odessa, FL: Psychological Assessment Resources, Inc.

Aos, Steve, Roxanne Lieb, Jim Mayfield, Marna Miller, and Annie Pennucci. 2004. Benefits and Costs of Prevention and Early Intervention Programs for Youth. Olympia: Washington State Institute for Public Policy.

Belsky, Jay. 2001. "Developmental Risks (Still) Associated with Early Child Care." Journal of Child Psychology and Psychiatry 42: 845-859.

Briggs-Gowan, Margaret, Alice Carter, Julia R. Irwin, Karen Wachtel, and Domenic Cicchetti. 2004. "The Brief Infant-Toddler Social and Emotional Assessment: Screening for SocialEmotional Problems and Delays in Competence." Pediatric Psychology 29: 143-155

Brooks-Gunn, Jeanne, Lisa J. Berlin, and Allison S. Fuligni. 2000. "Early Childhood Intervention Programs: What About the Family? Pages 549-588 in J. P. Shonkoff and S. J. Meisels (eds.), Handbook of Early Childhood Intervention (2nd ed.). New York: Cambridge University Press.

Brooks-Gunn, Jeanne, Wen-Jui Han, and Jane Waldfogel. 2002. "Maternal Employment and Child Cognitive Outcomes in the First Three Years of Life: The NICHD Study of Early Child Care." Child Development 73, 4: 1052-1072.

Brooks-Gunn, Jeanne, Pamela Kato Klebanov, and Fong-ruey Liaw. (1995). "The Learning, Physical, and Emotional Environment of the Home in the Context of Poverty: The Infant Health and Development Program." Children and Youth Services Review 17, 1-2: 251-276.

Brooks-Gunn, Jeanne, Pamela Kato Klebanov, Fong-ruey Liaw, and Donna Spiker. 1993. "Enhancing the Development of Low Birth Weight, Premature Infants: Changes in Cognition and Behavior Over the First Three Years. Child Development 64, 182: 736-753.

Campbell, Frances. A., and Craig T. Ramey. 1994. "Effects of Early Intervention on Intellectual and Academic Achievement: A Follow-Up Study of Children from Low-Income Families. Child Development 6: 684-698.

Capizzano, Jeff, and Gina Adams. 2003. "Children in Low-Income Families Are Less Likely to Be in Center-Based Care.” Washington, DC: Urban Institute.

Center for Law and Social Policy. 2008. "Early Head Start Participants, Programs, Families, and Staff in 2006." Washington, DC: Center for Law and Social Policy.

Danziger, Sandra K., Ariel Kalil, and Nathaniel J. Anderson. 2000. "Human Capital, Health and Mental Health of Welfare Recipients: Co-Occurrence and Correlates." Journal of Social Issues 54: 637-656. 
Dokecki, Paul R., Erwin C. Hargrove, and Howard Mark Sandler. 1983. "An Overview of the Parent Child Development Center Social Experiment." Pages 80-110 in R. Haskins and D. Adams (eds.), Parent Education and Public Policy. Norwood, NJ: Ablex.

Douglas-Hall, Ayana, and Michelle Chau. 2008. "Basic Facts about Low-Income Children: Birth to Age 3." New York: Columbia University, Mailman School of Public Health, National Center for Children in Poverty.

Downey, Geraldine, and James C. Coyne. 1990. "Children of Depressed Parents: An Integrative Review.” Psychological Bulletin 108: 50-76.

Duncan, Greg J., and Jeanne Brooks-Gunn. 1997. Consequences of Growing Up Poor. New York: Russell Sage Foundation.

Duncan, Greg J., and Jeanne Brooks-Gunn. 2000. "Family Poverty, Welfare Reform, and Child Development. Child Development 71: 188-196.

Duncan, Greg J., Jeanne Brooks-Gunn, and Pamela Kato Klebanov. 1994. "Economic Deprivation and Early Childhood Development." Child Development 65: 296-318.

Edin, Kathryn, and Laura Lein. 1997. Making Ends Meet. New York: Russell Sage Foundation.

Evans, Gary W. 2004. “The Environment of Childhood Poverty.” American Psychologist 59, 2: 77-92.

Evans, Gary W., and Kimberly English. 2002. "The Environment of Poverty: Multiple Stressor Exposure, Psychophysiological Stress, and Socioemotional Adjustment." Child Development 73: $1238-1248$.

Fass, Sarah, and Nancy K. Cauthen. 2008. "Who Are America's Poor Children? The Official Story." New York: Columbia University, Mailman School of Public Health, National Center for Children in Poverty.

Hoffman, Lois W. 1989. "Effects of Maternal Employment in the Two-Parent Family." American Psychologist 44, 2: 283-292.

Kessler, Ronald C., Peggy R. Barker, Lisa J. Colpe, Joan F. Epstein, Joseph C. Gfroerer, Eva Hiripi, Mary J. Howes, Sharon-Lise T. Normand, Ronald W. Manderscheid, Ellen E. Walters, and Alan M. Zaslavsky. 2003. "Screening for Serious Mental Illness in the General Population." Archives of General Psychiatry 60: 184-189.

Knox, Virginia W., Andrew S. London, and Ellen K. Scott with Susan Blank. 2003. "Welfare Reform, Work, and Child Care: The Role of Informal Care in the Lives of Low-Income Women and Children." Policy Brief. New York: MDRC.

Lowe, Edward, Thomas Weisner, Sonya Geis, and Aletha Huston. 2005. "Child Care Instability and the Effort to Sustain a Working Daily Routine: Evidence from the New Hope Ethnographic Study of Low-Income Families." Pages 121-144 in C. Cooper, C. Garcia-Coll, T. Bartko, H. Davis, and C. Chatman (eds.), Hills of Gold: Diverse Pathways Through Middle Childhood. Mahwah, NJ: Erlbaum. 
McCabe, Lisa A., M. Hernandez, S. L. Lara, and Jeanne Brooks-Gunn. 2000. “Assessing Preschoolers' Self-Regulation in Homes and Classrooms: Lessons from the Field. Behavioral Disorders 26, 1: 53-69.

McLoyd, Vonnie C. 1990. "The Impact of Economic Hardship on Black Families and Children: Psychological Distress, Parenting, and Socioeconomic Development." Child Development 61: 311-346.

Menaghan, Elizabeth G., and T. L. Parcel. 1995. "Social Sources of Change in Children's Home Environments: Effects of Parental Occupational Experiences and Family Conditions Over Time." Journal of Marriage and the Family 57: 69-84.

Murray, Kathleen T., and Grazyna Kochanska. 2002. "Effortful Control: Relation to Externalizing and Internalizing Behaviors and Factor Structure." Journal of Abnormal Child Psychology 30: 503-514.

NICHD Early Child Care Research Network. 2002a. "Child-Care Structure Process Outcome: Direct and Indirect Effects of Child-Care Quality on Young Children's Development." Psychological Science 13: 199-206.

NICHD Early Child Care Research Network. 2002b. "Early Child Care and Children's Development Prior to School Entry: Results from the NICHD Study of Early Child Care." American Educational Research Journal 39: 133-164.

NICHD Early Child Care Research Network. 2003a. "Does Amount of Time Spent in Child Care Predict Socioemotional Adjustment During the Transition to Kindergarten?" Child Development 74: 976-1005.

NICHD Early Child Care Research Network. 2003b. "Does Quality of Child Care Affect Child Outcomes at Age 4 1/2?" Developmental Psychology 39: 451-469.

NICHD Early Child Care Research Network. 2005. "Duration and Developmental Timing of Poverty and Children's Cognitive and Social Development from Birth Through Third Grade." Child Development 76, 4: 795-810.

NICHD Early Child Care Research Network and G. J. Duncan. 2003. "Modeling the Impacts of Child Care Quality on Children's Preschool Cognitive Development." Child Development 74: 1454-1475.

Olds, David L., Charles R. Henderson, Harriet J. Kitzman, John J. Eckenrode, Robert E. Cole, and Robert C. Tatelbaum. 1999. "Prenatal and Infancy Home Visitation by Nurses: Recent Findings." Future of Children 9, 1: 44-65.

Patterson, Gerald. 1982. Coercive Family Process. Eugene, OR: Castalia Publishing.

Ramey, Craig T., and Frances Campbell. 1991. "Poverty, Early Childhood Education, and Academic Competence: The Abecedarian Experiment." Pages 190-221 in A. Huston (ed.), Children Reared in Poverty. New York: Cambridge University Press. 
Sears, Heather A., and Nancy L. Galambos. 1992. "Women's Work Conditions and Marital Adjustment in Two-Earner Couples: A Structural Model." Journal of Marriage and the Family 54: 789-797.

Shonkoff, Jack, and Deborah Phillips. 2000. From Neurons to Neighborhoods: The Science of Early Childhood Development. Washington, DC: National Academy Press.

Smith-Donald, R., Cybele Raver, T. Hayes, and Bonham Richardson. 2007. "Preliminary Construct and Concurrent Validity of the Preschool Self-Regulation Assessment (PSRA) for Field-Based Research." Early Childhood Research Quarterly 22: 173-187.

St. Pierre, Robert G., Jean I. Layzer, Barbara D. Goodson, and Lawrence S. Bernstein. 1997. National Impact Evaluation of the Comprehensive Child Development Program: Final Report. Cambridge, MA: Abt Associates Inc.

Travers, Jeffrey, Marrit J. Nauta, and Nancy Irwin. (1982). The Effects of a Social Program: Final Report of the Child and Family Resource Program's Infant-Toddler Component. Cambridge, MA: Abt Associates Inc.

U.S. Department of Health and Human Services, Administration for Children and Families. 2002. Making a Difference in the Lives of Infants and Toddlers and Their Families: The Impacts of Early Head Start, Vol. I: Final Technical Report. Washington, DC: U.S. Department of Health and Human Services, Administration for Children and Families.

U.S. Department of Health and Human Services, Administration for Children and Families. 2007. Head Start Program Fact Sheet Fiscal Year 2007, FY-2006 Program Statistics. Web site: http://eclkc.ohs.acf.hhs.gov/hslc/About\%20Head\%20Start/cHeadStartProgr.htm.

Waldfogel, Jane, Wen-Jui Han, and Jeanne Brooks-Gunn. 2002. "The Effects of Early Maternal Employment on Child Cognitive Development." Demography 39, 2: 369-392.

Wasik, Barbara, Craig Ramey, Donna Bryant, and Joseph Sparling. 1990. "A Longitudinal Study of Two Early Intervention Strategies: Project CARE.” Child Development 61, 6: 1682-1696.

Watson, Janine E., Russell S. Kirby, Kelly J. Kelleher, and Robert H. Bradley. 1996. "Effects of Poverty on Home Environment: an Analysis of Three-Year Outcome Data for Low Birth Weight Premature Infants." Journal of Pediatric Psychology 21: 419-431.

Yoshikawa, Hirokazu. 1994. "Prevention as Cumulative Protection: Effects of Early Family Support and Education on Chronic Delinquency and Its Risks." Psychological Bulletin 115: 28-54.

Yoshikawa, Hirokazu, Thomas Weisner, and Edward Lowe (eds.). 2006. Making It Work: LowWage Employment, Family Life and Child Development. New York: Russell Sage Foundation. 


\section{Earlier MDRC Publications on the Enhanced Services for the Hard-to-Employ Demonstration and Evaluation}

Transitional Jobs: Background, Program Models, and Evaluation Evidence.

2010. Dan Bloom.

Alternative Welfare-to-Work Strategies for the Hard-to-Employ:

Testing Transitional Jobs and Pre-Employment Services in Philadelphia.

2010. Dan Bloom, Sarah Rich, Cindy Redcross, Erin Jacobs, Jennifer Yahner, and Nancy Pindus.

Working toward Wellness: Early Results from a Telephone Care Management Program for Medicaid Recipients with Depression.

2009. Sue Kim, Allen LeBlanc, and Charles Michalopoulos.

Transitional Jobs for Ex-Prisoners: Implementation, Two-Year Impacts, and Costs of the Center for Employment Opportunities (CEO) Prisoner Reentry Program.

2009. Cindy Redcross, Dan Bloom, Gilda Azurdia, Janine Zweig (Urban Institute), and Nancy Pindus (Urban Institute).

Transitional Jobs for Ex-Prisoners: Early Impacts from a Random Assignment Evaluation of the Center for Employment Opportunities (CEO) Prisoner Reentry Program.

2007. Working Paper. Dan Bloom, Cindy Redcross, Janine Zweig (Urban Institute), and Gilda Azurdia.

Four Strategies to Overcome Barriers to Employment:

An Introduction to the Enhanced Services for the Hard-to-Employ Demonstration and Evaluation Project.

2007. Dan Bloom, Cindy Redcross, JoAnn Hsueh, Sarah Rich, and Vanessa Martin.

The Power of Work:

The Center for Employment Opportunities Comprehensive Prisoner Reentry Program.

2006. The Center for Employment Opportunities and MDRC. 
